Saulo Aires de Souza

\title{
AVALIAÇÃO DAS METODOLOGIAS PARA DETERMINAÇÃO DE VALORES MÁXIMOS DE VARIÁVEIS HIDROLÓGICAS: APLICAÇÃO DO MÉTODO CONJUGADO
}

Dissertação apresentada à Escola de Engenharia de São Carlos, da Universidade de São Paulo, como parte dos requisitos para obtenção do Título de Mestre em Hidráulica e Saneamento.

Orientador: Prof. Dr. Rodrigo de Melo Porto

São Carlos

2006 
Ficha catalográfica preparada pela Seção de Tratamento da Informação do Serviço de Biblioteca - EESC/USP

Souza, Saulo Aires de

Avaliação das metodologias para determinação de valores máximos de variáveis hidrológicas: aplicação do método conjugado / Saulo Aires de Souza. -- São Carlos, 2006.

Dissertação (Mestrado) -- Escola de Engenharia de São Carlos-Universidade de São Paulo, 2006.

Área: Hidráulica e Saneamento.

Orientador: Prof. Dr. Rodrigo de Melo Porto.

1. Cheia de projeto. 2. Análise de freqüência de vazões. 3. Precipitação máxima provável. 4. Enchente máxima provável. I. Título. 
Dedico este trabalho aos meus pais, Máspoli Câncio e Margareth Rose, grandes companheiros e meus exemplos de vida. 


\section{AGRADECIMENTOS}

Ao Professor Doutor Rodrigo de Melo Porto pela orientação, apoio e sugestões na elaboração desta dissertação.

Ao professor Doutor Eduardo Mario Mendiondo, da EESC-SP pelo incentivo e sugestões.

À CNPQ, pela bolsa concedida.

Aos funcionários e colegas do Departamento de Hidráulica e Saneamento, em especial aos do Núcleo Integrado de Bacias Hidrográfica (NIBH) e do Laboratório de Hidráulica Computacional.

Ao amigo Carlos Eduardo A. G. Barreto pelo apoio e incentivo.

Aos amigos Francisco Fernando Frango Noronha Marcussi, Luiz Sérgio GariGari do Nascimento e Abner omifeio Soares pelo incentivo e pelo companheirismo na execução de nossos trabalhos.

Aos meus irmãos Francisco C. A. de Souza, Máspoli de Souza Filho e Maria Clara A. de Souza pelo incentivo, apoio e carinho.

Um agradecimento especial a minha querida tia Nizia pelo enorme carinho e incentivo.

Aos meus Avós, tios e primos pelo apoio e carinho.

Aos grandes amigos que ficaram em Natal por sempre torcerem e acreditarem.

Aos meus queridos pais, por serem a razão desta simples conquista. 


\section{SUMÁRIO}

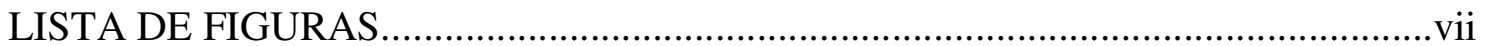

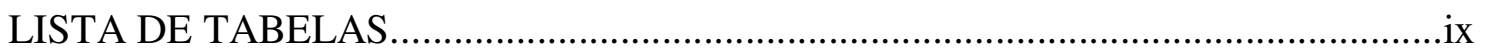

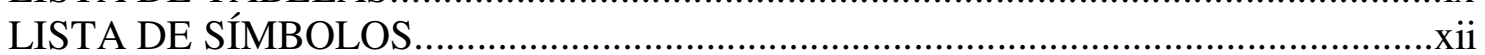

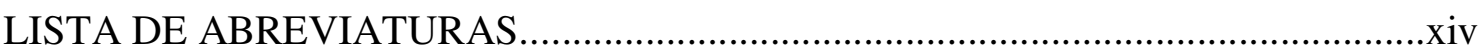

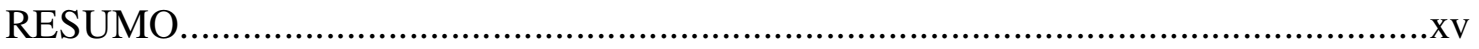

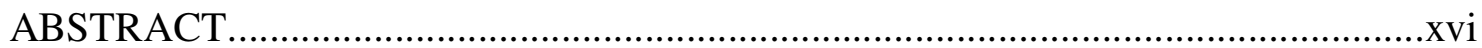

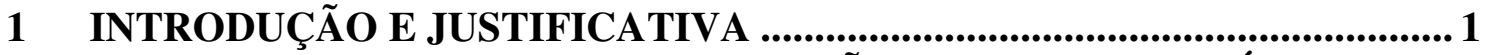

2 ESTADO DA ARTE NA DETERMINAÇÃO DE VALORES MÁXIMOS DE

VARIÁVEIS HIDROLÓGICAS ............................................................................ 6

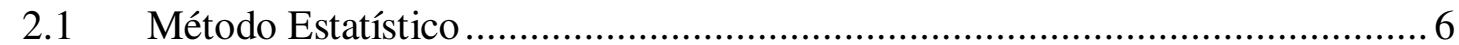

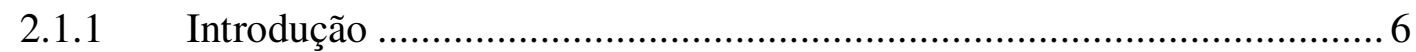

2.1.2 Ajuste da Distribuição Probabilística ................................................. 19

2.1.3 Inferência e Análise de Resultados....................................................... 39

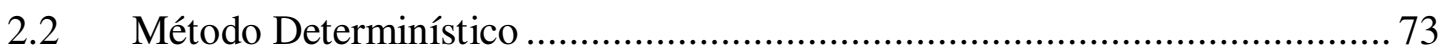

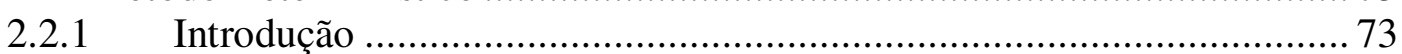

2.2.2 Metodologias para Obtenção da PMP .............................................. 76

2.2.3 Considerações Sobre a Determinação da PMP e EMP - Análise Crítica80

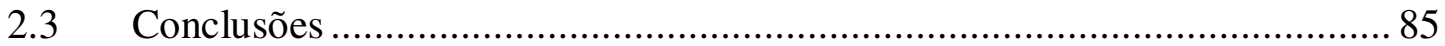

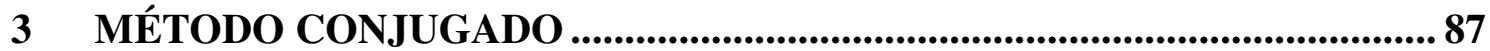

3.1 Limite Físico dos Valores Máximos......................................................... 87

3.2 Distribuição de Valores Máximos com Limite Físico Definido ..................... 88

3.3 Definição do Método Conjugado Utilizando a Distribuição Probabilística dos

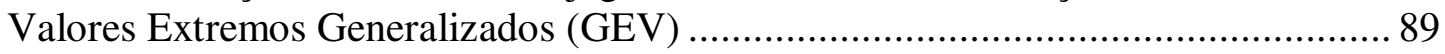

3.4 Determinação dos Parâmetros da Distribuição ............................................ 90

3.5 Definição do Método Conjugado Utilizando a Distribuição Probabilística

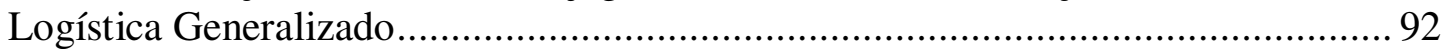

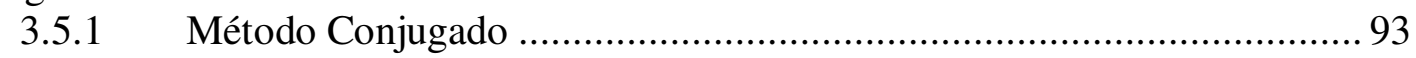

3.5.2 Estimação dos Parâmetros................................................................... 95

4 ESTUDOS DE CASOS ................................................................................ 97

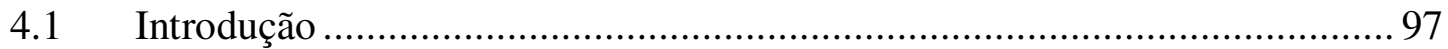

4.2 Aplicação do Método Conjugado para Verificação da sua Consistência ....... 99

4.2.1 Análise da influência da extensão da série de valores ......................... 101

4.2.2 Análise da influência da presença de "outliers" na série de valores .... 101

4.2.3 Análise da influência dos menores valores da série de valores máximos 103

4.3 Análise de Sensibilidade dos Valores Extremos em Relação ao VMP ........ 107

4.4 Análise Comparativa entre a Metodologia Estatística e o Método Conjugado 109

4.5 Verificação da Segurança de uma Barragem ......................................... 115

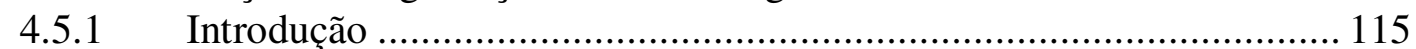

4.5.2 Descrição do projeto da UHE Caconde ........................................... 117

4.5.3 Análise da série de vazões máximas anuais ....................................... 117

4.5.4 Verificação da vazão de projeto utilizando a metodologia estatística e o

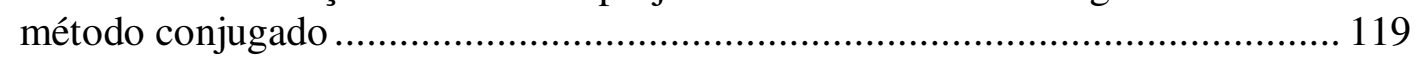

4.6 Aplicação do Método Conjugado em Séries de Vazões Médias Diárias e

Séries Vazões Máximas Instantâneas ................................................................... 127

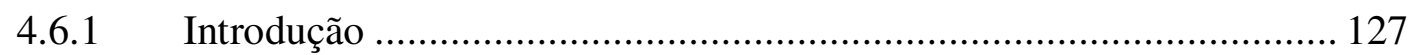

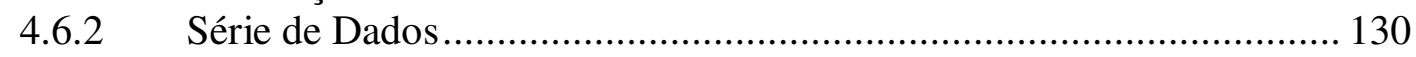


4.6.3 Aplicação do Método Conjugado ...................................................... 131 4.7 Aplicação do Método Conjugado em Séries Parciais e Séries de Máximos Anuais 142

4.7.1 Introdução 142

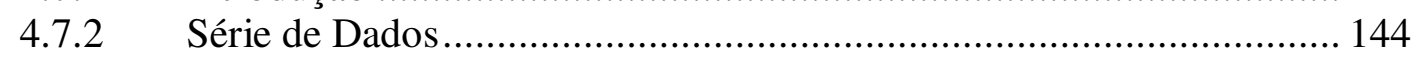

4.7.3 - Aplicação do Método Estatístico ...................................................... 146

4.7.4 - Aplicação do Método Conjugado .................................................. 150

4.8 Aplicação do Método Conjugado Utilizando a Distribuição Logística Generalizada Ajustada pelo Método dos Momentos com Pesos Probabilísticos ..... 155

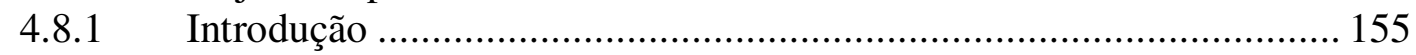

4.8.2 Aplicação da Distribuição Logística Generalizada ao Conceito do

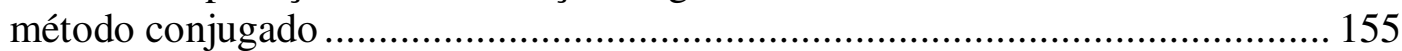

5 ANÁLISE CRÍTICA DO MÉTODO CONJUGADO..................................... 163

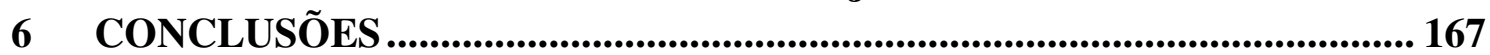

7 REFERENCIAS BIBLIOGÁFICAS ...................................................... 171

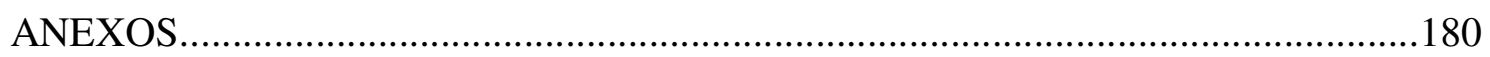




\section{LISTA DE FIGURAS}

Figura1- Representação gráfica de uma série de duração parcial e máximos anuais ..... 14 Figura2 - Diagrama que relaciona os momentos de distribuições teóricas de

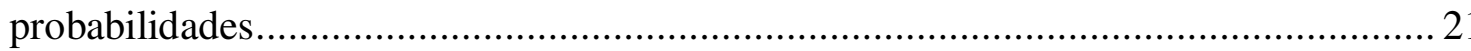

Figura3- Diagrama que relaciona os L-momentos de distribuições teóricas de

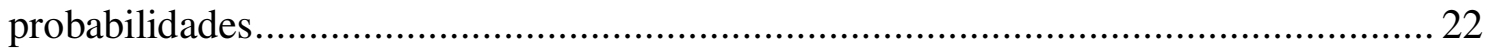

Figura4 - Método estatístico - Comparação das distribuições ajustadas pelo método dos momentos.

Figura5 - Método estatístico - Comparação das distribuições ajustadas pelo método da

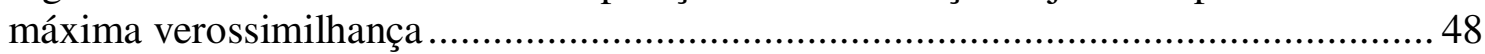
Figura6 - Método estatístico - Comparação das distribuições ajustadas pelo método dos momentos com pesos probabilísticos.

Figura7 - Diagrama da relação dos momentos - (MRD) e os coeficientes estatísticos dispostos no gráfico das sub-séries de sobradinho/BA ............................................. 55

Figura8 - Comparação da distribuição probabilística GEV ajustadas - método ML ..... 60 Figura9- Comparação da distribuição probabilística GEV ajustadas - método PWM... 61 Figura10- Comparação da distribuição probabilística GEV ajustadas - método MOM 62 Figura11- Comparação da distribuição probabilística GEV ajustadas - método MOMLH

Figura12 - Análise da influência do outlier - distribuição GEV - método ML ............ 68 Figura13- Análise da influência do outlier - distribuição GEV - método PWM .......... 68 Figura14 - Análise da influência do outlier - distribuição GEV - método MOM-L ..... 69 Figura 15 - Análise da influência do outlier - distribuição GEV - método MOM-LH . 69 Figura 16 - Análise da influencia dos menores valores - distribuição GEV - método PWM.

Figura 17 - Síntese conceitual de Maximização das Seqüências de Tormentas Severas81 Figura 18 - Análise de freqüência conjugada - exemplo da distribuição probabilística

Figura 19 - Análise de freqüência conjugada - Análise da influência da extensão da série de valores

Figura 20 - Análise de freqüência conjugada - Análise da influência da presença de "outliers".

Figura 21 - Análise de freqüência conjugada - Análise da influência dos menores valores da série de valores máximos.

Figura 22 - Análise de freqüência conjugada - Análise de sensibilidade do parâmetro VMP.

Figura 23 - Comparação entre os métodos estatístico e conjugado quanto a influência da extensão das séries .

Figura 24 - Comparação entre os métodos estatístico e conjugado quanto a influência da presença do outlier.....

Figura 25 - Comparação entre os métodos estatístico e conjugado quanto a influência dos valores mínimos ....

Figura 26 - Método estatístico - Comparação das distribuições ajustadas pelo método MOM.

Figura 27 - Método estatístico - Comparação das distribuições ajustadas pelo método ML

Figura 28 - Método estatístico - comparação das distribuições ajustadas pelo método PWM. 
Figura 29 - Método conjugado - curva da distribuição probabilística ajustadas para as diferentes séries utilizando o método MOM, ML e MLS

Figura 30 - Método conjugado - curva da distribuição probabilística ajustadas para as diferentes séries (médias diárias e instantâneas) utilizando o método MOM...

Figura 31 - Método conjugado - curva da distribuição probabilística ajustadas para as

diferentes séries (médias diárias e instantâneas) utilizando o método ML 140

Figura 32 - Método conjugado - curva da distribuição probabilística ajustadas para as

diferentes séries (médias diárias e instantâneas) utilizando o método MLS.

Figura 33 - Método Estatístico- comparação das distribuições ajustadas pelo método ML utilizando as diferentes séries (parcial-anual, duração parcial e máximos anuais).

Figura 34 - Método Estatístico- comparação das distribuições ajustadas pelo método MOM utilizando as diferentes séries (parcial-anual, duração parcial e máximos anuais).

Figura 35 - Método Estatístico- comparação das distribuições ajustadas pelo método PWM utilizando as diferentes séries (parcial-anual, duração parcial e máximos anuais).

Figura 36 - Método conjugado - curva da distribuição probabilística ajustadas para as diferentes séries (duração parcial e máximos anuais) utilizando os método MOM, ML e MLS

Figura 37 - Análise de freqüência conjugada/GLOG - Análise da influência da extensão da série de valores

Figura 38 - Análise de frequiência conjugada - Análise da influência da presença de "outliers".

Figura 39 - Análise de freqüência conjugada - Análise da influência dos menores valores da série de valores máximos.

Figura 40 - Análise de freqüência conjugada - Análise de sensibilidade do parâmetro VMP 


\section{LISTA DE TABELAS}

Tabela 1- Alternativas de posição de plotagem e suas motivações.

Tabela 2 - Série de Vazões Máximas Anuais da Usina Hidrelétrica de Sobradinho/BA.

Tabela 3 - Parâmetros estatísticos da série vazões máximas anuais da UHE de

Sobradinho/BA.

Tabela 4 - Parâmetros obtidos para diferentes distribuições probabilísticas e diferentes

estimadores (MOM, ML, PWM).

Tabela 5 - Parâmetros obtidos para diferentes distribuições probabilísticas e diferentes estimadores (MOM, ML, PWM).

Tabela 6 - Vazões máximas em função da probabilidade de excedência para diferentes distribuições probabilísticas ajustada pelo método dos momentos.

Tabela 7 - Vazões máximas em função da probabilidade de excedência para diferentes

distribuições probabilísticas ajustada pelo método da máxima verossimilhança........... 48

Tabela 8 - Vazões máximas em função da probabilidade de excedência para diferentes

distribuições probabilísticas ajustada pelo método dos momentos com pesos

probabilísticos.

Tabela 9 - Erro padrão em função da probabilidade de excedência para diferentes distribuições.

Tabela 10 - Erro padrão em função da probabilidade de excedência para diferentes

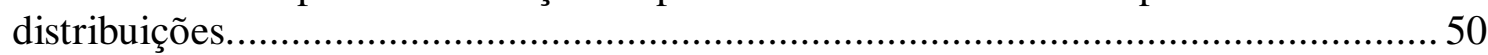

Tabela 11 - Subséries de vazões máximas da UHE de Sobradinho/BA ....................... 53

Tabela 12 - Parâmetros estatísticos das sub-séries da UHE de Sobradinho/BA ............. 55

Tabela 13 - Parâmetros obtidos para distribuição GEV ajustadas para a sub-séries selecionadas utilizando diferentes estimadores (MOM e ML). .................................. 58

Tabela 14- - Parâmetros obtidos para distribuição GEV ajustadas para a sub-séries selecionadas utilizando diferentes estimadores (MOM e ML). ..................................59

Tabela 15 - Vazões máximas obtidas pelo método estatístico - distribuição GEV -

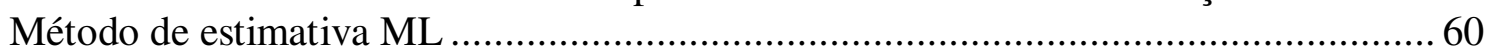

Tabela 16 - Vazões máximas obtidas pelo método estatístico - distribuição GEV -

Método de estimativa PWM.

Tabela 17 - Vazões máximas obtidas pelo método estatístico - distribuição GEV -

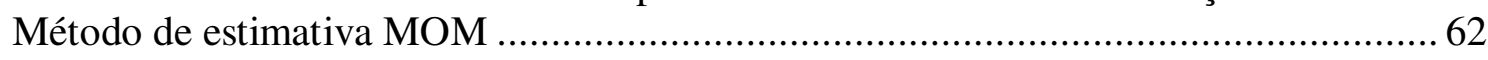

Tabela 18 - Vazões máximas obtidas pelo método estatístico - distribuição GEV -

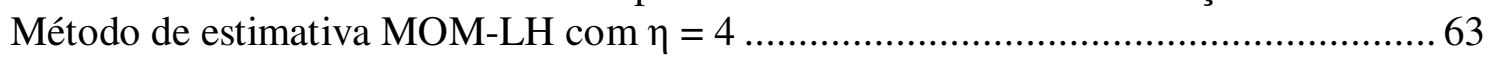

Tabela 19- Parâmetros obtidos para distribuição GEV ajustadas para as séries c/ e sem o

outliers utilizando diferentes estimadores (MOM e ML).

Tabela 20 - Parâmetros obtidos para distribuição GEV ajustadas para as séries c/ e sem

o outliers utilizando diferentes estimadores (ML e MOM-LH).................................. 67

Tabela 21 - Análise da influência do outlier - distribuição GEV - método ML, PWM,

MOM-L e MOM-LH ............................................................................................ 70

Tabela 22 - Vazões minoradas e majoradas para a série de vazões máximas de 1931 a

2001

Tabela 23 - Análise da influencia dos menores valores - distribuição GEV - método

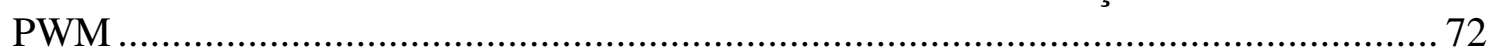

Tabela 24 - Subséries de vazões máximas da UHE de Sobradinho/BA ........................ 99

Tabela 25 - Parâmetros das subséries de vazões máximas da UHE de Sobradinho/BA -

Método da máxima verossimilhança (ML) 
Tabela 26 - Análise da influência da extensão da série de valores.............................. 102 Tabela 27 - Parâmetros da AFC para análise da influência da presença do "outlier".. 103 Tabela 28 - Análise da influência da presença de "outliers" ..................................... 104 Tabela 29 - Parâmetros da AFC para análise da influência dos menores valores da série de valores máximos

Tabela 30 - Análise da influência dos menores valores da série de valores máximos . 106 Tabela 31 - Parâmetros da AFC para análise de sensibilidade do parâmetro VMP ..... 107 Tabela 32 - Análise de sensibilidade do parâmetro VMP. 109

Tabela 33 - Análise de sensibilidade do parâmetro VMP - diferenças percentuais dos valores máximos

Tabela 34 - Diferenças das Vazões decamilenares para a UHE de Sobradinho/BA .... 110 Tabela 35 - Série de Vazões Instantâneas Máximas Anuais da Usina Hidrelétrica de Caconde/SP.

Tabela 36 - parâmetros estatísticos da série vazões instantâneas máximas anuais da UHE de Caconde/SP

Tabela 37 - Vazão decamilenar $\left(\mathrm{T}_{\mathrm{R}}=10.000\right.$ ANOS) ajustada pelo método MOM $\ldots 123$

Tabela 38 - Vazão decamilenar $\left(\mathrm{T}_{\mathrm{R}}=10.000\right.$ ANOS $)$ ajustada pelo método ML ....... 124

Tabela 39 - Vazão decamilenar $\left(\mathrm{T}_{\mathrm{R}}=10.000\right.$ ANOS) ajustada pelo método PWM.... 125

Tabela 40 - Vazão decamilenar $\left(T_{R}=10.000\right.$ ANOS) ajustada pelo método conjugado

Tabela 41- Equações entre $\mathrm{Q}_{\mathrm{mx}}$ e $\mathrm{Q}_{\mathrm{md}}$ da literatura

Tabela 42 - Série de Vazões Médias Diárias Máximas e Instantâneas com fator multiplicativo $\left(\mathrm{Q}_{\mathrm{mx}} / \mathrm{Q}_{\mathrm{md}}\right) \mathrm{K}=1,3$ e $\mathrm{K}=1,4$ do rio Paraguaçu em Pedra Cavalo.

Tabela 43 - Método Conjugado - análise utilizando as séries de valores máximos instantâneos e valores médios diários máximos - método MOM.

Tabela 44 - Método Conjugado - análise utilizando as séries de valores máximos instantâneos e valores médios diários máximos - método ML

Tabela 45 - Método Conjugado - análise utilizando as séries de valores máximos instantâneos e valores médios diários máximos - método MLS

Tabela 46 - Série de duração parcial de precipitações máxima de 12 horas da estação do observatório IAG localizado em São Paulo/SP

Tabela 47 - Série de máximos anuais de precipitações máxima de 12 horas da estação do observatório IAG localizado em São Paulo/SP .

Tabela 48 -Método Estatístico - Vazões máximas decamilenares $\left(\mathrm{Q}_{10000}\right)$, milenares $\left(\mathrm{Q}_{1000}\right)$ e centenárias $\left(\mathrm{Q}_{100}\right)$ ajustada pelo método $\mathrm{ML}$ para as diferentes séries (duração parcial (DP) e máxima anual (MA))

Tabela 49 - Método Estatístico - Vazões máximas decamilenares $\left(\mathrm{Q}_{10000}\right)$, milenares $\left(\mathrm{Q}_{1000}\right)$ e centenárias $\left(\mathrm{Q}_{100}\right)$ ajustada pelo método MOM para as diferentes séries (duração parcial (DP) e máxima anual (MA)).

Tabela 50 - Método Estatístico - Vazões máximas decamilenares $\left(\mathrm{Q}_{10000}\right)$, milenares $\left(\mathrm{Q}_{1000}\right)$ e centenárias $\left(\mathrm{Q}_{100}\right)$ ajustada pelo método $\mathrm{PWM}$ para as diferentes séries (duração parcial (DP) e máxima anual (MA)).

Tabela 51 - Método Conjugado - análise utilizando as séries de duração parcial e série de máximos anuais utilizando os métodos MOM, ML e MLS.

Tabela 52- Parâmetros do MC/GLOG das sub-séries de vazões máximas da UHE de Sobradinho/BA - Método dos momentos com pesos probabilísticos $(\mathrm{PWM})-\mathrm{VMP}=$ $36.300 \mathrm{~m}^{3} / \mathrm{s}$

Tabela 53 - Parâmetros do MC/GLOG para análise da influência da presença do "outlier" da série de vazões máximas da UHE de Sobradinho/BA - Método dos momentos com pesos probabilísticos (PWM) - VMP $=36.300 \mathrm{~m}^{3} / \mathrm{s}$ 
Tabela 54 - Parâmetros do MC/GLOG para análise da influência dos menores valores da série de valores máximos da série de vazões máximas da UHE de Sobradinho/BA Método dos momentos com pesos probabilísticos (PWM) - VMP $=36.300 \mathrm{~m}^{3} / \mathrm{s}$ Tabela 55 - Parâmetros da MC/GLOG para análise de sensibilidade do parâmetro VMP da série de valores máximos da série de vazões máximas da UHE de Sobradinho/BA Método dos momentos com pesos probabilísticos (PWM) - VMP $=36.300 \mathrm{~m}^{3} / \mathrm{s} \ldots \ldots 157$ Tabela 56 - Análise da influência da extensão da série de valores............................. 158 Tabela 57 - Análise da influência da presença de "outliers" 159 Tabela 58 - Análise da influência dos menores valores da série de valores máximos . 160 Tabela 59 - Análise de sensibilidade do parâmetro VMP. 161 Tabela 60 - Análise de sensibilidade do parâmetro VMP - diferenças percentuais dos valores máximos

Tabela 61 - Método Conjugado - Análise comparativa entre os valores obtidos utilizando a distribuição GEV com os obtidos utilizando a distribuição GLOG para diferentes análises 162 Tabela 62 - Comparação entre a vazão de 10.000 anos inferida pelo método conjugado e o maior valor observado no registro histórico das diferentes séries 165 Tabela 63 - Comparação entre o valor máximo provével (VMP) e a vazão de 10.000 anos $\left(\mathrm{Q}_{10000}\right)$ inferida pelo método conjugado 166 


\section{LISTA DE SÍMBOLOS}

$\mathrm{x}_{\mathrm{n}}=$ Variável aleatória (amostra)

$\mathrm{n}=$ Números de valores amostrais (tamanho da amostra)

$\mathrm{X}=$ Evento aleatório

$\mathrm{q}_{\mathrm{x}}=$ Evento de vazão

$\mathrm{Q}_{\mathrm{t}}=$ Magnitude da vazão dado seu período de retorno

$\mathrm{F}\left(\mathrm{Q}_{\mathrm{t}}\right)=$ Probabilidade acumulada de não-excedência

$\mathrm{N}=$ Número de anos da amostra

$\mathrm{i}=$ Ordem do valor na amostra ordenada do valor mais raro para o menos raro

$\alpha_{1}=$ Parâmetro das fórmulas de posição de plotagem (especifico da distribuição testada)

$\mathrm{Te}=$ Tempo de retorno para séries de durações parciais

$\mathrm{T}_{\mathrm{r}}=$ Tempo de retorno para séries de máximos anuais

$\lambda=$ Número médio de picos por ano incluídos na série de DP

$\mathrm{H}_{0}=$ Hipótese nula

$\mathrm{R}=$ Estatística usada no teste Wald-Wolfowitz

$\mathrm{H}=$ Estatística usada no teste Kruskall-Wallis

$\mathrm{m}_{\mathrm{r}}{ }^{\prime}=\mathrm{r}$-iésimo momento da amostra

$\mathrm{u}_{\mathrm{k}}=$ Momento central da amostra

$\bar{x}=$ Média amostral

$\mathrm{s}=$ Desvio padrão amostral

$\mathrm{k}_{\mathrm{n}}=$ Estatística do teste Grubbs e Beck para verificação da presença de outliers

$\mathrm{X}_{\mathrm{H}}=$ Alto outliers

$\mathrm{X}_{\mathrm{L}}=$ Baixo outliers

$f(x)=$ Função densidade de probabilidade

$\mathrm{F}(\mathrm{x})=$ Função cumulative de probabilidade

$\mathrm{C}_{\mathrm{v}}=$ Coeficiente de variação

$\mathrm{C}_{\mathrm{s}}=$ Coeficiente de assimetria

$\mathrm{C}_{\mathrm{k}}=$ Coeficiente de curtose

$\mathrm{L}(\theta)=$ Função de verossimilhança

$\mathrm{M}_{\mathrm{p}, \mathrm{r}, \mathrm{s}}=$ Momentos de pesos probabilísticos

$\mathrm{B}[]=$. Função beta

$\beta_{\mathrm{s}}=$ Momentos de pesos probabilísticos de ordem $\mathrm{s}$ igual a $\mathrm{M}_{1,0, \mathrm{~s}}$ 
$\beta_{\mathrm{r}}=$ Momentos de pesos probabilísticos de ordem $\mathrm{r}$ igual a $\mathrm{M}_{1, \mathrm{r}, 0}$

bs $=$ Estimador não viesado de $\beta_{\mathrm{s}}$

$\lambda_{\mathrm{r}}=$ Momentos de combinações lineares das estatísticas de ordem $r$

$\lambda_{r}^{\eta}=$ Momentos de combinações lineares das estatísticas $\eta$ de ordem $\mathrm{r}$

$\tau_{2}^{\eta}=$ Coeficiente de variação $\mathrm{LH}$

$\tau_{3}^{\eta}=$ Coeficiente de assimetria LH

$\tau_{4}^{\eta}=$ Coeficiente de curtose $\mathrm{LH}$

$\theta=$ vetor contendo um pequeno número de parâmetros

$\mathrm{K}_{\mathrm{t}}=$ fator de freqüência de uma distribuição teórica de probabilidades

$\mathrm{s}(\hat{\theta})=$ erro padrão de estimativa

$x_{b o o t}^{b}=$ Amostra Bootstrap

$W=$ massa de água por unidade de área $\left(\mathrm{g} / \mathrm{cm}^{2}\right)$

$\mathrm{q}_{\mathrm{s}}=$ umidade especifica

$\theta_{\mathrm{sw}}=$ temperatura pseudo-adiabática do bulbo úmido

$\mathrm{p}_{0}=$ pressão referente ao nível inferior da coluna de ar

$\mathrm{p}_{1}=$ pressão referente ao nível superior da coluna de ar

$\mathrm{e}_{\mathrm{i}}=$ desvios do método dos mínimos quadrados

$\mathrm{k}$ = Parâmetros de forma da distribuição GEV

$\alpha=$ Parâmetro de escala da distribuição GEV

$\mathrm{u}=$ Parâmetro de posicionamento da distribuição GEV

$\mathrm{Q}_{\mathrm{mx}}=$ Vazão máxima instantânea

$\mathrm{Q}_{\mathrm{md}}=$ Vazão média diária máxima

$\mathrm{Rm}=$ Razão de maximização

$\mathrm{K}$ = relação "vazão de ponta/vazão média diária" 


\section{LISTA DE ABREVIATURAS}

$\mathrm{EMP}=$ Enchente máxima provável

$\mathrm{PMP}=$ Precipitação máxima provável

MC - método conjugado

PMP - precipitação máxima próvavel

EMP - enchente máxima provável

MA - Séries de máximos anuais

DP - Séries de durações parciais

ST - Séries temporais

MRD - moment ratio diagram

MOM - método dos momentos

ML - método da máxima verossimilhança

PWM - método dos momentos com pesos probabilísticos

$\mathrm{N}$ - normal

EXP - exponencial

WEIB - Weibul

GAM - gamma

EV1 - valores extremos tipo - I

LN2 - log-normal 2 parametros

LN3 - log-normal 3 parametros

P-III - Peason tipo III

LP-III - log-Pearson tipo III

LOG - logística

WK4 - Wakeby 4 parâmetros

WK5 - Wakeby 5 parâmetros

GPAR - Pareto Generalizado

GLOG - logística generalizado 


\section{RESUMO}

A definição de valores máximos de variáveis hidrológicas na engenharia de recursos hídricos atua como ferramenta de extrema importância em vista de inúmeras aplicações práticas que se utilizam desses valores. Neste trabalho é apresentada uma revisão do estado da arte na definição de valores máximos de variáveis hidrológicas (metodologia estatística e determinística). Na metodologia estatística é mostrada uma avaliação conceitual e crítica, na qual é apresentado um exemplo numérico que demonstra as inconsistências ou falhas que caracterizam a necessidade de revisão nos conceitos. Na metodologia determinística é demonstrada as técnicas que definirão os valores da precipitação máxima provável e algumas considerações adicionais quanto à metodologia determinística, principalmente no que se refere às imprecisões dos valores determinados para a precipitação máxima provável/enchente máxima provável. A partir das conclusões sobre ambas as metodologias avaliadas é aplicado uma nova metodologia para determinação de valores máximos de projeto. Essa metodologia, denominada conjugada, resulta da combinação dos procedimentos atualmente usados: metodologia probabilística e determinística. Com o objetivo de caracterizar as importantes contribuições do método conjugado para engenharia, são apresentados alguns estudos de casos que procuram demonstrar a aplicabilidade prática do método e suas vantagens em detrimento aos métodos atuais. A conclusão é que o método conjugado representa um avanço em relação aos métodos atualmente utilizados, uma vez que é consistente com o fenômeno físico e permite atribuir probabilidades às variáveis hidrológicas, resultando em valores de projeto mais realista.

Palavras-chave: cheia de projeto; análise de freqüência; precipitação máxima provável; enchente máxima provável. 


\begin{abstract}
The description of extreme values of hydrological variables in water resources engineering is an extremely importance tool for innumerable practical applications. This work provides a review of statistical and deterministic methods that are used to estimate extreme values of hydrological variables. A critical and conceptual evaluation of statistical methods is presented along with a numerical example that demonstrates the inconsistencies or imperfections of such methods, characterizing the necessity of revisions of these concepts. Deterministic methods to estimate the Maximum Probable Precipitation are also presented and some additional considerations regarding the methodology are discussed, especially those concerned to the imprecise estimates of the maximum probable precipitation/flood. A new methodology to estimate extreme values of hydrologic variables for engineering projects is developed based upon conclusions about the evaluated methodologies. This new methodology is called conjugated, and results from the combination of the currently used statistical and deterministic procedures. In order to characterize the important contributions provided by the conjugated method, some case studies are presented as an attempt to demonstrate its practical applicability as well as its advantages over current methods. The conclusion is that the conjugate method represents an advance with respect to current methods because it is consistent with the physical phenomenon and it allows assigning probabilities to the hydrological variable, resulting in more realistic values to be employed in engineering projects.
\end{abstract}

Keywords: design flood; frequency analysis; probable maximum precipitation; probable maximum flood. 


\section{INTRODUÇÃO E JUSTIFICATIVA}

As enchentes podem ser consideradas como um dos fenômenos naturais que mais causa impactos socioeconômicos. Pela tendência de o homem se fixar nas margens e áreas de inundação dos rios, um eventual transbordamento de suas margens acarreta prejuízos incalculáveis à agricultura, à pecuária, às cidades, ao transporte, e não muito raro causando até perdas de vidas humanas. Por essas razões, a engenharia de recursos hídricos tem procurado definir medidas estruturais e não estruturais que visem à proteção dos bens e à vida das pessoas contra o excesso de água.

Os estudos das medidas a serem adotadas para proteção contra as enchentes fundamentam-se no estabelecimento de uma cheia de projeto, que pode ou não ter ocorrido no período de registro de dados. Assim, um prognóstico de vazões de cheias é importante e necessário. Para tal finalidade, tradicionalmente, a vazão de projeto é determinada com base na análise probabilística (análise de freqüência) ou na enchente máxima provável (EMP), obtida a partir da precipitação máxima provável (PMP).

$\mathrm{Na}$ análise de frequiência, considera-se que as vazões de cheias têm um comportamento aleatório, sendo necessária a definiçãa da distribuição de probabilidades do universo dessas vazões. Este enfoque probabilístico permite estimar as probabilidades de ocorrência para a magnitude das vazões de cheias dadas. Para isso utiliza-se como dado básico, registros históricos de descargas, de onde são obtidas as amostras de máximas ocorrências.

Quando o registro histórico de descargas é relativamente longo, a análise de freqüência das vazões de cheias pode ser feita a partir de interpolações na curva de distribuição das frequiências amostrais, que associa probabilidades acumuladas a cada ponto da amostra ordenada, de acordo com posições de plotagens em pápeis probabilísticos. No entanto, muito comumente o tamanho da amostra não é suficiente para fornecer informações a respeito de descargas com altos períodos de retorno 
(geralmente 100, 1000 e 10000 anos), sendo necessário fazer extrapolações na curva de freqüência, as quais dependem muito da subjetividade individual. Para contornar o problema, as vazões de cheias são consideradas como amostras de uma variável aleatória contínua, empregando-se modelos probabilísticos que são devidamente ajustados a essas amostras, permitindo que as extrapolações sejam feitas com menor subjetividade. Esta hipótese pode, entretanto, ser bastante enganosa.

Garcia (1996 apud Biwas (1971)) ${ }^{1}$ fornece um exemplo que caracteriza bem esta afirmação. O vertedouro da usina hidrelétrica de Rincon de Bonete, no Rio Negro no Uruguai, foi projetado para uma vazão de $9.200 \mathrm{~m} 3 / \mathrm{s}$, correspondendo a um período de retorno de 1.000 anos. Essa vazão foi inferida a partir de uma série hidrológica de 27 anos, onde o valor máximo observado foi de $3.820 \mathrm{~m}^{3} / \mathrm{s}$. Decorridos 14 anos após a construção (1959), ocorreu uma vazão de $17.130 \mathrm{~m} / \mathrm{s}$ que corresponderiam pela distribuição probabilística ajustada a um período de retorno de 500.000 anos.

No entanto, afirma Garcia (1996), essa metodologia tradicional tem sido utilizada para a definição das vazões de projeto de diferentes obras hidráulicas, dentre as quais se destacam as barragens. Assim, são dimensionadas obras de desvios do rio, os vertedouros e definidas as cotas das cristas das barragens. São usuais as definições de vazões máximas para períodos de retorno de 1.000 e 10.000 anos, visando o dimensionamento de vertedouros e cotas de cristas de barragens, seguindo os critérios recomendados nos manuais de projeto de usinas hidrelétricas da ELÉTROBRAS.

Essa metodologia apresenta vários aspectos que geram insegurança na determinação dos valores máximos relacionados a períodos de retorno muito superiores à extensão das séries históricas. A metodologia estatística é fortemente dependente da extensão da série histórica e é influenciada pela presença de um evento extraordinário (“outlier") que gera instabilidade ao método.

Além desses aspectos, a escolha da distribuição probabilística de melhor ajuste depende do julgamento do hidrólogo responsável pelos estudos. Muito embora existam alguns testes visando uma escolha mais objetiva (qui-quadrado, Kolmogorov-Smirnov, mínimos quadrados e outros), os resultados dependem da posição de plotagem e do índice adotado para análise comparativa dos ajustes.

\footnotetext{
${ }^{1}$ BIWAS, A.K. (1971). Some Thoughts on Estimatings Spillway Design Floods, Bull. IAHS, Vol. XVI, no 4, pp. 63-72.
} 
Além da instabilidade dos valores máximos inferidos a partir dessa metodologia, outro aspecto que merece crítica é a quase total desvinculação desses valores com a realidade física do fenômeno.

Por sua vez, a metodologia determinística utiliza-se de dados hidrometeorológicos para inferir a enchente máxima provável (EMP) a partir da precipitação máxima provável (PMP), definida pela World Meteorological Organization (WMO, 1973) como o limite superior de uma enchente potencial de uma bacia. No entanto, esta metodologia não permite estabelecer probabilidades ou efetuar análise de risco do evento de projeto.

Este aspecto expõe a metodologia à crítica tanto quanto a segurança quanto aos custos da obra. Um dos questionamentos tem sido que as evidências disponíveis são insuficientes e que as estruturas projetadas para a PMP/EMP não oferecem garantia, citando o fato que estes valores são frequentemente revisados após a ocorrência de enchentes extraordinárias. Por outro lado, tem-se afirmado que a metodologia determinística leva ao superdimensionamento e, consequentemente, ao sobrefaturamento, uma vez que o custo da obra pode vir a ser muitas vezes superior aos danos causados por uma enchente tão improvável.

A grande desvantagem da metodologia determinística recai no fato da metodologia não permitir associar riscos ou probabilidades. Ou seja, os projetos desenvolvidos com base na PMP/EMP não podem ser submetidos a análises de riscos. Em uma época de intensas pressões econômicas e acirrada competição por recursos, tem-se observado que a prática atual está, de modo crescente, voltada aos métodos clássicos de análises de sistemas visando a otimização dos riscos, os quais requerem descrições probabilísticas das variáveis de decisão. Neste contexto, estas considerações levam ao uso da tradicional metodologia estatística como a forma de avaliação dos riscos hidrológicos (GARCIA 1997).

O método conjugado (MC), apresentado por Garcia (1996), é conceituado através da combinação das virtudes dos métodos atuais e da coerência com o fenômeno físico. Assim, considera a série de valores observados das variáveis hidrológicas, seu comportamento estatístico e seus limites físicos, permitindo desenvolver análises de riscos de projetos hidráulicos de engenharia.

Ambas as metodologias atuais (estatística e determinística) apresentam algumas dificuldades, na qual o método conjugado fundamenta-se na minimização dessas dificuldades. A metodologia determinística vem sendo deteriorada pela falta de uma 
descrição probabilística objetiva. Por outro lado, a metodologia estatística perde credibilidade quando as distribuições probabilísticas são extrapoladas para faixa de valores de precipitação e vazão da ordem de magnitude da PMP e da EMP, para as quais as probabilidades não são objetivamente estimadas.

O método conjugado vem com o objetivo de estabelecer uma nova metodologia para definição dos valores máximos de projeto que considere a série de dados hidrológicos observados; que permita a definição de uma curva de distribuição probabilística, ou seja, que possam ser obtidos os valores máximos correspondentes e diferentes probabilidades de excedência; considere a existência de um limite dos fenômenos físicos de formação das chuvas e enchentes na bacia hidrográfica, permitindo que os valores máximos de projeto sejam obtidos por interpolação na curva de distribuição probabilísticas; e revele-se consistente, ou seja, que a extensão da série de dados hidrológicos observados, a presença de "outliers" e a variação dos menores valores da série de máximos tenham pouca influência nos valores máximos inferidos.

Vale ressaltar, que não existe uma uniformidade de critérios para a determinação das cheias de projeto (ver Anexo A). As metodologias empregadas variam desde a aplicação de um fator multiplicativo à maior vazão, ou mesmo à vazão média observada em um período, passando por fórmulas empíricas, análises de frequiência, até a aplicação de modelos hidrometeorológicos.

Diante do que foi colocado, fica evidente a necessidade de revisar os métodos atuais para determinação de valores máximos de variáveis hidrológicas ampliando os esforços com intuito de melhorar ambos os métodos e possibilitar aproximar essas metodologias com a realidade física em questão. Sendo assim o objetivo principal desta dissertação é:

- Avaliar a eficiência do método conjugado através de uma análise comparativa do mesmo com os métodos atuais (estatístico e determinístico) de determinação de valores máximos de projeto utilizando estudos de casos que procurem mostrar os principais inconvenientes práticos para determinação de valores máximos de projeto.

Para a conclusão do objetivo principal, é necessário um tratamento especifico para cada metodologia aqui citada (estatística, determinística e conjugada), sendo assim os objetivos específicos do trabalho são: 
- Avaliar a metodologia estatística considerando todas as etapas normalmente utilizados ou procedimentos necessários, permitindo com clareza demonstrar a melhor aplicação do método quanto à análise de dados, o ajuste da distribuição probabilística e a inferência/análise dos resultados;

- Avaliar a metodologia determinística tendo em vista as críticas decorrentes da utilização do método, visando o melhor desempenho nos critérios de determinação dos valores da PMP/EMP;

- Justificar a utilização do método conjugado fazendo uma análise crítica do estado da arte na definição dos valores máximos de projeto de obras hidráulicas, identificando os problemas nas metodologias probabilística e determinística; 


\section{ESTADO DA ARTE NA DETERMINAÇÃO DE VALORES MÁXIMOS DE VA̧RIÁVEIS HIDROLÓGICAS}

\subsection{Método Estatístico}

\subsubsection{Introdução}

O método estatístico para determinação de valores máximos de variáveis hidrológicas é denominado de análise de freqüência. O primeiro objetivo da análise de freqüência é relacionar a magnitude de eventos extremos com suas freqüências de ocorrência, através do uso das distribuições de probabilidade. Righetto (1998) mostra que sendo $x_{1}, x_{2}, x_{3}, \ldots, x_{n}, n$ valores amostrais ordenados de um evento aleatório $X$, de modo que $\mathrm{x}_{1} \leq \mathrm{x}_{2} \leq \mathrm{x}_{3} \leq \ldots \leq \mathrm{x}_{\mathrm{n}}$. Para o tipo de evento hidrológico considerado, uma ou mais distribuições teóricas são selecionadas com o objetivo de buscar aquela que melhor se ajuste à distribuição de freqüência da amostra. Na análise de frequiência são analisados dados históricos da variável hidrológica disponível no local de interesse ou por meio de regionalização.

O método estatístico ou análise de freqüência de dados hidrológicos envolve, basicamente, as seguintes etapas (GARCIA, 1996):

1. Definição de uma amostra, na forma de uma série de dados, que satisfaça os critérios estatísticos de aleatoriedade, independência, homogeneidade e estacionaridade e que tenha sido verificada à presença de "outliers";

2. Ajuste da melhor distribuição probabilística teórica aos dados utilizando a melhor técnica disponível;

3. Utilização da distribuição ajustada para inferir, estatisticamente, os valores referentes à população; i. e. uma hipotética série de dados muito longa. 
$\mathrm{Na}$ primeira etapa (definição da amostra) são tratados os termos que serão associados à amostra como o tempo de retorno (Tr), os métodos de locação das amostras (posições de plotagens), os modelos para definição da amostra e os testes que são recomendados pela literatura para verificar os critérios estatísticos requeridos pela análise de freqüência.

Na segunda etapa (ajuste da distribuição probabilística) da análise de freqüência são contempladas as principais técnicas de escolha e ajuste da melhor distribuição. E na terceira etapa trata-se da inferência e análise de resultados na qual se tem uma maior dificuldade de avaliar a extrapolação de valores.

A literatura neste campo é vasta e crescente. Ao longo dos anos tem havido muitas discussões de aspectos gerais da análise de frequiência. Podem-se citar alguns autores que em diferentes trabalhos procuraram desenvolver e aprimorar a análise de frequiência de variáveis hidrológicas. Os autores são: Chow (1964), Yevjevich (1972), Haan (1977), Kite (1978), e Rao e Hamed (2000).

Todd (1957) discutiu os princípios básicos de análise de frequiência com dados de vazão e delineou os procedimentos de cálculo. Linsley (1986) discutiu a precisão das estimativas de valores máximos de vazão. A distância entra a teoria e a prática na análise de frequiência de valores máximos e as estratégias para aproximá-los foram discutidas por Pilgrim (1986). Uma das conclusões de Pilgrim (1986) foi a desatenção dos pesquisadores aos problemas na qual é de grande importância prática.

No Brasil tem-se desenvolvido vários trabalhos específicos no assunto, sendo na maioria das vezes abordado em trabalhos de aspectos geral como: Righetto (1998), Tucci (1993) e Pinto (1976). Alguns trabalhos específicos podem ser destacados como os trabalhos de Costa et. al. (1981), Pinheiro e Guerrero-Salazar (1981), Pinheiro et. al (1981), Garcia (1996) e Queiroz (2002).

Diante da variedade de estudos e trabalhos envolvidos direta ou indiretamente com o assunto análise de freqüência observa-se a importância do estudo contínuo na procura da adequação da melhor técnica, método ou teoria.

\subsubsection{Definição da Amostra}

Esta primeira etapa é caracterizada pelo tratamento que se dá aos dados, sendo estes verificados segundo as hipóteses pré-estabelecidas no método estatístico. 
Segundo Tucci (In Tucci,1993) o ajuste de uma distribuição de probabilidade aos dados históricos (amostra) baseia-se nas seguintes hipóteses:

- A série dos valores amostrais das variáveis hidrológicas devem ser independentes;

- O processo natural de ocorrência das mencionadas variáveis é estacionário;

- A amostra é representativa da população. Portanto para a análise de frequiência é necessário que estas hipóteses sejam satisfeitas.

Para valores máximos de variáveis hidrológicas a chance de ocorrer dependência entre os valores extremos é pequena, devido ao tempo que separa cada enchente. A escolha da variável máxima é realizada, em geral, dentro do ano hidrológico. O ano hidrológico corresponde ao período de 12 meses a partir do início do período chuvoso e o fim da estação seca.

Morettin e Toloi (1981) comentam que uma das suposições mais freqüentes que se faz a respeito de uma série temporal é a de que ela é estacionária, ou seja, ela se desenvolve no tempo aleatoriamente ao redor de uma média constante, refletindo alguma forma de equilíbrio estável. Essa característica apresentada pela série garante a constância nos modelos probabilísticos usado na análise de freqüência. Para variáveis hidrológicas a não-estacionaridade de uma série pode ser provocada: pelo aumento da urbanização, resultando numa mudança gradual das características do escoamento; pela construção de reservatórios ou diques, alterando a série de vazões a jusante da barragem; pelo desmatamento, por exploração ou queima, mudando o comportamento do escoamento.

A análise da estacionaridade é, e deve ser prática comum na análise de dados, como a que Muller et. al. (1998) fizeram com as séries de vazões e precipitações das bacias hidrográficas dos rios afluentes à usina de Itaipu. Eles, também, elaboraram uma estimativa da percentagem de variação ocorrida nas vazões e precipitações médias após 1970. As análises foram baseadas em diferentes técnicas estatísticas aplicadas às séries históricas disponíveis na bacia do rio Paraná em Itaipu. Análises adicionais foram realizadas, em nível preliminar, envolvendo estimativas da evapotranspiração real e aspectos meteorológicos e de uso do solo. Os estudos desenvolvidos por eles, permitiram concluir que houve aumentos significativos de vazões e precipitações médias após 1970. Aparentemente, o fenômeno do aumento da vazão decorreu dos 
efeitos conjuntos do aumento da precipitação (que pode ser transitório), diminuição da evapotranspiração provocada pela retirada da mata nativa e aumento da infiltração da chuva, facilitada pelo adequado manejo do solo. Os aumentos de precipitação podem justificar o aumento de vazões nas regiões situadas a montante na área de estudo. Para as bacias situadas mais a jusante, o aumento de vazão é incompatível com o aumento da precipitação, indicando que outros fatores, como a mudança de uso do solo, interferem no processo.

O exemplo anterior demonstrou a importância da avaliação periódica da série com o objetivo de avaliar se as estimativas dos valores máximos de projeto continuam válidos. A utilização de modelos probabilísticos em hidrologia envolve dois tipos de incertezas: a incerteza na escolha do modelo que descreve o fenômeno em estudo (ex: distribuição normal ou log-normal) e a incerteza nos parâmetros, ou seja, incertezas na estimação dos parâmetros do modelo selecionado, causando o chamado erro amostral de estimação. Para aplicação correta destes modelos e dos métodos de estimação dos parâmetros é necessário que a série analisada seja representativa, ou seja, a série é representativa da população quando abrange, em termos de ordem de grandeza, os valores da população. Segundo Tucci (1993) alguns autores consideram que uma série amostral de $\mathrm{N}$ anos, pode estimar vazões com alguma confiabilidade para tempos de retorno de até $2 \mathrm{~N}$. Na realidade não é o numero de anos, mas a representatividade dos anos das séries que permite uma boa estimativa dos parâmetros da população.

\section{- Período de Retorno}

Eventos máximos de variáveis hidrológicas não seguem um padrão fixo nem no tempo nem na sua magnitude. Intervalos de tempo entre os máximos variam consideravelmente. Segundo Righetto (1998) a probabilidade de ocorrência de um evento hidrológico indesejável, seja com relação às grandes precipitações que provocam enchentes, seja com as grandes estiagens é um parâmetro fundamental para avaliação e projeto de sistemas hídricos, como reservatórios, canais, vertedores, bueiros, galerias de águas pluviais etc. O hidrólogo, afirma ele, ao analisar eventos raros ou extremos, prefere mensurar a probabilidade de ocorrência do evento em termos de valor esperado de tempo de ocorrência ou intervalo de tempo médio entre essas ocorrências. 
Sendo assim, o tempo de retorno é o tempo médio entre a ocorrência de eventos extremos. Valores altos de variáveis hidrológicas têm altos períodos de retorno e viceversa. Rao e Hamed (2000) apontam que a definição de período de retorno talvez não envolva alguma referência à probabilidade, no entanto, uma ligação entre a probabilidade de ocorrência de um evento e seu período de retorno pode ser justificada.

Uma dada vazão $\mathrm{q}_{\mathrm{x}}$ com período de retorno $\mathrm{T}$ pode ser excedida uma vez em $\mathrm{T}$ anos. Uma vez que a probabilidade de excedência é $P\left(Q_{t}>q\right)=1 / T$. A probabilidade acumulada de não-excedência, $\mathrm{F}\left(\mathrm{Q}_{\mathrm{t}}\right)$ é dada pela Eq. 1 (RAO E HAMED, 2000):

$$
\mathrm{F}\left(\mathrm{Q}_{\mathrm{t}}\right)=\mathrm{P}\left(\mathrm{Q}_{\mathrm{t}}<\mathrm{q}\right)=1-\mathrm{P}\left(\mathrm{Q}_{\mathrm{t}}>\mathrm{q}\right)=1-1 / \mathrm{T}_{\mathrm{r}}
$$

A Eq. 1 é a base para estimar a magnitude da vazão, $Q_{t}$, dado seu período de retorno $T_{r}$. Substituindo $F\left(Q_{t}\right)=1-1 / T_{r}$ em uma distribuição probabilística conhecida, pode-se determinar os valores de $\mathrm{Q}_{\mathrm{t}}$.

\section{- Posição de Plotagem}

A necessidade de se tratar da estimativa das probabilidades de excedência (ou sua recíproca, tempo de retorno) das amostras levou aos pesquisadores a desenvolver métodos que tratem com eficácia os valores dessas probabilidades. Dentre os diversos métodos para determinar a posição de plotagem dos dados, o método mais simples é o método Califórnia na qual a estimativa foi de igualar tais probabilidades as frequiências cumulativas de excedência, assim (LANNA In: TUCCI, 1993):

$$
\mathrm{P}\left[\mathrm{X} \geq \mathrm{X}_{\mathrm{i}}\right]=\mathrm{i} / \mathrm{n}
$$

onde i é a ordem do valor na amostra ordenada do valor mais raro para o menos raro e $\mathrm{n}$ é o tamanho da amostra. Lanna (In: TUCCI (1993) comenta que existem alguns estudos que mostram que esta abordagem não é a melhor escolha. Rao e Hamed (2000) apresentam algumas das principais contribuições de pesquisadores na análise da posição de plotagem. Cunnane (1978) fez um estudo na qual observou que as principais 
fórmulas apresentadas até o presente momento de sua análise se enquadravam em uma estrutura geral dada pela eq. 3 :

$$
\operatorname{Tr}=1 / \mathrm{P}[\mathrm{X} \geq \mathrm{x}]=\mathrm{n}-2 \alpha_{1}+1 / \mathrm{i}-\alpha_{1}
$$

em que $\alpha_{1}$ é um parâmetro especifico da distribuição testada. Os diferentes valores de $\alpha$ são propostos por vários autores, originando seus modelos, como resumido na tabela 1 (STEDINGER et al., 1993).

Tabela 1- Alternativas de posição de plotagem e suas motivações.

\begin{tabular}{|c|c|c|c|c|}
\hline Autor & Fórmula & $\alpha_{1}$ & Período de Retorno: $T_{\mathrm{r}}$ & Motivação \\
\hline Weibull & $\frac{i}{n+1}$ & 0 & $\mathrm{n}+1$ & $\begin{array}{l}\text { Probabilidade de excedência não } \\
\text { viesada para todas distribuições }\end{array}$ \\
\hline Median & $\frac{i-0,3175}{n+0,365}$ & 0,3175 & $1,57 \mathrm{n}+0,5$ & $\begin{array}{l}\text { Probabilidade de excedência mediana } \\
\text { para todas distribuições }\end{array}$ \\
\hline APL & $\frac{i-0,35}{n}$ & 0,35 & $1,54 \mathrm{n}$ & $\begin{array}{l}\text { Usada com momentos de pesos } \\
\text { probabilísticos }\end{array}$ \\
\hline Blom & $\frac{i-3 / 8}{n+1 / 4}$ & 0,375 & $1,6 \mathrm{n}+0,4$ & Quantis normais não viesados \\
\hline Cunnane & $\frac{i-0,40}{n+0,2}$ & 0,40 & $1,67 n+0,3$ & Quantis não viesados aproximadamente \\
\hline Gringorten & $\frac{i-0,44}{n+0,12}$ & 0,44 & $1,79 n+0,2$ & Otimizada para distribuição Gumbel \\
\hline Hazen & $\frac{i-0,5}{n}$ & 0,5 & $2 n$ & Uma escolha tradicional \\
\hline
\end{tabular}

Fonte: STEDINGER et al., 1993

\section{- Modelos Utilizados na Análise de Freqüiência de Variáveis Hidrológicas}

Em análise de freqüência de variáveis hidrológicas, procura-se determinar uma função única entre a magnitude da variável hidrológica analisada e seu correspondente período de retorno. A tarefa é extrair informações de registros de variáveis hidrológicas e estimar a relação entre $\mathrm{Q}_{\mathrm{t}}$ e Tr. Rao e Hamed (2000) apontam três diferentes modelos 
que podem ser considerados para este propósito. Os modelos são (1) Séries de máximos anuais (MA), (2) Séries de durações parciais (DP) e (3) Séries temporais (ST).

Nas séries de máximos anuais (MA) apenas o valor mais alto de cada ano do registro é considerado. No entanto, o uso da série MA pode envolver algumas perdas de informação. Como no caso do segundo e terceiro valor mais alto de um ano ser maior que o valor mais alto de outro ano (KITE, 1978). Esta situação é evitada nas séries DP onde todos os valores a partir de certo valor de referência são considerados. Em geral o valor de referência selecionado deve ser suficiente para incluir pelo menos um valor de máximos em cada ano, no entanto esta escolha é limitada pelo fato que as observações podem não ser independentes (RAO E HAMED, 2000).

De acordo com CUNNANE (1989), o modelo MA é estatisticamente mais eficiente que o modelo DP quando $\lambda$ é pequeno $(\lambda<1,65)$. Onde $\lambda$ é o número médio de picos por ano incluídos na série de DP. O período de retorno entre as séries MA e DP são diferentes e relacionados pela eq. 4 (RAO E HAMED, 2000):

$$
\mathrm{Te}=[\log (\operatorname{Tr} / \mathrm{Tr}-1)]^{-1}
$$

A relativa diferença entre Te e Tr é maior para pequenos valores de $\mathrm{T}$ e converge para 0,5 com o aumento de Tr. Rosbjerg (1977) demonstrou que quando os eventos seguem o modelo de Poisson, a relação entre os períodos de retornos das séries DP e MA dada na eq. 4 é exatamente satisfeita. As primeiras discussões e comparações das séries MA e DP é encontrada em Chow (1964). Cunnane (1973) demonstrou que a estimativa da variância baseados na série DP é menor que aquela baseada na série MA, caso a série DP apresenta-se no mínimo $1,65 \mathrm{~N}$ valores. Onde $\mathrm{N}$ é o número de anos do registro. A eficiência relativa do uso da série DP e MA em análise de frequiência de cheia foram analisados por Tavares, Valdares e da Silva (1983). Eles também apresentaram algumas recomendações sobre níveis de truncamento (valor de referência) para selecionar a série DP. Este procedimento é baseado na igualdade da média e variância da distribuição de Poisson.

Moreira et. al. (1983) compararam o emprego dos métodos de séries parciais e de máximos anuais para a estimativa de vazões com tempo de recorrência elevados. Para esta comparação foi utilizado um modelo matemático gerador de vazões diárias. Foram geradas, com o auxilio do modelo, séries representativas dos registros de vazões médias diárias de dois postos fluviométricos da bacia do rio Doce. Destas séries 
completas geradas, foram selecionadas para o estudo quatro séries de vazões extremas: séries de máximos anuais e séries parciais contendo um, dois e três picos por ano. A metodologia de avaliação dos métodos consistiu em subdividir estas quatro grandes séries de extremos em sub-amostras de diferentes tamanhos e, a partir de cada uma, estimar quantis com diferentes tempos de recorrência. A escolha, em cada caso, recaiu sobre o método que apresentou o menor erro médio na estimativa destes quantis. Os resultados obtidos revelaram que não se pode a priori optar por séries de máximos anuais ou séries parciais ao contrário do que é sugerido por alguns autores que recomendam o uso de séries parciais para pequenos registros.

Para exemplificar a diferença entre séries de durações parciais e séries de máximos anuais a figura 1 apresenta um gráfico em que à série de precipitações máximas anuais de $12 \mathrm{~h}$ são representados por pontos e a série parcial representado pelas barras. Essa série de precipitação foi retirada do Banco de Dados Pluviográficos do Estado de São Paulo (DAEE, 1988) observadas no observatório IAG localizado no município de São Paulo.

A série estende-se de 1934 a 1998, com 45 anos de precipitações máximas anuais, uma vez que a série apresenta inúmeros anos sem observação. Esse problema motivou a criação de uma série parcial de valores, adotando como o valor de referência (nível de truncamento) o menor valor obtido na série de máximos anuais (24 mm), assim todos os valores dentro de um ano quaisquer maiores que o valor de referência era selecionado para a formação da série de duração parcial. A série parcial adotada apresenta 123 valores de precipitações obtendo desta forma um coeficiente $\lambda=2,73(\lambda=$ $123 / 45=2,73$ ) ou seja, existe em média 2,73 picos por ano incluídos na série de DP.

No modelo ST se dispõe de dados seqüenciais onde o regime de valores de variáveis hidrológicas pode ser caracterizado por meio da análise da sequiência de valores numéricos ordenados cronologicamente de acordo com suas ocorrências (RIGHETTO, 1998). Esse modelo não será tratado no escopo dessa dissertação devido ao maior uso dos outros dois modelos na análise de frequiência. 


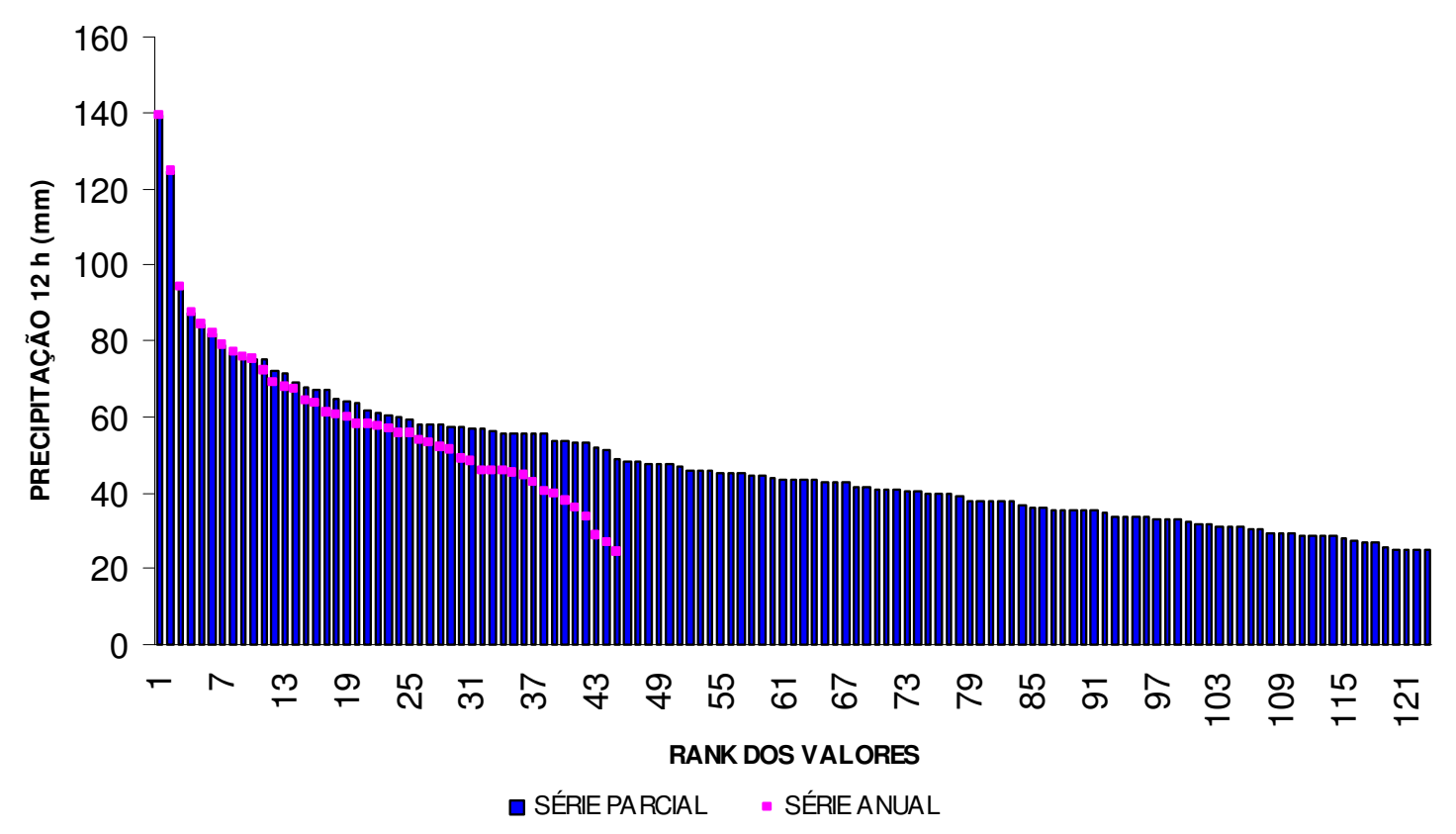

Figura1- Representação gráfica de uma série de duração parcial e máximos anuais

\section{- Testes de Dados Hidrológicos}

Como comentado na seção 2.1.1, as duas hipóteses básicas na análise de freqüência de variáveis hidrológicas são a independência e a estacionaridade da série de dados (amostra). Além disso, a necessidade de se considerar que os dados apresentem uma constância nos parâmetros (homogeneidade) deve ser feita. Vários testes estatísticos estão disponíveis para testar as hipóteses descritas acima. Em geral, os procedimentos usados na aplicação destes testes são (KITE, 1978):

1. Declarar a hipótese nula $\left(\mathrm{H}_{0}\right)$ que não existe diferença entre duas séries;

2. Escolher um teste estatístico;

3. Selecionar um nível de significância $(\alpha)$;

4. Definir a região de rejeição com base na distribuição do teste estatístico;

5. Calcular o valor do teste estatístico. Se o valor estiver na região de rejeição, rejeita-se $\mathrm{H}_{0}$.

Esses testes são divididos em paramétricos e não-paramétricos. Os testes nãoparamétricos são menos poderosos que seus equivalentes paramétricos. Devem ser utilizados nas situações em que os testes paramétricos não podem ser usados. Enquanto 
que nos testes paramétricos são comparados os parâmetros da população (média e variância), nos testes não-paramétricos comparam-se os postos ou "ranks" que cada observação recebe após sua ordenação.

Os testes paramétricos mais usuais na hidrologia são: Wald-Wolfowitz e t de Student. Já os teste não paramétricos usuais são: Cox-Stuart, Coeficiente de Correlação de Spearman, Mann-Kendall, Wilcoxon e Kruskal-Wallis.

\section{- Teste de Independência e Estacionaridade}

Dada uma amostra de tamanho N, o teste paramétrico de Wald-Wolfowitz (RAO E HAMED, 2000) é usado para testar a independência da série de dados e a existência de tendência na mesma. Para uma série de dados $\mathrm{x}_{1}, \mathrm{x}_{2}, \mathrm{x}_{3}, \ldots, \mathrm{x}_{\mathrm{n}}$ a estatística $\mathrm{R}$ é calculado pela eq. 5 :

$$
R=\sum_{i=1}^{N-1} x_{i} x_{i+1}+x_{1} x_{N}
$$

quando os elementos da mesma amostra são independentes, $\mathrm{R}$ segue uma distribuição normal com média e variância dada pela eq. 6 e 7 ,

$$
\begin{gathered}
\bar{R}=\frac{\left(s_{1}^{2}-s_{2}\right)}{N-1} \\
\operatorname{var}(R)=\frac{s_{2}^{2}-s_{4}}{N-1}-\bar{R}^{2}+\frac{\left(s_{1}^{4}-4 s_{1}^{2} s_{2}+4 s_{1} s_{3}+s_{2}^{2}-2 s_{4}\right)}{(N-1)(N-2)}
\end{gathered}
$$

em que $s_{r}=N_{r}$ e $m_{r}$ é o r-iésimo momento da amostra. A estatística $u=(R-\bar{R}) /(\operatorname{var}(R))^{1 / 2}$ é assintoticamente distribuído com média zero e variância um e é usada para testar a hipótese de independência com nível de significância $\alpha$, comparando a estatística $\mathrm{u}$ com a variável normal padrão $\mathrm{u}_{\alpha / 2}$ correspondendo a probabilidade de excedencia $\alpha / 2$.

- Teste de Homogeneidade e Estacionaridade 
Estudos desenvolvidos visando à análise da homogeneidade e estacionaridade das séries são essencialmente baseados em análises estatísticas. São aplicados testes paramétricos e não paramétricos. A seguir são comentados alguns destes testes que tratam da homogeneidade e estacionaridade das séries.

O teste paramétrico t de Student (SPIEGEL, 1978) é o mais simples e testa a igualdade das médias de duas sub-amostras.

No teste não-paramétrico de Wilcoxon (BUSSAB e MORETTIN, 2004) o interesse é saber se uma população tende a ter valores maiores do que a outra, ou se elas tem a mesma mediana ou média. Esse teste é baseado nos postos dos valores obtidos combinando-se duas amostras. Isso é feito ordenando-se esses valores, do menor para o maior, independentemente do fato de qual população cada valor provém. A estatística do teste é a soma dos postos associados aos valores amostrados de uma população, $\mathrm{P}_{1}$, por exemplo. Se essa soma for grande, isso é uma indicação de que os valores dessa população tendem a ser maiores do que os valores $\mathrm{P}_{2}$.

No teste Kruskal-Wallis (SIEGEL, 1956) trabalha-se com sub-amostras ordenadas da série total e verificam a posição relativa dos elementos das sub-amostras antes e depois da ordenação, para na seqüência aplicar a estatística $H$, em que:

$$
H=\frac{12}{N(N+1)} \sum_{j=1}^{k} \frac{R_{j}^{2}}{n_{j}}-3(N+1)
$$

K é o número de amostras, $\mathrm{R}_{\mathrm{j}}$ é a soma dos postos na j-ésima amostra, $\mathrm{n}_{\mathrm{j}}$ é o número de observações na j-ésima amostra e $\mathrm{N}=\sum_{j=1}^{k} n_{j}$, o número total de observações. Para todos $\mathrm{n}_{\mathrm{j}}>5$, H tem distribuição qui-quadrado com k-1 graus de liberdade. Se o valor calculado de $\mathrm{H}$ for menor que o valor crítico, a hipótese nula não pode ser rejeitada.

No teste não-paramétrico de Mann-Kendal (ELETROBRÁS, 1987a apud BRADLEY, 1968) ${ }^{2}$, a hipótese nula é de que todos os valores $\mathrm{x}_{\mathrm{i}}, \mathrm{i}=1, \ldots ., \mathrm{n}$, da série foram sorteados aleatoriamente e da mesma população. Se a hipótese nula é verdadeira, as $n$ ! permutações dos x's obtidos tem igual probabilidade de formarem a série temporal realmente obtida. No entanto, se houver uma tendência monótona no processo de sorteio

\footnotetext{
${ }^{2}$ BRADLEY, J.V. (1968), Distribution - Free Statistical Tests, Prentice Hall, Inc.
} 
dos X's, as permutações quem formarem séries monótonas serão mais prováveis. Para n $>10$, usa-se a distribuição normal padrão para se obter os valores críticos.

No teste não-paramétrico de Cox-Stuart (MORETTIN E TOLOI, 1981) agrupamos as observações em pares $\left(Z_{1}, Z_{1+c}\right),\left(Z_{2}, Z_{2+c}\right), \ldots .,\left(Z_{N-c}, Z_{N}\right)$, onde $c=N / 2$, se $\mathrm{N}$ é par e c $=(\mathrm{N}+1) / 2$, se $\mathrm{N}$ é impar. A cada par $\left(\mathrm{Z}_{\mathrm{i}}, \mathrm{Z}_{\mathrm{i}+\mathrm{c}}\right)$ associamos o sinal + se $\mathrm{Z}_{\mathrm{i}}<$ $Z_{i+c}$ e o sinal - se $Z_{i}>Z_{i+c}$, eliminando os empates. Seja $n$ o número de pares onde $Z_{i} \neq$ $\mathrm{Z}_{\mathrm{i}+\mathrm{c}}$. O teste é:

$\mathrm{H}: \mathrm{P}\left(\mathrm{Z}_{\mathrm{i}}<\mathrm{Z}_{\mathrm{i}+\mathrm{c}}\right)=\mathrm{P}\left(\mathrm{Z}_{\mathrm{i}}>\mathrm{Z}_{\mathrm{i}+\mathrm{c}}\right), \forall \mathrm{i}$ : não existe tendência contra

$\mathrm{K}: \mathrm{P}\left(\mathrm{Z}_{\mathrm{i}}<\mathrm{Z}_{\mathrm{i}+\mathrm{c}}\right) \neq \mathrm{P}\left(\mathrm{Z}_{\mathrm{i}}>\mathrm{Z}_{\mathrm{i}+\mathrm{c}}\right), \forall \mathrm{i}$ : existe tendência

Para $\mathrm{n} \leq$, a regra de decisão é baseada na distribuição binomial e para $n>20$ pode-se usar a aproximação normal.

O teste baseado no coeficiente de Correlação de Spearman (MORETTIN E TOLOI, 1981) é, em geral, mais poderoso que o teste de Cox-Stuart. Chamemos de $\mathrm{R}_{\mathrm{t}} \mathrm{o}$ posto $\mathrm{Z}_{\mathrm{t}}$ dentre as $\mathrm{N}$ observações. Se houver observações empatadas usa-se postos médios. Seja:

$$
T_{3}=\sum_{t=1}^{N}\left[R_{t}-t\right]^{2}
$$

em que $\mathrm{t}=1,2, \ldots, \mathrm{N}$ são os postos "naturais" dos instantes de tempo. Rejeita-se a hipótese de que não existe tendência se $T_{3}$ for grande ou pequeno. A distribuição $T_{3}$ é tabelada.

Outro teste usado na hidrologia é a análise de tendência polinomial (HOEL, 1984) para estimar a tendência. Este teste consiste em se ajustar aos valores observados da série temporal (vazão anual e precipitação total anual) modelos lineares e exponenciais. Neste teste os parâmetros dos modelos, geralmente, são estimados pelo método dos mínimos quadrados generalizado e considerando a hipótese de que os ruídos são correlacionados.

Cada um dos testes analisa a série temporal de observações de forma diferenciada, o que pode conduzir a diferenças nos resultados obtidos para cada um dos testes para um mesmo nível de significância. 


\section{- Teste de Verificação da Presença de Outliers}

Outliers são eventos extraordinários na série de valores, Rao e hamed (2000) definem como observações de determinada magnitude que desviam significativamente das magnitudes observadas em toda série e podem ocorrer devido a erros na coleta de dados e registros, ou devido a causas naturais. A presença de outliers nos dados causa dificuldades no ajuste de uma distribuição teórica aos dados observados. Baixos e altos outliers são frequentemente encontrado em séries de dados e causam diferentes efeitos na análise de freqüência. O teste de Grubbs e Beck (1972) recomendado pelo United States Water Resources Council (USWRC, 1981) pode ser usado para detectar outliers. Neste teste os valores $\mathrm{x}_{\mathrm{H}}$ e $\mathrm{x}_{\mathrm{L}}$ são calculados pela eq. 10 e 11 .

$$
\begin{aligned}
& x_{H}=\exp \left(\bar{x}+k_{N} s\right) \\
& x_{L}=\exp \left(\bar{x}-k_{N} s\right)
\end{aligned}
$$

em que $\bar{x}$ e s são a média e o desvio padrão dos logaritmos naturais da amostra, respectivamente, e $\mathrm{k}_{\mathrm{N}}$ é a estatística do teste de Grubbs e Beck tabelado para diferentes tamanho de amostras e níveis de significância. Para $10 \%$ de nível de significância, a seguinte aproximação proposta por Pilon et al. (1993) é usada, onde N é o tamanho da amostra.

$$
k_{N}=-3,62201+6,28446 N^{1 / 4}-2,49835 N^{1 / 2}+0,491436 N^{3 / 4}-0,037911 N
$$

Valores na amostra maiores que $\mathrm{x}_{\mathrm{H}}$ são considerados altos outliers, enquanto aqueles menores que $\mathrm{x}_{\mathrm{L}}$ são considerados baixos outliers.

Outros testes como o Shapiro-Wilk, Anderson-Darling, Skewness, Student deviation, RST e PPC (GOTTSCHALK E KUNDZEWICZ, 1994), são também usados para verificar a presença de Outliers. 


\subsubsection{Ajuste da Distribuição Probabilística}

Esta segunda etapa da metodologia estatística para determinação de valores máximos trata das principais técnicas de escolha e ajuste da melhor distribuição.

\section{- Estimativa Inicial da Distribuição da População das Variáveis Hidrológicas}

Na prática, a distribuição de probabilidade da população do local ou da região analisada é desconhecida. A hipótese de que dados de um sistema provêm de uma única distribuição pode ser questionável quando dados de uma extensa bacia é analisada. No entanto, para análise ser de uso prático, simples distribuições são frequentemente usados para caracterizar a relação entre a magnitude de eventos extremos e suas respectivas freqüências.

Devido à falta de bases sólidas para a escolha da distribuição que melhor se ajusta à série de dados, é recomendável testar diversas distribuições. Essas distribuições podem ser escolhidas, inicialmente, com base nos valores do coeficiente de assimetria e de curtose, através do diagrama das relações dos momentos ou MRD ("moment ratio diagrams") e também o L-MRD.

$\mathrm{O}$ momento de ordem $\mathrm{k}$ de uma variável aleatória discreta ou contínua com distribuição de probabilidades conhecida é uma estatística com a seguinte estrutura:

$$
m_{k}=E\left[X^{k}\right]
$$

$\mathrm{O}$ momento de primeira ordem, $\mathrm{m}_{1}$, é também denominado Esperança ou Valor Esperado da variável, sendo notado por E[X]. ou seja:

$$
m_{1} \equiv E[X]=\int_{-\infty}^{\infty} x f(x) d x
$$

Existe outro tipo de momento mais usado que é o momento central. Seu cálculo é realizado por: 


$$
u_{k}=E\left[\left(X-m_{1}\right)^{k}\right]=E\left\{(X-E[X])^{k}\right\}
$$

sendo $\mathrm{m}_{1} \mathrm{o}$ momento de primeira ordem. A importância dos momentos refere-se nas relações que estes têm com os coeficientes estatísticos (média, variância, curtose e etc...) da população ou da amostra. As relações dos momentos convencionais (momento da origem e momento central) são definidas abaixo (RAO E HAMED, 2000):

$$
\begin{aligned}
& \text { Coeficiente de Variação } C_{v}=z=\frac{u_{2}^{1 / 2}}{m_{1}^{\prime}} \\
& \text { Coeficiente de Assimetria } C_{s}=\gamma_{1}=\frac{u_{3}}{u_{2}^{3 / 2}} \\
& \text { Coeficiente de Curtose } \quad C_{c}=\gamma_{2}=\frac{u_{4}}{u_{2}^{2}}
\end{aligned}
$$

Para uma dada distribuição, Rao e Hamed (2000) afirmam que os momentos podem ser expressos através de funções dos parâmetros da distribuição, podendo um momento de uma ordem mais alta ser relacionado com o momento de ordem mais baixa. Para uma distribuição com dois parâmetros, o momento $m_{3}$ pode ser expresso como uma função única de $m_{2}$. Uma outra versão do diagrama da relação dos momentos (MRD) é a relação entre $\mathrm{C}_{\mathrm{s}}{ }^{2}$ e $\mathrm{C}_{\mathrm{k}}$. Esta relação é comumente chamada de $\mathrm{MRD}\left(\mathrm{C}_{\mathrm{s}}{ }^{2}-\right.$ $\mathrm{C}_{\mathrm{k}}$ ) e é mostrada na figura 2. Esta relação é similar ao diagrama $\mathrm{C}_{\mathrm{s}}-\mathrm{C}_{\mathrm{k}}$ exceto que o $\operatorname{MRD}\left(\mathrm{C}_{\mathrm{s}}{ }^{2}-\mathrm{C}_{\mathrm{k}}\right)$ tem o valor do $\mathrm{C}_{\mathrm{s}}$ elevado ao quadrado. Esse diagrama representa um estimador inicial das possíveis distribuições de probabilidade da população da variável aleatória.

Um outro diagrama utilizado para determinar quais distribuições testar é o diagrama de momentos L. Hosking (1990) introduziu os momentos L que são funções lineares dos momentos com pesos probabilísticos (PWMs). O diagrama de momentos $\mathrm{L}$ (L-MRD) é análogo ao MRDs convencional $\left(\mathrm{C}_{\mathrm{s}}-\mathrm{C}_{\mathrm{k}}\right)$ e também ilustra graficamente a relação entre a curtose- $\mathrm{L}$ e a assimetria-L, tanto da distribuição de probabilidade como da amostra em questão, ou seja, ele compara estimativas de razões de momentos L teóricos com suas contrapartidas amostrais. Vários estudos recentes documentam que o diagrama de momentos L são muito úteis para avaliar a qualidade de ajuste da 
distribuição de probabilidades à series de dados amostrais (HOSKING, 1990; RAO E HAMED, 2000, QUEIROZ, 2002). O diagrama de momentos L permite comparar várias distribuições, usando o mesmo gráfico como o mostrado na figura 3.

Vale salientar, que a aplicabilidade prática destes diagramas se dá na consideração de uma região homogênea, na qual existem diversas estações de medição. Para cada estação calculam-se os coeficientes estatísticos (assimetria e curtose), e assim, via avaliação visual permite determinar qual a maior tendência de concentração dos pontos que representam cada posto de medição no gráfico. Para cada distribuição teórica existe uma função que relaciona esses coeficientes estatísticos (assimetria e curtose), podendo assim estimar, inicialmente, quais distribuições sejam testadas a partir dos pontos, que representam os postos de medição, dispostos no gráfico.

\section{- Verificação das Distribuições}

As distribuições pré-selecionadas pelas relações dos momentos (MRD convencional, MRD e L-MRD) devem necessariamente se ajustar adequadamente à série de dados disponíveis. Esse ajuste adequado reflete a boa habilidade descritiva da função distribuição de probabilidade. Vale ressaltar que, embora o bom ajuste da distribuição com os dados seja uma condição necessária, não é suficiente para sua es-

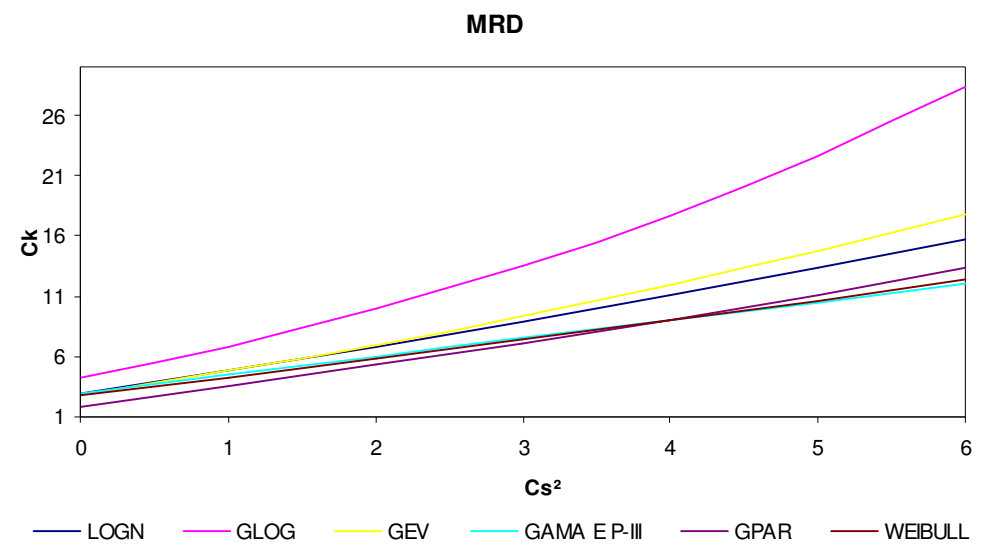

Figura2 - Diagrama que relaciona os momentos de distribuições teóricas de probabilidades 


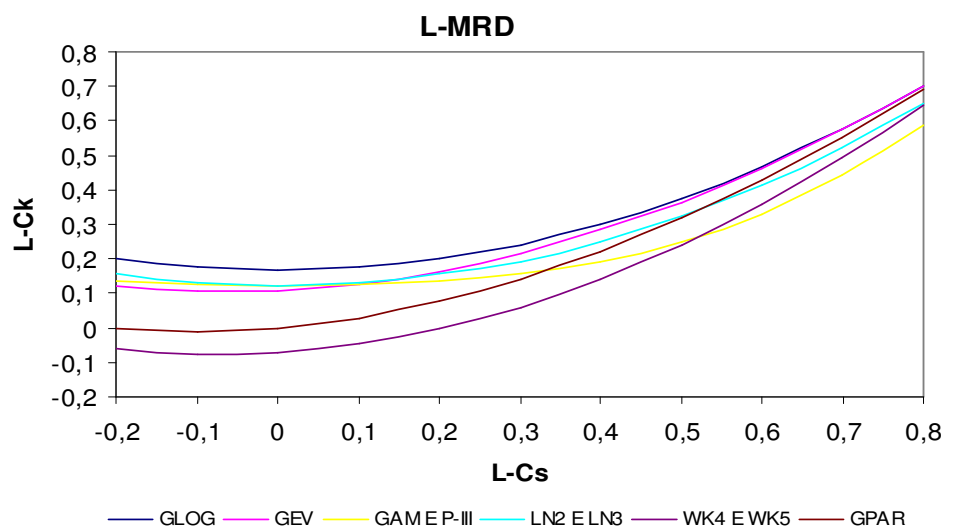

Figura3- Diagrama que relaciona os L-momentos de distribuições teóricas de probabilidades

colha (KITE, 1978). Os testes de aderência mais comuns de verificação do ajuste da distribuição à série de dados são o qui-quadrado, Kolmogorov-Smirnov (HAAN, 1977) e o teste da máxima verossimilhança (GOMIDE E KAVISKI, 1981). Ressalta-se que o teste qui-quadrado só apresentam bons resultados em amostras grandes $(\mathrm{N}>1000)$ e o Kolmogorv-Smirnov a qualidade dos resultados dependem da escolha das faixas, mas apresenta resultados melhores.

Gomide e Kaviski (1981) apresentaram uma verificação experimental do poder dos testes de adequação de ajuste normalmente utilizados por hidrólogos. Compararamse diversas possíveis versões do clássico teste do qui-quadrado com os testes de Kolmogorov-Smirnov e da relação de máximas verossimilhanças para uma situação hipotética em que a distribuição de probabilidades dos dados em manipulação ou foi gaussiana ou foi log-normal, para um valor fixo do coeficiente de variação populacional. Eles concluíram que o teste mais eficiente em termos globais foi exatamente o teste de mais simples aplicação: aquele baseado na relação de máxima verossimilhança; o teste Kolmogorov-Smirnov apresentou, para o caso de hipótese não completamente especificada, uma das maiores probabilidades do erro tipo I, e a menor probabilidade do erro tipo II, ganhando assim a classificação de teste mais poderoso, no sentido técnico da palavra; os testes do qui-quadrado são muito dependentes das decisões do pesquisador referentes a maneira de aplicá-los: algumas versões chegam perto do melhor teste (relação de máximas verossimilhanças) em termos de eficiência, e outras versões constituíram o pior teste, em termos globais; a dificuldade de previsão do número de graus de liberdade da estatística do teste do qui-quadrado ressalta a importância de hipóteses alternativas claramente especificadas. 
Esses testes são encontrados em diversas publicações na literatura especializada tais como: Yevjevich (1972), Haan (1977), Rao e Hamed (2000), Pinto (1976) e Righetto (1998).

\section{- Estimação dos Parâmetros e dos Quantis de Cheia}

Depois de definida quais as distribuições de probabilidade que serão analisadas, o próximo passo é a estimação dos parâmetros das distribuições escolhidas que servirão para determinar os valores de vazões máximas (quantis) associados a seus respectivos períodos de retorno.

Existem inúmeros métodos de determinação dos parâmetros da distribuição, entre os quais, podemos destacar o método dos momentos (MOM), o método da máxima verossimilhança (ML) e o método dos momentos com pesos probabilísticos (PWM). Outros métodos, pouco usados, estão dispostos na literatura como método dos mínimos quadrados, método da máxima entropia, método "mixed moments", método dos momentos generalizados e método da média incompleta (RAO E HAMED, 2000). Existem também derivações de métodos consagrados que objetivam determinar os parâmetros de uma distribuição especifica.

Diferentes métodos de estimação dos parâmetros da distribuição Log-Pearson III foram analisados por (ASHKAR e BOBÉE, 1991) que concluiu que os seguintes métodos são os mais recomendados: direct method of moments (BOB), method of mixed moments (MM1) e sundry averages method.

Para a distribuição GEV, derivações do PWM (momento com pesos probabilísticos) como o momentos $\mathrm{L}$ e o momentos $\mathrm{LH}$ foram analisados e comprovaram-se como métodos mais eficientes e assim são mais recomendados (QUEIROZ, 2002).

\section{- Método dos Momentos (MOM)}

O método dos momentos (MOM) é um estimador de parâmetros relativamente simples e fácil. No entanto, MOM tem uma qualidade inferior e menos eficiente do que outros métodos de estimação de parâmetros, como por exemplo, o método da máxima verossimilhança (ML). Esta baixa eficiência é notada principalmente quando se trata de 
distribuições com mais de três parâmetros, pois os momentos de ordem alta têm uma probabilidade maior de estar enviesado em amostras relativamente pequenas.

O método dos momentos utiliza as estimativas amostrais dos momentos centrais de uma distribuição teórica para ajustá-la a uma amostra.

Esse método, de uso freqüente, é apresentado em inúmeras publicações nas quais podemos destacar: Clarke (1994), Kite (1978), Haan (1977), Rao e Hamed (2000), Tucci (1993) e Yevjevich (1972).

\section{- Método da Máxima Verossimilhança (ML)}

Segundo Bussab e Morettin (2004) o princípio da verossimilhança afirma que devemos escolher aquele valor do parâmetro desconhecido que maximiza a probabilidade de obter a amostra particular observada, ou seja, o valor que torna aquela amostra a "mais provável". O uso desse princípio conduz a um método de estimação pelo qual se obtém os chamados estimadores de máxima verossimilhança (ML), em geral, tem propriedades muito boas. Yevjevich (1972) citou alguma dessas propriedades, tais como: são, usualmente, não-viesadas; se uma estimativa eficiente para os parâmetros de uma distribuição existir, esse método irá definilos; se uma estimativa adequada existir, as soluções das equações de verossimilhança serão funções dessa estimativa adequada.

O método ML apresenta uma desvantagem, na qual apresenta uma forte instabilidade quando aplicado a pequenas amostras e podem gerar valores absurdos em alguns parâmetros (RAO E HAMED, 2000).

Devido à necessidade da utilização de processos numéricos para resolver equações implícitas, o método ML cedeu lugar ao uso do método MOM, durante bastante tempo, motivadas pela facilidade de cálculo. Hoje em dia com o advento de computadores pessoais de alta velocidade esse problema não tem tanta significância.

A estimativa pelo método da máxima verossimilhança envolve a escolha da estimativa dos parâmetros que produz a probabilidade máxima de ocorrência das observações (RAO E HAMED, 2000). Suponha que $\mathrm{x}_{1}, \mathrm{x}_{2}, \ldots, \mathrm{x}_{\mathrm{n}}$ são valores máximos observados numa seqüência de anos. Considere que a densidade de probabilidade, comum a todos os $\mathrm{x}_{\mathrm{t}}$, é $\mathrm{f}(\mathrm{x} ; \theta)$, em que $\theta$ é um vetor contendo um pequeno número de parâmetros, normalmente dois ou três. $\mathrm{O}$ valor esperado de $\mathrm{x}_{\mathrm{t}}$ fica: 


$$
E\left[x_{t}\right]=\int_{-\infty}^{\infty} x f(x ; \theta) d x
$$

em que a integral será função dos parâmetros $\theta$. Como $x_{t}$, é estatisticamente independente, a probabilidade conjunta de obter as observações $\mathrm{x}_{t}$ é:

$$
F\left(x_{1} ; \theta\right) . F\left(x_{2} ; \theta\right) \ldots . F\left(x_{n} ; \theta\right)
$$

assumindo que $\mathrm{x}_{1}, \mathrm{x}_{2}, \ldots, \mathrm{x}_{\mathrm{n}}$ é uma amostra aleatória de uma população infinita. Conhecida as observações $x_{t}$, a função de verossimilhança $L\left(\theta ; x_{1}, x_{2}, \ldots, x_{n}\right)$ é definida como (CLARKE In TUCCI, 1993):

$$
L\left(\theta ; x_{1}, \ldots x_{n}\right)=\prod_{t=1}^{n} f\left(x_{t} ; \theta\right)
$$

ou seja, a função de verossimilhança é proporcional a probabilidade de obter as dadas observações, considerada como uma função dos parâmetros desconhecidos $\theta$. Clarke (In TUCCI (1993)) afirma que a função de verossimilhança é particularmente importante porque, quando o modelo estatístico é correto, a função $\mathrm{L}(\theta)$ contém todas as informações dos dados. Contudo, conclui, modelos diferentes resultarão em funções de verossimilhança diferentes e uma das tarefas necessárias é a de encontrar o modelo mais apropriado para representar as características de dados disponíveis.

Definida a função de verossimilhança é apresentada a estimativa dos parâmetros $\theta$. De todos os valores possíveis de $\theta$ pode-se intuitivamente esperar que o valor de $\theta$ mais apropriado será aquele que maximiza a probabilidade dos valores observados de $\mathrm{x}_{\mathrm{t}}$, ou seja, que maximiza a função de verossimilhança $L(\theta)$. Essa maximização é feita, na maioria das vezes, através de métodos numéricos que utilizam o gradiente da função $\mathrm{L}(\theta)$, como na eq. 21 .

$$
L(\theta)=\left\{\frac{\partial L\left(\theta_{1}, \theta_{2}, \ldots, \theta_{k}\right)}{\partial \theta_{i}}=0 ; i=1,2, \ldots ., k\right\}
$$


estas equações em geral não tem solução explicita para $\theta$. Como conseqüência será necessário resolver as equações interativamente. Rao e Hamed (2000) comentam que em muitos casos é mais fácil maximizar o logaritmo natural da função de verossimilhança usando a equação 22:

$$
\frac{\partial \ln L\left(\theta_{1}, \theta_{2}, \ldots, \theta_{k}\right)}{\partial \theta_{i}}=0 ; \mathrm{i}=1,2, \ldots, \mathrm{k}
$$

Esse método, de uso freqüente, é apresentado em inúmeras publicações nas quais podemos destacar: Clarke (1994), Kite (1978), Haan (1977), Rao e Hamed (2000), Tucci (1993) e Yevjevich (1972).

\section{- Método dos Momentos com Pesos Probabilísticos (PWM)}

O método dos momentos com pesos probabilísticos resulta em estimativas comparáveis com o estimador ML em alguns casos a estimativa é menos complicada e os procedimentos de cálculos são mais simples. A estimativa dos parâmetros pelo PWM apresenta em alguns casos valores mais precisos que o método ML (RAO E HAMED, 2000),.

A estimação dos parâmetros pelo PWM é obtida análoga ao método dos momentos (MOM) igualando cada momento com peso probabilístico teórico com sua estimativa amostral, formando um sistema de equações cujas incógnitas são os parâmetros da distribuição teórica. Righetto (1998) aponta o PWM como uma técnica eficiente para estimativa dos parâmetros de uma distribuição de probabilidades. Seja $\mathrm{x}_{1}$, $\mathrm{x}_{2}, \ldots, \mathrm{x}_{\mathrm{n}}$ uma amostra aleatória de uma população com função densidade de probabilidade $\mathrm{f}(\mathrm{x})$ e função distribuição $\mathrm{F}(\mathrm{x})$, e seja $\mathrm{x}_{\mathrm{i}: \mathrm{n}} \leq \mathrm{x}_{2: \mathrm{n}} \leq \ldots \leq \mathrm{x}_{\mathrm{n}: \mathrm{n}}$ as estatísticas de ordem obtidos da amostra acima. Denota-se o momento $E\left(X_{i: n}^{k}\right)$ através $M_{i: n}^{k}$. Então, considerando-se a função densidade $f_{i: n}(x)$ de $\mathrm{x}_{\mathrm{i}: \mathrm{n}}$, tem-se (QUEIROZ, 2002 apud DAVID, 1981) ${ }^{3}$ :

\footnotetext{
${ }^{3}$ DAVID, H.A.(1981). Order Statistics. 2nd ed. New York: Wiley.
} 


$$
M_{i: n}^{k}=E\left(X_{i: n}^{k}\right)=\int_{-\infty}^{\infty} x^{k} f_{i: n}(x) d x
$$

ou

$$
M_{i: n}^{k}=\frac{n !}{(n-1) !(i-1) !} \int_{0}^{1} x^{k}[F(x)]^{i-1}[1-F(x)]^{n-i} d F(x)
$$

$\mathrm{i}=1,2, \ldots, \mathrm{n}, \mathrm{k} \geq 1$

Uma função distribuição acumulada $F \equiv F(x)=P(X \leq x)$ pode ser caracterizada através dos momentos de pesos probabilísticos (PWMs), os quais são definidos como (GREENWOOD et al., 1979):

$$
M_{p, r, s}=E\left\{X^{p}[F]^{r}[1-F]^{s}\right\}=\int_{0}^{1}[x(F)]^{p} F^{r}(1-F)^{s} d F
$$

em que p, r e s são números reais. Greenwood et al., (1979) notaram que, no caso especial em que $\mathrm{p}, \mathrm{r}$ e s são inteiros não negativos, $\mathrm{M}_{\mathrm{p}, \mathrm{r}, \mathrm{s}}$ é proporcional ao p-ésimo momento em torno da origem da $(\mathrm{r}+1)$-ésima estatística de ordem, para uma amostra de tamanho $(s+r+1)$. Especificamente:

$$
M_{p, r, s}=B[r+1, s+1] E\left[X_{(r+1, s+r+1)}^{p}\right]
$$

em que B[.,.] é uma função beta.

Se $\mathrm{r}=\mathrm{s}=0$ e p é um inteiro não negativo, então $\mathrm{M}_{\mathrm{p}, 0,0}$ representam os momentos convencionais não centrais de $\mathrm{X}$. Se $\mathrm{M}_{\mathrm{p}, 0,0}$ de ordem $\mathrm{p}$ existe e x é uma função contínua de $\mathrm{F}$, então $\mathrm{M}_{\mathrm{p}, \mathrm{r}, \mathrm{s}}$ existe para todo número inteiro não negativo $\mathrm{r}$ e $\mathrm{s}$. Se $\mathrm{r}$ e $\mathrm{s}$ são não negativos inteiros, então: 


$$
\begin{aligned}
& M_{p, 0, s}=\sum_{r=0}^{s}\left(\begin{array}{l}
s \\
r
\end{array}\right)(-1)^{r} M_{p, r, 0} \\
& M_{p, r, 0}=\sum_{s=0}^{r}\left(\begin{array}{l}
r \\
s
\end{array}\right)(-1)^{s} M_{p, 0, s}
\end{aligned}
$$

em que, se $M_{p, 0, s}$ existe e $X$ é uma função contínua de $F, M_{p, r, 0}$ existe. Para estimar os parâmetros da distribuição de $\mathrm{X}$ é preferível usar $\mathrm{M}_{1, \mathrm{r}, \mathrm{s}}$, onde a ocorrência, somente, da primeira potencia de $\mathrm{X}$ na expressão de $\mathrm{M}_{1, \mathrm{r}, \mathrm{s}}$, significa que a relação entre parâmetros e momentos, toma, muitas vezes, uma forma mais simples. Neste caso, então, quando se usam momentos convencionais. Quando $\mathrm{r}$ e s são inteiros, $\mathrm{F}^{\mathrm{r}}(1-\mathrm{F})^{\mathrm{s}}$ pode ser expresso como uma combinação linear da potencia de F ou (1-F). Assim, é natural exprimir a distribuição através dos momentos $\mathrm{M}_{1, \mathrm{r}, 0,}(\mathrm{r}=0,1,2, \ldots)$ ou utilizando $\mathrm{M}_{1,0, \mathrm{~s}},(\mathrm{~s}=0,1,2$, $\ldots)$.

Greenwood et al. (1979) utilizaram a última aproximação. Portanto, considerando a eq. 27, os momentos definidos pela segunda aproximação, denotados por $\beta_{\mathrm{s}}$, corresponde a:

$$
\beta_{s}=M_{1,0, s}=\frac{1}{s+1} E\left[X_{1, s+1}\right]=\int_{0}^{1} x(1-F)^{s} d F
$$

em que

$$
B[r+1, s+1]=\int_{0}^{1} x^{(r+1)-1}(1-x)^{(s+1)-1} d x
$$




$$
B[1, s+1]=\int_{0}^{1} x^{0}(1-x)^{(s+1)-1} d x=\frac{1}{s+1}
$$

A estimativa não viesada de $\beta_{\mathrm{s}}, \mathrm{b}_{\mathrm{s}}$, de uma amostra de tamanho $\mathrm{n}$, onde s é um inteiro não negativo, é obtida como segue.

Dada uma amostra aleatória de tamanho n de uma distribuição F, a estimação de $\beta_{\mathrm{s}}$ é mais convenientemente baseada na amostra ordenada $\mathrm{x}_{1} \leq \mathrm{x}_{2} \leq \ldots . \leq \mathrm{x}_{\mathrm{n}}$. O número total de possíveis caminhos para formar uma subamostra de tamanho (s+1) é:

$$
N=\left(\begin{array}{c}
n \\
s+1
\end{array}\right)
$$

dessas $\mathrm{N}$ sub-amostras, o número que contém $\mathrm{x}_{1}$, que corresponde ao número de possíveis sub-amostras em que $\mathrm{x}_{1}$ pode ser a menor observação, é:

$$
N_{1}=\left(\begin{array}{c}
n-1 \\
s
\end{array}\right)
$$

similarmente, das $\mathrm{N}$ sub-amostras, o número que pode conter $\mathrm{x}_{2}$ mas não $\mathrm{x}_{1}$, que corresponde ao número de possíveis sub-amostras em que $x_{2}$ é a menor observação, é

$$
N_{2}=\left(\begin{array}{c}
n-2 \\
s
\end{array}\right)
$$

em geral, das $\mathrm{N}$ possíveis sub-amostras de tamanho $(\mathrm{s}+1)$, retirada da amostra original de tamanho n, o número de sub-amostras que contém a i-ésima estatística de ordem $\mathrm{x}_{\mathrm{i}}$, mas, nenhuma das menores observações $\mathrm{x}_{1}, \ldots ., \mathrm{x}_{\mathrm{i}-1}$, é: 


$$
N_{i}=\left(\begin{array}{c}
n-i \\
s
\end{array}\right)
$$

note-se que se $\mathrm{i} \geq \mathrm{n}-\mathrm{s}+1, \mathrm{~N}_{\mathrm{i}}=0$.

Dado que existem $\mathrm{N}$ total possíveis sub-amostras, e, $\mathrm{N}_{\mathrm{i}}$ em que $\mathrm{x}_{\mathrm{i}}$ pode ser a menor observação, uma estimativa da probabilidade que $\mathrm{x}_{\mathrm{i}}$ é a menor observação em uma amostra de tamanho (s+1), retirada de uma amostra de tamanho n, é:

$$
P=\frac{N_{i}}{N}=\frac{\left(\begin{array}{c}
n-1 \\
s
\end{array}\right)}{\left(\begin{array}{c}
n \\
s+1
\end{array}\right)}
$$

enquanto que, uma estimativa da primeira estatística de ordem de uma sub-amostra de tamanho $(\mathrm{s}+1)$, retirada de uma amostra de tamanho n, corresponde a:

$$
E\left[X_{1, s+1} \mid n\right]=\sum_{i=1}^{n} x_{i} \frac{\left(\begin{array}{c}
n-1 \\
s
\end{array}\right)}{\left(\begin{array}{c}
n \\
s+1
\end{array}\right)}
$$

contudo, da relação estabelecida em (30), obtém-se:

$$
b_{s}=\frac{1}{s+1} \sum_{i=1}^{n} x_{i} \frac{\left(\begin{array}{c}
n-i \\
s
\end{array}\right)}{\left(\begin{array}{c}
n \\
s+1
\end{array}\right)}=\frac{1}{n} \sum_{i=1}^{n} x_{i} \frac{\left(\begin{array}{c}
n-i \\
s
\end{array}\right)}{\left(\begin{array}{c}
n-1 \\
s
\end{array}\right)}
$$

ou 


$$
b_{s}=\frac{1}{n} \sum_{i=1}^{n-s} \frac{(i-1)(i-2) \ldots(i-s)}{(n-1)(n-2) \ldots(n-s)} x_{i}
$$

em que $b_{\mathrm{s}}$ é um estimador não viesado $\beta_{\mathrm{s}}$.

Esse método foi apresentado em inúmeras publicações nas quais podemos destacar: Righetto (1998), Rao e Hamed (2000) e Queiroz (2002).

Os PWMs (ou momentos com pesos probabilístico) podem ser relacionados por funções lineares chamadas de momentos L. Os momentos lineares ou momentos L são descritores das distribuições de probabilidade semelhantes aos momentos tradicionais (média, desvio padrão e etc.) cujos estimadores são combinações lineares dos dados observados. Entre as vantagens dos estimadores dos momentos L sobre os estimadores dos momentos tradicionais pode-se citar:

- Pelo fato de serem funções lineares dos dados sofrem menos os efeitos de observações atípicas;

- Desde que exista a média, sempre existirão todos os demais momentos.

A partir dos PWM os estimadores os estimadores dos momentos-L podem ser calculados através das formulas (HOSKING, 1986):

$$
\begin{aligned}
& \hat{\lambda}_{1}=b_{0} \\
& \hat{\lambda}_{2}=2 b_{1}-b_{0} \\
& \hat{\lambda}_{3}=6 b_{2}-6 b_{1}+b_{0}
\end{aligned}
$$

Para os estimadores dos momentos-L de ordem superior a três existem expressões similares. Assim como no caso dos momentos tradicionais, os momentos de ordem igual ou superior a dois são expressos através de seus coeficientes adimensionais de variação $\left(\tau_{2}\right)$, assimetria $\left(\tau_{3}\right)$ e curtose $\left(\tau_{4}\right)$ :

$$
\begin{aligned}
& \hat{\tau}_{2}=\lambda_{2} / \lambda_{1} \\
& \hat{\tau}_{3}=\lambda_{3} / \lambda_{2} \\
& \hat{\tau}_{4}=\lambda_{4} / \lambda_{2}
\end{aligned}
$$


Os estimadores para $\tau_{\mathrm{r}}$, são obtidos substituindo-se $\lambda_{\mathrm{r}}$ por seu estimador $\hat{\lambda}_{r}$. Destaca-se que embora os $\hat{\lambda}_{r}$ obtidos por (40) e (41) são não tendenciosos os $\hat{\tau}_{r}$ serão tendenciosos (QUEIROZ, 2002).

Momentos L foram introduzidos por HOSKING (1990) como uma alternativa aos momentos ordinários para caracterizar distribuições e dados (WANG, 1997b). A análise estatística de extremos é, muitas vezes, conduzida para predizer eventos de grande período de retorno, onde o mais relevante para a análise é a cauda superior da distribuição e os eventos amostrais mais extremos. Neste sentido, momentos e razões de momentos tem sido criticados, por serem, também, sensíveis a cauda superior da distribuição e, portanto, aos outliers amostrais (VOGEL e FENNESSY, 1993). O problema é que os momentos L são sensíveis à parte inferior dos dados e dá insuficiente peso aos valores amostrais mais altos, faixa que contém informação útil sobre a parte superior da cauda da distribuição.

Com base nessas questões e seguindo o mesmo raciocínio empregado na definição de momentos de altos pesos probabilísticos, WANG (1997b) propôs o método baseado na combinação linear das mais elevadas estatísticas de ordem, que representa uma generalização dos momentos L, chamado Momentos LH. Neste método, tal como nos momentos de altos pesos probabilísticos, busca-se a caracterização da parte superior da distribuição e dos maiores eventos amostrais.

Dada uma amostra de tamanho m retirada de uma distribuição $\mathrm{F}(\mathrm{x})=\mathrm{P}(\mathrm{X} \leq \mathrm{x})$. Baseado na combinação linear das mais elevadas estatísticas de ordem e na equação (26), os momentos LH são definidos como:

$$
\begin{gathered}
\lambda_{1}^{\eta}=E\left[X_{(\eta+1)(\eta+1)}\right] \\
\lambda_{2}^{\eta}=\frac{1}{2} E\left[X_{(\eta+2)(\eta+2)}-X_{(\eta+1)(\eta+2)}\right] \\
\lambda_{3}^{\eta}=\frac{1}{3} E\left[X_{(\eta+3)(\eta+3)}-2 X_{(\eta+2)(\eta+3)}+X_{(\eta+1)(\eta+3)}\right] \\
\lambda_{4}^{\eta}=\frac{1}{4} E\left[X_{(\eta+4)(\eta+4)}-3 X_{(\eta+3)(\eta+4)}+3 X_{(\eta+2)(\eta+4)}-X_{(\eta+1)(\eta+4)}\right]
\end{gathered}
$$


em que $\lambda_{1}^{\eta}$, maior valor esperado na amostra de tamanho $\eta+1$, corresponde a uma medida de posicionamento da distribuição; $\lambda_{2}^{\eta}$, metade da diferença entre o maior e segundo maior valor esperado na amostra de tamanho $\eta+2$, caracteriza a expansão da parte superior da distribuição; $\lambda_{3}^{\eta}$, reflete como está a assimetria da parte superior da distribuição, através dos três maiores valores esperados na amostra de tamanho $\eta+3$; e $\lambda_{4}^{\eta}$ prover uma medida de pontiagudez da parte superior da distribuição através dos quatro maiores valores esperados na amostra da tamanho $\eta+4$.

Quando $\eta=0$, momentos $\mathrm{LH}$ tornam-se iguais aos momentos L. Como $\eta$ aumenta, os momentos LH refletem mais e mais as características da parte superior da distribuição e dos valores extremos máximos dos dados. Momentos LH são chamados momentos $\mathrm{L}_{1}$, momentos $\mathrm{L}_{2}, \ldots$ para $\eta=1,2, \ldots$ respectivamente. Normalizando os momentos LH, obtém-se o coeficiente de variação LH $\left(\tau_{2}^{\eta}\right)$, assimetria $\left(\tau_{3}^{\eta}\right)$ e curtose $\left(\tau_{4}^{\eta}\right)$, respectivamente, como:

$$
\tau_{2}^{\eta}=\frac{\lambda_{2}^{\eta}}{\lambda_{1}^{\eta}} \quad \tau_{3}^{\eta}=\frac{\lambda_{3}^{\eta}}{\lambda_{2}^{\eta}} \quad \tau_{4}^{\eta}=\frac{\lambda_{4}^{\eta}}{\lambda_{2}^{\eta}}
$$

ordenada a amostra em $\mathrm{x}_{(1)} \leq \mathrm{x}_{(2)} \leq \ldots \ldots \leq \mathrm{X}_{(\mathrm{n})}$, a estimativa dos momentos LH é feita como segue:

$$
\begin{aligned}
& \lambda_{1}^{\eta}=\frac{1}{{ }^{n} C_{\eta+1}} \sum_{i=1}^{n}{ }^{i-1} C_{\eta} x_{(i)} \\
& \lambda_{2}^{\eta}=\frac{1}{2} \frac{1}{{ }^{n} C_{\eta+2}} \sum_{i=1}^{n}\left({ }^{i-1} C_{\eta+1}-{ }^{i-1} C_{\eta}{ }^{n-i} C_{1}\right) x_{(i)} \\
& \lambda_{3}^{\eta}=\frac{1}{3} \frac{1}{{ }^{n} C_{\eta+3}} \sum_{i=1}^{n}\left({ }^{i-1} C_{\eta+2}-2^{i-1} C_{\eta+1}{ }^{n-i} C_{1}+{ }^{i-1} C_{\eta}{ }^{n-i} C_{2}\right) x_{(i)} \\
& \lambda_{4}^{\eta}=\frac{1}{4} \frac{1}{{ }^{n} C_{\eta+4}} \sum_{i=1}^{n}\left({ }^{i-1} C_{\eta+3}-3^{i-1} C_{\eta+2}{ }^{n-i} C_{1}+3^{i-1} C_{\eta+1}{ }^{n-i} C_{2}-{ }^{i-1} C_{\eta}{ }^{n-i} C_{3}\right) x_{(i)}
\end{aligned}
$$




$$
{ }^{m} C_{j}=\left(\begin{array}{c}
m \\
j
\end{array}\right)=\frac{m !}{j !(m-j) !} \quad \text { e } \quad{ }^{\mathrm{m}} \mathrm{C}_{\mathrm{j}}=0 \text { quando } \mathrm{j}>\mathrm{m} .
$$

\section{- Estimativa dos Quantis}

Depois de estimado os parâmetros, o passo seguinte é a estimação dos quantis $\left(\mathrm{x}_{\mathrm{t}}\right)$ com seus respectivos períodos de retorno. O período de retorno é relacionado com a probabilidade de não-excedência $(\mathrm{F})$ pela relação:

$$
F=1-\frac{1}{T}
$$

$\mathrm{m}$ que $\mathrm{F}=\mathrm{F}\left(\mathrm{x}_{\mathrm{t}}\right)$ é a probabilidade de uma variável ser menor ou igual à variável $\mathrm{x}_{\mathrm{t}} \mathrm{O}$ problema deste modo reduz ao cálculo de $\mathrm{x}_{\mathrm{t}}$ para um dado valor de $\mathrm{F}$. Na prática, dois tipos de funções de distribuição podem ser encontrados. O primeiro tipo é a função que pode ser expressa em sua forma inversa $x_{t}=\Phi(F)$. Neste caso, $x_{t}$ é calculado de forma explicita na qual $\mathrm{F}$ é encontrado substituindo o período de retorno da variável a ser estimada na equação (19) e aplicada diretamente na função de distribuição acumulada. Distribuições como GEV, Wakeby e Logística podem ser representadas desta forma. O segundo tipo é o caso da função distribuição não poder ser colocada na forma inversa. Neste caso métodos numéricos são usados para determinar $\mathrm{x}_{\mathrm{t}}$ associado a seu respectivo período de retorno. Chow (1964) propôs uma forma geral para os cálculos de $\mathrm{x}_{\mathrm{t}}$ :

$$
x_{t}=m_{1}+K_{t} \sqrt{u_{2}}
$$

em que $K_{t}$ é o fator de freqüência que é função do período de retorno e dos parâmetros da distribuição, $m_{1}$ é o momento de primeira ordem e $u_{2}$ é o momento central de segunda ordem. A expressão de $\mathrm{K}_{\mathrm{t}}$ pode ser determinada usando a mesma técnica para os dois tipos de função de distribuição citados acima. 


\section{- Erro padrão de estimativa (E.P.)}

Segundo Yevjevich (1972) a incerteza de uma estimativa depende da diferença entre os parâmetros da população e da amostra usada. Os limites de confiança procuram medir o grau dessa incerteza.

Há dois tipos de erros associados à estimação dos quantis de variáveis hidrológicas (precipitação e vazão). O primeiro tipo surge da hipótese que os dados observados seguem uma particular distribuição. Este erro pode ser checado pelos testes de aderência (qui-quadrado e Kolmogorov-Smirnov). O segundo tipo de erro é inerente aos parâmetros estimados de pequenas amostras. Este erro pode ser reduzido usando o método de estimação que dar a menor variância na estimativa dos parâmetros, tendo como conseqüência uma menor variância na estimativa dos quantis das variáveis envolvidas. A partir desse conceito é possível construir intervalos de confiança para a estimativa dos quantis de cheia usando as informações relativas à variância da estimativa dos parâmetros da amostra (RAO E HAMED, 2000).

A medida da variabilidade ou variância do valor estimado do parâmetro é chamada de erro padrão de estimativa $s(\hat{\theta})$ a qual é definido por:

$$
s(\hat{\theta})=\sqrt{E\{\hat{\theta}-E(\hat{\theta})\}^{2}}
$$

O erro padrão de estimativa determina o erro devido ao pequeno tamanho da amostra, mas não devido ao erro na escolha inapropriada da distribuição. Em geral, o erro padrão depende do método de estimação dos parâmetros. Conseqüentemente, cada método tem um valor diferente para o erro padrão. O método mais eficiente é o método que dá o menor erro padrão de estimativa.

Diversos pesquisadores já atentaram para o fato que o erro padrão de estimativa pode ser muito importante. Uma forma tradicional de se considerar a incerteza nos parâmetros de modelos probabilísticos é o uso dos chamados intervalos de confiança. $\mathrm{O}$ intervalo de confiança de um parâmetro é dado em função do desvio padrão de seu estimador da seguinte forma:

$$
\hat{\theta}-z_{(1-\alpha / 2)} s(\hat{\theta}) \leq \theta \leq \hat{\theta}+z_{(1-\alpha / 2)} s(\hat{\theta})
$$


em que $\hat{\theta}$ é a estimativa do parâmetro $\theta, S(\hat{\theta})$ é o desvio padrão de $\hat{\theta}$ ou erro padrão de estimativa e $\mathrm{Z}_{(1-\alpha / 2)}$ é o valor obtido de uma distribuição padronizada. Um método para o cálculo de $S(\hat{\theta})$ é sem duvida fundamental para a construção de intervalos de confiança. No caso de parâmetros usuais, tais como média e variância de processos aleatórios, o hidrólogo encontrará na estatística clássica fórmulas já consagradas para o cálculo de $\mathrm{S}(\hat{\theta})$. Segundo Costa et al. (1987) para parâmetros mais específicos tais como "valor esperado do tamanho do reservatório" estas fórmulas precisam ainda ser derivadas. Nestes casos o hidrólogo tem como alternativa o uso das chamadas técnicas de reamostragem (COSTA et. al., 1987 apud EFROM, 1982) ${ }^{4}$. Como se verá adiante o cálculo de $S(\hat{\theta})$ por estas técnicas é extremamente intuitivo e simples. Esta seção abordará duas técnicas de reamostragem: a Jackknife e a Bootstrap.

A idéia original do Jackknife foi proposta por Quenouille (COSTA et al. 1987 apud QUENOUILLE, 1949) ${ }^{5}$, sendo seu uso generalizado por Tuckei (COSTA et al. 1987 apud TUCKEI, 1958) ${ }^{6}$.

O Jackknife consiste em, dado uma amostra $\mathrm{x}=\left\{\mathrm{x}_{1}, \mathrm{x}_{2}, \ldots, \mathrm{x}_{\mathrm{n}}\right\}$ contendo $\mathrm{n}$ sorteios independentes da variável aleatória $\mathrm{X}$, dividi-la em $\mathrm{w}$ grupos de tamanho $\mathrm{h}$, onde $\mathrm{n}=$ wh, e tomar $\hat{\theta}_{\text {-i }}$ como a estimativa do parâmetro $\theta$ tendo omitido o i-ésimo grupo de observações. Exceto quando o volume de dados é muito grande, deve-se usar $\mathrm{w}=\mathrm{ne} \mathrm{h}=1$.

O Bootstrap foi desenvolvido por Efron (COSTA et al., 1987 apud EFROM, 1982) e exige um esforço computacional maior que o Jackknife. A metodologia Bootstrap para determinar a distribuição empírica de probabilidades de $\hat{\theta}$, assim como para a estimação de seu desvio padrão, pode ser resumida no seguinte algoritmo:

1. Faz-se uma reamostragem com reposição das observações da amostra $x$ formando um "pseudo-amostra" (ou amostra Bootstrap), $x_{\text {boot }}^{b}$

$$
x_{b o o t}^{b}=\left\{x_{1}^{*}, x_{2}^{*}, \ldots, x_{n}^{*}\right\}
$$

\footnotetext{
4 EFRON,B. (1982), The Jackknife, the Bootstrap and Otner Resampling Plans, Society for Industrial and Applied Mathematics, Philadelfia, Pennsylvania.

${ }^{5}$ QUENOUILLE,M.H.(1949), Aproximate Tests of Correlation in Time Series, J.Roy.Statist. Soc.Ser.B., 11, pag. 13-84

6 TUCKEY,J.W. (1958), Bias and Confidence em Not Quite Large Sample, Ann. Math Statist., 29, pag 614
} 
2. A partir da "pseudo-amostra" $x_{\text {boot }}^{b}$, pode-se calcular a estimativa do parâmetro $\theta$ de interesse,

$$
\theta_{\text {boot }}^{b}=g\left\{x_{1}^{*}, x_{2}^{*}, \ldots, x_{n}^{*}\right\}
$$

Repetições independentes dos passos 1 e 2 , fornecem $\theta_{b o o t}^{1}, \theta_{b o o t}^{2}, \ldots, \theta_{b o o t}^{B}$, estimativas do parâmetro $\theta$ com as quais é possível determinar a distribuição empírica de probabilidades de $\theta_{\text {boot }}^{b}$.

O estimador Bootstrap do desvio padrão de $\hat{\theta}$ é:

$$
\hat{s}_{\text {boot }}=\left\{\frac{1}{B-1} \sum_{b=1}^{B}\left(\hat{\theta}_{\text {boot }}^{b}-\hat{\theta}_{\text {boot }}\right)^{2}\right\}^{1 / 2}
$$

em que:

$$
\hat{\theta}_{b o o t}=\frac{1}{B} \sum_{b=1}^{B} \hat{\theta}_{b o o t}^{b}
$$

Costa et al. (1987) reportaram-se de experiências controladas para avaliar a eficiência de métodos de estimação $S(\hat{\theta})$ quando aplicados a problemas de hidrologia. As análises dos resultados obtidos permitiram concluir que as técnicas de reamostragem experimentadas (Bootstrap e Jackknife) são razoavelmente precisas, podendo ser usadas na construção de intervalos de confiança para parâmetros hidrológicos.

\section{- Principais Distribuições Usadas na Hidrologia}

As variáveis aleatórias discretas em hidrologia são geralmente relacionadas com o número de ocorrência ou intervalos de tempo até a ocorrência de um evento de interesse. Mais comumente as variáveis são contínuas. Este é o caso de vazões, chuva, temperatura, etc. O ajuste de funções teóricas ás distribuições amostrais de freqüência dessas variáveis requer o conhecimento de modelos probabilísticos ou distribuições de probabilidades teóricas que não são deduzidas tão naturalmente como nos casos das distribuições de variáveis discretas. 
Muitas distribuições teóricas de probabilidade têm sido testadas e recomendadas em diversos trabalhos nos últimos 50 anos (RAO E HAMED, 2000). Em geral tem-se procurado adotar modelos para $\mathrm{F}(\mathrm{x})$ coerentes com o fenômeno físico e com as evidencias empíricas. Assim $\mathrm{F}(\mathrm{x})$ deve ser contínua, possuir limite inferior não negativo (embora possa se considerar aceitável modelos que forneçam baixas probabilidades para eventos negativos), assimetria positiva e unicidade da moda. Uma condição discutível, até o momento, é a existência do limite superior sendo em geral aceito o uso de distribuições não limitadas superiormente.

Em geral o estudo probabilístico de vazões e precipitações extremas tem sido muito mais direcionado por evidências empíricas do que por processos dedutivos baseados na compreensão do fenômeno físico. A Eletrobrás (1987a) cita o exemplo que a verificação de que as distribuições empíricas dos dados se mostravam assimétricas forçou os hidrólogos do início do século a abandonarem os resultados estabelecidos a partir da teoria dos erros (distribuição normal) procurando então usar distribuições capazes de reproduzir a assimetria empírica. A partir deste primeiro avanço outras verificações empíricas colocaram em evidência distribuições tais como a log-normal, Pearson tipo III, log-Pearson tipo III e mais recentemente as distribuições Wakeby e Lambda.

Uma notável exceção pode ser feita ao trabalho de Gumbel em teoria de valores extremos. No entanto, como as condições para a aplicação desta teoria não são exatamente as reais condições encontradas na prática e, mais importante, não há como se deduzir teoricamente qual dentre os três tipos de distribuição de extremos (Gumbel, Frechet e Weibull), sugeridos por Gumbel, deve ser utilizado, é necessário considerável evidencia empírica para demonstrar a aplicação deste ou daquele tipo de distribuição de extremos. Uma alternativa é a utilização da distribuição de extremos generalizada proposta por Jenkinson (1955), capaz de representar qualquer dos três tipos de distribuições de extremos, conforme o valor de um de seus parâmetros.

Foram estudadas nesta dissertação as distribuições mais usuais utilizadas na determinação de valores máximos de variáveis hidrológicas. As distribuições analisadas foram: normal, log-normal 2 parâmetros (LN 2), log-normal 3 parâmetros (LN 3), gama (GAM), Pearson tipo III (P-III), Log-Pearson tipo III (LP-III), Gumbel ou valores extremos tipo - I (EVI), Weibul (WEIB), logística (LOG), GEV, Wakeby 4 parâmetros (WK4), Wakeby 5 parâmetros (WK5), Pareto Generalizado (GPAR) e logística generalizado (GLOG). 
Essas distribuições são analisadas detalhadamente em Rao e Hamed (2000) que apresenta as funções de densidade e cumulativa de probabilidades. Eles também detalham os métodos de determinação dos parâmetros e dos quantis para cada distribuição citada nesta dissertação. Outras publicações da literatura especializada podem ser citadas no tratamento das principais distribuições usadas na hidrologia, como: Clarke (1994), Kite (1978), Haan (1977), Tucci (1993) e Yevjevich (1972).

\subsubsection{Inferência e Análise de Resultados}

\section{- Introdução}

Esta terceira etapa do método estatístico trata dos valores inferidos pelas distribuições escolhidas nas etapas anteriores. Neste trabalho foram utilizados dois critérios para análise dos resultados da metodologia estatística, estes critérios são: análise conceitual da metodologia estatística e análise crítica da metodologia estatística. Estes critérios foram também utilizados por Garcia (1996), Garcia (1997) e Souza (2005a,b e c).

$\mathrm{Na}$ análise conceitual do método estatístico, nesta dissertação, o objetivo foi obter a distribuição da população das variáveis hidrológicas, na qual consiste em escolher uma distribuição probabilística que tenha habilidade descritiva e predictiva, conforme foi definido por Garcia (1996) apud Cunnane (1986) ${ }^{7}$. A primeira refere-se à habilidade da distribuição em ajustar-se a maior parte da amostra (série de dados). A segunda relaciona-se com a capacidade de estimar valores com alta probabilidade de inexcedência (tempo de recorrência superior ao número de eventos da amostra, $T_{r}>n$ ).

Assim, uma distribuição probabilística com uma boa habilidade descritiva é aquela que permite uma boa interpolação dos dados. No entanto, essa distribuição poderá não ser adequada para extrapolação de valores com probabilidade de inexcedência superior às atribuídas aos dados da série por considerar um "peso" excessivo para as características da amostra. Por outro lado, uma distribuição com uma boa habilidade predictiva é aquela que adequa-se melhor para extrapolação, embora

\footnotetext{
7 CUNNANE, C. (1986), Review of Statistical Models for Flood Frequency Estimation., Hydrologic Frequency Modeling; Proceedings of the Int. Symp. On Flood Frequency and Risk analysis, Baton Rouge, La. U.S.A, D. Reidel Publishing Company.
} 
possa não se ajustar muito bem aos dados. A habilidade predictiva de tal distribuição origina-se na sua relativa insensibilidade aos erros da amostra.

Garcia (1996) comenta que teoricamente, dever-se-ia escolher uma distribuição probabilística que fosse mais adequada para interpolação e extrapolação. No entanto, conclui, não há teste que permita definir, de forma objetiva, a melhor habilidade predictiva de uma distribuição, ou seja, a maior precisão na extrapolação. Dessa forma, os teste e critérios de escolha da distribuição probabilística concentram-se na habilidade descritiva, ou seja, no ajuste em relação aos dados.

$\mathrm{Na}$ análise crítica do método estatístico para determinação de valores máximos de variáveis hidrológicas são utilizados critérios que permitem avaliar o método quanto aos principais inconvenientes práticos que ocorrem no processo de determinação de valores máximos. Esta análise crítica é baseada na análise feita por Klemes (1995), na qual apresentou os seguintes problemas de ordem conceitual da metodologia:

- Pré-determina o comportamento estatístico até mesmo dos maiores extremos, através de uma simples equação que é ajustada por poucos e, freqüentemente, baixos valores da variável hidrológica;

- Não tem critério ou procedimento válido para estimar os limites razoáveis para a validação da sua extrapolação;

- É baseada na hipótese de que cada observação representa um "pacote" igualmente válido de informação verdadeira da distribuição da população da variável hidrológica; uma vez que esta hipótese é manifestamente falsa (as observações tem erros e estão sujeitas às incertezas), as refinadas técnicas para obter informações podem extrair, também, muitas informações imprecisas e, portanto, comprometer sua habilidade de discernir entre modelos de distribuição bons e ruis.

Garcia (1996) ainda acrescenta que a maioria das distribuições adotadas ignora o fato de existir um limite físico que impõe um valor máximo. Este fato exigiria que a distribuição a adotar devesse ser assintótica e ter sua cauda côncava no papel de probabilidade normal e não convexa.

Assim, diante das implicações apontadas por Klemes (1995), o critério na análise crítica do método estatístico recai na análise da consistência do método quanto: 
- A extensão da série de dados hidrológicos observados;

- A presença de "outliers" e a;

- Variação dos menores valores da série de máximos tenha pouca influência nos valores máximos inferidos.

\section{- Análise conceitual da metodologia estatística}

\section{- Série de dados}

A tabela 2 apresenta a série de vazões máximas anuais para o período de 1931 a 2001 da UHE (Usina Hidroelétrica) de Sobradinho/BA retirado do relatório da ONS (Operador Nacional do Sistema Elétrico, 2004). A UHE de Sobradinho está localizada na Bacia hidrográfica do rio São Francisco.

O rio São Francisco, com área de drenagem de 641.000 km² (7,4 \% do território nacional) tem sua bacia abrangendo partes de sete unidades da federação (Minas Gerais, Distrito Federal, Goiás, Bahia, Pernambuco, Alagoas e Sergipe) as quais cinco são banhadas por seu curso. A maior parte da bacia (84 \%) situa-se nos estados de Minas Gerais e Bahia. Na parte média estão inseridas pequenas parcelas das duas unidades não banhadas pelo curso: o estado de Goiás e o Distrito Federal (Staico, 1981).

Segundo o relatório da ONS (2004) A avaliação das vazões naturais foi procedida por uma ampla análise de consistência de dados fluviométricos e pluviométricos disponíveis nas principais estações hidrométricas existentes em cada bacia, bem como de uma abrangente análise de consistência dos dados operativos dos aproveitamentos. As vazões afluentes foram obtidas, preferencialmente, valorizando os dados operativos, a partir do processo de balanço hídrico em base mensal, considerando os níveis d'água, as curvas cota-volume e as vazões defluentes. A partir dessas análises, foi possível estabelecer séries consistentes de vazões observadas em cada estação fluviométrica e de vazões afluentes e defluentes do aproveitamento. As vazões naturais foram obtidas no local de aproveitamento, retirando os efeitos da operação dos reservatórios existentes a montante e incorporando as vazões relativas à evaporação, com base em vetores de evaporação líquida (diferença entre evaporação de lago e evapotranspiração real) correspondentes aos valores das Normais Climatológicas (INMET) do período 1961/1990. 
Foram ainda avaliados e incorporados os usos consuntivos da água na bacia incremental do aproveitamento, desde janeiro/1931 a dezembro/2001. Para isso, foram avaliadas, para cada mês desse período, as vazões de retirada, de retorno e de consumo para os usos de irrigação, abastecimento urbano, rural, animal e industrial. Para avaliação das demandas de irrigação, foram utilizados os valores dos principais parâmetros das Normais Climatológicas dos períodos 1931/1960 e 1961/1990, bem como as precipitações mensais observadas em centenas de estações pluviométricas existentes nas bacias em estudo.

Analisando a série disposta na tabela 2, notou-se que a vazão máxima de 15.676 m³/s, correspondente ao ano de 1979, é bem superior aos demais. Dessa forma, inicialmente, foi aplicado o teste de Grubbs e Beck (1972) recomendado pelo United States Water Resources Council (WRC, 1981). Para esta série de vazões com 71 elementos resulta em um coeficiente estatístico $\mathrm{K}_{\mathrm{N}}=2,897$, para um nível de significância de $10 \%$, e limites superior $\mathrm{X}_{\mathrm{H}}=14.980$ e inferior $\mathrm{X}_{\mathrm{L}}=.2 .343$ Portanto, a vazão de. $15.676 \mathrm{~m} 3 / \mathrm{s}$ é considerada um valor extraordinário e, assim, foi retirada da série para o desenvolvimento das demais análises. Não foi feito teste de independência por considerar que a amostra por ser formada por séries anuais tem mínimas chances de ocorrer dependência entre os valores, devido ao tempo que separa cada valor (SOUZA, 2005a). A tabela 3 apresenta os parâmetros estatísticos da série.

Foi aplicado o teste de Mann-Whitney (RAO E HAMED, 2000) para verificação das hipóteses de homogeneidade e estacionaridade da série de vazões. Para isso, a série foi dividida em diferentes sub-séries complementares. A aplicação deste teste para diferentes amostras resultou, invariavelmente, em coeficientes estatísticos $\mathrm{u}<\mathrm{u}_{\alpha / 2}=$ 1,96, que permite aceitar a hipótese de homogeneidade.

Portanto, conclui-se que a série de vazões máximas pode ser considerada consistente, significativa e representativa.

\section{- Ajuste das distribuições}

Seguindo-se a recomendação do método estatístico, apontada na seção 2.1.3, foram testadas diversas distribuições probabilísticas. As distribuições foram escolhidas com base nos valores do coeficiente de assimetria e de curtose através do diagrama 
MRD, figura 2, tendo como abscissa o quadrado do coeficiente de assimetria $\mathrm{C}_{\mathrm{s}}{ }^{2}$ e na ordenada o coeficiente de curtose $\mathrm{C}_{\mathrm{k}}$. Como se pode constatar na tabela 3 , o valor do

Tabela 2 - Série de Vazões Máximas Anuais da Usina Hidrelétrica de Sobradinho/BA.

\begin{tabular}{cccccccccc}
\hline \hline Ano & $\begin{array}{l}\text { Vazão } \\
\left(\mathrm{m}^{3} / \mathrm{s}\right)\end{array}$ & Ano & $\begin{array}{c}\text { Vazão } \\
\left(\mathrm{m}^{3} / \mathrm{s}\right)\end{array}$ & Ano & $\begin{array}{c}\text { Vazão } \\
\left(\mathrm{m}^{3} / \mathrm{s}\right)\end{array}$ & Ano & $\begin{array}{c}\text { Vazão } \\
\left(\mathrm{m}^{3} / \mathrm{s}\right)\end{array}$ & $\begin{array}{c}\text { Ano } \\
\text { Vazão } \\
\left(\mathrm{m}^{3 / \mathrm{s}}\right)\end{array}$ \\
\hline \hline 1931 & 7333 & 1945 & 8764 & 1959 & 3660 & 1973 & 4644 & 1988 & 5163 \\
1932 & 4531 & 1946 & 10080 & 1960 & 6124 & 1974 & 5184 & 1989 & 5073 \\
1933 & 5516 & 1947 & 7283 & 1961 & 7765 & 1975 & 4301 & 1990 & 9467 \\
1934 & 6110 & 1948 & 6343 & 1962 & 5406 & 1976 & 4818 & 1991 & 5139 \\
1935 & 5442 & 1949 & 13034 & 1963 & 6556 & 1977 & 5751 & 1992 & 12915 \\
1936 & 4174 & 1950 & 4716 & 1964 & 7732 & 1978 & 6259 & 1993 & 5840 \\
1937 & 5598 & 1951 & 4855 & 1965 & 5836 & 1980 & 10490 & 1994 & 5366 \\
1938 & 6307 & 1952 & 6938 & 1966 & 6708 & 1981 & 6170 & 1995 & 3244 \\
1939 & 5897 & 1953 & 3741 & 1967 & 5105 & 1982 & 7990 & 1996 & 4478 \\
1940 & 5500 & 1954 & 4405 & 1968 & 6495 & 1983 & 9245 & 1997 & 6202 \\
1941 & 5004 & 1955 & 4051 & 1969 & 4879 & 1984 & 6328 & 1998 & 3360 \\
1942 & 5277 & 1956 & 5370 & 1970 & 6441 & 1985 & 7789 & 1999 & 4212 \\
1943 & 9469 & 1957 & 7965 & 1971 & 6411 & 1986 & 7556 & 2000 & 5271 \\
1944 & 6328 & 1958 & 5212 & 1972 & 4959 & 1987 & 3709 & 2001 & 3158 \\
\hline \hline
\end{tabular}

Fonte: ONS (2004) - www.ons.org.br

Tabela 3 - Parâmetros estatísticos da série vazões máximas anuais da UHE de Sobradinho/BA.

\begin{tabular}{cc}
\hline \hline Número de elementos & 70 \\
Média & 6121 \\
Desvio-padrão & 2004 \\
Assimetria & 1,422 \\
Coeficiente de curtose & 5,690 \\
\hline \hline
\end{tabular}

coeficiente de assimetria é 1,422 (1,422 - no gráfico) e do coeficiente de curtose é 5,690 .

Para esses valores são sugeridas no citado diagrama MRD (figura 2) e L-MRD (figura 3), via avaliação visual, as seguintes distribuições probabilísticas: log-normal 2 parâmetros, log-normal 3 parâmetros, gama, Pearson tipo III, log-Pearson tipo III, Gumbel (EV1), Weibull, logística e GEV. Essa consideração, subjetiva, de considerar um número grande de distribuições a serem testadas, deve-se ao fato de se utilizar apenas um ponto no gráfico. Vale salientar, que o uso desses diagramas serve para determinar para uma região hipoteticamente homogênea qual distribuição deve ser ajustadas para a análise de freqüência regional.

Para análise da verificação do ajuste das distribuições à série de dados foi utilizado os testes qui-quadrado e Kolmogorov-Smirnov (K-S), estes testes apesar do baixo poder é frequentemente usado na hidrologia. Foram analisadas as seguintes distribuições: normal, log-normal 2 parâmetros, log-normal 3 parâmetros, gama, 
Pearson tipo III, log-Pearson tipo III, Gumbel (EV1), Weibull, logística, GEV, wakeby 4 parâmetros, wakeby 5 parâmetros, pareto generalizado e logística generalizado.

As distribuições log-normal 2 parâmetros, log-normal 3 parâmetros, gama, Pearson tipo III, log-Pearson tipo III, Gumbel, logística, logística generalizado e GEV apresentaram o coeficiente estatístico, tanto do teste qui-quadrado como do Kolmogorov-Smirnov, menor que o valor padronizado com o nível de confiança de 95\%. O teste foi feito para os três métodos de estimação dos parâmetros utilizados no trabalho (MOM, ML e PWM).

A distribuição Normal teve a hipótese rejeitada no teste qui-quadrado para os três métodos de estimação dos parâmetros, mas no teste Kolmogorov-Smirnov a hipótese não foi rejeitada para os três métodos. A distribuição exponencial teve a hipótese rejeitada no teste qui-quadrado para os três métodos de estimação dos parâmetros e também foi rejeitada no testes K-S para o método ML, já para os métodos MOM e PWM a hipótese não foi rejeitada. A distribuição Weibull foi rejeitada no testes K-S para o método ML. A distribuição Wakeby 4 e 5 parâmetros foi rejeitada no teste qui-quadrado para os três métodos de estimação dos parâmetros e também foi rejeitada no testes K-S para o método ML. A distribuição Pareto generalizado teve a hipótese rejeitada no teste qui-quadrado para o método ML e também foi rejeitada no teste K-S para os métodos MOM e PWM. De acordo com os resultados dos testes de aderência optou-se pelas distribuições que não foram rejeitadas em todos os testes para todos os métodos de estimação dos parâmetros.

Por fim, As distribuições escolhidas foram baseadas no diagrama MRD e nos testes de aderência, sendo assim as distribuições escolhidas para análise de freqüência foram: log-normal 2 parâmetros, log-normal 3 parâmetros, gama, Pearson tipo III, logPearson tipo III, Gumbel, logística e GEV.

As distribuições foram ajustadas à série de vazões máximas, cuja posição de plotagem foi definida pela fórmula de Weibull. A estimativa dos parâmetros das diferentes distribuições foi feita pelo método dos momentos (MOM), método da máxima verossimilhança (ML) e método dos momentos com pesos probabilísticos (PWM). A seguir, tabela 4 e 5 são apresentados os parâmetros obtidos para cada uma das distribuições: 
Tabela 4 - Parâmetros obtidos para diferentes distribuições probabilísticas e diferentes estimadores (MOM, ML, PWM).

\begin{tabular}{|c|c|c|c|c|c|c|c|c|}
\hline Método & Par. & LN 2 & Par. & LN 3 & Par. & Gama & Par. & LP -III \\
\hline \multirow{3}{*}{ MOM } & $\mu$ & 8,669 & $\mu$ & 8,323 & $\alpha$ & 656,105 & $\alpha$ & 0,045 \\
\hline & $\sigma$ & 0,319 & $\sigma$ & 0,425 & $\beta$ & 9,329 & $\beta$ & 45,261 \\
\hline & & & $\mathrm{a}$ & 1613,170 & & & $\gamma$ & 6,620 \\
\hline \multirow{3}{*}{ ML } & $\mu$ & 8,673 & $\mu$ & 8,303 & $\alpha$ & 558,394 & $\alpha$ & 0,058 \\
\hline & $\sigma$ & 0,298 & $\sigma$ & 0,426 & $\beta$ & 10,961 & $\beta$ & 26,090 \\
\hline & & & $\mathrm{a}$ & 1699,360 & & & $\gamma$ & 7,150 \\
\hline \multirow{3}{*}{ PWM } & $\mu$ & 8,672 & $\mu$ & 8,147 & $\alpha$ & 584,606 & $\alpha$ & 0,070 \\
\hline & $\sigma$ & 0,308 & $\sigma$ & 0,490 & $\beta$ & 10,470 & $\beta$ & 18,193 \\
\hline & & & $\mathrm{a}$ & 2228,930 & & & $\gamma$ & 7,400 \\
\hline
\end{tabular}

Tabela 5 - Parâmetros obtidos para diferentes distribuições probabilísticas e diferentes estimadores (MOM, ML, PWM).

\begin{tabular}{ccccccccc}
\hline \hline Método & Par. & GEV & Par. & Gumbel & Par. & LOGG & Par. & P-III \\
\hline \hline \multirow{2}{*}{ MOM } & $\alpha$ & 1471,890 & $\alpha$ & 1562,460 & $\mathrm{~m}$ & 6120,000 & $\alpha$ & 1424,420 \\
& $\mathrm{k}$ & $-0,043$ & $\mathrm{u}$ & 5218,720 & $\mathrm{a}$ & 1104,820 & $\beta$ & 1,979 \\
& $\mathrm{u}$ & 5205,920 & & & & & $\gamma$ & 3301,390 \\
& $\alpha$ & 1406,630 & $\alpha$ & 1442,000 & $\mathrm{~m}$ & 5878,470 & $\alpha$ & 1110,370 \\
ML & $\mathrm{k}$ & $-0,069$ & $\mathrm{u}$ & 5258,870 & $\mathrm{a}$ & 1031,530 & $\beta$ & 3,055 \\
& $\mathrm{u}$ & 5205,240 & & & & & $\gamma$ & 2728,010 \\
& $\alpha$ & 1373,780 & $\alpha$ & 1521,400 & $\mathrm{~m}$ & 6120,600 & $\alpha$ & 1417,710 \\
PWM & $\mathrm{k}$ & $-0,101$ & $\mathrm{u}$ & 5242,440 & $\mathrm{a}$ & 1054,560 & $\beta$ & 1,971 \\
& $\mathrm{u}$ & 5176,540 & & & & & $\gamma$ & 3326,510 \\
\hline \hline
\end{tabular}

\section{- Análise dos resultados}

As figuras 4 a 6 apresentam, no mesmo gráfico, os pontos correspondentes às vazões máximas observadas e as curvas das diferentes distribuições probabilísticas ajustadas pelos métodos MOM, ML e PWM respectivamente. As tabelas 6 a 8 apresentam, para cada uma das distribuições e para cada método de estimação dos parâmetros, as vazões máximas para diferentes probabilidades de excedência, inferidas através da metodologia estatística. A ultima coluna das mesmas tabelas apresentam, para cada probabilidade de excedência, as diferenças percentuais máximas entre os valores obtidos para as diferentes distribuições. As tabelas 9 e 10 apresentam, para cada uma das distribuições e para cada método de estimação dos parâmetros, o erro padrão para os períodos de retornos de 10000, 2000 e 1000 anos (valores usuais de projeto), inferido através da metodologia estatística.

As análises das figuras 4 a 6 e das tabelas 6 a 8 permitem verificar que todas as curvas das diferentes distribuições apresentam um ótimo ajuste em relação aos pontos correspondentes aos valores observados. Nota-se nas tabelas 6 a 8 que as diferenças máximas entre os valores inferidos a partir das distribuições para períodos de retorno 
entre 2 e 50 anos é inferior a 16\%. Portanto, em decorrência da própria metodologia, as curvas das distribuições praticamente se sobrepõem na faixa dos dados observados. Assim, para o objetivo de interpolação de valores para períodos de retorno inferiores a 50 anos, as diversas distribuições levariam a resultados muito semelhantes. Observando as tabelas 9 e 10 nota-se que o método da máxima verossimilhança se mostrou mais eficiente que os outros métodos, devido aos menores valores apresentados no erro padrão de estimativa.

No entanto, o método estatístico de ajuste das distribuições freqüentemente é aplicado para inferir valores extremos, correspondentes a períodos de retorno de 1.000 ou 10.000 anos. Verifica-se que, embora todas as distribuições apresentem uma boa aderência em relação aos pontos, existe uma forte divergência das curvas para períodos de retorno acima de 200 anos.

Conceitualmente, esse caso exemplifica que o bom ajuste da distribuição em relação aos pontos, ou seja, a habilidade descritiva, não garante a consistência da extrapolação, ou seja, a habilidade predictiva. Ao engenheiro e, muitas vezes, ao decisor fica a pergunta: qual distribuição escolher?

Suponha, como é usual, que tivesse que projetar um vertedor em Sobradinho/BA para uma vazão decamilenar. A análise dos resultados apresentados nas tabelas 6 a 8 levaria a vazões de projeto entre 22.062 a 16.296 m³/s para o MOM, 23.329 a 15.379 $\mathrm{m}^{3} / \mathrm{s}$ para o ML e 26.030 a $15.746 \mathrm{~m}^{3} / \mathrm{s}$ para o $\mathrm{PWM}$, ou seja, diferença de $35 \%$ para o MOM, diferença de $52 \%$ para o ML e diferença de $65 \%$ para PWM. 


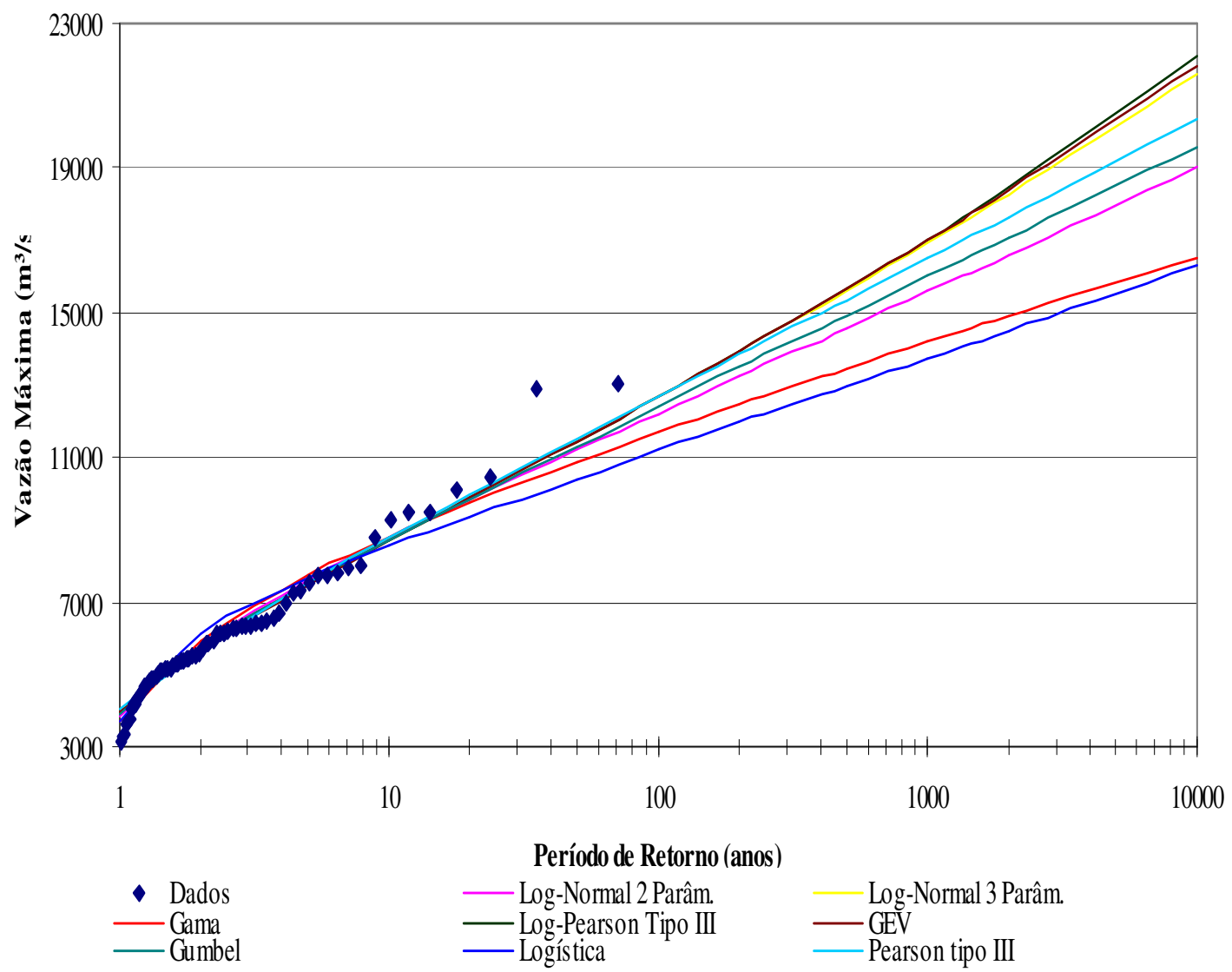

Figura4 - Método estatístico - Comparação das distribuições ajustadas pelo método dos momentos.

Tabela 6 - Vazões máximas em função da probabilidade de excedência para diferentes distribuições probabilísticas ajustada pelo método dos momentos.

\begin{tabular}{|c|c|c|c|c|c|c|c|c|c|c|}
\hline \multicolumn{11}{|c|}{ Vazões Máximas $\left(\mathrm{m}^{3} / \mathrm{s}\right)$ - MÉTODO DOS MOMENTOS - MOM } \\
\hline \multirow{2}{*}{ P.E. ${ }^{1}$} & \multirow{2}{*}{$\begin{array}{l}\text { P.R. }^{2} \\
\text { (anos) }\end{array}$} & \multicolumn{8}{|c|}{ Distribuições Probabilísticas } & \multirow{2}{*}{$\begin{array}{c}\text { D.M. }^{3} \\
(\%)\end{array}$} \\
\hline & & LN 2. & LN 3 & Gama & LP-III & GEV & Gumbel & $\overline{\text { LOG }}$ & P-III & \\
\hline 0,0001 & 10000 & 19059 & 21598 & 16485 & 22062 & 21834 & 19609 & 16296 & 20324 & 35 \\
\hline 0,0005 & 2000 & 16623 & 18273 & 14910 & 18466 & 18434 & 17094 & 14518 & 17653 & 27 \\
\hline 0,001 & 1000 & 15594 & 16915 & 14207 & 17029 & 17041 & 16011 & 13751 & 16507 & 24 \\
\hline 0,002 & 500 & 14573 & 15597 & 13485 & 15651 & 15688 & 14927 & 12984 & 15361 & 21 \\
\hline 0,005 & 200 & 13233 & 13912 & 12497 & 13913 & 13958 & 13493 & 11969 & 13845 & 17 \\
\hline 0,01 & 100 & 12220 & 12675 & 11717 & 12654 & 12692 & 12406 & 11197 & 12694 & 13 \\
\hline 0,02 & 50 & 11202 & 11466 & 10901 & 11434 & 11458 & 11315 & 10420 & 11535 & 11 \\
\hline 0,05 & 20 & 9832 & 9895 & 9746 & 9866 & 9869 & 9860 & 9374 & 9980 & 6 \\
\hline 0,1 & 10 & 8756 & 8711 & 8788 & 8693 & 8684 & 8735 & 8548 & 8774 & 3 \\
\hline
\end{tabular}




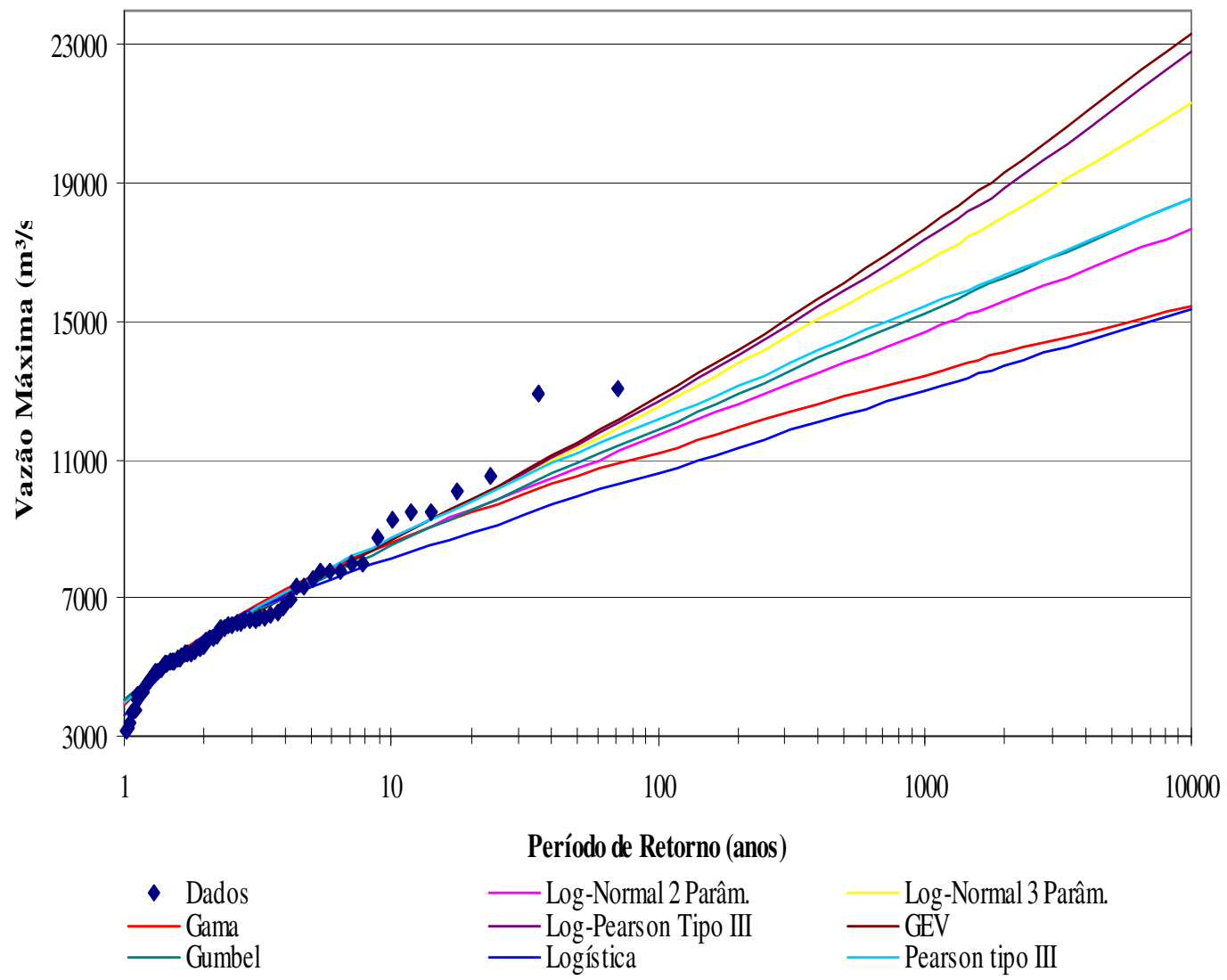

Figura5 - Método estatístico - Comparação das distribuições ajustadas pelo método da máxima verossimilhança

Tabela 7 - Vazões máximas em função da probabilidade de excedência para diferentes distribuições probabilísticas ajustada pelo método da máxima verossimilhança.

\begin{tabular}{|c|c|c|c|c|c|c|c|c|c|c|}
\hline \multirow{3}{*}{ P.E. ${ }^{1}$} & \multicolumn{9}{|c|}{ Vazões Máximas (m³/s) - MÉTODO DA MÁXIMA VEROSSIMILHANÇA - ML } & \multirow{3}{*}{$\begin{array}{c}\text { D.M. }^{3} \\
(\%)\end{array}$} \\
\hline & \multirow{2}{*}{$\begin{array}{l}\text { P.R. }^{2} \\
\text { (anos) }\end{array}$} & \multicolumn{8}{|c|}{ Distribuições Probabilísticas } & \\
\hline & & L" 2. & LN 3 & Gama & LP-III & "GEV & Gumbel & LOG & P-III & \\
\hline 0,0001 & 10000 & 17695 & 21352 & 15469 & 22824 & 23329 & 18540 & 15379 & 18558 & 52 \\
\hline 0,0005 & 2000 & 15575 & 18076 & 14070 & 18887 & 19275 & 16219 & 13719 & 16356 & 41 \\
\hline 0,001 & 1000 & 14673 & 16738 & 13445 & 17336 & 17663 & 15219 & 13003 & 15401 & 36 \\
\hline 0,002 & 500 & 13774 & 15440 & 12801 & 15862 & 16127 & 14219 & 12287 & 14439 & 31 \\
\hline 0,005 & 200 & 12588 & 13781 & 11918 & 14023 & 14203 & 12895 & 11339 & 13153 & 25 \\
\hline 0,01 & 100 & 11686 & 12564 & 11219 & 12704 & 12825 & 11892 & 10618 & 12166 & 21 \\
\hline 0,02 & 50 & 10775 & 11374 & 10486 & 11440 & 11507 & 10886 & 9893 & 11161 & 16 \\
\hline 0,05 & 20 & 9539 & 9828 & 9444 & 9833 & 9844 & 9542 & 8916 & 9790 & 10 \\
\hline 0,1 & 10 & 8560 & 8664 & 8577 & 8646 & 8631 & 8504 & 8145 & 8703 & 7 \\
\hline
\end{tabular}




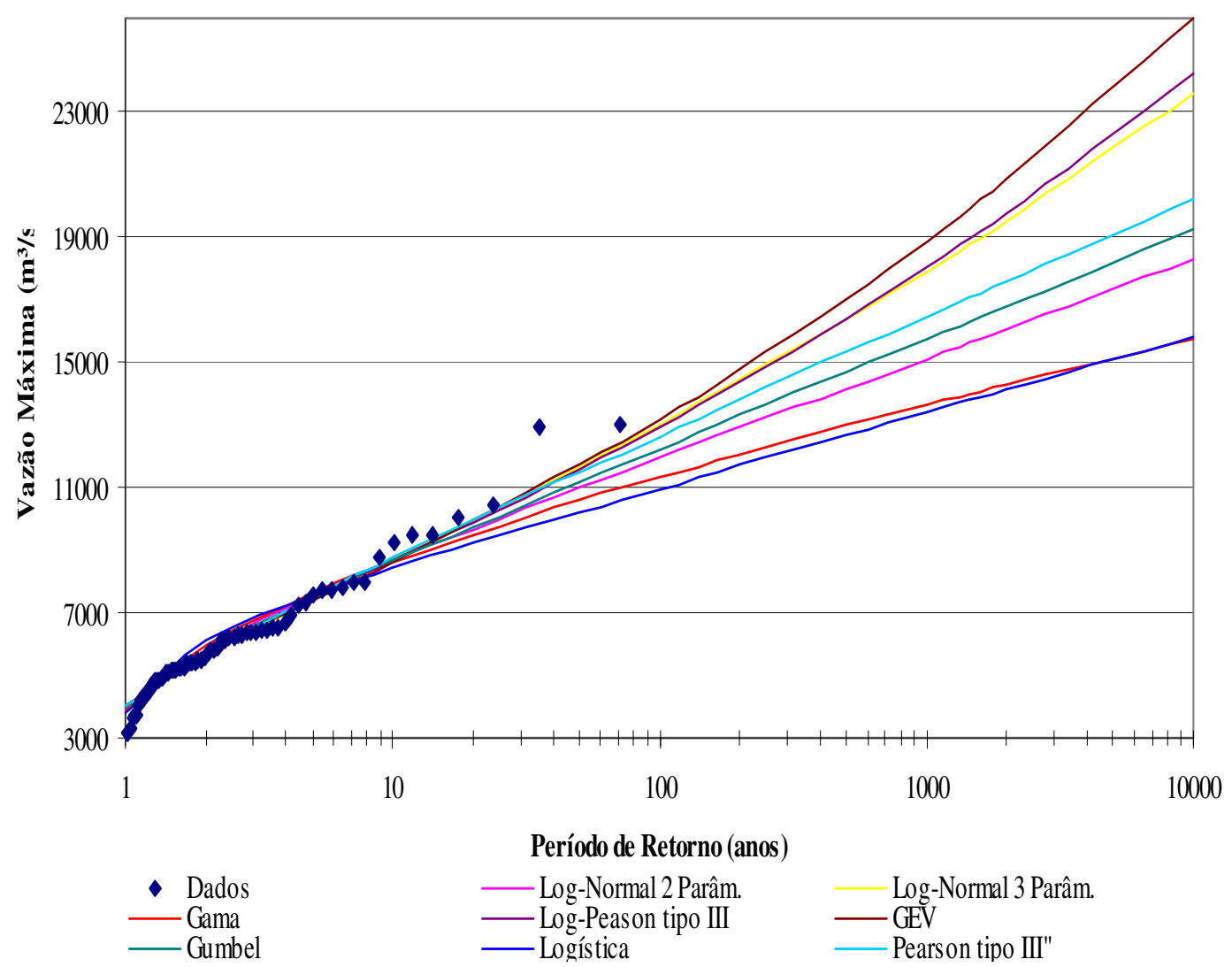

Figura6 - Método estatístico - Comparação das distribuições ajustadas pelo método dos momentos com pesos probabilísticos.

Tabela 8 - Vazões máximas em função da probabilidade de excedência para diferentes distribuições probabilísticas ajustada pelo método dos momentos com pesos probabilísticos.

\begin{tabular}{|c|c|c|c|c|c|c|c|c|c|c|}
\hline \multirow{2}{*}{ P.E. $^{1}$} & \multirow{2}{*}{$\begin{array}{l}\text { P.R. }{ }^{2} \\
\text { (anos) }\end{array}$} & \multicolumn{8}{|c|}{ Distribuições Probabilísticas } & \multirow{2}{*}{$\begin{array}{c}\text { D.M. }^{3} \\
(\%)\end{array}$} \\
\hline & & LN 2. & LN 3 & Gama & LP-III & GEV & Gumbel & LOG & P-III & \\
\hline 0,0001 & 10000 & 18339 & 23575 & 15746 & 24209 & 26030 & 19255 & 15833 & 20242 & 65 \\
\hline 0,0005 & 2000 & 16073 & 19533 & 14300 & 19756 & 20867 & 16806 & 14136 & 17585 & 48 \\
\hline 0,001 & 1000 & 15112 & 17915 & 13653 & 18027 & 18888 & 15751 & 13404 & 16445 & 41 \\
\hline 0,002 & 500 & 14157 & 16367 & 12988 & 16400 & 17042 & 14696 & 12672 & 15305 & 34 \\
\hline 0,005 & 200 & 12899 & 14421 & 12077 & 14390 & 14789 & 13300 & 11703 & 13797 & 26 \\
\hline 0,01 & 100 & 11945 & 13018 & 11356 & 12965 & 13216 & 12241 & 10966 & 12652 & 21 \\
\hline 0,02 & 50 & 10984 & 11669 & 10600 & 11612 & 11743 & 11179 & 10225 & 11500 & 15 \\
\hline 0,05 & 20 & 9685 & 9956 & 9527 & 9914 & 9933 & 9761 & 9226 & 9955 & 8 \\
\hline 0,1 & 10 & 8660 & 8696 & 8635 & 8676 & 8647 & 8666 & 8438 & 8756 & 4 \\
\hline
\end{tabular}


Tabela 9 - Erro padrão em função da probabilidade de excedência para diferentes distribuições.

\begin{tabular}{|c|c|c|c|c|c|c|c|c|c|c|c|c|}
\hline \multirow{3}{*}{$\begin{array}{l}\text { Período de } \\
\text { Retorno } \\
\text { (anos) } \\
\end{array}$} & \multicolumn{12}{|c|}{ Erro Padrão - $\mathrm{m}^{3} / \mathrm{s}$ - Distribuições probabilísticas } \\
\hline & \multicolumn{3}{|c|}{ LN 2.} & \multicolumn{3}{|c|}{ LN 3} & \multicolumn{3}{|c|}{ Gama } & \multicolumn{3}{|c|}{ LP-III } \\
\hline & MOM & ML & $\begin{array}{l}\text { PWM } \\
\end{array}$ & MOM & $\begin{array}{l}\mathrm{ML} \\
\end{array}$ & $\begin{array}{l}\text { PWM } \\
\end{array}$ & MOM & ML & $\begin{array}{l}\text { PWM } \\
\end{array}$ & MOM & ML & PWM \\
\hline 10000 & 223 & 208 & IND & 287 & 219 & IND & 234 & 67 & IND & 280 & 217 & IND \\
\hline 2000 & 363 & 311 & IND & 390 & 342 & IND & 329 & 166 & IND & 398 & 341 & IND \\
\hline 1000 & 480 & 411 & IND & 504 & 492 & IND & 421 & 261 & IND & 498 & 496 & IND \\
\hline
\end{tabular}

Tabela 10 - Erro padrão em função da probabilidade de excedência para diferentes distribuições.

\begin{tabular}{|c|c|c|c|c|c|c|c|c|c|c|c|c|}
\hline \multirow{3}{*}{$\begin{array}{l}\text { Período de } \\
\text { Retorno } \\
\text { (anos) }\end{array}$} & \multicolumn{12}{|c|}{ Erro Padrão - m³/s - Distribuições probabilísticas } \\
\hline & \multicolumn{3}{|c|}{ GEV } & \multicolumn{3}{|c|}{ Gumbel } & \multicolumn{3}{|c|}{ LOG } & \multicolumn{3}{|c|}{ P-III } \\
\hline & MOM & ML & PWM & MOM & ML & PWM & MOM & ML & PWM & MOM & ML & PWM \\
\hline 10000 & 255 & 215 & 217 & 220 & 202 & 214 & 240 & 214 & 218 & 543 & 201 & IND \\
\hline 2000 & 385 & 337 & 348 & 370 & 311 & 345 & 290 & 257 & 263 & 651 & 347 & IND \\
\hline 1000 & 493 & 492 & 517 & 500 & 398 & 453 & 353 & 311 & 320 & 554 & 559 & IND \\
\hline
\end{tabular}

Adotar um valor superior tem como conseqüência um aumento significativo do custo da obra. Utilizar um valor inferior, da mesma ordem de grandeza do valor considerado "outlier" (15.676 m³/s), levaria a uma forte insegurança. Concluindo-se, nas etapas da metodologia estatística para definição de valores máximos recorre-se a sucessivas extrapolações, nem sempre confiáveis. Para o caso dos estudos de vazões máximas, a curva chave (cota-descarga) do posto fluviométrico é ajustada com base nas medições de descarga e é utilizada, por extrapolação, para cotas limnimétricas mais altas. Posteriormente, as curvas-chave das distribuições probabilísticas ajustadas aos dados da série são usados para estimar, por extrapolação, valores máximos superiores aos já inferidos por extrapolação a partir da curva chave (cota-descarga) do posto.

Conseqüentemente, a probabilidade de excedência de um evento máximo obtido com base na análise de freqüência resulta, na melhor das hipóteses, de extrapolações subseqüentes, não se dispondo de um valor ou parâmetro para controlar este procedimento, aumentando mais ainda a incerteza do método.

A análise das Figuras 4 a 6 permite concluir que as curvas representativas das diferentes distribuições apresentam um bom ajuste com os pontos, correspondentes às vazões observadas. Julgando-se que estas distribuições apresentam uma boa habilidade descritiva, ou seja, permitiram uma interpolação precisa para a faixa correspondente às vazões observadas (períodos de retorno entre 2 e 100 anos). Desta forma, no aspecto prático dos estudos hidrológicos, quaisquer umas das distribuições acima poderiam ser justificadas com base no bom ajuste aos valores observados. Os gráficos apresentados, os testes estatísticos de ajuste (qui-quadrado e Kolmogorov-Smirnov) e algumas 
justificativas bibliográficas formariam um relatório que justificaria a escolha de qualquer uma das citadas distribuições.

Sendo assim, a questão volta ao mesmo ponto. Qual distribuição escolher? De acordo com Damázio et al (1983) a tendência mundial é a de se escolher a distribuição que forneça o melhor ajuste aos dados, aceitando-se que nenhum tipo de distribuição forneça constantemente o melhor ajuste.

Conclusões importantes sobre o uso do critério do melhor ajuste foram obtidos nos estudos de cheias feito pelos ingleses (NERC, 1975). Neste estudo foram testadas 7 distribuições a partir de dados da Grã-Bretanha. Os resultados mostraram que os testes de qui-quadrado e Kolmogorv-Smirnov não são suficientemente potentes para definir uma distribuição e os índices baseados em desvios à sensibilidade à posição de plotagem e ao tipo de índice usado (erro médio quadrático). Concluiu-se que se pode no máximo definir um conjunto de distribuições de melhor ajuste, mas que a escolha de uma única distribuição de melhor ajuste depende do tipo de índice e da posição de plotagem usada. É por isso que hidrólogos independentes, mesmo quando de posse dos mesmos dados, possam optar por diferentes distribuições, aumentando a natural variabilidade das estimativas de vazões de projeto. Depreende-se daí a necessidade de uma certa padronização institucional.

Um exemplo de escolha de distribuição com o objetivo básico de padronizar o cálculo de cheias é a recomendação do comitê de hidrologia de Water Resources Council (1977) do Estados Unidos da América que optou pelo uso da distribuição logPearson tipo III baseando-se em critérios relacionados com a bondade de ajuste em longas séries de vazões máximas.

O NATIONAL ENVIROMENT RESEARCH COUNCIL - NERC (1975) do Reino Unido analisou dados de cheias de 30 estações do reino unido, com registros acima de 30 anos, dos quais, apenas quatro excederam os 60 anos. 7 distribuições testadas, 4 com 2 parâmetros (log-normal 2, Gumbel, gama e log-normal 3) e o restante com 3 parâmetros (GEV, Pearson tipo-III e log-Pearson III). Os testes qui-quadrado e o Kolmogorov-Smirnov mostraram-se insensíveis aos afastamentos das distribuições adotadas para os tamanhos das amostras utilizadas. O estudo foi repetido usando as diferenças entre os pontos plotados e as distribuições teóricas. Verificou-se que os resultados se mostraram sensíveis às fórmulas de posição de plotagem e, embora, a distribuição log-Pearson III tenha se revelado melhor com o uso da formula de posição de plotagem de Weibull, a distribuição GEV foi a mais estável para todas as fórmulas. 
Com base neste resultado, a distribuição GEV foi recomendada para ser usada em análise de frequiência de cheias no Reino Unido.

Na Austrália, um extensivo e comparativo estudo feito por CONWER (1971), utilizando dados de cheias de New South Wales, e por KOPITTKE et al. (1976), usando dados de cheias de Queensland, concluiu que a distribuição log-Pearson III teve o melhor desempenho entre as distribuições examinadas. O INSTITUTION OF ENGINNERS AUSTRALIAN - I.E.A. (1972) publicou Australian Rainfall and Runoff, em que a distribuição log-Pearson III é recomendada para a Austrália. MCMAHON E SRIKANTHAN (1981) usando diagramas de momentos do coeficiente de assimetria- $\mathrm{C}_{\mathrm{s}}$ com o coeficiente de variação- $\mathrm{C}_{\mathrm{v}}$ e da curtose-k com o coeficiente de assimetria- $\mathrm{C}_{\mathrm{s}}$ ajustaram várias distribuições de probabilidades (log-Pearson III, Normal, retangular, Gumbel, Pearson V, Weibull, gama, exponencial e log-normal 2 parametros) aos picos de descargas anuais de 172 cursos d'água da Austrália. Os resultados indicam que a distribuição log-Pearson III é apropriada para análise de freqüência de cheias.

Pinheiro et. al (1981) realizaram uma análise de freqüência de máximos anuais de vazões diárias, para 316 postos fluviométricos das regiões sul e sudeste do Brasil, utilizou-se várias distribuições de probabilidade usualmente empregadas em análise de freqüência de cheias. Para medir a eficiência do ajuste das distribuições, adotou-se um método de amostras particionadas. Eles concluíram que em média, a distribuição logPearson tipo III apresentou o melhor ajuste, sendo recomendado o seu uso nas regiões estudadas, para estimativa de vazões com tempo de recorrência da ordem do comprimento do registro.

A ELETROBRÁS (1987a) desenvolveu pesquisa com o objetivo de definir os métodos mais robustos de análise de frequiência de cheias, tendo em vista a determinação de cheias de projeto de vertedores no Brasil. O estudo indicou preferencialmente a distribuição exponencial de 2 parâmetros, baseada na hipótese de que a assimetria de população situa-se entre 1,0 e 2,5. porém, a distribuição Gumbel poderia ser utilizada quando a assimetria da população se encontrar próxima ao limite inferior de citado intervalo.

Outra questão a ser comentada é que as distribuições ajustadas à série de valores máximos tiveram seus limites superiores convergindo para $+\infty$. Este limite teórico contraria a mais evidente realidade física, colocando, a priori, em suspeição as previsões obtidas por extrapolação analítica efetuada na cauda superior da distribuição. Assim, não há procedimento estatístico que assegure confiabilidade às extrapolações 
computadas. As extrapolações sempre suscitam controvérsias uma vez que, irão depender dos critérios do hidrólogo responsável pelo estudo. Além disso, a adoção arbitraria de distribuições probabilísticas ajustadas ás séries de valores máximos, em geral com períodos muito inferiores aos que se pretende prever, sempre gera dúvidas.

Conclui-se, portanto, que por melhor que seja o ajuste da distribuição adotada à serie de dados, não há garantias de que os valores computados por extrapolação para os intervalos de recorrência, em geral estabelecidos para obras hidráulicas de monta, entre 1.000 ou 10.000 anos, sejam irrefutáveis.

Finalmente, a maioria das questões acima levantadas resulta das incertezas inerentes aos valores obtidos por extrapolação analítica em uma cauda sensivelmente instável e comprovadamente dissociada da realidade física, que constitui a base do método estatístico. Portanto, a metodologia estatística é inconsistente, insegura e não considera o comportamento físico das variáveis hidrológicas envolvidas nos fenômenos de enchentes.

\section{- Análise Crítica da Metodologia Estatística}

\section{- Série de Dados}

A partir da série de vazões máximas anuais utilizadas na seção 2.1.3 - tabela 2, foram selecionadas 5 sub-series de vazões máximas, respeitando a seqüência cronológica de ocorrência, conforme definido na tabela 11. Com o objetivo de ter em mente a responsabilidade dos estudos de definição das vazões de projeto, imagine que esta obra poderia ter sido construída ao término dos estudos hidrológicos em 1950, 1970 e 2001.

Tabela 11 - Subséries de vazões máximas da UHE de Sobradinho/BA

\begin{tabular}{ccc}
\hline \hline Série de Vazões Máximas & Período (anos) & Número de Eventos \\
\hline \hline 1 & $1931-1950$ & 20 \\
2 & $1931-1970$ & 40 \\
3 & $1931-2001$ & 70 (sem o evento de 1979) \\
4 & $1951-2001$ & 50 (sem o evento de 1979) \\
5 & $1971-2001$ & 30 (sem o evento de 1979) \\
\hline \hline
\end{tabular}


Deve-se ressaltar que na escolha de uma dada série de vazões foi verificada os seguintes critérios:

- A série não apresenta uma vazão cuja magnitude é muito superior às demais, ou seja, não existem "outliers".

- Os eventos extremos (1946, 1949, 1980 e 1992) estão distribuídos na série de forma que as sub-séries de vazões contém, pelo menos, dois deles.

Desta forma, garantiu-se que as discrepâncias, a serem verificadas a seguir, decorressem da metodologia e não de características particulares da série histórica de vazões.

\section{- Ajuste e Escolha da Distribuição Teórica de Probabilidades}

Como observado na seção 2.1.3 - Análise Conceitual, foram testadas diferentes distribuições probabilísticas, com base nos parâmetros estatísticos e nas distribuições recomendadas pela literatura. Para se evitar a argumentação que as eventuais discrepâncias dos valores extremos obtidos pelo método estatístico se devem à utilização de diferentes distribuições probabilísticas ajustadas às diferentes séries de vazões máximas, optou-se por adotar uma única distribuição. Ressalta-se, no entanto, que esta é uma das importantes críticas ao método estatístico, ou seja, a subjetividade na seleção da distribuição probabilística. Esta escolha depende da experiência do hidrólogo, da disponibilidade de programas computacionais, de testes estatísticos (quiquadrado e Kolmogorov-Smirnov), entre outros critérios.

Como considerado na seção 2.1.2, os valores do coeficiente de assimetria e curtose são importantes indicativos para a definição da distribuição probabilística a ser adotada. Com base nesta consideração utilizou-se o diagrama MRD ("moment ratio diagrams"), tendo como abscissa o quadrado do coeficiente de assimetria $\mathrm{Cs}^{2}$ e na ordenada o coeficiente de curtose Ck. Neste diagrama são definidas as regiões de aplicação de diferentes distribuições observadas na figura 7 


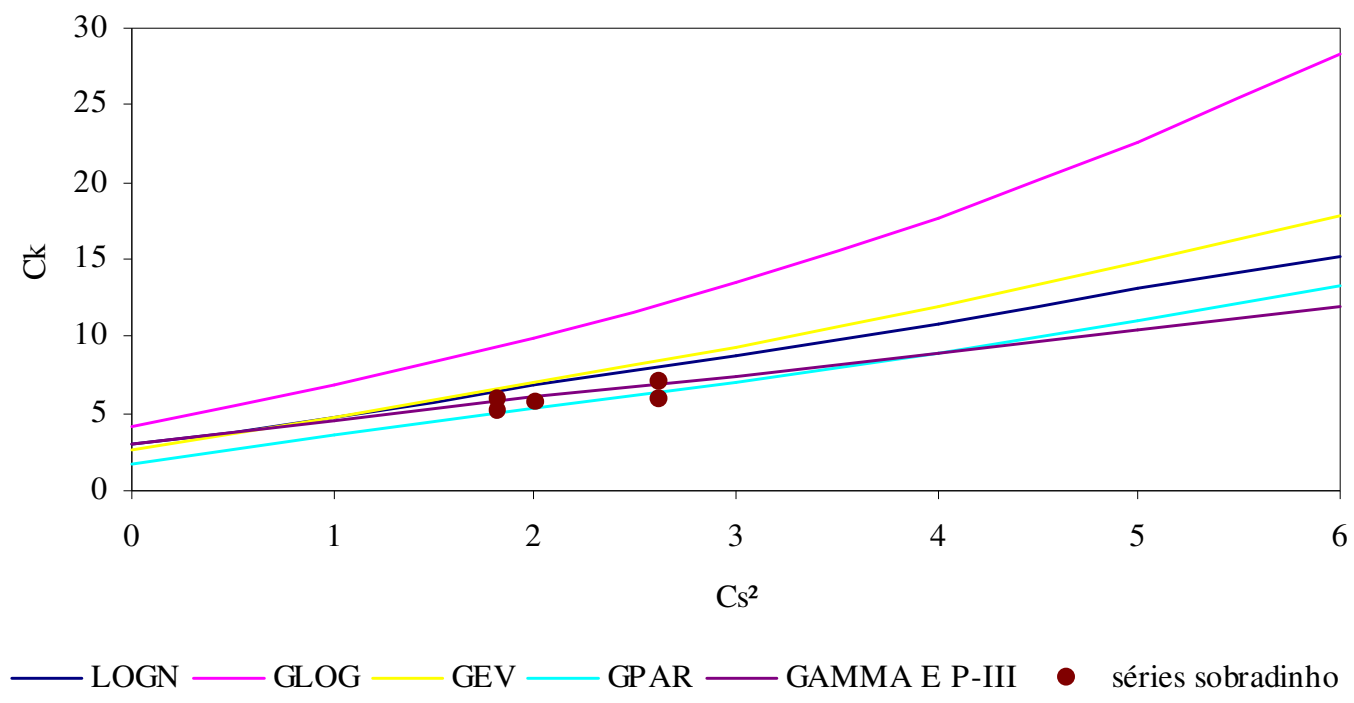

Figura7 - Diagrama da relação dos momentos - (MRD) e os coeficientes estatísticos dispostos no gráfico das sub-séries de sobradinho/BA

Como se pode constatar na tabela 12 , os valores do coeficiente de assimetria estão entre 5,22 e 7,05 e do coeficiente de curtose entre 1,35 e 1,62. Para essa faixa de valores, de acordo com a Figura 6, são sugeridas as distribuições probabilísticas GEV (extremos valores generalizados), log-Pearson tipo III, log-normal 2 e 3 parâmetros e pareto generalizado.

Tabela 12 - Parâmetros estatísticos das sub-séries da UHE de Sobradinho/BA

\begin{tabular}{cccccc}
\hline \hline & \multicolumn{5}{c}{ Período (anos) } \\
\cline { 2 - 6 } Parâmetros Estatísticos & $31-50$ & $31-70$ & $31-01$ & $51-01$ & $71-01$ \\
\hline \hline Número de Elementos & 20 & 40 & 70 & 50 & 30 \\
Máximo & 13034 & 13034 & 13034 & 12915 & 12915 \\
Mínimo & 4531 & 3660 & 3158 & 3158 & 3158 \\
Média & 6121 & 6669 & 6199 & 5915 & 6016 \\
Desvio Padrão & 2004 & 2154 & 1836 & 1909 & 2237 \\
Coeficiente de Assimetria & 5,69 & 5,95 & 7,05 & 5,91 & 5,22 \\
Curtose & 1,42 & 1,62 & 1,62 & 1,35 & 1,35 \\
\hline \hline
\end{tabular}

As diferentes séries de vazões máximas foram ordenadas e a sua posição de plotagem foi definida pela fórmula de Weibull. Através de alguns testes estatísticos (qui-quadrado e Kolmogorov-Smirnov), avaliando visualmente o ajuste das curvas das distribuições às séries de dados e a consideração em adotar uma distribuição assintótica (para se aproximar mais da realidade física), verificou-se que a distribuição GEV é, neste caso, a mais adequada. 
Uma variável aleatória, $x$, tem distribuição GEV se a função densidade de probabilidade puder ser expressa por (RAO E HAMED, 2000):

$$
f(x)=\frac{1}{\alpha}\left[1-k\left(\frac{x-u}{\alpha}\right)\right]^{1 / k-1} e^{\left[1-k\left(\frac{x-u}{\alpha}\right)\right]^{1 / k}}
$$

onde $\alpha$, k e u são os parâmetros da distribuição.

A função de distribuição GEV aplicada na forma geral é dada por (Rao e Hamed, 2000):

$$
\left.x_{t}=u+\frac{\alpha}{k}[1-\Gamma(1+k)]+K_{t} \sqrt{\frac{\alpha}{k^{2}}\left[\Gamma(1+2 k)-\Gamma^{2}(1+k)\right.}\right]
$$

em que $\alpha$, k e u são os parâmetros da distribuição. Os estimadores dos parâmetros e do $\mathrm{K}_{\mathrm{t}}$ pode ser encontrado em (RAO E HAMED, 2000).

Recentemente, a distribuição de probabilidade generalizada de valores extremos (GEV), introduzida por Jenkinson (1955), tem encontrado muitas aplicações em hidrologia, com crescente aceitação para a descrição dos eventos máximos naturais, principalmente dados de cheias máximas anuais. Decorrente da consideração teórica de que a distribuição de valores extremos de uma amostra, converge assintóticamente para uma das três formas de valores máximos reunidas através da GEV, independente de sua distribuição subjacente (WANG, 1997 b).

Garcia (1997) afirma que as chuvas máximas observadas nas bacias hidrográficas, assim como as máximas enchentes, tendem a alcançar um limite superior que depende de suas características fisiográficas e hidrometeorológicas. Os picos e volumes de hidrogramas têm um limite físico superior ditado pelo contexto hidrogeográfico de sua bacia. Assim, é razoável esperar que a distribuição de valores máximos de variáveis hidrológicas naturais seja limitada na sua parte superior. Jenkinson (1955) observou que a distribuição de valores extremos (GEV) do tipo VEIII é a mais freqüente encontrada na natureza.

Queiroz (2002) comenta que na prática, a distribuição GEV tem sido usada para modelar uma extensa variedade de máximos naturais, incluindo, cheias, chuvas, velocidade do vento, temperaturas, picos de onda de mar e outros máximos. Ele conclui que seu uso associado aos métodos de estimação de parâmetros como: momentos de 
pesos probabilísticos; momentos de combinações lineares das estatísticas de ordens momentos L; momentos de altos pesos probabilísticos e momentos de combinações lineares das estatísticas de altas ordens - momentos LH têm produzido bons resultados de ajuste aos dados de vazões máximas anuais de várias localidades.

Gunasekara e Cunannane (1992) com a aplicação dados sintéticos, experimentaram o ajuste de 13 métodos aos dados gerados, através de 7 diferentes distribuições populacionais, concluíram que a distribuição GEV com estimação dos parâmetros através dos métodos dos momentos de pesos probabilísticos, foi a que melhor se ajustou, no local, para estimar cheias de 100 e 1000 anos, utilizando amostras de 20 eventos.

Usando o diagrama de Momentos L, Pearson et al. (1991) observaram que a distribuição GEV foi o modelo que melhor se aproximou da distribuição de fluxos de cheias do sudoeste da Austrália e Victoria central.

Martins e Stedinger (2000) citam o emprego da GEV no ajuste de vários máximos naturais como: cheias anuais, temperatura, chuva, velocidade do vento, alturas de ondas do mar, profundidade de camadas de neve e outros máximos. Além de mostrar a substancial qualidade de estimação de quantis da GEV, em amostras pequenas, utilizando a máxima verossimilhança generalizada para a faixa de valores do parâmetro de forma $\mathrm{k}$ entre $-0,4$ e 0.

Onoz e Bayazit (1995) avaliaram registros de cheias de 19 estações, variando entre 60 e 165 anos, dos quais, 9 pertencem ao Reino Unido e o restante foram fornecidos pela UNESCO. Neste estudo, foram consideradas 7 distribuições de probabilidades (normal, log-normal e Gumbel, com 2 parâmetros; log-normal, GEV, Pearson tipo-III e log-Pearson IIII, com 3 parâmetros). Para selecionar a distribuição mais conveniente, foram usados os seguintes procedimentos estatísticos: teste quiquadrado, teste Kolmogorov-Smirnov, teste de coeficiente de correlação do gráfico de probabilidade, teste Anderson-Darling, diagrama de momentos-L e o número esperado de excedência. Embora tenham ocorrido diferenças com respeito ao local e procedimento, a distribuição GEV foi superior às demais distribuições testadas.

Garcia (1996) propôs o método conjugado que considera o limite superior da GEV tipo VEIII igual a cheia máxima provável, obtida deterministicamente, na análise de freqüência de cheia.

Definida a distribuição GEV (valores extremos generalizado), deve-se verificar os diferentes métodos de estimação dos parâmetros (ajuste da distribuição) para esta 
distribuição. Wang (1997 a,b) demonstrou a eficiência dos métodos de estimação de parâmetros: momentos de altos pesos probabilísticos e momentos $\mathrm{LH}$, propostos por ele, no ajustes da distribuição GEV aos dados de cheia da Austrália. Madsen et al., (1997 a,b) descrevem a relativa precisão da estimação de quantis de cheias. Obtidos com ajustes da GEV às séries parcial e total de cheias máximas, utilizando momentos, momentos L e máxima verossimilhança para estimação dos parâmetros. Uma análise dos trabalhos citados acima (Queiroz, 2002) concluiu que os seguintes métodos são os mais recomendados:

- Método de momentos (MOM)

- Método dos momentos com pesos probabilísticos (PWM) ou dos momentos L (MOM-L)

- Método dos momentos LH com $\eta=4$ (MOM-LH)

Esses métodos são descritos de forma detalhada em (Queiroz, 2002). Além desses, foi incluído o método da máxima verossimilhança (ML), que é assintoticamente ótimo, não viesado, rende mínima variância, mas pode produzir estimativas ruins em amostras pequenas, especialmente quando a variável aleatória está restrita ao intervalo do qual dependem os parâmetros (BOBÉE et al, 1993). Portanto, ressalta-se que foi escolhida a distribuição probabilística e os métodos de estimação dos parâmetros que geram o melhor ajuste em relação aos valores observados. Aplicando-se essa metodologia para cada uma das séries de vazões, foram definidos os parâmetros da distribuição probabilística GEV, apresentados nas tabelas 13 e 14.

Tabela 13 - Parâmetros obtidos para distribuição GEV ajustadas para a sub-séries selecionadas utilizando diferentes estimadores (MOM e ML).

\begin{tabular}{ccccccc}
\hline \hline \multirow{2}{*}{ Período } & \multicolumn{3}{c}{ MOM } & \multicolumn{3}{c}{ ML } \\
& $\mathrm{k}$ & $\alpha$ & $\mathrm{u}$ & $\mathrm{k}$ & $\alpha$ & $\mathrm{u}$ \\
\hline $31-50$ & $-0,06881$ & 1545,792 & 5630,660 & & & \\
$31-70$ & $-0,06832$ & 1296,806 & 5356,660 & $-0,08168$ & 1253,496 & 5366,119 \\
$31-01$ & $-0,04293$ & 1471,892 & 5205,917 & $-0,06923$ & 1406,631 & 5205,242 \\
$51-01$ & $-0,03324$ & 1422,085 & 5045,631 & $-0,04764$ & 1384,945 & 5407,315 \\
$71-01$ & $-0,03350$ & 1665,790 & 4997,932 & $-0,12064$ & 1487,997 & 4961,505 \\
\hline \hline
\end{tabular}


Tabela 14- - Parâmetros obtidos para distribuição GEV ajustadas para a sub-séries selecionadas utilizando diferentes estimadores (MOM e ML).

\begin{tabular}{ccccccc}
\hline \hline \multirow{2}{*}{ Período } & \multicolumn{4}{c}{ PWM } & & \multicolumn{3}{c}{ MOM-LH } \\
& $\mathrm{k}$ & $\alpha$ & $\mathrm{u}$ & $\mathrm{k}$ & $\alpha$ & $\mathrm{u}$ \\
\hline $31-50$ & $-0,31743$ & 1080,620 & 5557,844 & $-0,10681$ & 1776,938 & 5064,475 \\
$31-70$ & $-0,10618$ & 1243,969 & 5335,329 & $-0,21742$ & 996,007 & 5449,737 \\
$31-01$ & $-0,10125$ & 1373,334 & 5179,316 & $-0,11396$ & 1376,198 & 5110,911 \\
$51-01$ & $-0,05531$ & 1393,168 & 5030,680 & $-0,13691$ & 1197,025 & 5112,206 \\
$71-01$ & $-0,14135$ & 1485,650 & 4919,093 & $-0,08555$ & 1728,612 & 4686,031 \\
\hline \hline
\end{tabular}

\section{- Análise da Influência da Extensão da Série de Valores}

A primeira análise a ser desenvolvida refere-se à influência da extensão da série e do período de observações nos valores extremos de projeto. As séries de vazões da UHE de Sobradinho/BA, definidas na tabela 12, têm o objetivo de permitir esta análise.

A partir da aplicação do método estatístico, apresenta-se nas figuras 8 a 11, para cada método de estimação dos parâmetros, as curvas de distribuição probabilística GEV ajustadas para as diferentes séries. As tabelas 15 a 18 apresentam, para cada método de estimação dos parâmetros, as vazões máximas para diferentes períodos de retorno, inferidas a partir das distribuições probabilísticas ajustadas a cada uma das séries de vazões. Essas tabelas apresentam na última coluna, para cada período de retorno, a diferença percentual máxima entre as vazões inferidas para as diferentes séries.

A análise das citadas tabelas e figuras permitem verificar a significante diferença entre as vazões com período de retorno superiores a 100 anos, correspondendo aos valores usuais utilizados para definir as vazões de projeto. As menores diferenças foram obtidas para o método dos momentos LH o que mostra que a caracterização da parte superior da distribuição e dos maiores eventos da amostra diminui a dependência do método a extensão da série de valores.

Para caracterizar a importância desses resultados, suponha que os estudos tenham concluído pela utilização da distribuição probabilística GEV e que os parâmetros tenham sido obtidos pelo método PWM - momentos de pesos probabilísticos, ambos recomendados pela bibliografia (WANG, 1997 a,b).

Se esses estudos tivessem sido concluídos em 1950, o vertedouro teria sido dimensionado a partir de uma série de 20 anos (1931 a 1950) e, como é usual, para a vazão decamilenar obter-se-ia $65.501 \mathrm{~m}^{3} / \mathrm{s}$. Se estudos hidrológicos de verificação da segurança da barragem fossem efetuados em 2001, chegar-se-ia à conclusão que o 


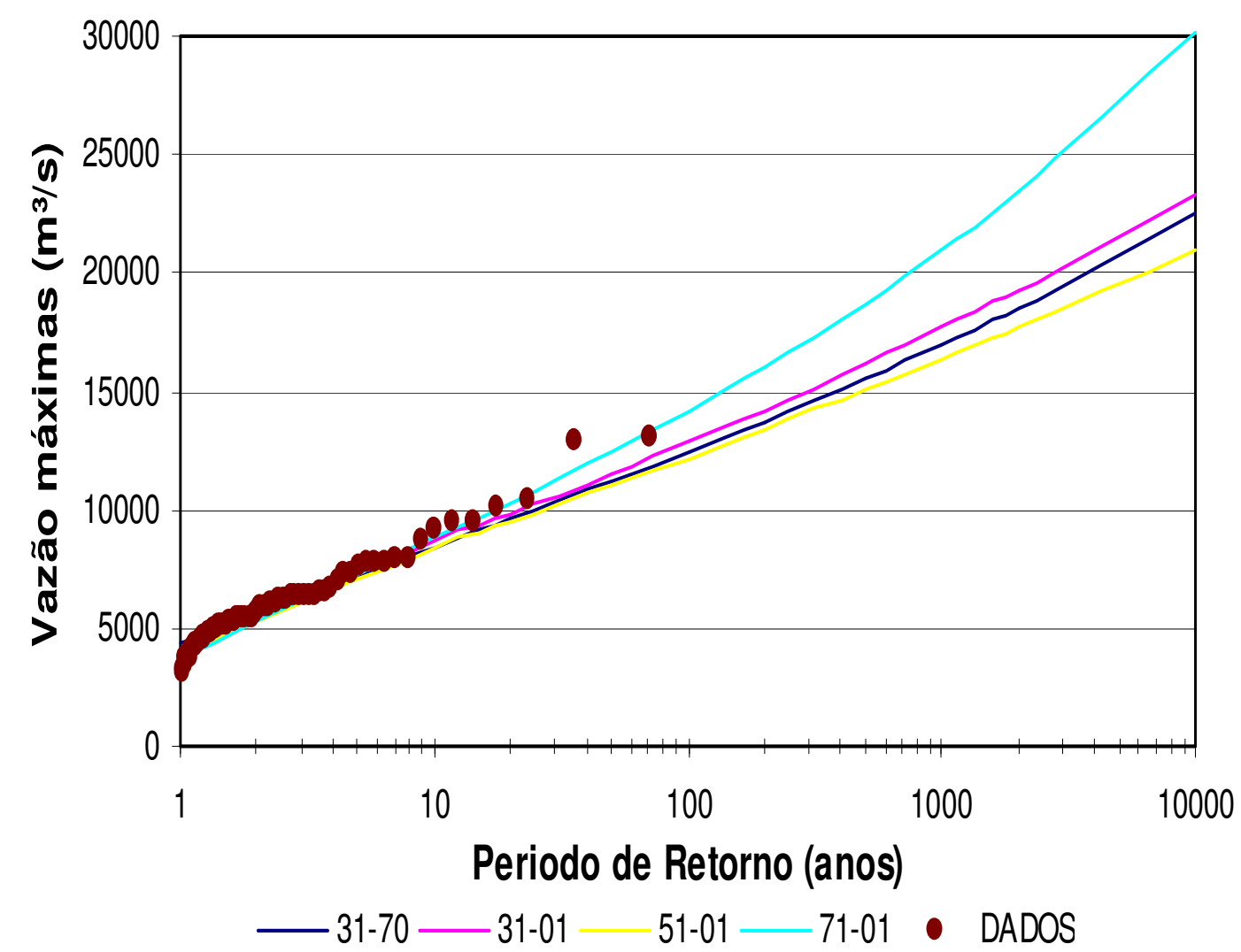

Figura8 - Comparação da distribuição probabilística GEV ajustadas - método ML

Tabela 15 - Vazões máximas obtidas pelo método estatístico - distribuição GEV - Método de estimativa ML

\begin{tabular}{|c|c|c|c|c|c|c|c|}
\hline \multirow{2}{*}{$\begin{array}{l}\text { Probabilidade } \\
\text { de Excedência }\end{array}$} & \multirow{2}{*}{$\begin{array}{c}\text { Período de } \\
\text { Retorno (anos) }\end{array}$} & \multicolumn{5}{|c|}{ Distribuições Probabilísticas } & \multirow{2}{*}{$\begin{array}{c}\text { Diferença } \\
\text { Máxima (\%) }\end{array}$} \\
\hline & & $31-50$ & $31-70$ & 31-01 & "51-01 & $71-01$ & \\
\hline 0,0001 & 10000 & *IND. & 22583 & 23329 & 21060 & $\overline{30096}$ & 43 \\
\hline 0,0005 & 2000 & IND. & 18571 & 19275 & 17732 & 23483 & 32 \\
\hline 0,001 & 1000 & IND. & 16999 & 17663 & 16375 & 21007 & 28 \\
\hline 0,002 & 500 & IND. & 15513 & 16127 & 15062 & 18729 & 24 \\
\hline 0,005 & 200 & IND. & 13672 & 14203 & 13390 & 15993 & 19 \\
\hline 0,01 & 100 & IND. & 12365 & 12825 & 12170 & 14112 & 16 \\
\hline 0,02 & 50 & IND. & 11126 & 11507 & 10986 & 12376 & 13 \\
\hline 0,05 & 20 & IND. & 9580 & 9844 & 9466 & 10277 & 9 \\
\hline 0,1 & 10 & IND. & 8463 & 8631 & 8337 & 8809 & 6 \\
\hline
\end{tabular}

*IND: valor indefinido - não convergiu 


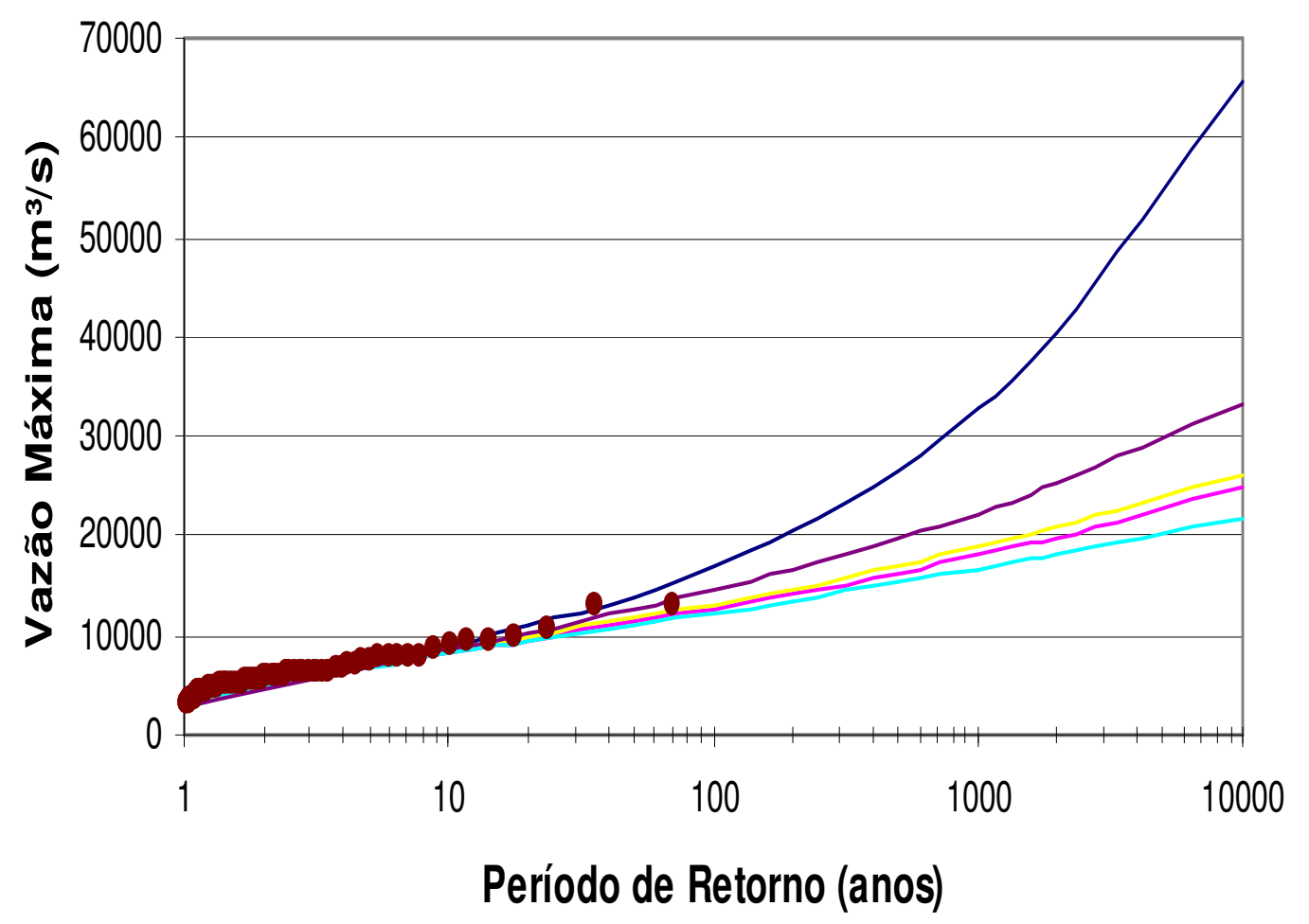

$$
-31-50-31-70-31-01-51-01-71-01 \text { - DADOS }
$$

Figura9- Comparação da distribuição probabilística GEV ajustadas - método PWM

Tabela 16 - Vazões máximas obtidas pelo método estatístico - distribuição GEV - Método de estimativa PWM

\begin{tabular}{|c|c|c|c|c|c|c|c|}
\hline \multirow{2}{*}{$\begin{array}{l}\text { Probabilidad } \\
\text { e de } \\
\text { Excedência }\end{array}$} & \multirow{2}{*}{$\begin{array}{c}\text { Período de } \\
\text { Retorno (anos) }\end{array}$} & \multicolumn{5}{|c|}{ Distribuições Probabilísticas } & \multirow{2}{*}{$\begin{array}{c}\text { Diferença } \\
\text { Máxima (\%) }\end{array}$} \\
\hline & & $31-50$ & $31-70$ & 31-01 & 51-01 & 71-01 & \\
\hline $\begin{array}{l}0,0001 \\
\end{array}$ & 10000 & 65501 & 24772 & 26081 & 21764 & 33047 & 201 \\
\hline 0,0005 & 2000 & 40158 & 19878 & 20898 & 18193 & 25184 & 121 \\
\hline 0,001 & 1000 & 32649 & 18014 & 18912 & 16750 & 22311 & 95 \\
\hline 0,002 & 500 & 26623 & 16282 & 17061 & 15361 & 19705 & 73 \\
\hline 0,005 & 200 & 20438 & 14177 & 14803 & 13603 & 16627 & 50 \\
\hline 0,01 & 100 & 16815 & 12714 & 13226 & 12329 & 14546 & 36 \\
\hline 0,02 & 50 & 13901 & 11349 & 11751 & 11098 & 12654 & 25 \\
\hline 0,05 & 20 & 10893 & 9679 & 9938 & 9528 & 10403 & 14 \\
\hline 0,1 & 10 & 9108 & 8497 & 8650 & 8369 & 8855 & 9 \\
\hline
\end{tabular}




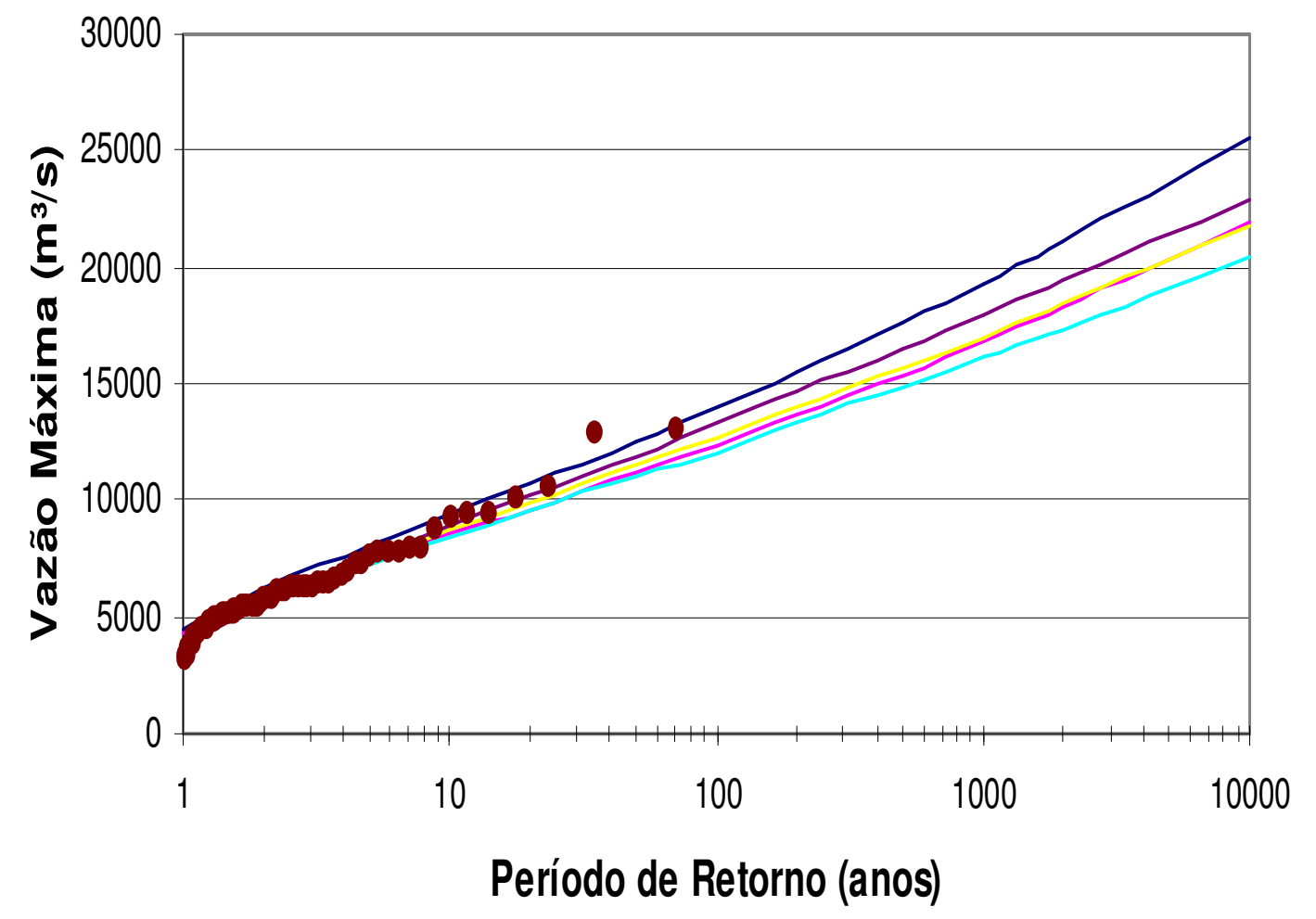

$$
\text { -31-50-31-70-31-01-51-01-71-01 • DADOS }
$$

Figura10- Comparação da distribuição probabilística GEV ajustadas - método MOM

Tabela 17 - Vazões máximas obtidas pelo método estatístico - distribuição GEV - Método de estimativa MOM

\begin{tabular}{|c|c|c|c|c|c|c|c|}
\hline \multicolumn{8}{|c|}{ Vazões Máximas (m³/s) - MÉTODO DOS MOMENTOS - MOM } \\
\hline \multirow{2}{*}{$\begin{array}{c}\text { Probabilida } \\
\text { de de } \\
\text { Excedência }\end{array}$} & \multirow{2}{*}{$\begin{array}{c}\text { Período de } \\
\text { Retorno (anos) }\end{array}$} & \multicolumn{5}{|c|}{ Distribuições Probabilísticas } & \multirow{2}{*}{$\begin{array}{c}\text { Diferença } \\
\text { Máxima }(\%)\end{array}$} \\
\hline & & $31-50$ & $31-70$ & $31-01$ & $51-01$ & $71-01$ & \\
\hline 0,0001 & 10000 & 25505 & 21988 & 21834 & 20370 & 22970 & 25 \\
\hline 0,0005 & 2000 & 21066 & 18279 & 18434 & 17343 & 19417 & 21 \\
\hline 0,001 & 1000 & 19300 & 16803 & 17041 & 16088 & 17944 & 20 \\
\hline 0,002 & 500 & 17616 & 15395 & 15688 & 14861 & 16504 & 19 \\
\hline 0,005 & 200 & 15507 & 13631 & 13958 & 13280 & 14650 & 17 \\
\hline 0,01 & 100 & 13996 & 12366 & 12692 & 12114 & 13283 & 16 \\
\hline 0,02 & 50 & 12550 & 11155 & 11458 & 10970 & 11942 & 14 \\
\hline 0,05 & 20 & 10725 & 9627 & 9869 & 9485 & 10200 & 13 \\
\hline 0,1 & 10 & 9393 & 8511 & 8684 & 8369 & 8891 & 12 \\
\hline
\end{tabular}




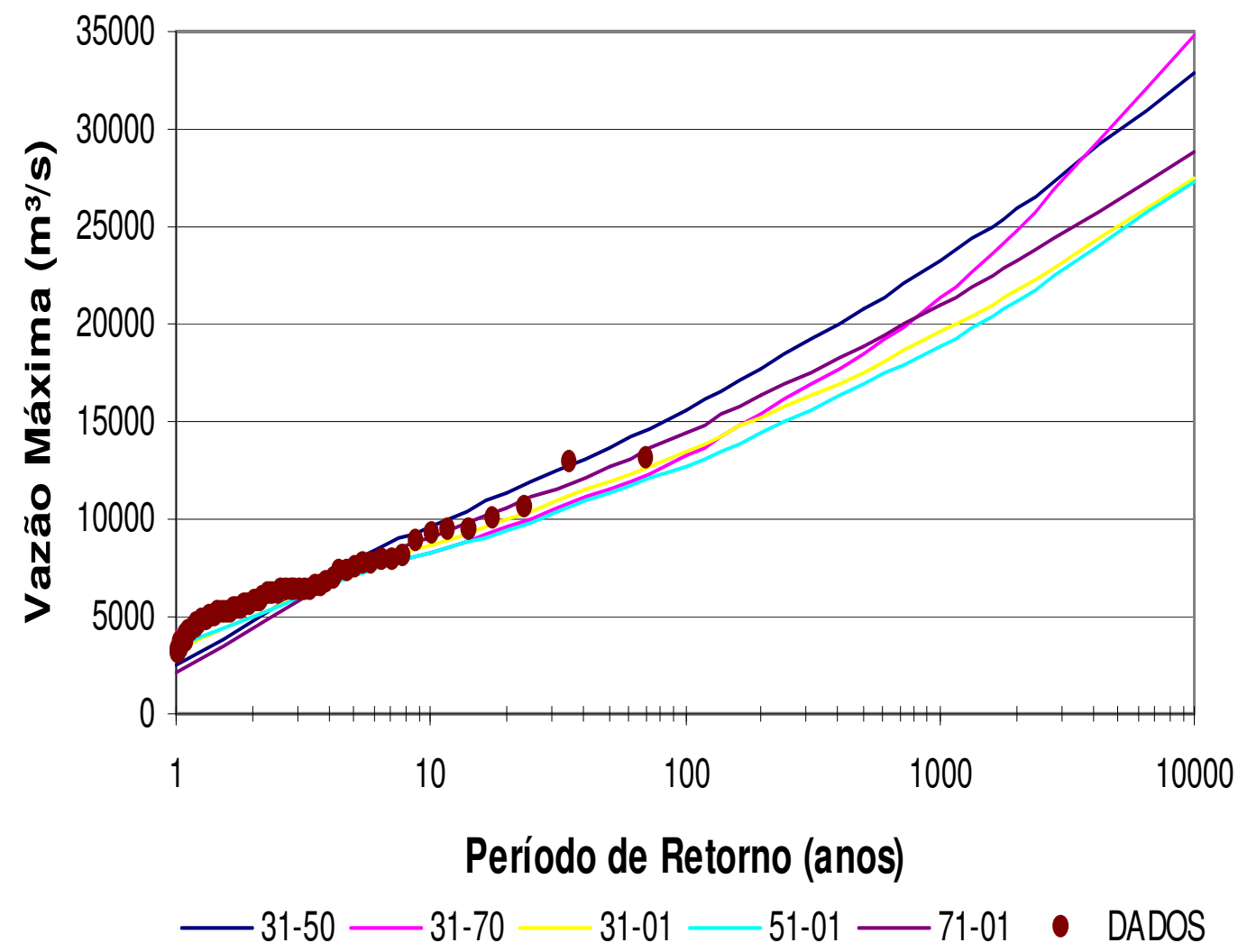

Figura11- Comparação da distribuição probabilística GEV ajustadas - método MOM-LH

Tabela 18 - Vazões máximas obtidas pelo método estatístico - distribuição GEV - Método de estimativa MOM-LH $\operatorname{com} \eta=4$

\begin{tabular}{cccccccc}
\hline \hline \multicolumn{2}{c}{ Vazões Máximas (m³/s) - MÉTODO DOS MOMENTOS LH - MOM-LH com $\eta=4$} \\
\cline { 3 - 7 } $\begin{array}{c}\text { Probabilidade de } \\
\text { Excedência }\end{array}$ & $\begin{array}{c}\text { Período de } \\
\text { Retorno (anos) }\end{array}$ & $31-50$ & $31-70$ & $31-01$ & $51-01$ & $71-01$ & Distribuições Probabilísticas \\
\hline \hline 0,0001 & 10000 & 32922 & 34803 & 27530 & 27223 & 28911 & 28 \\
0,0005 & 2000 & 25894 & 24782 & 21749 & 21121 & 23195 & 23 \\
0,001 & 1000 & 23219 & 21436 & 19567 & 18879 & 20965 & 23 \\
0,002 & 500 & 20735 & 18557 & 17551 & 16840 & 18863 & 23 \\
0,005 & 200 & 17718 & 15357 & 15116 & 14422 & 16266 & 23 \\
0,01 & 100 & 15621 & 13323 & 13433 & 12782 & 14430 & 22 \\
0,02 & 50 & 13666 & 11569 & 11873 & 11286 & 12693 & 21 \\
0,05 & 20 & 11276 & 9607 & 9975 & 9499 & 10532 & 19 \\
0,1 & 10 & 9585 & 8341 & 8641 & 8267 & 8976 & 16 \\
\hline \hline
\end{tabular}


vertedouro estaria superdimensionado em $39.420 \mathrm{~m} 3 / \mathrm{s}$, ou seja, que a vazão de projeto seria $151 \%$ maior que o necessário!

Agora, suponha que o posto fluviométrico tivesse sido instalado em 1951 e que a série hidrológica tivesse sido definida para o período de 1951 a 2001 (50 anos, sem considerar o outlier). Os estudos concluiriam que a vazão de projeto do vertedouro (decamilenar) seria $21.764 \mathrm{~m} 3 / \mathrm{s}$. No entanto, a vazão (decamilenar) inferida para a série completa de 1931 a 2001 foi de $26.081 \mathrm{~m}^{3} / \mathrm{s}$, mostrando que o valor inferido para a série de 1951 a 2001 está subdimensionado.

Estas dúvidas, que freqüentemente são constatadas nos estudos hidrológicos de projeto de engenharia, induzem as controvérsias e incertezas quanto à segurança e aos custos das obras hidráulicas. Torna-se problemática a decisão sobre quais os valores máximos de projeto a adotar e como justificar de forma objetiva a metodologia de ajuste de distribuições probabilísticas selecionadas.

Este exemplo demonstra a forte dependência do método estatístico com a extensão da série de vazões e a inconsistência dos valores máximos inferidos utilizandose a metodologia usual de ajuste de distribuições probabilísticas. Ressalta-se que a utilização de diferentes distribuições probabilísticas levaria a valores ainda mais discrepantes ou a decisões ainda mais controversas.

\section{- Análise da Influência da Presença de “Outliers" na Série de Valores}

A análise a ser desenvolvida refere-se à influência da presença de eventos extraordinários ("outlier") na série de valores. A presença destes eventos é relativamente freqüente. Destaca-se, por exemplo, os eventos ocorridos entre os meses de junho e julho de 1983 na bacia do rio Paraná. Eventos julgados extraordinários ocorreram, também, na bacia do rio Tocantins entre fevereiro e março de 1980. Estes eventos sempre trazem discussões técnicas, gerando muita insegurança e controvérsia.

Garcia (1996) mostrou, por exemplo, que o evento na bacia do rio Paraná ocorreu durante a construção da UHE (Usina Hidroelétrica) Porto primavera. Em função desta ocorrência, a CESP solicitou a revisão dos estudos hidrológicos referentes a esta obra e, posteriormente, desenvolveu reavaliações hidrológicas nas demais barragens construídas e em construção. 
Outro caso de evento extraordinário ocorrido na bacia do rio Tocantins durante o desvio de $1^{\text {a }}$ fase da UHE Tucuruí levou a ELETRONORTE solicitar a revisão dos estudos hidrológicos, encomendando os estudos de determinação da precipitação máxima provável (PMP) e da Enchente máxima provável (EMP)

Estes fatos evidenciam, claramente, a insegurança gerada pelo método estatístico, utilizado na definição das vazões de projeto do desvio do rio e do vertedouro das citadas usinas hidrelétricas. Esta insegurança é confirmada verbalmente por diversos hidrólogos que tem a responsabilidade de definir as vazões de projetos de obras hidráulicas.

A ocorrência destes eventos extraordinários provoca, nos estudos hidrológicos que utilizam o método estatístico, a necessidade de analisar as alternativas de inclusão ou não destes valores. Na alternativa que exclui o "outlier" da série de valores são ajustadas distribuições probabilísticas e, então, inferida a probabilidade de excedência (ou período de retorno) do valor extraordinário. Na alternativa que inclui o "outlier" na série de valores são obtidas vazões de projeto significativamente maiores, aumentando os custos das obras de desvio de rio e das estruturas extravasoras. Esses resultados são apresentados ao decisor que na verdade, resumem-se nas seguintes alternativas:

- Aceita que se trata de um evento extraordinário. Conseqüentemente, as obras a serem executadas serão mais econômicas. No entanto, pergunta-se: será que com essa decisão estou comprometendo a segurança da obra? Qual a probabilidade desse evento ser excedido?

- Não aceita que se trata de um evento extraordinário. Conseqüientemente, as obras a serem executadas serão mais onerosas. No entanto, pergunta-se: será que essa decisão não levou ao superdimensionamento da obra?

Esses exemplos, que ocorrem no dia a dia da engenharia, são resultantes da insegurança gerada pelo método estatístico que não impõe um limite superior aos eventos hidrometeorológicos. Uma vez que a extensão da série de valores é, invariavelmente, curta ( $\leq 70$ anos) em relação à probabilidade de excedência dos eventos que se pretende avaliar ( $\mathrm{TR}=1000,10000$ anos) é sempre muito difícil caracterizar um evento extraordinário ou verificar a credibilidade dessa observação.

O "United States Water Resources Council" (USWRC, 1981) recomenda o teste de Grubbs e Beck (1972) para verificação da presença de outliers na série de valores. 
Para aplicar este teste, deve-se aceitar a hipótese que os logaritmos, ou outra função da série de valores, têm distribuição normal.

Este teste foi aplicado à série de vazões máximas anuais para a UHE de Sobradinho/BA, apresentada na tabela 2, que se estende de 1931 a 2001, correspondendo a 71 anos de observação. Para este caso, seguindo-se a recomendação da USWRC (1981), supôs-se que o logaritmo das vazões máximas anuais tenha distribuição normal. Esse teste revelou que a vazão máxima referente ao ano de 1979 $(15.676 \mathrm{~m}$ 3/s) é considerada um evento extraordinário (“outlier").

$\mathrm{Na}$ seção análise da influência da extensão da série, foram apresentados os ajustes da distribuição probabilística GEV, utilizando diferentes métodos de estimação dos parâmetros, para a série de vazões de 1931 a 2001, excluindo o evento extraordinário de 1979. Para exemplificar a influencia da presença desse "outlier" na serie de vazões, foi aplicada a mesma metodologia para a série completa de vazões máximas anuais.

As figuras 12 a 15 apresentam, para cada um dos diferentes métodos de estimação utilizados para definição dos parâmetros da distribuição probabilísticas GEV, as curvas obtidas para os casos de inclusão e exclusão do "outliers". As vazões máximas foram ajustadas com posição de plotagem definida pela fórmula de Weibull. A tabela 19 e 20 apresentam os parâmetros da distribuição GEV ajustadas para a séries com e sem o outliers.

Com o objetivo de verificar a influência da presença do "outlier" na série de vazões utilizando o método estatístico, procedeu-se uma análise comparativa das vazões máximas obtidas excluindo-se e incluindo-se o valor extraordinário referente ao ano de 1979.

A tabela 21 apresenta, para os diversos métodos de estimação dos parâmetros, as vazões máximas para as diferentes probabilidades de excedência, inferidas a partir das distribuições probabilísticas ajustadas à série de vazões de 1931 a 2001, para os casos de inclusão e exclusão do evento extraordinário do ano de 1979. Essa tabela contém uma coluna que apresenta, para cada período de retorno, a diferença percentual entre as vazões máximas inferidas para os casos analisados. 
Tabela 19- Parâmetros obtidos para distribuição GEV ajustadas para as séries c/ e sem o outliers utilizando diferentes estimadores (MOM e ML).

\begin{tabular}{|c|c|c|c|c|c|c|}
\hline \multirow{2}{*}{ SÉRIES } & \multicolumn{3}{|c|}{ MOM } & \multicolumn{3}{|c|}{ ML } \\
\hline & $\mathrm{k}$ & $\alpha$ & $\mathrm{u}$ & $\mathrm{k}$ & $\alpha$ & $\mathrm{u}$ \\
\hline C/ OUTLIER & $-0,12641$ & 1450,153 & 5210,400 & $-0,09135$ & 1557,838 & 5202,147 \\
\hline S/OUTLIER & $-0,04293$ & 1471,892 & 5205,917 & $-0,06923$ & 1406,631 & 5205,242 \\
\hline
\end{tabular}

Tabela 20 - Parâmetros obtidos para distribuição GEV ajustadas para as séries c/ e sem o outliers utilizando diferentes estimadores (ML e MOM-LH).

\begin{tabular}{ccccccc}
\hline \hline \multirow{2}{*}{ SÉRIES } & \multicolumn{3}{c}{ PWM } & $\mathrm{k}$ & \multicolumn{3}{c}{ MOM-LH } \\
& $\mathrm{k}$ & $\alpha$ & $\mathrm{u}$ & $\mathrm{k}$ & $\alpha$ & $\mathrm{u}$ \\
\hline C/ OUTLIER & $-0,18687$ & 1348,592 & 5218,371 & $-0,19865$ & 1343,793 & 5132,624 \\
S/OUTLIER & $-0,10125$ & 1373,334 & 5179,316 & $-0,11396$ & 1376,198 & 5110,911 \\
\hline \hline
\end{tabular}

A análise da tabela 21 e das figuras 12 a 15 permite concluir que, utilizando-se o método estatístico, a inclusão do evento extraordinário na série de vazões máximas altera, significativamente, as vazões de projeto relacionadas, usualmente, a períodos de retorno acima de 200 anos.

A UHE de Sobradinho/BA tem como objetivo regularizar vazões para irrigação, geração de energia hidrelétrica e controle de cheias. Os estudos hidrológicos têm como um dos objetivos fornecerem as vazões de projeto para dimensionamento do vertedouro que, por sua vez, deverá atender os critérios de controle de cheias e segurança da barragem. Tendo em vista esse objetivo, os estudos hidrológicos devem fornecer as vazões de projeto milenar e decamilenar $\left(\mathrm{T}_{\mathrm{r}}=1000\right.$ e 10000 anos $)$

Assim, analisando a tabela 21, nota-se que a inclusão do evento extraordinário na série de vazões provoca um incremento entre 19 e $28 \%$ na vazão milenar e de 27 a $47 \%$ na vazão decamilenar. Conseqüentemente, utilizando-se o método estatístico, a decisão de considerar o "outlier" na série de vazões implicará em um aumento significativo do custo da obra. Como conseqüência direta, aumentará o custo de produção agrícola e energética. Ressalta-se que, em alguns casos, essa decisão poderá inviabilizar a obra. 


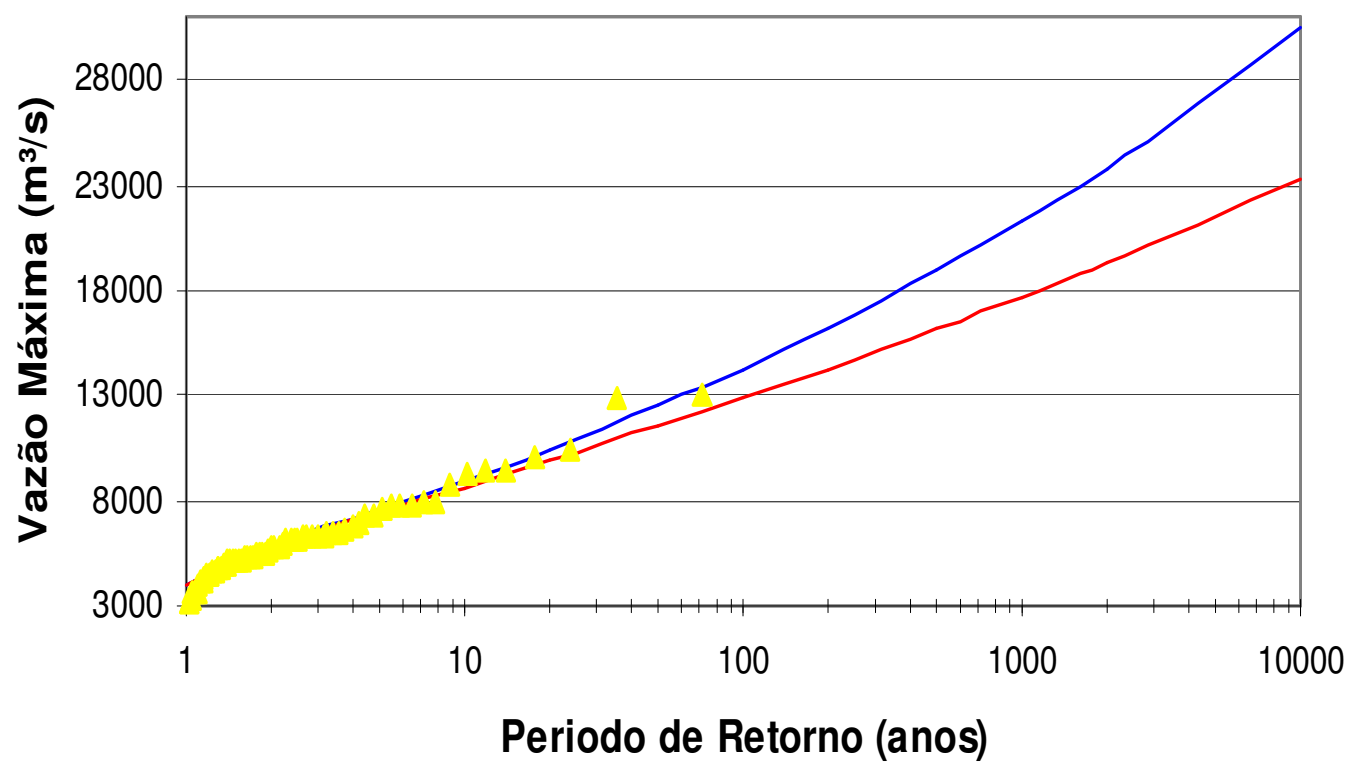

com "outlier" sem 0 "outlier"

DADOS

Figura12 - Análise da influência do outlier - distribuição GEV - método ML

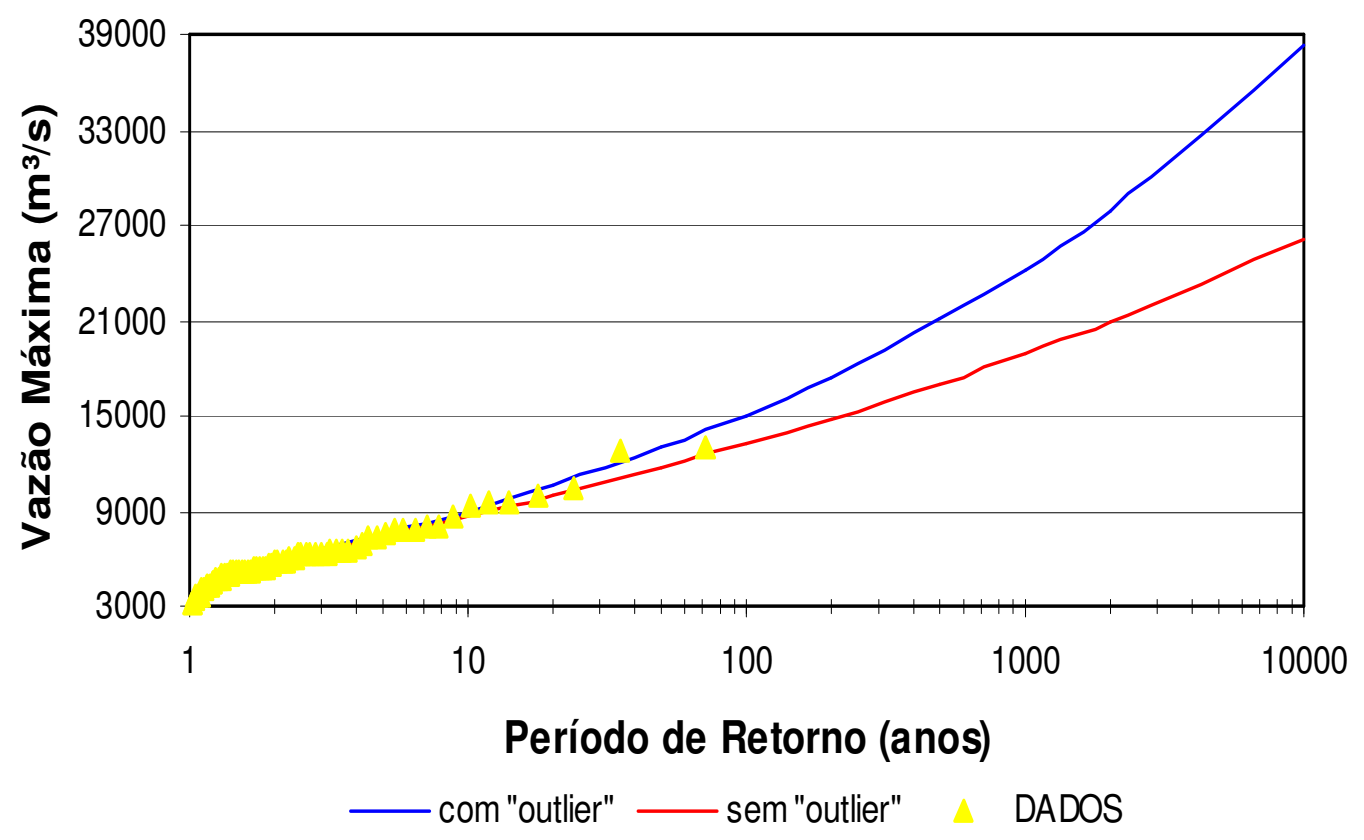

Figura13- Análise da influência do outlier - distribuição GEV - método PWM 


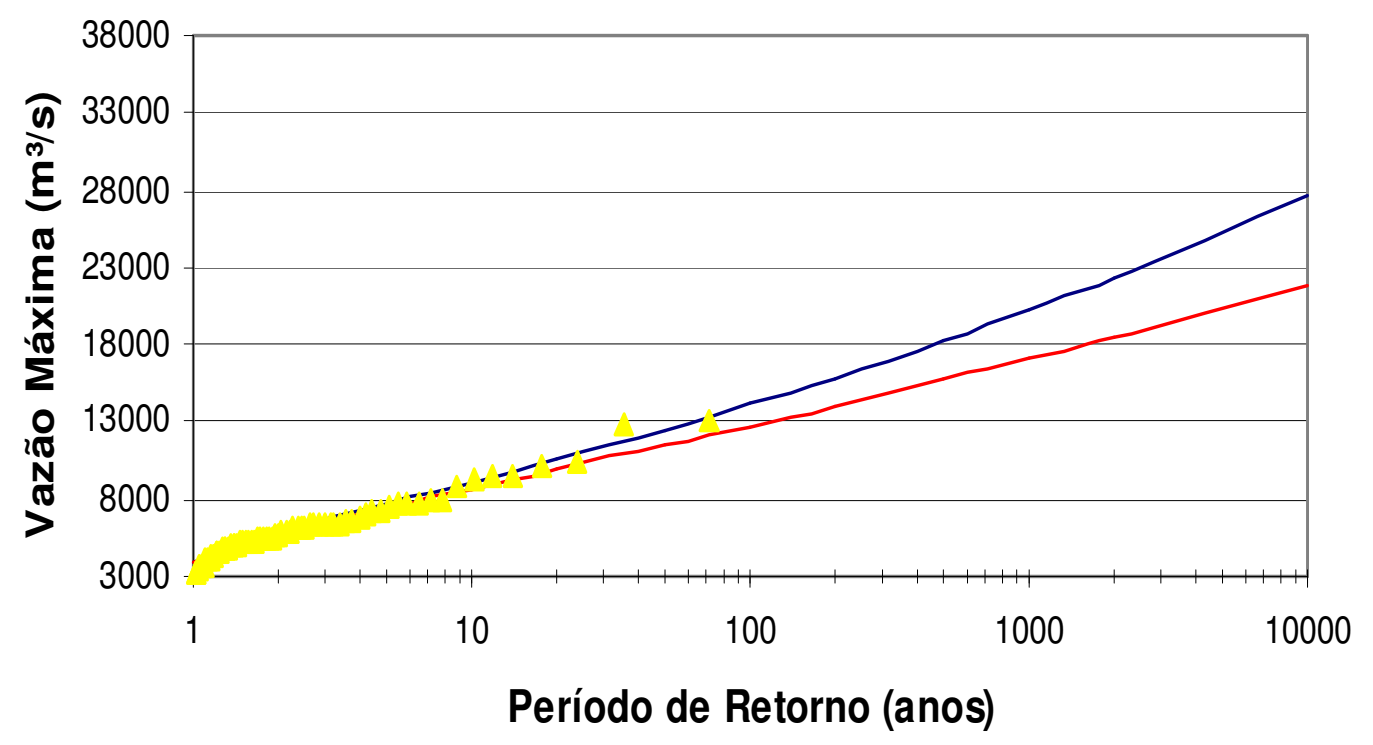

— com "outlier" —_ sem "outlier" $\triangle$ DADOS

Figura14 - Análise da influência do outlier - distribuição GEV - método MOM-L

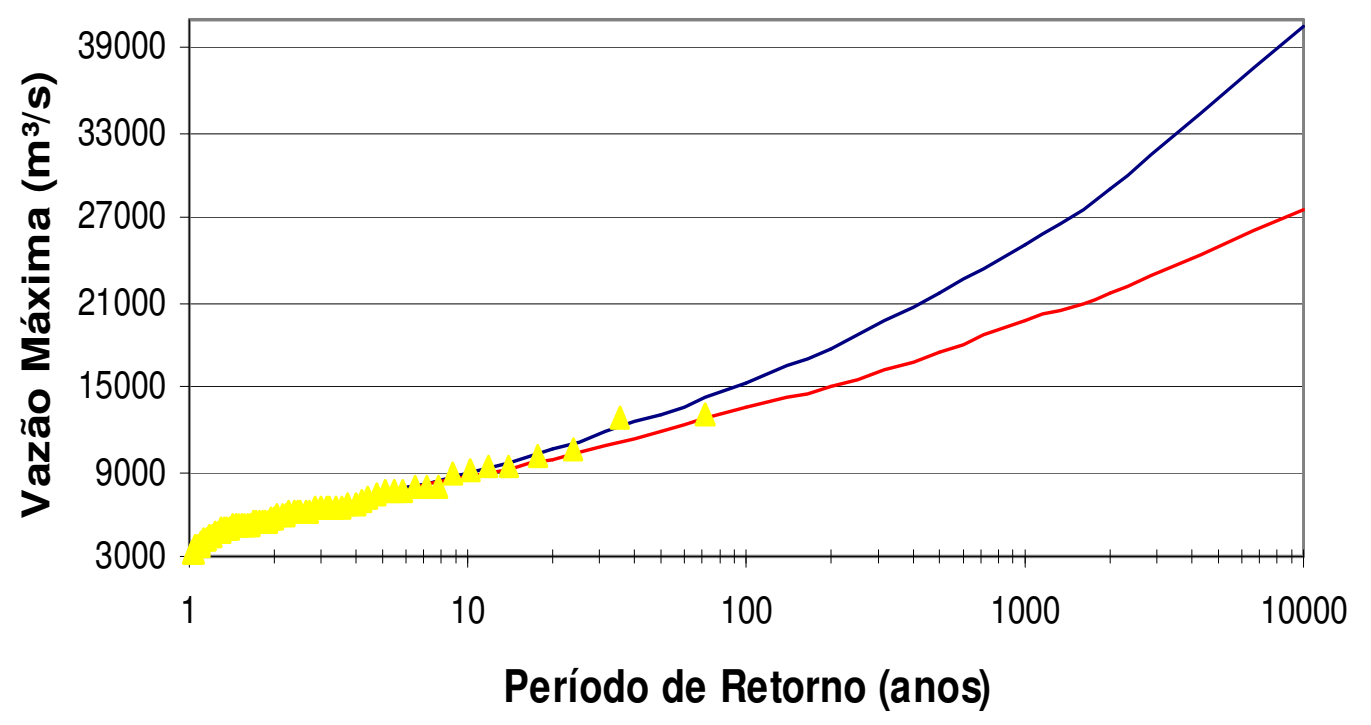

— com "outlier" —_ sem "outlier" _ DADOS

Figura 15 - Análise da influência do outlier - distribuição GEV - método MOM-LH 
Tabela 21 - Análise da influência do outlier - distribuição GEV - método ML, PWM, MOM-L e MOM-LH

\begin{tabular}{|c|c|c|c|c|c|c|c|c|c|c|c|c|c|}
\hline & & & & & & & & & & & \multirow{2}{*}{\multicolumn{2}{|c|}{ MOM-LH }} & \multirow{3}{*}{$\begin{array}{c}\mathrm{D} \\
(\%)\end{array}$} \\
\hline \multirow[t]{2}{*}{$\mathrm{PE}^{1}$} & \multirow[t]{2}{*}{$\mathrm{TR}^{2}$} & \multicolumn{2}{|c|}{$\overline{M L}$} & \multirow{2}{*}{$\begin{array}{c}\mathrm{D}^{3} \\
(\%) \\
\end{array}$} & \multicolumn{2}{|c|}{ PWM } & \multirow{2}{*}{$\begin{array}{c}\mathrm{D} \\
(\%)\end{array}$} & \multicolumn{2}{|c|}{ MOM } & \multirow{2}{*}{$\begin{array}{c}\mathrm{D} \\
(\%)\end{array}$} & & & \\
\hline & & c/outl. & s/outl & & c/outl. & s/outl & & c/outl. & s/outl & & c/outl. & s/outl. & \\
\hline 0,0001 & 10000 & 30489 & 23329 & 31 & 38350 & 26081 & 47 & 27704 & 21834 & 27 & 40522 & 27530 & 47 \\
\hline 0,0005 & 2000 & 23723 & 19275 & 23 & 27868 & 20898 & 33 & 22295 & 18434 & 21 & 28986 & 21749 & 33 \\
\hline 0,001 & 1000 & 21207 & 17663 & 20 & 24239 & 18912 & 28 & 20200 & 17041 & 19 & 25046 & 19567 & 28 \\
\hline 0,002 & 500 & 18901 & 16127 & 17 & 21049 & 17061 & 23 & 18232 & 15688 & 16 & 21612 & 17551 & 23 \\
\hline 0,005 & 200 & 16145 & 14203 & 14 & 17416 & 14803 & 18 & 15812 & 13958 & 13 & 17738 & 15116 & 17 \\
\hline 0,01 & 100 & 14258 & 12825 & 11 & 15050 & 13226 & 14 & 14109 & 12692 & 11 & 15238 & 13433 & 13 \\
\hline 0,02 & 50 & 12525 & 11507 & 9 & 12964 & 11751 & 10 & 12505 & 11458 & 9 & 13053 & 11873 & 10 \\
\hline 0,05 & 20 & 10438 & 9844 & 6 & 10573 & 9938 & 6 & 10518 & 9869 & 7 & 10572 & 9975 & 6 \\
\hline 0,1 & 10 & 8985 & 8631 & 4 & 8991 & 8650 & 4 & 9094 & 8684 & 5 & 8946 & 8641 & 4 \\
\hline 0,2 & 5 & 7605 & 7429 & 2 & 7553 & 7404 & 2 & 7706 & 7486 & 3 & 7481 & 7362 & 2 \\
\hline 0,5 & 2 & 5754 & 5727 & 0 & 5730 & 5692 & 1 & 5783 & 5750 & 1 & 5644 & 5626 & 0 \\
\hline
\end{tabular}

Assim esse exemplo demonstra a significativa influência de eventos extraordinários ("outliers") na determinação dos valores máximos através do método estatístico e a conseqüente insegurança gerada por essa metodologia na definição das vazões de projeto.

\section{- Análise da Influência dos Menores valores da Série de Valores Máximos}

A análise a ser desenvolvida refere-se à influência da magnitude dos menores valores de uma série de valores máximos na definição dos valores extremos (valores de projeto) utilizando o método estatístico.

Para isso, será desenvolvida uma análise comparativa dos valores extremos obtidos através do método estatístico de ajuste de distribuições, adotando-se como referência a série de vazões máximas de 1931 a 2001, excluindo-se o evento extraordinário de 1979, apresentada na tabela 2. Na seção análise da influência da extensão da série de valores, foram apresentados os ajustes da distribuição probabilísticas GEV a esta série de vazões, utilizando diferentes métodos de estimação dos parâmetros, cujo os resultados foram apresentados nas tabelas 15 a 18 e nas figuras 8 a 11.

Para desenvolver a análise, foram selecionados os 3 menores valores das séries de vazões máximas. Esses valores foram minorados e majorados, conforme apresentado na tabela 22 . 
Tabela 22 - Vazões minoradas e majoradas para a série de vazões máximas de 1931 a 2001

\begin{tabular}{|c|c|c|c|c|c|c|c|}
\hline \multirow{2}{*}{ Ano } & \multicolumn{2}{|c|}{ Diferença } & \multirow{2}{*}{$\begin{array}{l}\text { Vazão } \\
\text { minorada }\end{array}$} & \multirow{2}{*}{$\begin{array}{c}\text { Vazão } \\
\text { original }\end{array}$} & \multirow{2}{*}{$\begin{array}{c}\text { Vazão } \\
\text { Majorada }\end{array}$} & \multicolumn{2}{|c|}{ Diferença } \\
\hline & $(\%)$ & $\left(\mathrm{m}^{3} / \mathrm{s}\right)$ & & & & $\left(\mathrm{m}^{3} / \mathrm{s}\right)$ & $(\%)$ \\
\hline 2001 & -20 & 632 & 2526 & 3158 & 3790 & 632 & 20 \\
\hline 1995 & -20 & 649 & 2595 & 3244 & 3893 & 649 & 20 \\
\hline 1998 & -20 & 672 & 2688 & 3360 & 3763 & 403 & 12 \\
\hline
\end{tabular}

Mantendo-se os demais valores e modificando-se esses 3 menores valores, resultaram em 2 novas séries de vazões máximas, denominadas séries minoradas e majoradas. A mesma metodologia de ajuste da distribuição probabilística GEV foi aplicada a essas 2 novas séries, utilizando o método dos momentos com pesos probabilísticos (PWM).

A figura 16 apresenta para o método dos momentos com pesos probabilísticos (PWM), as vazões máximas, destacando-se os valores originais, com a posição de plotagem definida pela fórmula de Weibull e as curvas da distribuição probabilística ajustada.

A tabela 23 apresenta para o método dos momentos com pesos probabilísticos (PWM) os valores máximos para diferentes probabilidades de excedência, inferidas através da metodologia estatística de ajuste de distribuições, para a série de vazões máximas original, minorada e majorada. Essa mesma tabela apresenta as diferenças percentuais dos valores máximos obtidos para a série minorada e majorada em relação ao inferido para a série original. A análise da tabela 23 e da figura 16 permite verificar que a minoração em $20 \%$ dos menores valores da série de vazões resulta em diminuição dos valores extremos (TR $\geq 1000$ anos) de 7 a $13 \%$. Por sua vez, a majoração entre 12 a $20 \%$ dos menores valores da série de vazões ocasiona o incremento dos valores extremos de 7 a $13 \%$.

Portanto, conclui-se que no método estatístico as pequenas modificações dos menores valores da série de valores máximos resultam em alterações, de mesma ordem de grandeza, nos valores extremos. Ressalta-se que a série utilizada é relativamente extensa e, portanto, a influência dos menores valores deveria ser ainda menos intensa. A mesma conclusão foi obtida por Garcia (1996), utilizando 46 elementos, e Klemes (1986) utilizando uma série de vazões máximas com 30 elementos.

A análise desenvolvida neste item restringiu-se à aplicação da metodologia estatística e os resultados seriam julgados consistentes por profissionais que utilizam o ajuste de distribuição para definição dos valores extremos. As modificações seriam jus- 


\section{Análise da Influência dos Menores Valores - Distrib. GEV - Método PWM}

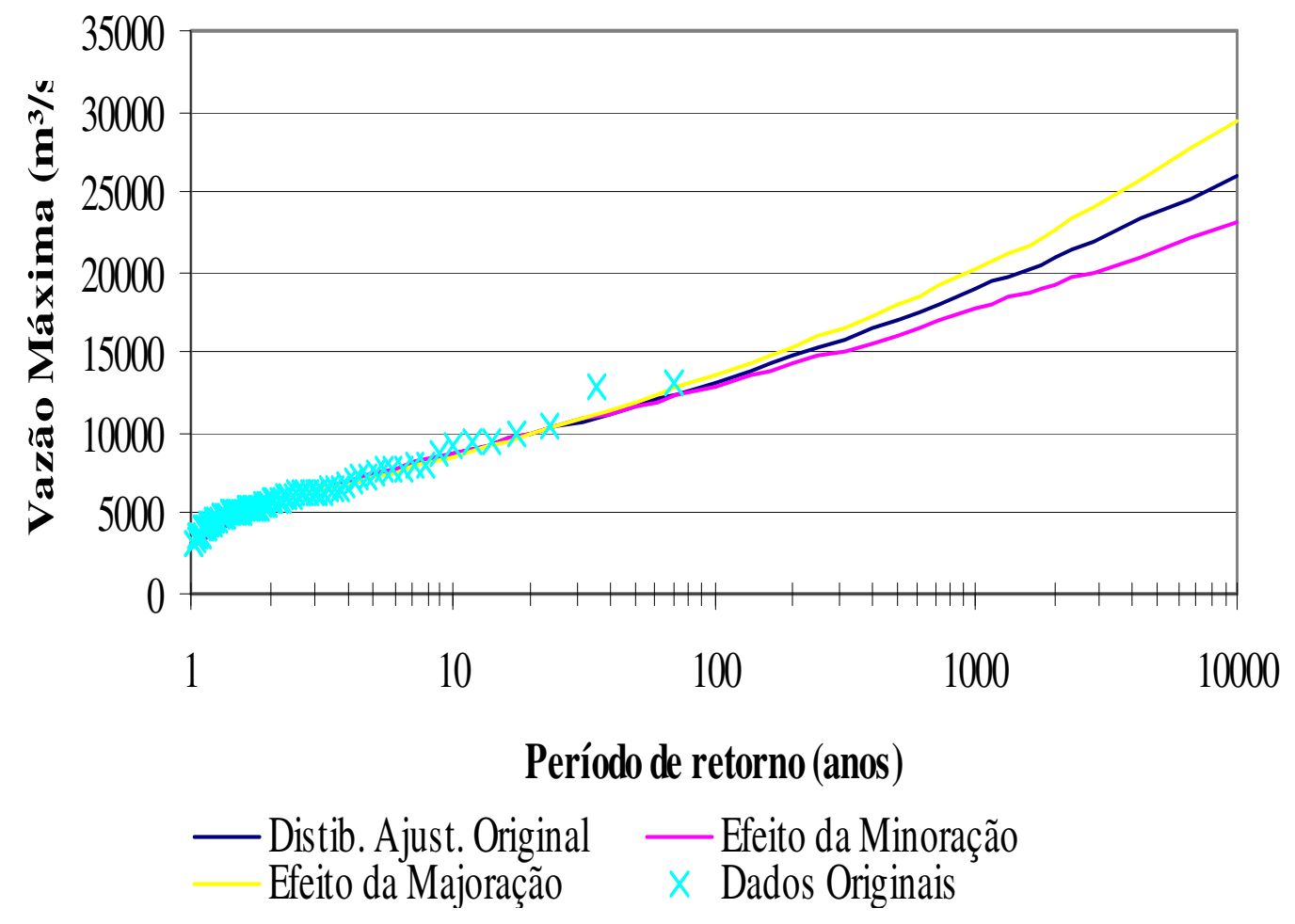

Figura 16 - Análise da influencia dos menores valores - distribuição GEV - método PWM

Tabela 23 - Análise da influencia dos menores valores - distribuição GEV - método PWM

\begin{tabular}{|c|c|c|c|c|c|c|}
\hline \multicolumn{7}{|c|}{ Vazões Máximas (m³/s) - MÉTODO DOS MOMENTOS DE PESOS PROBABILISTICOS - PWM } \\
\hline $\begin{array}{c}\text { Probabilidade } \\
\text { de } \\
\text { Excedência }\end{array}$ & $\begin{array}{l}\text { Período de } \\
\text { Retorno } \\
\text { (anos) }\end{array}$ & $\begin{array}{c}\text { Série } \\
\text { ORIGINA } \\
\text { L }\end{array}$ & $\begin{array}{c}\text { Série com } \\
\text { valores } \\
\text { máximos } \\
\text { MINORADOS }\end{array}$ & $\begin{array}{c}\text { Série com } \\
\text { valores } \\
\text { máximos } \\
\text { MAJORADOS }\end{array}$ & $\begin{array}{l}\text { Diferenças das } \\
\text { vazões } \\
\text { máximas em } \\
\text { relação a série } \\
\text { original }(\%) \text { - } \\
\text { MINORADOS }\end{array}$ & $\begin{array}{c}\text { Diferenças } \\
\text { das vazões } \\
\text { máximas em } \\
\text { relação a série } \\
\text { original }(\%) \text { - } \\
\text { MAJORADO } \\
\text { S } \\
\end{array}$ \\
\hline 0,0001 & 10000 & 26081 & 23036 & 29396 & 13 & 13 \\
\hline 0,0005 & 2000 & 20898 & 19197 & 22646 & 9 & 8 \\
\hline 0,001 & 1000 & 18912 & 17649 & 20177 & 7 & 7 \\
\hline 0,002 & 500 & 17061 & 16161 & 17937 & 6 & 5 \\
\hline 0,005 & 200 & 14803 & 14279 & 15290 & 4 & 3 \\
\hline 0,01 & 100 & 13226 & 12918 & 13499 & 2 & 2 \\
\hline 0,02 & 50 & 11751 & 11604 & 11869 & 1 & 1 \\
\hline 0,05 & 20 & 9938 & 9931 & 9929 & 0 & 0 \\
\hline 0,1 & 10 & 8650 & 8697 & 8595 & -1 & -1 \\
\hline 0,2 & 5 & 7404 & 7465 & 7341 & -1 & -1 \\
\hline 0,5 & 2 & 5692 & 5700 & 5681 & 0 & 0 \\
\hline
\end{tabular}


tificadas pela alteração da série de dados que, conseqüentemente, provocam um diferente ajuste da curva da distribuição probabilística.

No entanto, fisicamente não existe significado em afirmar que o regime das enchentes mais intensas seria afetado pelo regime de vazões nos anos que, praticamente, não ocorreram enchentes. Da mesma forma, não existe significado físico na dependência entre a probabilidade de excedência de uma enchente catastrófica com o regime de vazões dos 3 anos menos severos.

Assim, esse exemplo demonstra, para o método estatístico, a dependência da cauda superior da curva da distribuição probabilística com os menores valores de uma série de valores máximos. Dessa forma, o método estatístico reflete a dependência entre a probabilidade de excedência de uma enchente catastrófica com o regime de vazões dos 3 anos menos severos. No entanto, fisicamente essa dependência não é evidente e, a principio, contraria o bom senso. Uma forma de diminuir os efeitos da influência dos menores valores é estimando os parâmetros via momentos-LH. Wang (1997 b) mostrou através das análises de dados observados e dados obtidos via simulação Monte Carlo, que o estimador momentos-LH reduzem as influências indesejáveis que os menores eventos amostrais podem exercer na estimação de eventos com grandes períodos de retorno. Assim uma forma de manter uma coerência com a realidade física é aplicando o método dos momentos - LH para estimação dos parâmetros.

\subsection{Método Determinístico}

\subsubsection{Introdução}

A definição de valores hidrológicos máximos (precipitação e vazão) de projeto para obras hidráulicas pode ser feita, também, através da metodologia determinística que desenvolve análises hidrometeorológicas através das quais determina a chamada precipitação máxima provável (PMP) e a enchente máxima provável (EMP).

O método hidrometeorológico para o dimensionamento de vertedores de grandes barragens está intimamente ligado à estimação da PMP sobre a área de drenagem a montante do aproveitamento hidroelétrico em questão. 
A definição da Organização Meteorológica Mundial (WMO) de PMP é (WMO, 1973) “ ... maior altura de precipitação para uma dada duração meteorologicamente possível, para uma determinada bacia, numa certa época do ano, sem consideração de mudanças climáticas". De fato, conhecendo-se os máximos teóricos de altura de chuva sobre uma dada bacia, para cada duração, é possível determinar também os hidrogramas correspondentes no fecho da bacia, através de modelos de transformação chuva-vazão. Com isso, seria possível calcular a capacidade de vertimento necessária para dar passagem à cheia associada à PMP, usualmente denominada EMP (enchente máxima provável).

Na prática, conforme observa o próprio manual da WMO (WMO, 1973), não há suficiente conhecimento dos processos atmosféricos para uma avaliação quantitativa precisa da máxima altura de chuva numa bacia, para uma dada duração. Os métodos existentes propõem-se a estimar a PMP através da análise quantitativa de séries históricas de dados hidrometeorológicos (tipicamente, dados de chuva e umidade atmosférica) bem como do conhecimento qualitativo que o meteorologista possui dos processos de formação de precipitações na bacia, tais como o avanço de frentes, fontes de umidade e direção dos fluxos de ar úmido que alimentam as tempestades, barreiras orográficas, etc. (ELETROBRÁS, 1987a).

Klemes (1991) comenta que os métodos empregados evitam, deliberadamente, conceitos probabilísticos. Ele conclui afirmando que o conceito de PMP/EMP veio a existir, pelo menos em parte, como defesa contra a invasão das metodologias probabilísticas na hidrologia.

Garcia (1996) afirma que a metodologia determinística é fundamentada na hipótese que os mecanismos físicos que regem a dinâmica interna de um fenômeno são relativamente estáveis e os seus processos componentes elementares operam dentro de limites finitos, os quais são razoavelmente representados através das séries de dados observados de 50 a 100 anos. Os eventos extremos deste processo são interpretados como combinações raras de fenômenos elementares relativamente usuais. Uma vez que estes fenômenos elementares são considerados como tendo uma limitação física, por consequiência, os eventos extremos, também, são considerados limitados. O principal objetivo e desafio desta metodologia é determinar os supostos limites superiores dos processos componentes e sua combinação factível, a partir das observações e da teoria física. Esta metodologia é resumida pelos conceitos de PMP e EMP. 
De acordo com Occhipinti (1989) e atendendo à definição apresentada pela WMO (1973), a designação mais correta seria "precipitação máxima possível". Entretanto, em virtude das incertezas que envolvem a determinação da PMP, os hidrometeorologistas julgaram por bem designá-la por "precipitação máxima provável". Sem dúvida, essa designação não é a mais apropriada uma vez que os modelos de tormenta usados para estimar a PMP são essencialmente determinísticos.

Assim, segundo Occhipinti (1989) na medida em que o conhecimento dos processos físicos envolvidos na avaliação da PMP aumenta, a precipitação máxima provável converge para a precipitação máxima possível.

No entanto, independente do problema semântico, por definição (World Meteorological Organization, 1973) a precipitação máxima provável (PMP) tem probabilidade de inexcedência igual a 1,0, ou seja, representa o limite físico máximo. Da mesma forma, a enchente máxima provável (EMP), definida a partir da PMP e das características fisiográficas da bacia hidrográfica, representa o limite físico máximo em termos de vazão e, assim, tem probabilidade de inexcedência igual a 1,0.

Vários estudos foram desenvolvidos no sentido de relacionar uma probabilidade á PMP e/ou EMP. Sugai e Fill (1990) avaliaram o tempo de recorrência associado à PMP para durações de 1 e 2 dias em 45 postos pluviométricos na região Sul do Brasil. Observou-se uma grande variabilidade no "período de retorno" da PMP não se podendo inferir nenhuma conclusão. Não obstante, o trabalho conclui que "pode-se considerar como valor de referencia um tempo de recorrência de 10.000 anos no caso de se utilizar o método hidrometeorológico para cálculo da PMP”. Essa consideração não encontra respaldo técnico uma vez que a correlação entre a precipitação de 1 dia com período de retorno de 10.000 anos e a PMP obtida pelo método hidrometeorológico é baixa (GARCIA, 1996).

Asbahr et. al. (1985) apresentaram uma comparação entre Probable Maximum Storm Sequences (PMSS) ou Seqüências de Chuvas Máximas Prováveis (SCMP) com a chuva decamilenar da bacia do rio Xingu. Para o tratamento estatístico foram utilizadas as distribuições Normal, Log-normal, Gumbel e Exponencial. Avaliando os resultados eles concluíram que não se pode afirmar que a PMSS apresenta-se incoerente com as estimativas estatísticas. Pelo contrário, eles admitiram, que além de se manter coerente com os resultados de um método de avaliação probabilística (lognormal), a PMSS, gerada unicamente por processo hidrometeorológico, constitui-se num limite físico, que no caso dos modelos estatísticos de Gumbel e exponencial não estaria sendo respeitado. 
Fill e Zschoerper (1981) fizeram uma comparação do valor da precipitação máxima provável na bacia do rio Iguaçu a jusante de Foz de Areia com os resultados de uma chuva decamilenar obtida pela aplicação da distribuição Gumbel. Eles concluíram que as precipitações decamilenares obtidas pelo método de Gumbel são equivalentes à PMP.

\subsubsection{Metodologias para Obtenção da PMP}

As estimativas da PMP partem da utilização de informação histórica na bacia hidrográfica ou fora dela. Esta informação é "maximizada" de diversas formas, não excludentes entre si, com o objetivo de se obter o "evento extremo" na bacia, para a duração desejada. Estes estudos deverão contar com o apoio de meteorologistas.

Os métodos mais utilizados para a "maximização" de eventos históricos e obtenção da PMP tem sido (ELETROBRÁS, 1987a):

- A transposição de tempestades ocorridas em outras bacias, levando-se em conta as diferenças de altitude do terreno entre as bacias, barreiras orográficas, etc.

- A maximização da umidade disponível em uma precipitação histórica, utilizando-se séries de pontos de orvalho de um ou mais postos hidrometeorológicos situados nas "regiões-fonte" de umidade para as tempestades na bacia (recomendado pela WMO).

- A maximização seqüencial que consiste em combinar diversas tempestades históricas num "trem" de eventos, considerado meteorologicamente possível de ocorrer e que seja crítico do ponto de vista hidrológico, para a formação de cheias no local do barramento.

- A maximização espacial, ou seja, a modificação da localização das tempestades dentro da bacia, de novo com o objetivo de estabelecer condições extremas para a formação de cheias na bacia.

A ELETROBRÁS (1987a) aponta os seguintes passos que são necessários em estudos da PMP em grandes bacias, em regiões tropicais:

- Identificação das piores tempestades ocorridas na região, bem como de eventos que possam ser transpostos para ela. Em bacias grandes, dados diários de precipitação são suficientes. Não é necessário construir curvas área-altura-duração, uma vez que as 
técnicas de maximização serão aplicadas às próprias seqüências históricas, e não a estas curvas, como por vezes ocorre em pequenas bacias em regiões temperadas.

- Escolha de um modelo de transformação chuva-vazão e sua calibração para grandes cheias ocorridas na bacia.

- Preparo de seqüências tentativas de precipitações históricas na bacia e/ou em transposições, que sejam criticas do ponto de vista da vazão de projeto (maximização temporal e Espacial).

- Aplicação de fatores de maximização da umidade às sequiências de precipitação.

Os passos anteriores permitem obter um conjunto de padrões temporais e espaciais que são "candidatos" à PMP na bacia. O uso do modelo de transformação chuva-vazão permite escolher o padrão mais crítico para a bacia em questão, isto é: que dá origem à cheia mais adversa no local da obra.

Ressalta-se que não é objetivo desta dissertação reapresentar as etapas da metodologia determinística, que já são bem conhecidas e que podem ser consultadas em vários trabalhos, dentre os quais destacam-se os seguintes: (WORLD METEOROLOGICAL ORGANIZATION, 1973), (ELETROBRÁS, 1987a) e (OCCHIPINTI, 1989).

\section{- Maximização da Umidade}

Segundo Bertoni e Tucci (In: TUCCI, 1993) a maximização da umidade baseiase no seguinte:

- A precipitação observada é diretamente proporcional à massa de vapor de água na atmosfera (altura de água precipitável);

- A condição extrema de chuva é obtida somente pela maximização de referida massa de vapor.

O conteúdo de umidade numa coluna vertical de ar de área unitária é obtido por (ELETROBRÁS, 1987a):

$$
W=1 / g \bullet \int_{p_{0}}^{p_{1}} q_{s}\left(\theta_{s w}, p\right) d p
$$


em que $W=$ a massa de água por unidade de área $\left(\mathrm{g} / \mathrm{cm}^{2}\right) ; \mathrm{q}_{\mathrm{s}}=$ a umidade especifica; $\theta_{\mathrm{sw}}$ $=$ a temperatura pseudo-adiabática do bulbo úmido; $\mathrm{p}_{0}$ e $\mathrm{p}_{1}=$ pressões referentes aos níveis inferior e superior da coluna de ar. Conhecida a distribuição de $\mathrm{q}_{\mathrm{s}}$ entre os níveis $\mathrm{p}_{0}$ e $\mathrm{p}_{1}$, a Equação (60) fornece a quantidade de água precipitável na coluna de ar.

O método é aplicável quando existem dados pluviométricos de um número significativo de tormentas severas observadas na bacia de projeto. Os passos básicos de cálculo consistem em:

a) Seleção das maiores chuvas intensas observadas na região;

b) Obtenção da umidade representativa e máxima provável de cada evento selecionado e;

c) Cálculo dos fatores de maximização da umidade e estimativa das chuvas maximizadas.

Larrosa et. al. (1983) apresentaram uma metodologia de cálculo do fator de maximização para a determinação da precipitação máxima provável em regiões tropicais. Foram utilizados dados de bacias dos rios Xingu e Araguaia, regiões de grande superfície que se caracterizaram pelo elevado teor de umidade. Eles procuraram dar um novo tratamento ao problema, tendo por base a metodologia clássica preconizada pela W.M.O. Os resultados dessas investigações foram utilizados na determinação da PMP da UHE de Santa Isabel, no rio Araguaia.

Siciliano et al. (1981) apresentaram uma adaptação e aperfeiçoamento da metodologia para determinação de enchentes máximas prováveis (EMP), a partir de aplicações de PMPs (através da maximização), para grandes bacias. Eles calcularam a PMP para toda a bacia do rio Tocantins até Tucuruí a partir da aplicação da razão de maximização aos totais pluviométricos de 115 postos nos períodos chuvosos de 7,10 , 15, 20 e 25 dias da grande cheia de 1980. A precipitação foi distribuída espacial e temporalmente ao longo da bacia por diversos setores climatológicos pré-definidos. Foram também criadas condições antecedentes de precipitação as mais críticas possíveis, em função das diversas tempestades registradas de forma a que, em cada intervalo de tempo de aplicação das precipitações máximas calculadas, se pudessem obter escoamento máximos. O modelo utilizado para fornecer resultados que permitiram definir a vazão máxima afluente foi o modelo SSARR.

\section{- Transposição de Tormentas Severas}


Quando o número de observações severas não é suficiente na bacia de interesse, é possível recorrer à transposição de eventos. A transposição é valida se existirem reais condições de que a tormenta possa ocorrer na bacia, para regiões meteorologicamente homogêneas, quando estão expostas à incursão das mesmas massas de ar e aos mesmos tipos de tormentas (OCCHIPINTI, 1989).

\section{- Maximização das Seqüiências de Tormentas Severas (MSTS) - grandes bacias}

Aplica-se em grandes bacias, nas quais a área de drenagem supera significativamente a extensão das tormentas. Para tanto é preciso definir o sincronismo mais adverso entre máximas precipitações acumuladas e o desenvolvimento e propagação das enchentes (BERTONI e TUCCI In: TUCCI, 1993).

Para grandes bacias hidrográficas não são aplicáveis os procedimentos gerais de estudos de precipitação máxima provável (PMP) estabelecidos nos manuais da WMO (1973). Esse métodos são recomendados para bacias até $50.000 \mathrm{~km}^{2}$, para regiões de média latitude, sujeitas ou não à problemas de orografia.

É interessante observar que no manual da WMO (1973), na parte do prefácio, é destacada a questão da impossibilidade de padronização dos métodos de avaliação da PMP, uma vez que as próprias condições de uma bacia e sua localização exigem, em cada caso, ajustes e procedimentos específicos.

Asbahr et. al (1985) cita que no caso de bacias muito extensas e alongadas, como por exemplo aquelas dos afluentes da margem direita do rio Amazonas, torna-se importante dar grande peso para condições desfavoráveis de posicionamento espacial e sincronismo de temporais, bem como para as chuvas antecedentes e seus quantitativos. Ainda, comentam eles, para grandes tributários do amazonas, cujas bacias hidrográficas abrangem terrenos das zonas tropicais e equatoriais há necessidade de métodos de maximização próprios para esses climas, o que implica na utilização de procedimentos não estabelecidos nos manuais da WMO.

Os estudos de cheia máxima provável para o local da obra deverão contemplar alternativas de Maximização das Seqüências de Tormentas Severas (MSTS), as quais serão concebidas tendo em conta variações das chuvas no tempo e no espaço; isto, tanto para o período em que se posicionará no tempo as chuvas máximas prováveis, as quais terão durações críticas em função do tempo de resposta das sub-parcelas da bacia hidrográfica. 
Cada alternativa de MSTS terá que ser analisada quanto à sua possibilidade meteorológica, estando então, apta para ser incluída entre os casos a serem explorados. Para tanto, haverá necessidade de um modelo hidrológico confiável e calibrado, que simule fielmente as transformações chuva-defluvio que ocorrem nos solos e nos canais e lagos da bacia.

Um sumário geral, abordando um conceito de MSTS é apresentado na figura 17. No esquema aí apresentado pode-se constatar que a procura, ou avaliação, do pior efeito no local da barragem é o alvo do processo. Para atingi-lo, as atividades a serem desenvolvidas enfeixa-se em dois conjuntos básicos: o primeiro agrupa as tarefas que levam a definição das seqüências críticas de temporais, as quais englobam as condições antecedentes e a PMP (chuva máxima provável para durações definidas em função do tempo de concentração da bacia); o segundo conjunto contém tarefas ligadas às analises de sensibilidade, as quais visam apreciar a importância dos diversos componentes que entram em jogo na geração das vazões máximas no local de interesse. Desse modo, pode-se balizar os estudos segundo a importância dos seus diversos componentes no resultado que se procura, o que permite minimizar as alternativas de MSTS a serem exploradas no modelo hidrológico.

\subsubsection{Considerações Sobre a Determinação da PMP e EMP - Análise Crítica}

O objetivo deste item é tecer algumas considerações sobre a metodologia determinística para a definição da precipitação máxima provável (PMP) e da enchente máxima provável (EMP). No entanto, serão feitas considerações relacionadas ao problema de especificar uma probabilidade de excedência da PMP/EMP. Analisando-se alguns trabalhos desenvolvidos nesta área (SUGAI E FILL, 1990; KLEMES, 1993; KLEMES, 1995; OCCHIPINTI, 1989; GARCIA, 1996; SICILIANO et. al 1981; MUÑOZ-ESPINOSA, 1981; GOMES et. al, 1983; LARROSA, 1983; ASBAH et. al, 1985) pode-se concluir que este problema deveria ser dividido em duas categorias, a saber: a relacionada com a precisão das estimativas da PMP/EMP e a relacionada com a pertinente probabilidade. Esta distinção é fundamental, para não se confundir probabilidade de excedência atribuída a um valor de PMP/EMP com imprecisão ou subavaliação deste valor. 
Uma vez que a PMP/EMP é um valor fisicamente possível, conclui-se que poder-se-ia atribuir uma probabilidade de ocorrência. Apesar da PMP/EMP não poder ser excedido, ainda assim existiria a possibilidade do mesmo se repetir com uma dada

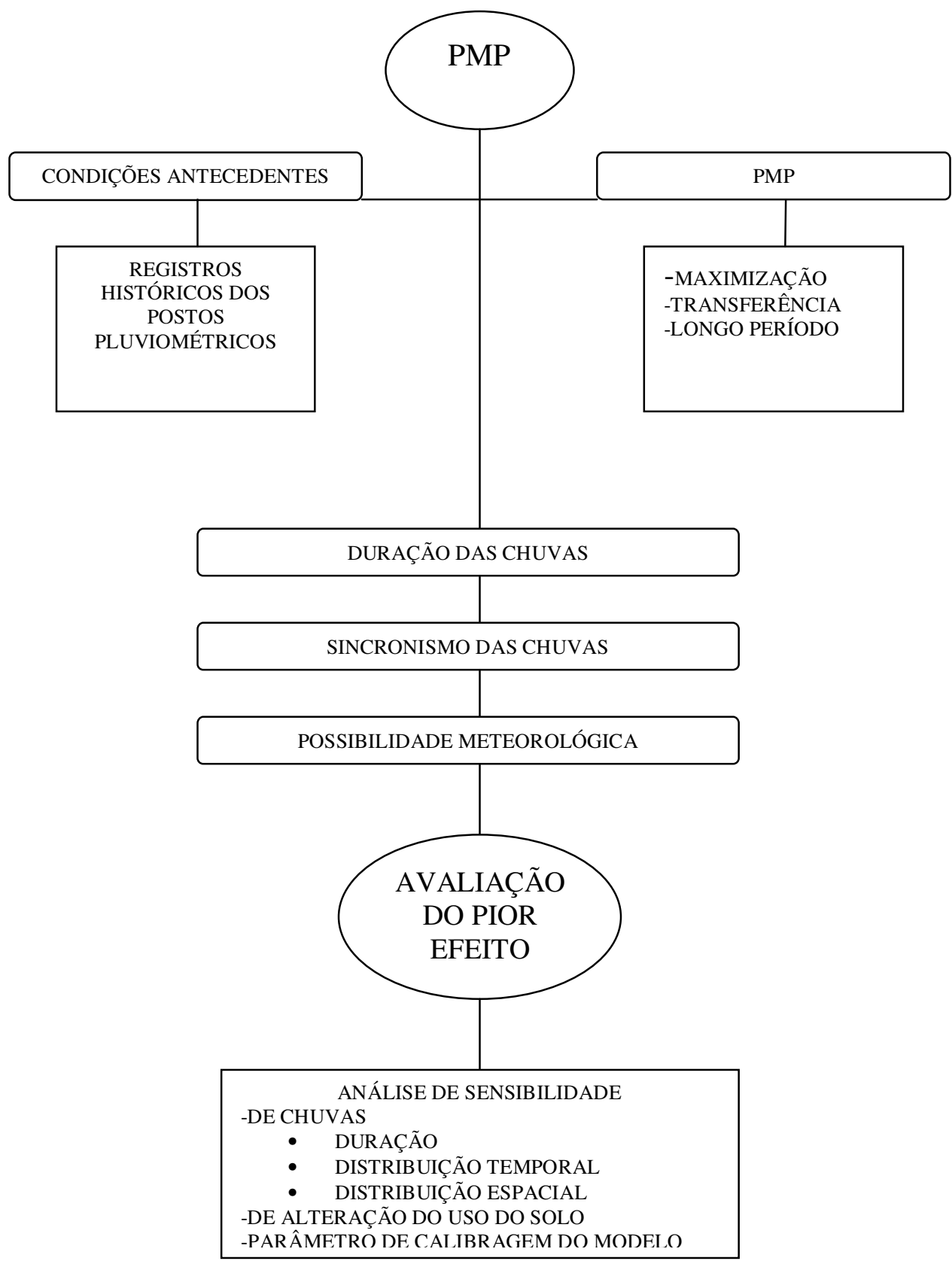

Figura 17 - Síntese conceitual de Maximização das Sequiências de Tormentas Severas Fonte: Asbahr et. al (1985)

freqüência, por mais rara que fosse. Nesta hipótese conceitual, poder-se-ia associar a PMP/EMP uma probabilidade de ocorrência repetitiva, mas não fisicamente idêntica. 
Garcia (1996) apresentou que com relação a estas possibilidades existe, hoje, um consenso em afirmar que isto não é possível. No entanto, ele comenta, que intuitivamente, pode-se inferir que a probabilidade de ocorrência da PMP/EMP deve corresponder a valores extremamente baixos. Assim, raciocinando em termos práticos de engenharia, o mesmo questionou-se qual é a real importância de se chegar a este número e se este número alteraria o dimensionamento de um vertedouro que faz parte de obras com vida útil da ordem de 50 a 100 anos.

Em termos teóricos, por definição (WMO, 1973) a PMP/EMP é considerado um limite superior e, portanto, sua probabilidade de excedência é nula. Assim, caso algum estudo venha a definir uma probabilidade de excedência para a PMP/EMP superior a zero, deverá ser tratado simplesmente como um indicativo que o valor da PMP/EMP foi sub-avaliado.

Portanto, pelo exposto, as considerações relativas à determinação da PMP/EMP ficarão limitadas à análise da sua precisão.

A metodologia para cálculo da PMP/EMP envolve aproximações, combinações e extrapolações e, portanto, não pode ser considerada exata. O método de estimativa deve ser selecionado para cada bacia em função das condições meteorológicas, da disponibilidade de dados, do número e grandeza das tormentas observada. No entanto, para qualquer método, não existe uma meio objetivo de avaliar a precisão da PMP (OCCHIPINTI, 1989).

Occhipinti (OCCHIPINTI, 1989) fornece uma lista de fatores que influem no grau de aproximação das estimativas da PMP.

- disponibilidade de dados hidrometeorológicos: séries representativas, confiáveis e suficientemente longas de dados pluviométricos;

- número suficiente de tormentas de grande intensidade observadas sobre a bacia de projeto ou em regiões vizinhas consideradas meteorologicamente homogêneas e cujas tormentas possam ser transportadas para a bacia de projeto;

- disponibilidade de modelos apropriados ao inter-relacionamento das precipitações às demais variáveis hidrometeorológicas;

- disponibilidade de dados, informações e seleção de procedimento adequado de maximização de tormentas;

- combinações física e estatisticamente factíveis das probabilidades de ocorrência dos valores das variáveis hidrometeorológicas usadas nos modelos e na maximização das tormentas; 
- análise crítica comparativa do valor da PMP em relação aos valores das precipitações extremas observadas na região.

Pelo exposto, Occhipinti (OCCHIPINTI, 1989) concluiu que, de acordo com os dados e critérios utilizados, podem-se ter resultados mais conservadores ou mais liberais. Complementa, afirmando que pode-se mesmo estimar os limites inferior e superior da PMP a fim de testa-los no projeto e efetuar, assim, uma análise de sensibilidade e, a partir desta, estabelecer a PMP de projeto. Devido à freqüente utilização deste enfoque de cálculo, Wang e Revell (WANG E REVELL, 1983) definem um índice indicativo do conservantismo relativo na estimativa da EMP. Assim, sabendo quão conservativo é o valor da EMP na faixa de estimativas possíveis, o decisor poderá indicar como esse valor deverá ser usado no projeto das estruturas.

Além das variações nos valores da PMP/EMP devido ao grau de conservantismo utilizado, esses valores apresentam uma estimativa cuja precisão não pode ser avaliada de forma objetiva. As imprecisões advém de vários fatores, relacionados a seguir com base em Garcia (1996) apud Klemes (1991) ${ }^{8}$ :

- a precisão das medidas de precipitação não é quantificada, embora sabe-se que está sujeita a erros aleatórios e sistemáticos, estes últimos sendo principalmente significativos nas áreas montanhosas.

- as diferenças nas estimativas da altura de água precipitável com base no ponto de orvalho da superfície e no perfil vertical de umidade medido são raramente quantificadas;

- a precisão de dados meteorológicos empregados é, geralmente, não quantificada;

- quando julgamentos subjetivos são empregados, as conseqüências das possibilidades alternativas não são quantificadas;

- implicações na estimativa da PMP dos vários parâmetros padrão, como fator orográfico, intensidade dos ventos, fator de maximização da umidade, entre outros, não são quantificados em uma análise de sensibilidade, embora seja reconhecido que cada um varia dentro de uma larga faixa;

- parece não existir nenhuma análise sistemática das diferenças nas respectivas magnitudes dos componentes básicos da PMP (convergência, efeito orográfico, processo convectivo) obtidos pelos diferentes modelos;

${ }^{8}$ KLEMES, V., (1981), Probability of PMP and PMF: Assessmente of Feasibility, report for B.C. Hydro, Vancouver, B.C., Canada. 
- parece não haver um consenso dos limites físicos a partir dos quais os vários modelos empregados no procedimento padrão de cálculo da PMP não possam ser julgados factíveis;

Além desses, a imprecisão no cálculo da EMP é acrescida dos seguintes fatores:

- a limitada e frequentemente desconhecida precisão dos dados (umidade do solo, temperatura, rugosidade das seções do rio, etc...) favorece a redução da precisão da estimativa da EMP;

- a influência das características fisiográficas da bacia, da cobertura vegetal, do uso do solo e das condições antecedentes;

- não existe uma análise sistemática da precisão dos modelos hidrológicos usados, embora esteja bem documentado que, devido às suas diferenças estruturais (e experiência dos seus usuários), podem produzir resultados bem diferentes a partir dos mesmos dados;

- as maiores fontes de imprecisão na estimativa da EMP podem estar na limitada validação das calibrações com base em enchentes observadas para um regime de escoamento abaixo das condições da EMP e em uma limitada possibilidade de adequação da estrutura de um dado modelo hidrológico para o regime de escoamento da EMP;

- existe uma opinião muito difundida que a precisão das vazões extremas observadas quer diretamente medidas ou restituídas através de cálculo hidráulicos, não é maior que, aproximadamente, $\pm 25 \%$. Portanto, a principio, a precisão da EMP seria, ainda, menor.

Observa-se, como exposto acima, que os valores da PMP/EMP vêm raramente acompanhados por estimativas do seu grau de precisão. Occhipinti (OCCHIPINTI, 1989) afirma categoricamente que "não existe meio objetivo de avaliar a precisão da PMP”. No entanto, este fato acaba por gerar um contraste entre a aparente precisão das estimativas e a sua imprecisão intríseca caracterizada pelo termo "provável". Consequentemente, a metodologia fica sujeita a críticas da consistência conceitual do seu procedimento. 


\subsection{Conclusões}

Diante das análises feitas e das considerações apresentadas concluiu-se que para este estudo de caso a metodologia estatística se mostrou inconsistente, pois:

- No exemplo apresentado demonstrou-se a forte dependência do método estatístico com a extensão da série de vazões e a inconsistência dos valores máximos inferidos utilizando a metodologia usual de ajuste de distribuições probabilísticas.

- Verificou-se a significativa influência de eventos extraordinários ("outliers") na determinação dos valores máximos através do método estatístico e a conseqüente insegurança gerada por essa metodologia na definição das vazões de projeto.

- Verificou-se, também, a dependência da cauda superior da curva da distribuição probabilística com os menores valores de uma série de valores máximos. Vale ressaltar que não existe significado físico na dependência entre a probabilidade de excedência de uma enchente catastrófica com o regime de vazões dos 3 anos menos severos.

É importante frisar que o trabalho não visa invalidar, nem tem a pretensão de desaconselhar o uso da metodologia estatística, mas sim servir como alerta para o projetista que fará uso da metodologia, reapresentando alguns inconvenientes práticos que porventura possa vir a aparecer na utilização do método. Desta forma, poderá se obter um valor mais crítico e, talvez, mais preciso.

Já na metodologia determinística observou-se que as maiores objeções à metodologia determinística são mais de natureza operacional do que uma questão de princípios. Em termos gerais, embora seja reconhecido que os processos hidroclimáticos operam dentro de limites finitos, ainda não está claro quais são esses limites, a despeito de ser possível estimar os limites geográficos de variáveis envolvidas tais como umidade relativa, umidade do solo, temperatura do ar, temperatura da água, ponto de orvalho, intensidade dos ventos e outros semelhantes.

Ressalta-se que a maior crítica a metodologia hidrometeorológica está no campo prático das decisões, que devem ser fundamentadas em algum tipo de análise de risco como é o caso das decisões da vazão de projeto do vertedouro ou na verificação da segurança de barragens - e onde formulações probabilísticas são indispensáveis, uma vez que, de outra forma, os resultados de soluções alternativas não podem ser comparadas de forma efetiva. 
Por outro lado, a grande vantagem da metodologia determinística está na sua abertura para progredir através do avanço da ciência geofísica e do maior entendimento dos fenômenos hidro-climáticos.

Dessa forma, Garcia (1996) apresentou o método conjugado que vem com a proposta de considerar o comportamento estatístico das variáveis hidrológicas, respeitando os seus limites físicos determinados através da metodologia determinística e que, a despeito das imprecisões dos valores da PMP/EMP, permita inferir, com segurança, as suas distribuições probabilísticas. 


\section{MÉTODO CONJUGADO}

\subsection{Limite Físico dos Valores Máximos}

Pela observação histórica da natureza, constata-se que dentro da atual era climática, para cada região da terra, existem limites máximos para os fenômenos hidrológicos naturais, tais como chuvas, deflúvios, distribuição de temperatura e da umidade do ar, transporte de umidade, tipo e natureza das tormentas. Esses limites máximos atingíveis não são tão raros de ocorrer quanto se presume teoricamente.

As chuvas máximas observadas nas bacias hidrográficas, assim como as máximas enchentes, tendem a alcançar um limite superior que depende de suas características fisiográficas e hidrometeorológicas. Os picos e volumes de hidrogramas têm um limite físico superior ditado pelo contexto hidrogeográfico de sua bacia.

Assim, admitindo-se a existência destes limites físicos máximos para os processos hidrológicos naturais, os métodos hidrometeorológicos permitem sua avaliação. Estes limites são definidos, como visto no capitulo anterior, pelo método determinístico através de procedimentos hidrometeorológicos, resultando na precipitação máxima provável (PMP) e no hidrograma da enchente máxima provável (EMP). Estes valores, entretanto, nem sempre são considerados no dimensionamento de obras hidráulicas, razão pela qual a PMP e a EMP deixam de ser estimadas, recorrendose, em seu detrimento, ao método estatístico de análise de freqüência, que não considera estes limites físicos.

Garcia (1996) comenta que a diferença entre estes dois métodos descritos no capítulo 2 pode ser, de forma conceitual, reduzida às suas implicações na forma das caudas superiores das distribuições probabilísticas das variáveis hidrológicas 
envolvidas. Em termos práticos, a diferença básica reside no fato que o método estatístico, fundamentado nos modelos de distribuição probabilísticas acreditados como sendo legítimos e comumente usados na análise de freqüência, tem a cauda superior infinita e assimetria positiva, i.e., sua função de distribuição acumulada tem a forma de curvas convexas no papel de probabilidade normal (ou seja, a inclinação da sua cauda superior aumenta gradualmente e tende ao infinito).

Por outro lado, as distribuições compatíveis com a filosofia da PMP/EMP (método determinístico) teriam um limite superior finito, para o qual sua cauda superior deveria convergir assintoticamente. Dessa forma, sua cauda superior seria assintótica no papel de probabilidade normal e a distribuição tenderia a ter assimetria negativa. $\mathrm{O}$ método conjugado foi desenvolvido com base nesta filosofia.

\subsection{Distribuição de Valores Máximos com Limite Físico Definido}

O objetivo de inferir os valores máximos para diferentes intervalos de recorrência, impõe a necessidade de utilizar uma distribuição probabilística. Por sua vez, essa distribuição probabilística deve ajustar-se satisfatoriamente aos valores máximos da série histórica e ter como limite superior a EMP ou a PMP. Dessa forma, as características que constituem um modelo de previsão nos limites da realidade física e oferecendo respostas satisfatórias para as questões levantadas na seção 3.1, são apresentadas a seguir (GARCIA, 1996):

- a probabilidade de inexcedência da PMP ou EMP é igual a 1,0;

- os valores de projeto com probabilidade de inexcedência superior a do valor máximo da série e inferior à da PMP ou EMP seja inferidos por interpolação em vez de extrapolação, resultando sempre em valores compreendidos dentro de um intervalo de magnitude factível;

- os valores da PMP e da EMP estejam sempre incluídos como um limite superior da distribuição cujos parâmetros serão obtidos por métodos de estimativas, aplicados diretamente aos dados de série histórica;

- a distribuição probabilística ajustada não esteja sujeita a variações significativas em função da inclusão de eventos extraordinários ("outliers") ou da extensão da série de dados. 


\subsection{Definição do Método Conjugado Utilizando a Distribuição Probabilística dos Valores Extremos Generalizados (GEV)}

O método conjugado é um método que une as ferramentas matemáticas para determinação de valores máximos de variáveis hidrológicas, precipitação e vazão, com parâmetros físicos da área em análise, ou seja, o método é conceituado através da combinação das virtudes dos métodos atuais (metodologia estatística) e da coerência com o fenômeno físico (metodologia determinística).

O método considera a série de valores observados das variáveis hidrológicas, seu comportamento estatístico e seus limites físicos, permitindo desenvolver análises de riscos de projetos hidráulicos de engenharia (GARCIA, 1997).

Para definição da analise de freqüência conjugada, Garcia (1996) pesquisou dentre as diferentes distribuições probabilísticas, as que apresentassem as seguintes características:

- Assintótica a um valor máximo definido;

- Flexível, permitindo o ajuste para diferentes séries de valores máximos;

- Que os parâmetros fossem de fácil definição, para diferentes séries de valores.

Garcia (1996) escolheu para compor a análise de frequiência conjugada a distribuição probabilística dos Valores Extremos Tipo III (GEV- Tipo III ou EV3), uma vez que atende aos aspectos conceituais e práticos. Segundo Jenkinson (1955), a função geral da distribuição de frequiência acumulada dos valores extremos é representada por:

$$
F(x)=\exp \left\{-\left[1-\frac{k \cdot(x-u)}{\alpha}\right]^{1 / k}\right\}
$$

em que x é um valor máximo qualquer, $\alpha$ é o parâmetro de escala $(\alpha>0)$, k é o parâmetro de forma e u é o parâmetro de localização. A distribuição probabilística EV3 tem $\mathrm{k}>0$, é definida por 3 parâmetros e tem uma forma assintótica com um limite superior, onde $-\infty<x \leq u+(\alpha / k)$. A aplicação desta distribuição à análise de freqüência conjugada requer as seguintes considerações iniciais: 
- A variável x será renomeada como V, nome genérico para os valores máximos de precipitações e/ou vazões;

- VMP é o valor máximo provável, nome genérico para a PMP (precipitação máxima provável e a EMP(enchente máxima provável).

Introduzindo-se nesta distribuição o conceito de VMP, tem-se que:

$$
V M P=u+\frac{\alpha}{k}
$$

Sendo um limite superior, seu valor terá probabilidade de não-excedência unitária, ou seja, $\mathrm{F}(\mathrm{VMP})=1,0$. Substituindo-se a equação (62) em (61), e atendendo às considerações de nomenclatura feitas anteriormente, tem-se:

$$
F(V)=\exp \left\{-\left[1-\frac{(V-u)}{(V M P-u)}\right]^{1 / k}\right\}
$$

desenvolvendo-se a equação acima e considerando-se $\mathrm{k}^{*}=1 / \mathrm{k}$, tem-se:

$$
F(V)=\exp \left[-\left(\frac{V M P-V}{V M P-u}\right)^{k^{*}}\right]
$$

com $\mathrm{V} \leq \mathrm{VMP}$ e $\mathrm{k}^{*}>0$, onde $\mathrm{F}(\mathrm{V})$ é a probabilidade de não-excedência de $\mathrm{V}$. Para facilitar a apresentação, o parâmetro k* será renomeado, doravante, de k.

Assim, Garcia (1996) definiu a distribuição probabilística da análise de freqüência conjugada (AFC), cujo limite superior (VMP) é estabelecido pelo método determinístico e os dois parâmetros u e k são obtidos através do ajuste com série de valores máximos.

\subsection{Determinação dos Parâmetros da Distribuição}

São vários os métodos de estimação dos parâmetros da distribuição de probabilidade do método conjugado, obtida a partir da distribuição probabilística dos 
valores extremos - Tipo III. Os métodos utilizados por Garcia (1996) foram: o método dos mínimos quadrados, o método dos momentos e o método da máxima verossimilhança. Em Garcia (1996) apresenta uma descrição detalhada dos processos para obtenção dos parâmetros pra cada metodologia analisada.

De forma geral, o método de estimação através dos mínimos quadrados é eficiente quando são atendidas as seguintes condições (YEVJEVICH, 1972):

- que os desvios $\mathrm{e}_{\mathrm{i}}$, do método, sejam distribuídos de forma normal

- que a variância da população dos desvios $e_{i}$ seja independente da posição de um dado grupo de valores $e_{i}$, ou que os desvios sejam mutuamente independentes ao longo da distribuição;

- que a variância da população dos desvios e $e_{i}$ ao longo da curva da distribuição seja constante.

Estas condições são raramente satisfeitas em hidrologia e, assim, resultam em um estimador viesado. A vantagem deste método é a facilidade de determinação dos parâmetros, definidos através de equações explicitas. No entanto, devido às características apresentadas e às atuais facilidades computacionais existentes, este método é, hoje, dificilmente recomendado.

A estimativa através do método dos momentos (YEVJEVICH, 1972), conforme foi demonstrado por R. A. Fisher, é assintoticamente eficiente. Sua eficiência é, usualmente, inferior à unidade, principalmente para distribuições assimétricas.

No caso particular em que a distribuição de probabilidade é simétrica e particularmente normal, pode-se demonstrar que a eficiência do método do momentos é muito próxima da unidade e, portanto, não deve ser preterido em relação aos demais métodos. No entanto, a grande maioria das distribuições probabilísticas de valores máximos em hidrologia é assimétrica e, assim, a estimativa pelo método dos momentos é considerada uma primeira aproximação.

A estimativa pelo método da máxima verossimilhança (YEVJEVICH, 1972) tem as seguintes propriedades:

- são, usualmente, não viesadas;

- se uma estimativa eficiente para os parâmetros u e k existir, esse método irá defini-los; - se uma estimativa adequada existir, as soluções das equações de verossimilhança serão funções dessa estimativa adequada.

Frequentemente, a equação de verossimilhança fornece uma solução para estimativa que converge para o valor verdadeiro da população conforme o número de 
valores da série $(\mathrm{N})$ tende ao infinito, com probabilidade unitária, concluindo-se que a estimativa é consistente. Dessa forma, a estimativa dos parâmetros pelo método da máxima verossimilhança é fortemente recomendada (GARCIA, 1996). A maior complexidade nos cálculos dos parâmetros, feita através do processo iterativo não pode ser considerada, hoje, uma dificuldade, devido à grande velocidade de processamento dos computadores pessoais e à facilidade para elaboração dos programas.

\subsection{Definição do Método Conjugado Utilizando a Distribuição Probabilística Logística Generalizado}

Na forma mais geral, a distribuição Logística generalizada é representada através da função de distribuição de frequiência acumulada $\mathrm{F}(\mathrm{x})$, cuja equação é apresentada a seguir (HOSKING, 1986):

$$
F(x)=\left[1+\left\{1-k\left(\frac{x-\varepsilon}{\alpha}\right)\right\}^{1 / k}\right]^{-1}
$$

$\mathrm{X}$ é um valor máximo qualquer;

$\alpha$ é o parâmetro de escala;

k é o parâmetro de forma;

$\varepsilon$ é o parâmetro de localização.

A distribuição logística generalizado tem as seguintes características em função de k:

- $\mathrm{k}=0$ : a distribuição logística é definida por apenas 2 parâmetros $(\alpha$ e $\varepsilon$ ) e não apresenta limitações nos extremos $(-\infty<\mathrm{x}<\infty)$, a distribuição logística é um casa especial da distribuição logística generalizado com $\mathrm{k}=0, \mathrm{~m}=\varepsilon$ e $\mathrm{a}=\alpha$;

- $\mathrm{k}<0$ : a distribuição é definida por 3 parâmetros com um limite inferior, onde $\varepsilon+\alpha / \mathrm{k} \leq \mathrm{x} \leq \infty$

- $\mathrm{k}>0$ : a distribuição é definida com 3 parâmetros com um limite superior, onde $\infty \leq \mathrm{x} \leq \varepsilon+\alpha / \mathrm{k}$

A distribuição logística generalizado é equivalente à distribuição log-logística (AHMAD et al., 1988). A função distribuição de probabilidade log-logística é dada por: 


$$
F(x)=\left[1+\left\{\frac{x-a}{b}\right\}^{-1 / c}\right]^{-1}
$$

A relação entre os parâmetros da equação (65) e (66 ) é, c $=-k, b=\alpha / k$ e a $=\varepsilon+\alpha / k$.

\subsubsection{Método Conjugado}

O método conjugado conjuga o método hidrometeorológico, que permite definir o limite superior, e o método estatístico, que permite inferir valores para diferentes probabilidades.

Será utilizada a distribuição logística generalizada com o objetivo de avaliar essa distribuição no que se refere às 2 (duas) últimas características apontadas na seção 3.3, uma vez que a mesma apresenta a $1^{\text {a }}$ característica como mostrado na seção item 3.3. Assim, o método conjugado caracteriza-se por um novo conceito e não por uma nova distribuição probabilística ou formulação matemática.

A aplicação da distribuição logística generalizada ao método conjugado requer as seguintes considerações iniciais:

- a variável x será renomeada como $\mathrm{V}$, nome genérico para os valores máximos de precipitações e/ou vazões;

- VMP é o valor máximo provável, nome genérico para a precipitação máxima provável (PMP) e para enchente máxima provável (EMP).

Como exposto anteriormente, a distribuição logística generalizada com k $>0$ é limitada na extremidade superior. Assim, introduzindo nesta distribuição o conceito de PMP, no caso da série de precipitações máximas, ou EMP, no caso da série de vazões máximas, tem-se que:

$$
V M P=\varepsilon+\frac{\alpha}{k}
$$


sendo um limite superior, seu valor terá probabilidade de inexcedência unitária, ou seja, $\mathrm{F}(\mathrm{VMP})=1,0$. Substituindo-se a equação (67) em (65), e atendendo as considerações de nomenclatura feitas anteriormente, tem-se:

$$
F(V)=\left[1+\left\{1-\frac{k V}{\alpha}+\frac{k \varepsilon}{\alpha}\right\}^{1 / k}\right]^{-1}
$$

Como:

$$
\frac{k}{\alpha}=\frac{1}{V M P-\varepsilon}
$$

Tem-se:

$$
F(V)=\left[1+\left\{1-\frac{V}{V M P-\varepsilon}+\frac{\varepsilon}{V M P-\varepsilon}\right\}^{1 / k}\right]^{-1}
$$

Assim,

$$
F(V)=\left[1+\left\{-\left(\frac{V M P-V}{V M P-\varepsilon}\right)\right\}^{1 / k}\right]^{-1}
$$

Com $\mathrm{V} \leq \mathrm{VMP}$ e $\mathrm{k}>0$, em que:

$\mathrm{F}(\mathrm{V})$ é a probabilidade de inexcedência de $\mathrm{V}$,

VMP é o valor máximo provável, nome genérico da precipitação máxima provável (PMP) e enchente máxima provável (EMP),

V é o valor de um dado evento (vazão ou precipitação), tal que VMP $\geq V>0$.

Assim, apresenta-se a distribuição do método conjugado, cujo limite superior (VMP) é estabelecido pelo método hidrometeorológico e os dois parâmetros $\varepsilon$ e k são obtidos através dos métodos de estimação que utilizam a série de valores máximos.

Os quantis da distribuição podem ser determinados por:

$$
V_{t}=\varepsilon+(V M P-\varepsilon)\left[1-(T-1)^{-k}\right]
$$




\subsubsection{Estimação dos Parâmetros}

- Método dos Momento com Pesos Probabilísticos

Os momentos L da distribuição logística generalizada são dados como (HOSKING, 1986):

$$
\begin{gathered}
\lambda_{1}=\varepsilon+\frac{\alpha}{k}[1-\Gamma(1+k) \Gamma(1-k)] \\
\lambda_{2}=\alpha \Gamma(1+k) \Gamma(1-k) \\
\tau_{3}=-k
\end{gathered}
$$

As estimativas dos parâmetros são obtidos pela substituição de $\lambda_{1}, \lambda_{2}$ e $\tau_{3}$ pelas suas estimativas $\hat{\lambda}_{1}, \hat{\lambda}_{2}$ e $\hat{\tau}_{3}$ dados pelas eq. (41) e (42), assim:

$$
\begin{gathered}
\hat{k}=-\hat{\tau}_{3} \\
\hat{\alpha}=\hat{\lambda}_{2} /[\Gamma(1+\hat{k}) \Gamma(1-\hat{k})] \\
\hat{\varepsilon}=\hat{\lambda}_{1}+\left(\hat{\lambda}_{2}-\hat{\alpha}\right) / \hat{k}
\end{gathered}
$$

Para determinar os parâmetros $\varepsilon, \mathrm{k}$ da distribuição de frequiência conjugada, inicialmente calcula-se o valor do parâmetro $V \hat{M} P$ através das estimativas de $\hat{k}, \hat{\alpha}$ e $\hat{\varepsilon}$ dados pelas eq. (73), (74) e (75), assim:

$$
V M P=\hat{\varepsilon}+\frac{\hat{\alpha}}{\hat{k}}
$$


Por fim o valor dos parâmetros $\varepsilon$, e k (da distribuição conjugada) se iguala a $\hat{\varepsilon}$ e $\hat{k}$ quando por meio de um método iterativo têm-se a convergência do processo através da comparação entre o valor calculado do parâmetro $V \hat{M P}$ e Valor Máximo Provável (VMP) determinado pelo método determinístico. A convergência do processo iterativo é verificada através do erro $\varepsilon_{\mathrm{r}}\left(-0,1 \leq \varepsilon_{\mathrm{r}} \leq 0,1\right)$, calculado como a diferença entre o Valor Máximo Provável obtido pelo método determinístico e o parâmetro $V \hat{M} P$. A escolha da metodologia para o processo iterativo é livre, sendo recomendado o método da bisseção pois como o valor do parâmetro $V \hat{M} P$ é decrescente com o aumento do parâmetro $\hat{k}$ a dinâmica do processo é regida pelo sinal do erro $\left(\varepsilon_{\mathrm{r}}\right)$. Neste processo, o valor do parâmetro $\hat{k}$ é acrescido no caso do erro ser positivo e decrescido no caso contrário. 


\section{ESTUDOS DE CASOS}

\subsection{Introdução}

Este capítulo apresenta alguns exemplos de aplicação do método conjugado com o objetivo de avaliar o método, constatar sua eficiência e verificar suas vantagens em relação aos métodos estatístico e determinístico. Como exemplos de aplicação foram selecionados 3 séries de vazões máximas anuais e uma de precipitações máximas. Ressalta-se que em todas as análises procurou-se considerar os critérios que estimaram o valor do parâmetro Valor Máximo Provável (VMP), de forma a enfatizar e caracterizar ainda mais a etapa determinística do método conjugado.

Inicialmente utilizou-se para aplicar o método conjugado a série de vazões máximas anuais da barragem de Sobradinho/BA, localizado no rio São Francisco. Essa série é a mesma que foi analisada no capitulo 2 , na análise conceitual e crítica da metodologia estatística. Foram realizadas as mesmas análises utilizadas na análise crítica da metodologia estatística, para desta forma analisar a consistência do método quanto aos efeitos causados pelas diferentes análises.

Uma outra análise, utilizando à mesma série de Sobradinho/BA, foi a de verificar a sensibilidade do parâmetro VMP. Este tipo de análise objetiva caracterizar o quanto o grau de imprecisão a cerca do valor estimado da PMP/EMP influencia nos valores inferidos através da análise de freqüência conjugada. As duas primeiras análises permitem fazer uma análise comparativa com os resultados obtidos com Garcia (1996) podendo, assim corroborar com as conclusões obtidas por ele utilizando outras séries.

A partir dos resultados obtidos aplicando a metodologia estatística e o método conjugado para mesma série e para as mesmas análises, procurou-se neste terceiro estudo de caso fazer uma análise comparativa mais abrangente entre ambas as 
metodologias. A utilização da distribuição GEV na aplicação da metodologia estatística permite fazer uma comparação mais direta sobre a vantagem em se utilizar um limite superior na distribuição (método conjugado).

O quarto estudo de caso objetiva verificar a vazão de projeto através do método conjugado, para isso foi selecionada a série de máximos anuais da Usina Hidrelétrica de Caconde, também denominada Graminha, localizada no rio Pardo, no município de Caconde, estado de São Paulo. A série estende-se de 1938 a 1989 correspondendo a 52 anos de vazões máximas. O estudo propõe avaliar quantitativamente os resultados apresentados pelo método conjugado e em contrapartida comparar estes resultados com os estimados através da metodologia estatística e determinística.

O quinto estudo de caso propõe aplicar o método conjugado a séries de médios diários máximos e série de máximos instantâneos, para esse exemplo foi selecionada a série histórica de vazões máximas médias diárias observadas no Rio Paraguaçu em Pedra Cavalo, no período de 1941 a 1978. Para a definição das séries de vazões máximas instantâneas foram utilizados os métodos convencionais que relacionam as vazões máximas instantâneas e as vazões máximas médias diárias. O objetivo deste estudo é avaliar o ganho obtido aplicando a metodologia conjugada em uma série de máximos instantâneos para valores com altos períodos de retorno.

O sexto estudo de caso propõe aplicar o método conjugado em uma série de precipitação de máximos anuais e com durações parciais, para esse exemplo foi selecionada a série histórica de precipitação máximas de 12 horas, observadas na estação do observatório IAG localizado no município de São Paulo pertencente à bacia hidrográfica do rio Tamanduateí. A série estende-se de 1934 a 1998, com 45 anos de precipitações máximas anuais, uma vez que a série apresenta inúmeros anos sem observação.. Este estudo objetiva verificar os resultados obtidos aplicando o método conjugado em uma série parcial de precipitação, comparando os resultados obtidos com os resultados definidos utilizando a metodologia estatística.

Por fim, o sétimo estudo de caso aplica o conceito do método conjugado utilizando a distribuição probabilística logística generalizada. Foi utilizada a mesma série e as mesmas análises feitas no primeiro e segundo estudos de caso. 


\subsection{Aplicação do Método Conjugado para Verificação da sua Consistência}

Como exemplo de aplicação do método conjugado (MC) e com o objetivo de verificar suas vantagens em relação ao método estatístico e determinístico, foi selecionada uma série de máximos da UHE (Usina Hidroelétrica) de Sobradinho/BA retirado do relatório da ONS (Operador Nacional do Sistema Elétrico, 2004). A tabela 2 apresenta a série de vazões médias diárias máximas anuais para o período de 1931 a 2001 da UHE de Sobradinho/BA. Como mostrado na seção 2.1.3 a vazão máxima de $15.676 \mathrm{~m} 3 / \mathrm{s}$, correspondente ao ano hidrológico de 1979 , foi considerado um valor extraordinário ("outlier") e, assim, foi retirada da série para o desenvolvimento das demais análises. A partir da série de vazões máximas anuais da UHE de Sobradinho/BA, tabela 2, foram selecionadas cinco sub-séries de vazões máximas, respeitando a seqüência cronológica de ocorrência, conforme definido na tabela 24. Esse exemplo é o mesmo utilizado no Capitulo 2, durante a análise crítica da metodologia estatística.

Com o objetivo de ter em mente a responsabilidade dos estudos de definição das vazões de projeto, imagine que esta obra poderia ter sido construída ao término dos estudos hidrológicos em 1950, 1970 e 2001.

As diferentes séries de vazões máximas foram ordenadas e a sua posição de plotagem foi definida pela fórmula de Weibull. Os parâmetros foram estimados através do método da máxima verossimilhança (ML).

Tabela 24 - Subséries de vazões máximas da UHE de Sobradinho/BA

\begin{tabular}{ccc}
\hline \hline Série de Vazões Máximas & Período (anos) & Número de Eventos \\
\hline \hline 1 & $1931-1950$ & 20 \\
2 & $1931-1970$ & 40 \\
3 & $1931-2001$ & 70 (sem o evento de 1979) \\
4 & $1951-2001$ & 50 (sem o evento de 1979) \\
5 & $1971-2001$ & 30 (sem o evento de 1979) \\
\hline \hline
\end{tabular}

Aplicando-se o método conjugado, para cada uma das séries de vazões, foram definidos os parâmetros da distribuição apresentados na tabela 22. Com o objetivo ilustrativo, apresenta-se na figura 18 a curva da distribuição acumulada para a série de 
vazões 1931-2001, ajustada pela análise de freqüência conjugada utilizando o método da máxima verossimilhança.

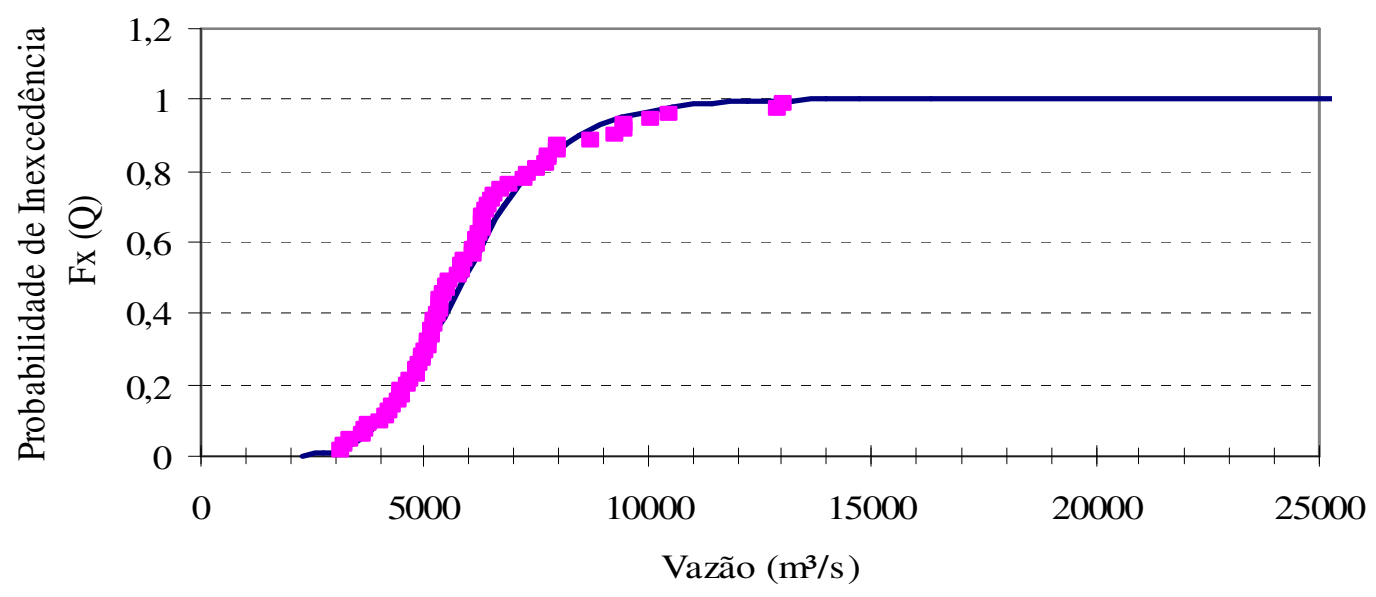

—Distribuição Ajustada Dados Observados - Weibull

Figura 18 - Análise de freqüência conjugada - exemplo da distribuição probabilística

Tabela 25 - Parâmetros das subséries de vazões máximas da UHE de Sobradinho/BA - Método da máxima verossimilhança (ML)

\begin{tabular}{cccc}
\hline \hline & & & \\
$\mathrm{n}^{\mathbf{0}}$ & Série de vazões & \multicolumn{2}{c}{ Parâmetros } \\
& & Forma k & Posição u \\
\hline \hline 1 & $1931-1950$ & 21,2631 & 5781,513 \\
2 & $1931-1970$ & 23,3098 & 5455,302 \\
3 & $1931-2001$ & 20,9877 & 5297,930 \\
4 & $1951-2001$ & 21,6623 & 5120,578 \\
5 & $1971-2001$ & 19,3130 & 5107,132 \\
\hline \hline
\end{tabular}

Percebe-se a forma assintótica do ramo superior da curva da distribuição, compatível com o fenômeno físico. Ressalta-se que, embora a escala horizontal esteja limitada a $25.000 \mathrm{~m}^{3} / \mathrm{s}$, a curva é assintótica a VMP $\left(363000 \mathrm{~m}^{3} / \mathrm{s}\right)$.

O valor da VMP foi retirado de trabalhos publicados por Anjos e Almedia (1981) e Staico (1981). O valor da EMP admitida para a barragem de Sobradinho/BA foi definido a partir da PMP calculada usando os critérios definido pela WMO (1973) através da maximização das tormentas severas. Através de um modelo chuva-vazão e com o valor estimado para PMP obteve-se um pico calculado em $36.300 \mathrm{~m}^{3} / \mathrm{s}$ e seu volume, para um período de 150 dias, resultou em $290 \times 10^{9} \mathrm{~m}^{3}$, com o hidrograma composto de nova onda se sobrepondo à da enchente de projeto com picos defasados em cerca de 40 dias. Desta forma, o valor considerado como valor máximo provável foi 
estabelecido em $36.300 \mathrm{~m}$ 3/s. Este valor foi adotado como o parâmetro VMP para as demais análises utilizando a série de Sobradinho/BA.

\subsubsection{Análise da influência da extensão da série de valores}

A primeira análise a ser desenvolvida refere-se à influência da extensão da série e do período de observações nos valores extremos de projeto. As séries de vazões da UHE de Sobradinho/BA, definidas na tabela 24, têm o objetivo de permitir esta análise.

A partir da aplicação do método conjugado, apresenta-se na figura 19, para o método da máxima verossimilhança, as curvas de distribuição probabilística ajustadas para as diferentes séries. A tabela 26 apresenta as vazões máximas para diferentes períodos de retorno (PR), inferidas a partir das distribuições probabilísticas ajustadas a cada uma das séries de vazões. Essa tabela apresenta na ultima coluna, para cada período de retorno, a diferença percentual máxima entre as vazões inferidas para as diferentes séries.

A análise das citadas tabelas e figuras permitem verificar que, para toda gama de probabilidades (períodos de retorno), a diferença entre as vazões é, no máximo, de $9 \%$. Esta diferença é pouco significativa em termos tanto de segurança da obra (p.ex.barragem), quanto ao aspecto de custo do vertedouro ou da obra.

Assim, através deste exemplo demonstra-se que o método conjugado depende muito pouco da extensão da série de vazões e os valores obtidos para as vazões de projeto (por exemplo, $\mathrm{PR}=10.000$ anos) não diferem significativamente.

Para este mesmo tipo de análise, Garcia (1996) aplicou o método conjugado nas sub-séries selecionadas da série de vazões máximas anuais do aproveitamento múltiplo (A. M). Jequitaí com 46 elementos. A diferença máxima obtida por ele foi 11,2\%. Corroborando com os resultados obtidos para as sub-séries da série de Sobradinho/BA.

\subsubsection{Análise da influência da presença de "outliers" na série de valores}

A análise a ser desenvolvida refere-se à influência da presença de eventos extraordinários (“outlier") na série de valores. Para verificar esta influência, foi aplicada 


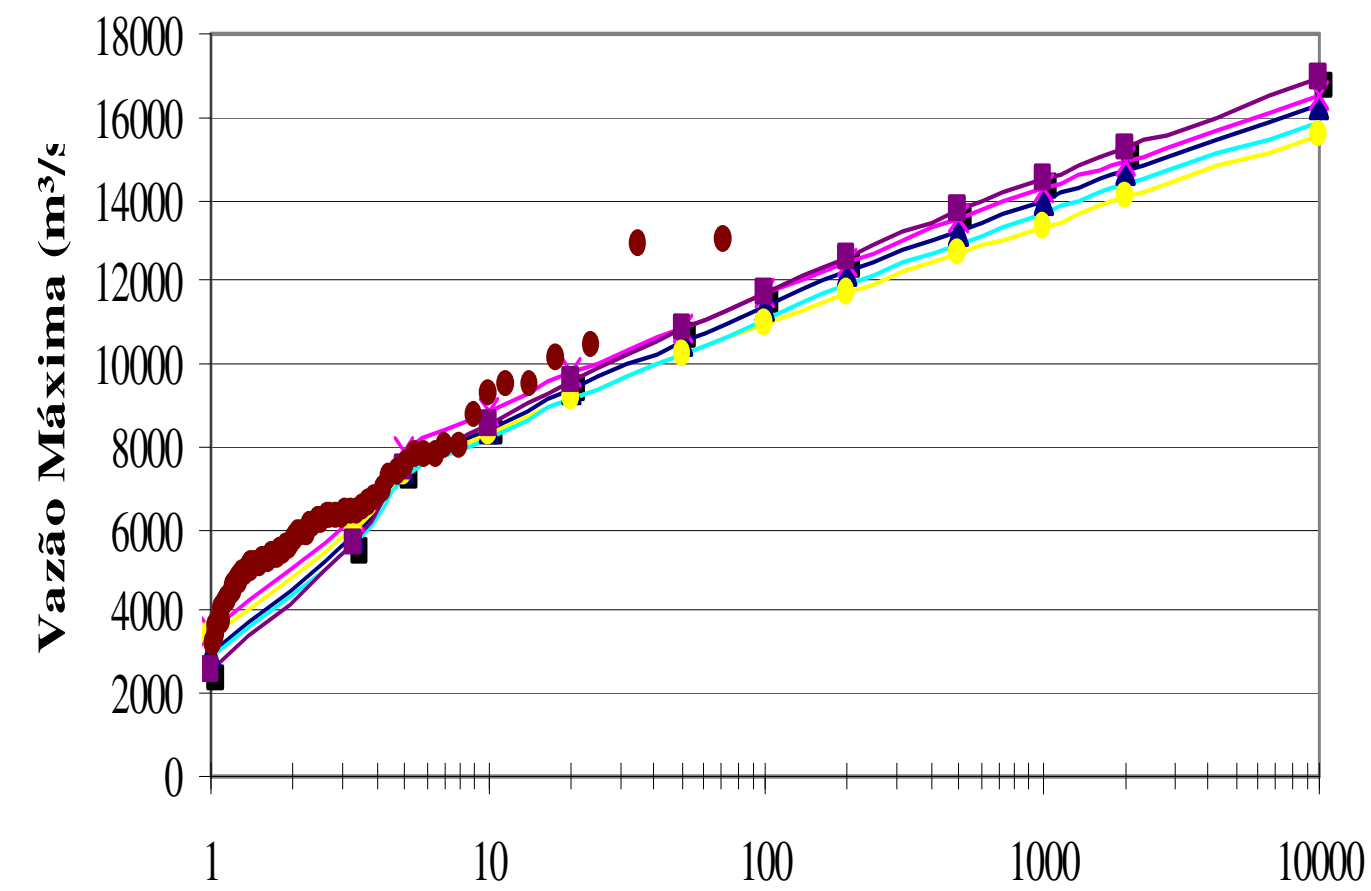

Período de Retorno (anos)

$\leftarrow 31-01 \div 31-50-31-70 \longrightarrow 51-01 \rightarrow-71-01 \quad$ • Dados

Figura 19 - Análise de frequiência conjugada - Análise da influência da extensão da série de valores

Tabela 26 - Análise da influência da extensão da série de valores

\begin{tabular}{cccccccc}
\hline \hline Probabilidade & $\begin{array}{c}\text { Período } \\
\text { de Excedência }\end{array}$ & \multicolumn{7}{c}{ Distribuições Probabilísticas } & Rerença \\
& $\begin{array}{c}\text { Retorno } \\
\text { (anos) }\end{array}$ & $31-50$ & $31-70$ & $31-01$ & $51-01$ & $71-01$ & $\begin{array}{c}\text { Dáxima } \\
(\%)\end{array}$ \\
\hline \hline 0,0001 & 10000 & 16510 & 15523 & 16310 & 15919 & 16938 & 9 \\
0,0005 & 2000 & 14954 & 14038 & 14717 & 14347 & 15256 & 9 \\
0,001 & 1000 & 14246 & 13366 & 13992 & 13633 & 14486 & 8 \\
0,002 & 500 & 13515 & 12673 & 13242 & 12896 & 13689 & 8 \\
0,005 & 200 & 12510 & 11724 & 12212 & 11883 & 12588 & 7 \\
0,01 & 100 & 11719 & 10979 & 11400 & 11086 & 11718 & 7 \\
0,02 & 50 & 10898 & 10210 & 10558 & 10260 & 10813 & 7 \\
0,05 & 20 & 9760 & 9146 & 9389 & 9116 & 9554 & 7 \\
0,1 & 10 & 8846 & 8294 & 8450 & 8197 & 8538 & 8 \\
\hline \hline
\end{tabular}


a análise de freqüência conjugada para a série completa de vazões máximas anuais da UHE de Sobradinho/BA, com e sem o outlier. Na Tabela 27 são apresentados os parâmetros da distribuição probabilística, obtidos pelo método da máxima verossimilhança, para os dois casos.

Tabela 27 - Parâmetros da AFC para análise da influência da presença do "outlier"

\begin{tabular}{ccc}
\hline \hline \multirow{2}{*}{ Série de Vazões } & \multicolumn{2}{c}{ Parâmetros } \\
& Forma k & Posição u \\
\hline \hline 1948-1994 (sem outlier) & 20,9877 & 5297,930 \\
1948-1994 (com outlier) & 19,5528 & 5360,180 \\
\hline \hline
\end{tabular}

A Tabela 28 apresenta as vazões máximas para as diferentes probabilidades de excedência. A Figura 20 apresenta as curvas obtidas para o caso de inclusão e exclusão do outlier. A análise da Tabela 28 e da Figura 20 permite concluir que, utilizando-se a análise de freqüência conjugada, a inclusão do evento extraordinário na série de vazões máximas não altera, significativamente, as vazões de projeto.

Verifica-se que a inclusão do outlier provoca um incremento de, apenas, $4 \%$ na vazão decamilenar. Conseqüentemente, utilizando-se a análise de frequiência conjugada, a decisão de considerar o outlier na série de vazões implicará em um pequeno aumento no custo da obra. Assim, este exemplo demonstra a diminuta influência de eventos extraordinários (outliers) na determinação dos valores máximos e na definição das vazões de projeto utilizando a análise de freqüência conjugada.

Para este mesmo tipo de análise, Garcia (1996) aplicou o método conjugado nas sub-séries selecionadas da série de vazões máximas anuais do aproveitamento múltiplo (A. M). Jequitaí com 46 elementos. A diferença máxima obtida por ele foi $11 \%$. Corroborando com os resultados obtidos para as séries com e sem o evento extraordinário da série de Sobradinho/BA.

\subsubsection{Análise da influência dos menores valores da série de valores máximos}

A análise a ser desenvolvida refere-se à influência da magnitude dos menores valores de uma série de valores máximos na definição dos valores extremos (valores de projeto) utilizando o método conjugado. Para verificar esta influência, foi aplicada a 


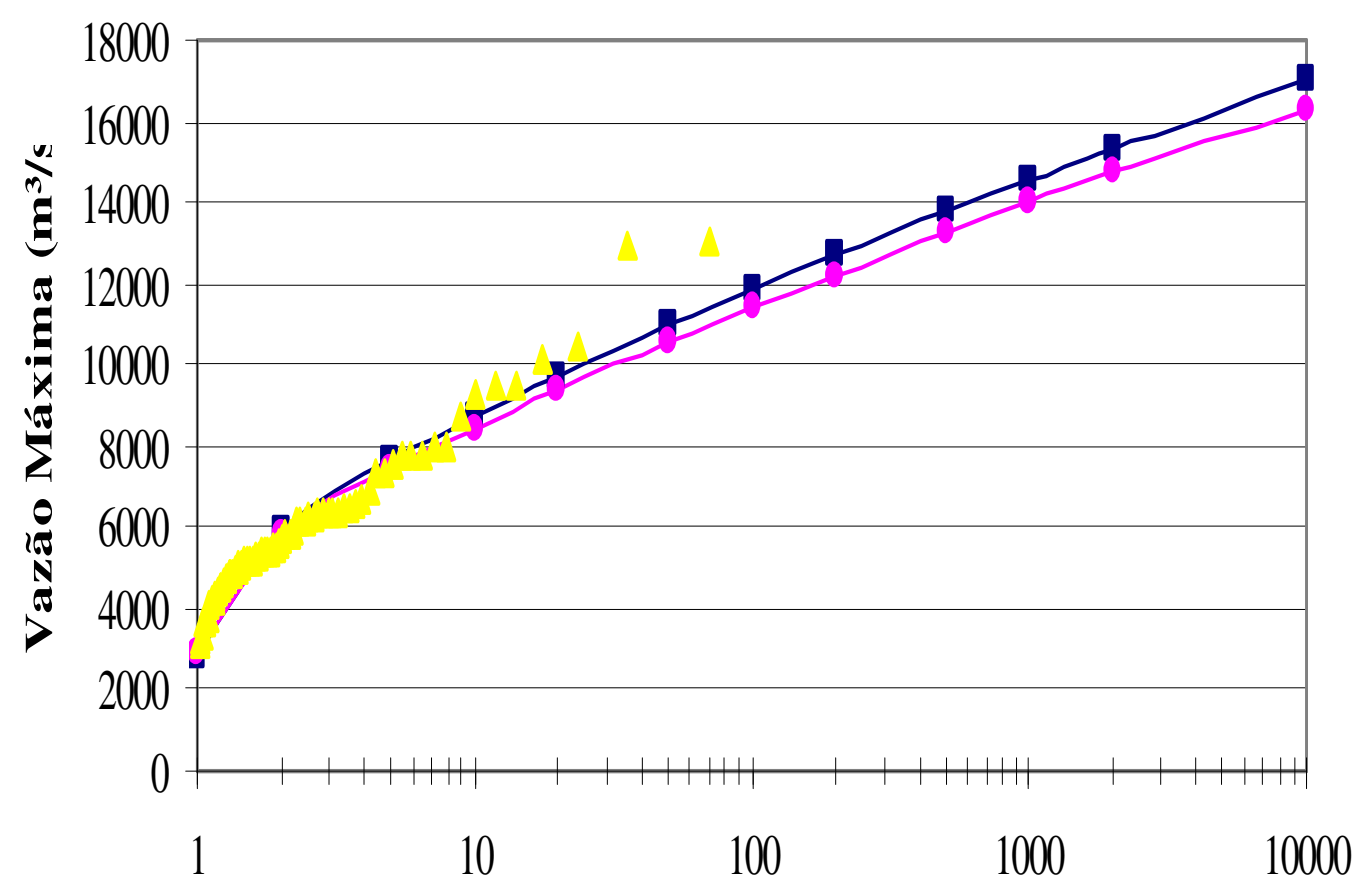

Período de Retorno (anos)

$\rightarrow$ —com "outlier" do ano $1979-$ —-semo "outlier" $\triangle$ Dados

Figura 20 - Análise de freqüência conjugada - Análise da influência da presença de "outliers"

Tabela 28 - Análise da influência da presença de "outliers"

\begin{tabular}{rrrrr}
\hline \hline & $\begin{array}{c}\text { Período } \\
\text { de } \\
\text { Probabilidade } \\
\text { de Excedência }\end{array}$ & $\begin{array}{c}\text { Retorno } \\
\text { (anos) }\end{array}$ & Distribuições Probabilísticas & \multirow{2}{*}{$\begin{array}{c}\text { Diferença } \\
\text { Máxima } \\
(\%)\end{array}$} \\
\hline \hline 0,0001 & 10000 & 16983 & 16310 & 4 \\
0,0005 & 2000 & 15325 & 14717 & 4 \\
0,001 & 1000 & 14568 & 13992 & 4 \\
0,002 & 500 & 13783 & 13242 & 4 \\
0,005 & 200 & 12701 & 12212 & 4 \\
0,01 & 100 & 11846 & 11400 & 4 \\
0,02 & 50 & 10957 & 10558 & 4 \\
0,05 & 20 & 9721 & 9389 & 4 \\
0,1 & 10 & 8724 & 8450 & 3 \\
\hline \hline
\end{tabular}


análise de freqüência conjugada para a série completa de vazões máximas anuais da UHE de Sobradinho/BA, excluindo-se outlier.

Foram selecionados os três menores valores da série de vazões máximas. Esses valores foram minorados (20\%) e majorados (20\% e 12\%), resultando em duas novas séries de vazões máximas denominadas séries minoradas e majoradas. A análise de freqüência conjugada foi aplicada a essas séries de vazões, utilizando o método da máxima verossimilhança para a determinação dos parâmetros. Na tabela 29 são apresentados os parâmetros da distribuição para cada uma das séries.

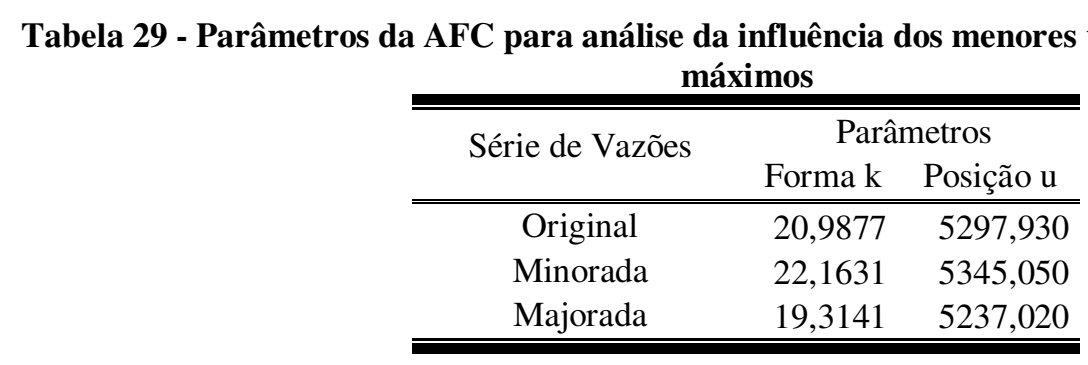

A figura 21 apresenta os valores originais das vazões máximas observadas com posição de plotagem definida pela fórmula de Weibull e as curvas da distribuição probabilística ajustadas. A tabela 30 apresenta os valores máximos para diferentes probabilidades de excedência, inferidas através da análise de frequiência conjugada para as séries de vazões máximas original, minorada e majorada.

A análise da tabela 30 e da figura 21 permite verificar que a minoração em $20 \%$ dos valores mínimos da série de vazões resulta em diminuição dos valores extremos de, no máximo, 0,03 \%. Por sua vez, a majoração entre 12 a 20\% dos valores mínimos das séries de vazões resulta no incremento dos valores extremos de, no máximo, $4 \%$. Assim, constata-se que, na análise de frequiência conjugada, os valores extremos não são influenciados significativamente pelos valores mínimos da série de valores máximos. Isto mostra que a forma da cauda superior da distribuição sugerida pela análise de freqüência conjugada está em concordância com o bom senso, ou seja, mostra a independência entre a probabilidade de excedência de uma enchente catastrófica com o regime de vazões dos anos menos severos.

Para este mesmo tipo de análise, Garcia (1996) aplicou o método conjugado nas sub-séries selecionadas da série de vazões máximas anuais do aproveitamento múltiplo (A. M). Jequitaí com 46 elementos. A diferença máxima obtida por ele foi $3 \%$. Corro- 


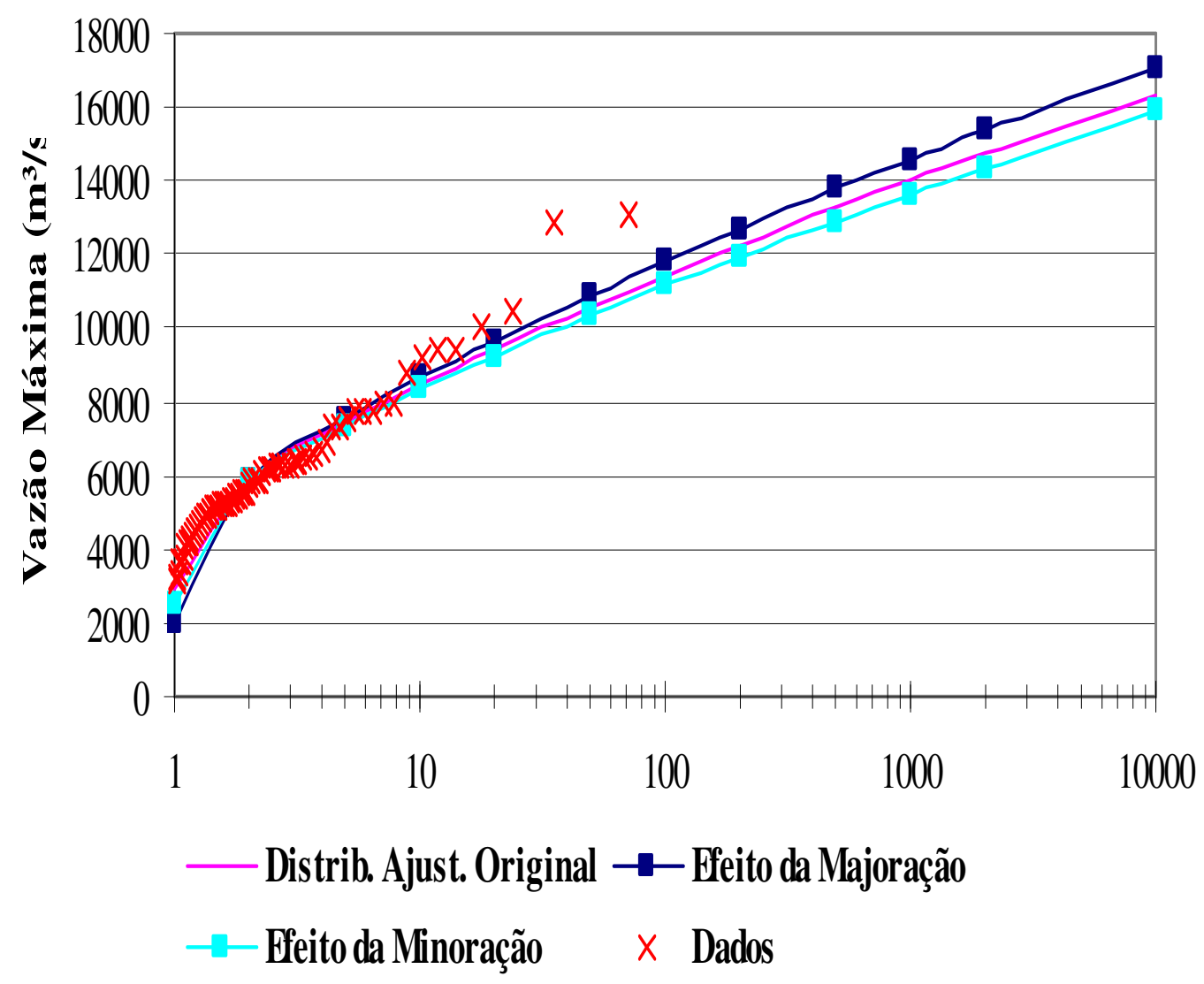

Figura 21 - Análise de freqüência conjugada - Análise da influência dos menores valores da série de valores máximos

Tabela 30 - Análise da influência dos menores valores da série de valores máximos

\begin{tabular}{|c|c|c|c|c|c|c|}
\hline $\begin{array}{c}\text { Probabilidade } \\
\text { de } \\
\text { Excedência }\end{array}$ & $\begin{array}{l}\text { Período } \\
\text { de } \\
\text { Retorno } \\
\text { (anos) }\end{array}$ & $\begin{array}{c}\text { Série } \\
\text { ORIGINAL }\end{array}$ & $\begin{array}{c}\text { Série com } \\
\text { valores } \\
\text { mínimos } \\
\text { MINORADOS }\end{array}$ & $\begin{array}{c}\text { Série com } \\
\text { valores } \\
\text { mínimos } \\
\text { MAJORADOS }\end{array}$ & $\begin{array}{l}\text { Diferenças das } \\
\text { vazões } \\
\text { máximas em } \\
\text { relação a série } \\
\text { original (\%) - } \\
\text { MINORADOS }\end{array}$ & $\begin{array}{l}\text { Diferenças das } \\
\text { vazões } \\
\text { máximas em } \\
\text { relação a série } \\
\text { original (\%) - } \\
\text { MAJORADOS }\end{array}$ \\
\hline 0,0001 & 10000 & 16310 & 15871 & 17018 & 0,03 & $\begin{array}{ll} & 4\end{array}$ \\
\hline 0,0005 & 2000 & 14717 & 14332 & 15343 & 0,03 & 4 \\
\hline 0,001 & 1000 & 13992 & 13634 & 14577 & 0,03 & 4 \\
\hline 0,002 & 500 & 13242 & 12913 & 13782 & 0,03 & 4 \\
\hline 0,005 & 200 & 12212 & 11924 & 12686 & 0,02 & 4 \\
\hline 0,01 & 100 & 11400 & 11147 & 11820 & 0,02 & 4 \\
\hline 0,02 & 50 & 10558 & 10342 & 10919 & 0,02 & 3 \\
\hline 0,05 & 20 & 9389 & 9228 & 9665 & 0,02 & 3 \\
\hline 0,1 & 10 & 8450 & 8334 & 8653 & 0,01 & 2 \\
\hline
\end{tabular}


borando com os resultados obtidos para as séries minoradas e majoradas da série de Sobradinho/BA.

\subsection{Análise de Sensibilidade dos Valores Extremos em Relação ao VMP}

Um dos parâmetros principais do método conjugado é o VMP, que corresponde ao nome genérico utilizado para representar a PMP e a EMP. O valor desse parâmetro é obtido através do método determinístico. Como já comentado, no presente trabalho foi adotado como valor da VMP de $36.300 \mathrm{~m}^{3} / \mathrm{s}$ (ANJOS E ALMEIDA (1981)). Como vimos na seção 2.2 a estimativa do valor da VMP (EMP) apresenta imprecisões. Desta forma Garcia (1996) afirma que se deve utilizar o valor do VMP em termos de limites superior e inferior ou ordens de magnitude.

Assim, no método conjugado, como em qualquer metodologia que utilize o VMP, devem ser desenvolvidas análises para verificação da sensibilidade dos resultados em função da sua imprecisão. Para desenvolver esta análise será utilizada a série de vazões máximas da UHE de Sobradinho/BA (1931 a 2001), eliminando-se o evento extraordinário do ano de 1979 (outlier).

Conforme já apresentado, o Valor Máximo Provável (VMP) adotado para UHE de Sobradinho/BA foi de $36.300 \mathrm{~m}^{3} / \mathrm{s}$. Considerando esse valor como central, foram feitas variações de 10 e $20 \%$ correspondendo à suposta imprecisão da EMP. Assim, o método conjugado foi aplicado à série de vazões máximas, utilizando-se os seguintes valores do VMP: 29040, 32.670, 36.300, 39.930, e $43.560 \mathrm{~m} 3 / \mathrm{s}$. Os parâmetros da distribuição foram estimados pelo método da máxima verossimilhança e são apresentados na tabela 31 .

Tabela 31 - Parâmetros da AFC para análise de sensibilidade do parâmetro VMP

\begin{tabular}{cccc}
\hline \hline VMP & Variação & \multicolumn{2}{c}{ Parâmetros } \\
$\left(\mathrm{m}^{3} / \mathrm{s}\right)$ & $(\%)$ & Forma k & Posição u \\
\hline \hline 29040 & -20 & 15,9176 & 5310,851 \\
32670 & -10 & 18,4554 & 5303,463 \\
36300 & (original) & 20,9877 & 5297,930 \\
39930 & 10 & 23,5166 & 5293,626 \\
43560 & 20 & 26,0432 & 5290,177 \\
\hline \hline
\end{tabular}


A figura 22 apresenta as vazões máximas observadas com posição de plotagem definida pela fórmula de Weibull e as curvas da distribuição probabilística ajustadas para o valor original do VMP $\left(36.300 \mathrm{~m}^{3} / \mathrm{s}\right)$ e para as variações de $20 \%$. A tabela 32 apresenta os valores máximos para diferentes probabilidades de excedência, inferidas através do método conjugado para os diferentes valores do VMP. A tabela 33 apresenta as diferenças percentuais dos valores máximos obtidos em relação aos inferidos para a série original.

A análise da tabela 32,33 e da figura 22 permite verificar que as variações de $20 \%$ no valor do VMP refletem-se em variações de, no máximo, $4 \%$ nos valores extremos. Isto se deve ao comportamento assintótico do ramo superior da distribuição probabilística do método conjugado. Portanto, constata-se que as variações no valor do VMP devido, por exemplo, às imprecisões, não influenciam significativamente as vazões extremas.

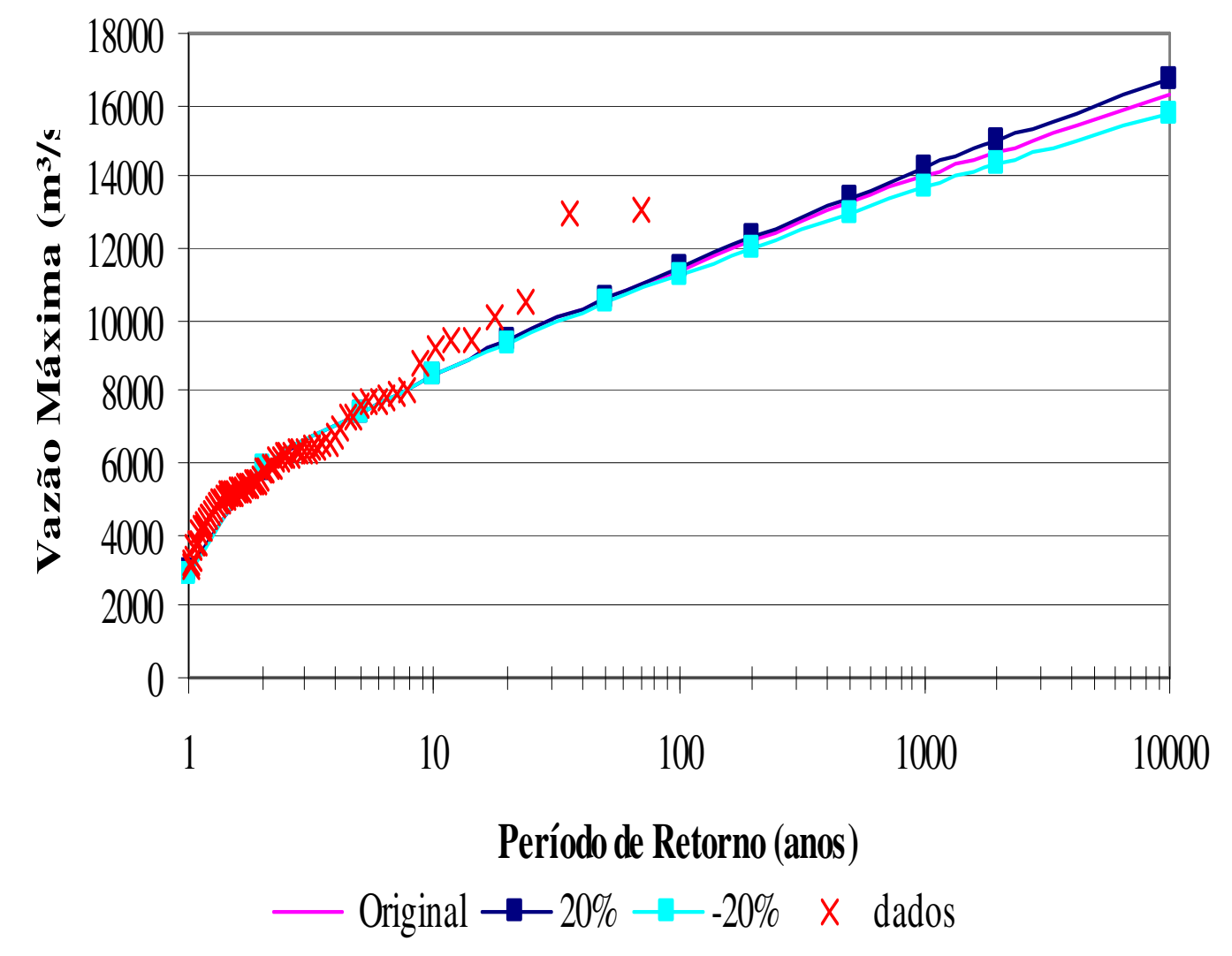

Figura 22 - Análise de freqüência conjugada - Análise de sensibilidade do parâmetro VMP 
Tabela 32 - Análise de sensibilidade do parâmetro VMP

\begin{tabular}{|c|c|c|c|c|c|c|}
\hline \multirow{3}{*}{$\begin{array}{l}\text { Probabilidade } \\
\text { de Excedência }\end{array}$} & \multirow{3}{*}{$\begin{array}{c}\text { Período } \\
\text { de } \\
\text { Retorno } \\
\text { (anos) }\end{array}$} & \multicolumn{5}{|c|}{ Valor Máximo Provável VMP $\left(\mathrm{m}^{3} / \mathrm{s}\right)$} \\
\hline & & $-20 \%$ & $-10 \%$ & original & $10 \%$ & $20 \%$ \\
\hline & & 29040 & 32670 & 36300 & 39930 & 43560 \\
\hline 0,0001 & 10000 & 15736 & 16056 & 16310 & 16518 & 16690 \\
\hline 0,0005 & 2000 & 14320 & 14542 & 14717 & 14859 & 14977 \\
\hline 0,001 & 1000 & 13665 & 13847 & 13992 & 14109 & 14206 \\
\hline 0,002 & 500 & 12980 & 13127 & 13242 & 13336 & 13413 \\
\hline 0,005 & 200 & 12027 & 12130 & 12212 & 12278 & 12332 \\
\hline 0,01 & 100 & 11267 & 11341 & 11400 & 11447 & 11487 \\
\hline 0,02 & 50 & 10470 & 10519 & 10558 & 10589 & 10615 \\
\hline 0,05 & 20 & 9350 & 9372 & 9389 & 9403 & 9415 \\
\hline 0,1 & 10 & 8439 & 8445 & 8450 & 8454 & 8458 \\
\hline
\end{tabular}

Tabela 33 - Análise de sensibilidade do parâmetro VMP - diferenças percentuais dos valores máximos

\begin{tabular}{ccrrrr}
\hline \hline \multirow{2}{*}{$\begin{array}{c}\text { Probabilidade } \\
\text { de Excedência }\end{array}$} & $\begin{array}{c}\text { Período } \\
\text { de }\end{array}$ & \multicolumn{4}{c}{ Variação dos Valores das Vazões Máximas } \\
\cline { 3 - 6 } & Retorno & $-20 \%$ & $-10 \%$ & $10 \%$ & $20 \%$ \\
\hline \hline 0,0001 & 10000 & 4 & 2 & 1 & 2 \\
0,0005 & 2000 & 3 & 1 & 1 & 2 \\
0,001 & 1000 & 2 & 1 & 1 & 2 \\
0,002 & 500 & 2 & 1 & 1 & 1 \\
0,005 & 200 & 2 & 1 & 1 & 1 \\
0,01 & 100 & 1 & 1 & 0 & 1 \\
0,02 & 50 & 1 & 0 & 0 & 1 \\
0,05 & 20 & 0 & 0 & 0 & 0 \\
0,1 & 10 & 0 & 0 & 0 & 0 \\
\hline \hline
\end{tabular}

\subsection{Análise Comparativa entre a Metodologia Estatística e o Método Conjugado}

Com o objetivo de desenvolver uma análise comparativa final entre a metodologia estatística, utilizada atualmente, e a conjugada, aplicada nesta dissertação, de forma a caracterizar a contribuição dessa dissertação para os projetos de engenharia de obras hidráulicas, optou-se por aplicar essas duas técnicas ao mesmo conjunto de dados. Esses dados referem-se à série de vazões máximas da UHE Sobradinho/BA. Foi utilizada a distribuição GEV (Valores Extremos Generalizados) para aplicação da metodologia estatística, como apresentada na seção 2.1.3; uma vez que a distribuição GEV foi utilizada no método conjugado poderá ter-se uma real vantagem do método conjugado em relação ao método estatístico.

Quando é escolhida a metodologia estatística, para dimensionamento de obras hidráulicas de maior vulto é, usualmente, recomendada a utilização de valores extremos 
das variáveis hidrológicas correspondentes ao período de retorno de 10.000 anos (“decamilenar"), ou seja, uma probabilidade de excedência anual de 0,0001. Esse critério é freqüentemente utilizado para a definição das vazões de projeto para dimensionamento dos vertedouros de barragens, tendo sido aplicado para diversos aproveitamentos do Sistema Hidroelétrico Brasileiro (ELETROBRÀS, 1996).

Assim, a análise comparativa entre os resultados da aplicação do método estatístico e conjugado concentrou-se no valor da vazão decamilenar da UHE Sobradinho/BA, cujos valores foram obtidos nos capítulos 2 e 4 . A tabela 34 apresenta, para cada uma das análises comuns de consistência desenvolvidas nos capítulos 2 e 4, as máximas diferenças percentuais entre as vazões decamilenares inferidas para cada um dos métodos de estimação dos parâmetros da distribuição GEV. Nota-se que para todas as análises o método conjugado apresenta as menores diferenças, caracterizando uma maior consistência do procedimento de cálculo.

Uma análise comparativa mais abrangente pode ser feita através das figuras 23, 24 e 25, onde são apresentadas as curvas de distribuições probabilísticas ajustadas para os métodos conjugado e estatístico (distribuição GEV), nas diferentes análises: influência da extensão das séries de vazões máximas, influência da presença de outlier na série e influência da variação dos menores valores na série de máximos.

Tabela 34 - Diferenças das Vazões decamilenares para a UHE de Sobradinho/BA

\begin{tabular}{|c|c|c|c|c|c|}
\hline \multirow{3}{*}{ ANÁLISES } & $\begin{array}{l}\text { Método } \\
\text { Conjugado }\end{array}$ & \multicolumn{4}{|c|}{ Método Estatístico } \\
\hline & \multicolumn{5}{|c|}{$\begin{array}{c}\text { Metodologia para Determinação dos Parâmetros das } \\
\text { Distribuições Probabilísticas }\end{array}$} \\
\hline & ML & ML & PWM & MOM & MOM-LH \\
\hline Influência da extensão das séries & 9 & 43 & 201 & 25 & 28 \\
\hline $\begin{array}{c}\text { Influência da presença do "outlier" } \\
\text { na série }\end{array}$ & 4 & 31 & 47 & 27 & 47 \\
\hline \multicolumn{6}{|l|}{$\begin{array}{c}\text { Influência dos valores mínimos na } \\
\text { série }\end{array}$} \\
\hline Minoração & 0,03 & 24 & 13 & 13 & 0 \\
\hline Majoração & 4 & 30 & 13 & 13 & 0 \\
\hline
\end{tabular}




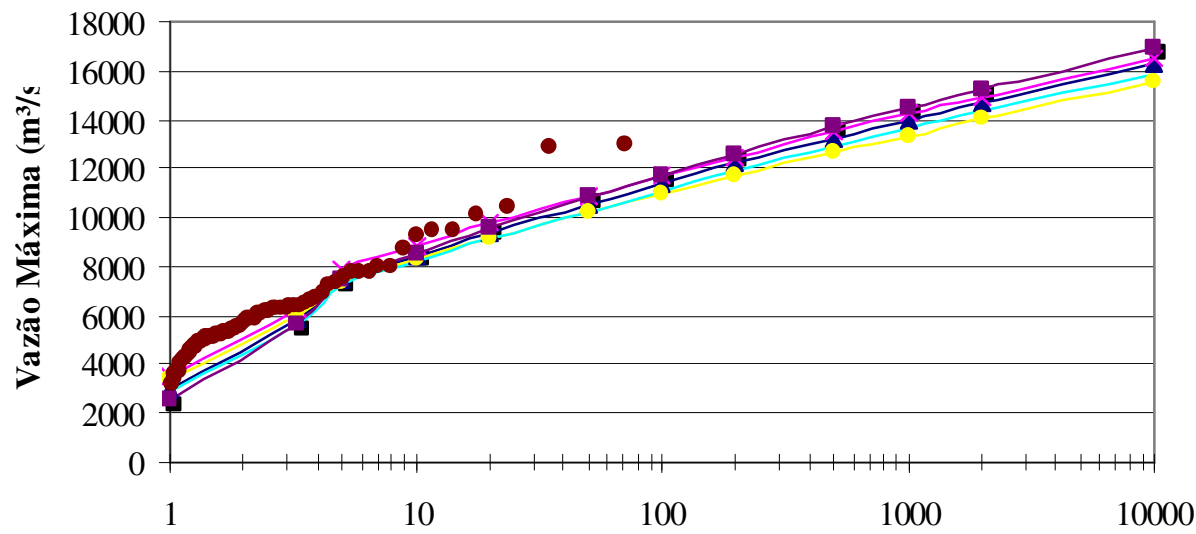

Período de Retorno (anos)

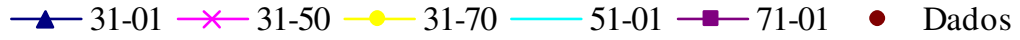
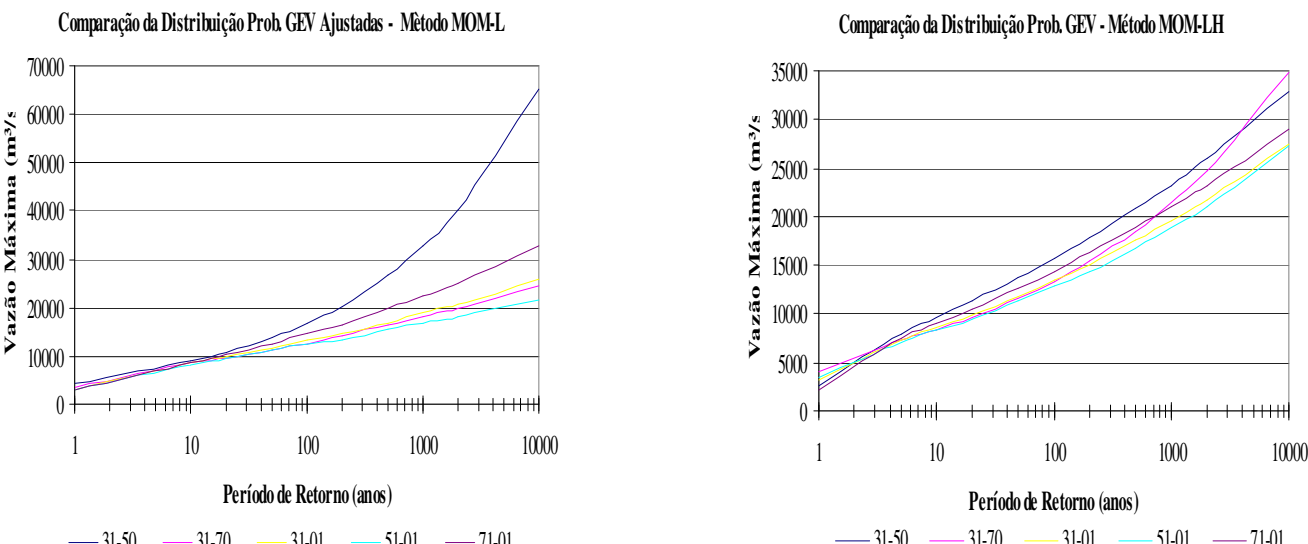

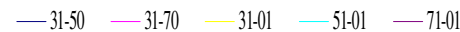

$-31-50-31-70 \quad 31-01-51-01-71-01$
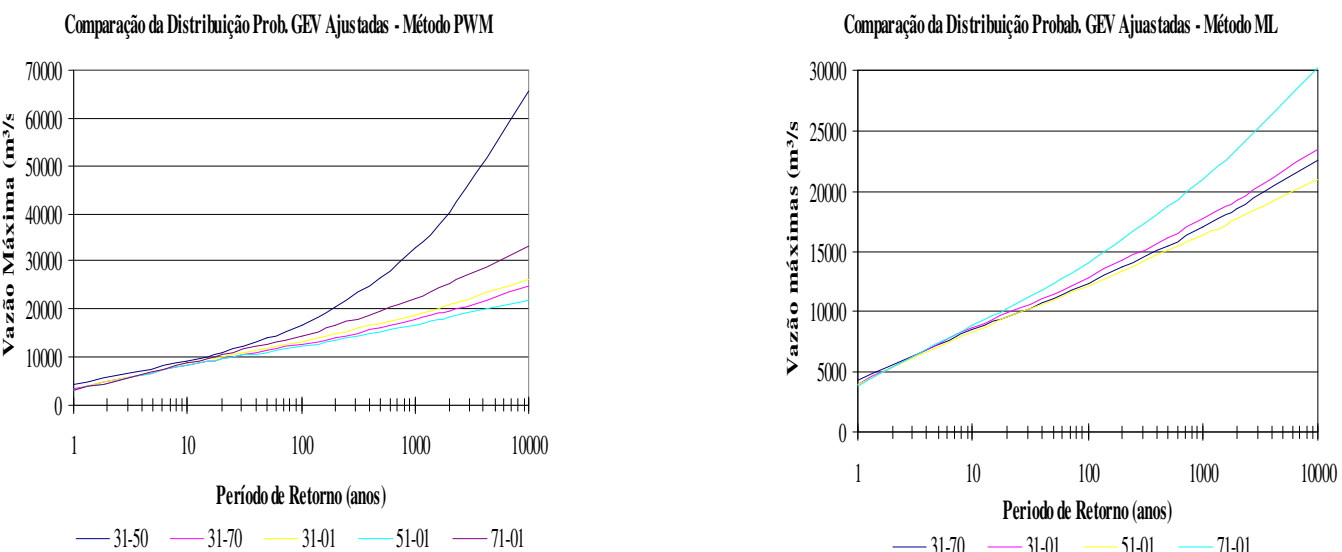

Figura 23 - Comparação entre os métodos estatístico e conjugado quanto a influência da extensão das séries 

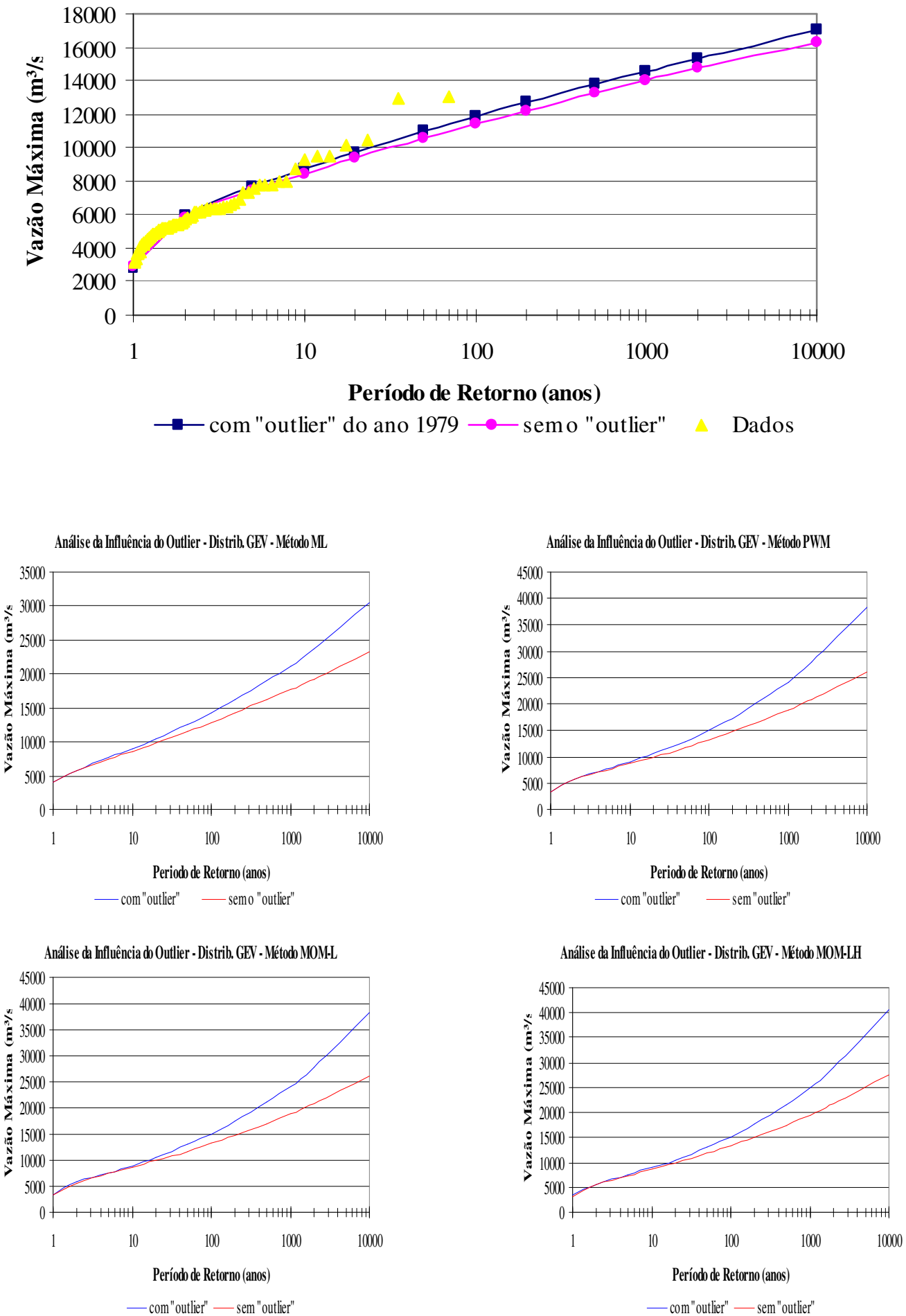

Figura 24 - Comparação entre os métodos estatístico e conjugado quanto a influência da presença do outlier 


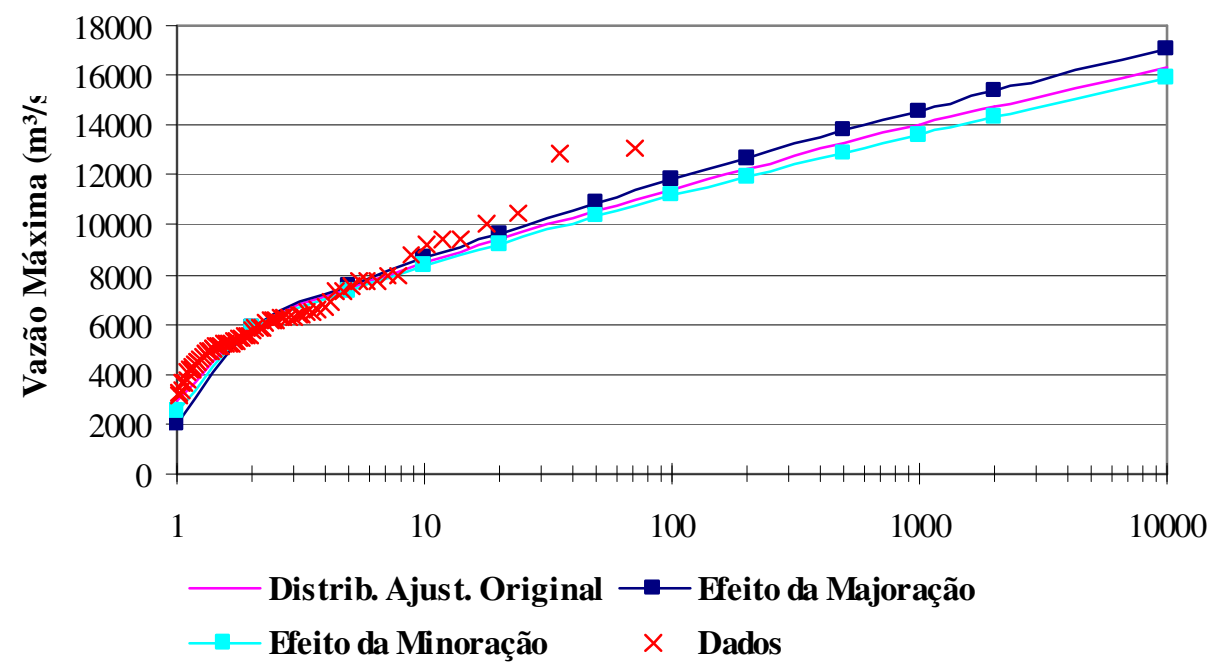

Análise da Influencia dos Menores Valores - Distrib. GEV - Método

ML

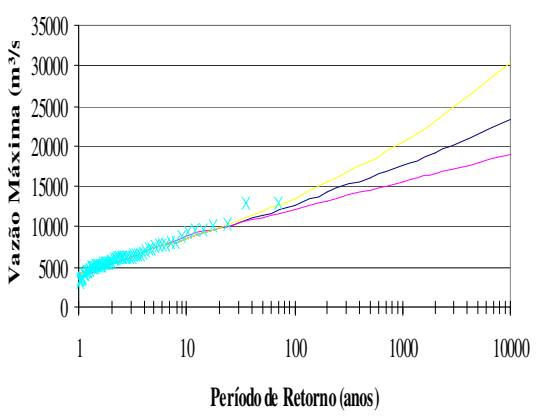

—Distib. Ajust. Original —Efeito da Minoração

Efeito da Majoração $\times$ Dados Originais

Análise da Influência dos Menores Valores - Distrib. GEV - Método MOM-L

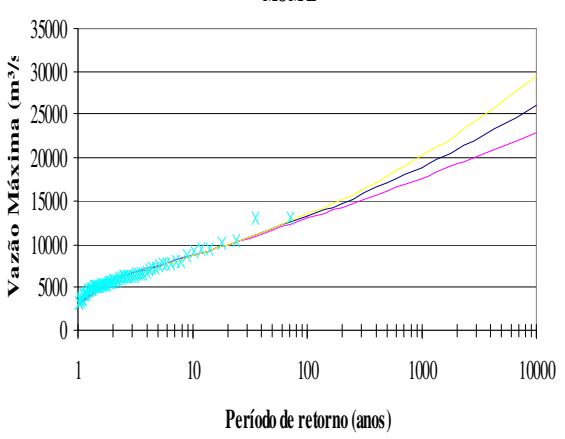

— Distib. Ajust. Original —Efeito da Minoração Efeito da Majoraçãa $\times$ Dados Originais
Análise dă Influência dos Menores Valores - Distrib. GEV - Método PWM

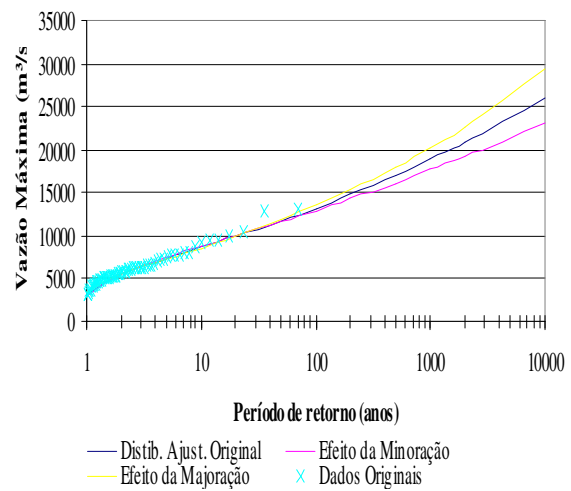

Análise da Influência dos Menores Valores - Distrib. GEV - Método MOM-LH

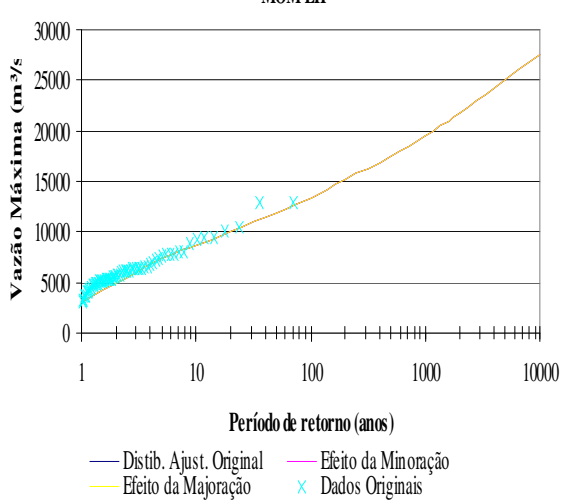

Figura 25 - Comparação entre os métodos estatístico e conjugado quanto a influência dos valores mínimos 
A comparação das diferenças entre as curvas das distribuições probabilísticas ajustadas permite constatar que as citadas influências são praticamente insignificantes para o método conjugado. Por sua vez, o oposto se observa para a metodologia estatística.

A aplicação de conceitos probabilísticos em série de dados hidrometeorológicos parte do princípio que foram atendidos os critérios estatísticos de aleatoriedade, independência, homogeneidade e estacionaridade.

Neste princípio é que reside um dos maiores paradoxos da aplicação do método estatístico aos dados hidrometeorológicos (Garcia, 1996 apud Klemes, 1989) ${ }^{9}$. Teoricamente, quanto maior a extensão da série de dados, maior a confiabilidade da estimativa do tipo da distribuição e seus parâmetros. No entanto, quanto maior a extensão da série hidrológica, menor fica a credibilidade em relação às hipóteses de estacionaridade e homogeneidade dos dados.

Esse paradoxo é minimizado no método conjugado, uma vez que, conforme mostrados neste trabalho, os valores extremos das variáveis hidrológicas não dependem significativamente da extensão da série hidrológica. Assim, quando existe dificuldade em garantir as hipóteses de estacionaridade e homogeneidade de uma série extensa de dados, pode-se optar por utilizar apenas uma parte dessa série nas quais esses critérios sejam atendidos sem prejuízo dos resultados a serem inferidos pelo método conjugado.

Garcia (1996) afirma que outro aspecto importante no método conjugado é que, conforme foi verificado nas tabelas 32, 33 e figura 22, as imprecisões do procedimento de cálculo do método determinístico na definição do VMP (PMP/EMP) não resultam em variações significativas dos valores extremos das variáveis hidrológicas, limitadas ao período de retorno de 10.000 anos. Não obstante, ressalta ele, que os progressos que forem sendo conseguidos no cálculo do VMP (PMP/EMP), através das pesquisas que estão sendo desenvolvidas e da maior precisão nas observações das variáveis hidrometeorológicas, resultarão na conseqüente melhora no método conjugado.

Quanto ao aspecto conceitual, o método conjugado tem a vantagem de transformar a extrapolação com limite infinito e forma convexa da curva de distribuição da metodologia estatística em uma interpolação com limite superior e forma assintótica, traduzindo, pelo menos, o que parece fisicamente intuitivo.

\footnotetext{
${ }^{9}$ KLEMES, V. (1989), The improbable Probabilities of Extreme Floods and Droughts, In: Hydrology and Disasters (O. Starosolsky and O.M. Melder, editors), James \& James, London.
} 
Uma das maiores inseguranças na aplicação da metodologia estatística para determinação de valores extremos de variáveis hidrológicas relaciona-se com as séries curtas de observações, que não são raras de ocorrer. Essa é uma das importantes contribuições do método conjugado que, incluindo o limite superior (VMP) na curva da distribuição probabilística, permite uma maior segurança na determinação dos valores extremos através de interpolações, evitando as extrapolações do método estatístico através de curvas definidas com base em séries não suficientemente longas.

\subsection{Verificação da Segurança de uma Barragem}

\subsubsection{Introdução}

O objetivo de uma avaliação de segurança de barragem é determinar as condições relativas à segurança estrutural e operacional de uma barragem. A avaliação deve identificar os problemas e recomendar tanto os reparos corretivos, restrições operacionais e/ou modificações quanto as análise e os estudos para determinar as soluções para os problemas (ELETROBRÁS, 1987b).

Anjos e Almeida (1981) afirmam que durante uma conferencia realizada no Centro de Pesquisas Hidráulicas da universidade de São Paulo, em julho de 1978, o professor Ven Te Chow apresentou o resultado de um levantamento de acidentes ocorridos em 1600 barragens, indicando que o mau dimensionamento do vertedor teria sido responsável por $23 \%$ dos problemas. Este número subia a $35 \%$, considerando-se apenas as 300 maiores barragens acidentadas. Este alerta e o resultado da análise de projetos hidrelétricos brasileiros, realizada normalmente pela ELETROBRAS, indicaram a necessidade de se proceder a um levantamento, periódico, dos critérios empregados na determinação das cheias de projetos de vertedores das barragens em operação ou em construção no país.

A ELETROBRÁS (1987b) afirma que a capacidade do vertedouro pode não estar adequada para manejar, em condições de segurança, as cheias afluentes prováveis. A cheia de projeto, determinada por cálculos atualizados, poderá ser muito maior do que a empregada no projeto original, devido aos métodos aperfeiçoados de hidrologia da cheia e á disponibilidade dos registros de cheias abrangendo períodos mais longos. 
Portanto, o vertedouro existente pode não estar apropriado para escoar com segurança a cheia atualmente prevista, resultando no galgamento da barragem e possivelmente ocasionando sua falha. Em alguns casos, as obras de restituição são usadas para auxiliar o vertedouro ou, até mesmo, podem ficar dependentes para operarem sozinhas na propagação e/ou no amortecimento da cheia de projeto. Caso a cheia prevista tenha aumentado, as obras de restituição podem estar subdimensionadas e incapazes de cumprir as funções para as quais foram projetadas. Um vertedouro ou obras de restituição subdimensionadas podem exigir a operação limitada do reservatório ou uma modificação da estrutura. A ultima estimativa de IDF - Cheia Afluente de Projeto (Inflow Design Flood) deve ser revista, a fim de comprovar se ainda é válida e se está baseada em critérios correntes.

Desta forma, verifica-se que os estudos hidrológicos para determinação de valores máximos de projeto servem a dois aspectos fundamentais:

- Como um elemento de projeto imprescindível à tomada de decisão no dimensionamento dos extravasores dos reservatórios e na definição da cota da crista das barragens;

- Como uma ferramenta para simular as condições mais adversas da realidade, isto é, as condições limites suscetíveis de virem a ocorrer.

Constatam-se uma significativa relação de ambos os aspectos. Entretanto, existe uma importante diferença, uma vez que o decisor pode aceitar a realidade de um evento, mas desprezá-la quanto à sua relevância ou significância para a tomada de decisão. Neste caso, há de elegerem-se critérios que permitam ao decisor definir as dimensões a adotar. Não raramente, o decisor tem dificuldades em eleger os critérios ou até definir a metodologia a ser adotada para apoiar a sua decisão.

A proposta deste estudo é ampliar as possibilidades do decisor na suas decisões e, também, verificar de forma quantitativa os resultados apresentados pelo método conjugado. 


\subsubsection{Descrição do projeto da UHE Caconde}

A usina Hidrelétrica de Caconde, também denominada Graminha, está localizada no rio Pardo, no município de Caconde, estado de São Paulo. Esta usina hidrelétrica da CESP, cuja operação teve inicio em 1962, tem 69,6 MW de potência nominal e é parte do Sistema Interligado Sul/Sudeste/Centro-Oeste. Sendo uma usina de Cabeceira, tem objetivos de geração de energia e de controle de cheias.

O reservatório da UHE Caconde tem uma capacidade de regularização de 36 $\mathrm{m}^{3} / \mathrm{s}$ e sua bacia hidrográfica tem uma área de drenagem de $2.566 \mathrm{~km}^{2}$. O órgão principal de descarga era constituído, originalmente, por um vertedouro tipo Tulipa, com capacidade de 700 m³/s (Garcia, 1996 apud Oliveira Filho, 1993).

Esta usina tem a jusante as UHE`s de Euclides da Cunha e Armando Sales de Oliveira, que sofreram um acidente em janeiro de 1977. Este acidente resultou na reavaliação dos estudos hidrológicos, no projeto e na construção do vertedor suplementar de comportas da UHE Caconde. Essa reavaliação hidrológica, desenvolvida em 1977, consistiu na aplicação dos métodos estatístico e determinístico.

Na aplicação do método estatístico foi ajustada uma distribuição Log-Normal, resultando uma vazão de pico decamilenar de $1270 \mathrm{~m}^{3} / \mathrm{s}$. Através do método determinístico foi avaliada a Vazão Máxima Provável (VMP), que resultou em 3082 m³/s (vazão de pico). Segundo Garcia (1996) apud Oliveira Filho (1993) ${ }^{10}$ com base em dados técnicos e na avaliação das incertezas inerente aos processos, a CESP concluiu pela adequação do vertedouro para a vazão de pico de $2.500 \mathrm{~m} 3 / \mathrm{s}$, correspondente a $80 \%$ da VMP.

\subsubsection{Análise da série de vazões máximas anuais}

O relatório da THEMAG (GARCIA, 1996 apud THEMAG, 1991) ${ }^{11}$ apresenta a série de vazões médias diárias máximas anuais no período entre os anos hidrológicos de 1938 e 1989. Segundo este relatório, o fator multiplicativo "vazão de ponta/vazão média

\footnotetext{
10 OLIVEIRA FILHO, J.E. (1993), Vertedor Suplementar de Caconde, Aumento da Capacidade de Descarga, Hidrologia e Hidráulica, XII Seminário Nacional de Produção e Transmissão de Energia Elétrica, Recife.

11 THEMAG ENGENHARIA LTDA (1991), Revisão das Equações de Regionalização de Cheias e Verificação da Cheia de Projeto de Caconde, para CESP, relatório n. 3055-02-001-RT-4-04-01-0299-0 Revisão 0A.
} 
diária" foi definida em 1,60. Aplicando-se este fator a série de vazões médias diárias máximas anuais, resultou a série de vazões máximas anuais apresentadas na tabela 35 . A tabela 36 apresenta os principais parâmetros estatísticos, que revela, uma distribuição dos valores próxima a normal.

A aplicação do teste de Grubbs e Beck (GRUBBS e BECK, 1972) na série de vazões com 52 elementos determinou um coeficiente estatístico $K_{N}=2,7750$, para um nível de significância de $10 \%$, que resultou nos limites superior $X_{H}=1316 \mathrm{~m}^{3} / \mathrm{s}$ e inferior $\mathrm{X}_{\mathrm{L}}=122 \mathrm{~m} / \mathrm{s}$. Uma vez que os valores de vazões máximas da série estão dentro destes limites, conclui-se que não existem "outliers" na série.

A série de vazões foi submetida ao teste de Wald-Wolfowitz (RAO E HAMED, 2000) para verificação da independência e estacionaridade dos valores. O valor do coeficiente estatístico deste teste resultou em $u=0,473$. Uma vez que este coeficiente não é significante ao nível de $\alpha=5 \%$, porque $|u|<\mathrm{u}_{\alpha / 2}=1,96$, a hipótese de independência da série de vazões é aceita.

Tabela 35 - Série de Vazões Instantâneas Máximas Anuais da Usina Hidrelétrica de Caconde/SP.

\begin{tabular}{cccccccc}
\hline \hline Ano & $\begin{array}{l}\text { Vazão } \\
\left(\mathrm{m}^{3} / \mathrm{s}\right)\end{array}$ & Ano & Vazão $\left(\mathrm{m}^{3} / \mathrm{s}\right)$ & Ano & $\begin{array}{l}\text { Vazão } \\
\left(\mathrm{m}^{3} / \mathrm{s}\right)\end{array}$ & Ano & $\begin{array}{c}\text { Vazão } \\
\left(\mathrm{m}^{3} / \mathrm{s}\right)\end{array}$ \\
\hline \hline 1938 & 378 & 1951 & 330 & 1964 & 334 & 1977 & 499 \\
1939 & 538 & 1952 & 448 & 1965 & 523 & 1978 & 290 \\
1940 & 397 & 1953 & 238 & 1966 & 640 & 1979 & 229 \\
1941 & 176 & 1954 & 456 & 1967 & 826 & 1980 & 414 \\
1942 & 325 & 1955 & 163 & 1968 & 288 & 1981 & 726 \\
1943 & 443 & 1956 & 464 & 1969 & 154 & 1982 & 402 \\
1944 & 211 & 1957 & 443 & 1970 & 854 & 1983 & 733 \\
1945 & 523 & 1958 & 501 & 1971 & 173 & 1984 & 728 \\
1946 & 720 & 1959 & 443 & 1972 & 320 & 1985 & 427 \\
1947 & 635 & 1960 & 566 & 1973 & 274 & 1986 & 209 \\
1948 & 485 & 1961 & 594 & 1974 & 362 & 1987 & 598 \\
1949 & 456 & 1962 & 406 & 1975 & 256 & 1988 & 262 \\
1950 & 470 & 1963 & 435 & 1976 & 346 & 1989 & 395 \\
\hline \hline
\end{tabular}

Fonte: Garcia, 1996 apud THEMAG, 1991

Tabela 36 - parâmetros estatísticos da série vazões instantâneas máximas anuais da UHE de Caconde/SP.

\begin{tabular}{lc}
\hline \hline Número de elementos & 52 \\
Máximo & 854 \\
Mínimo & 154 \\
Média & 433 \\
Desvio-padrão & 173 \\
Assimetria & 0,504 \\
Coeficiente de curtose & $-0,171$ \\
\hline \hline
\end{tabular}


Foi aplicado, também, o teste de Mann-Whitney (RAO E HAMED, 2000) para verificação das hipóteses de estacionaridade dos valores da série de vazões. Deve-se ressaltar que a série histórica de vazões é hibrida na sua origem, o que poderia comprometer a homogeneidade temporal. As vazões máximas para o período de 1938 a 1965 foram obtidas por correlação com o posto fluviométrico de São José do Rio Pardo. Já as vazões máximas para o período de 1966 a 1989 foram inferidas por balanço hídrico no reservatório da UHE Caconde. Assim, o referido teste foi aplicado subdividindo-se a série nestes dois períodos, resultando em um coeficiente estatístico u $=-0,61$. Uma vez que $|u|<\mathrm{u}_{\alpha / 2}=1,96$, a hipótese de homogeneidade é aceita para $\mathrm{o}$ nível de significância de $5 \%$.

Portanto, conclui-se que a série de vazões máximas pode ser considerada consistente, significativa e representativa.

\subsubsection{Verificação da vazão de projeto utilizando a metodologia estatística e o método conjugado}

A verificação da vazão de projeto será feita utilizando a série de vazões instantâneas máximas anuais apresentadas na tabela 35. A série será subdividida em 3 novas séries, respeitando a seqüência cronológica de ocorrência. Com o objetivo de ter em mente a responsabilidade dos estudos de definição das vazões de projeto, imagine que esta obra poderia ter sido construída ao término dos estudos hidrológicos em 1959, 1977 e 1989.

A primeira sub-série (1938-1959) foi escolhida considerando o fato de que esta série era a disponível na definição da vazão de projeto no início da construção da UHE de Caconde (REVISTA CONSTRUÇÃO PESADA, 1975). A segunda sub-série (19381977) foi escolhida devido a esta série ter sido utilizada na reavaliação hidrológica, desenvolvida em 1977, devido aos acidentes sofridos por usinas a jusante da barragem. E a terceira sub-série (1938-1989) é a série completa disponível no momento.

Em ambas as séries foram aplicados as metodologias estatística e conjugada. $\mathrm{Na}$ utilização da metodologia estatística foram testadas quinze distribuições. Estas distribuições foram verificadas utilizando os testes qui-quadrado e KolmogorovSmirnov (K-S). Foram analisadas as seguintes distribuições: normal (N), log-normal 2 
parâmetros (LN2), log-normal 3 parâmetros (LN3), gama (GAM), Pearson tipo III (PIII), log-Pearson tipo III (LP-III), Gumbel (EV1), Weibull (WEIB), logística (LOG), GEV, wakeby 4 parâmetros (WK4), wakeby 5 parâmetros (WK5), pareto generalizado (GPAR) e logística generalizado (GLOG).

As distribuições foram ajustadas à série de vazões máximas, cuja posição de plotagem foi definida pela fórmula de Weibull. A estimativa dos parâmetros das diferentes distribuições foi feita pelo método da máxima verossimilhança (ML), método dos momentos e método dos momentos com pesos probabilísticos.

Na aplicação do Método Conjugado foi utilizado a forma definida por Garcia (1996) que utilizou a distribuição GEV tipo III. As diferentes séries de vazões máximas foram ordenadas e a sua posição de plotagem foi definida pela fórmula de Weibull. Os parâmetros foram estimados através do método dos momentos, da máxima verossimilhança (ML), e dos mínimos quadrados. O valor da Enchente Máxima Provável (EMP) foi o definido no relatório de reavaliação hidrológica feita em 1977, que resultou num valor de $3.082 \mathrm{~m} / \mathrm{s}$.

A partir da aplicação da metodologia estatística, apresenta-se na figura 26 a 28 para cada método de estimação dos parâmetros, as curvas das distribuições probabilísticas ajustadas para as diferentes séries. As tabelas 37 a 39 apresentam para cada método de estimação dos parâmetros, as vazões máximas decamilenares, inferidas a partir das distribuições probabilísticas ajustadas a cada uma das séries de vazões. Estas tabelas apresentam uma coluna com o valor da vazão de projeto utilizado pelos projetistas no período correspondente a cada série. A diferença percentual máxima (D\%) entre o valor inferido, utilizando diversas distribuições e estimadores, e o valor estabelecido de projeto, é apresentada como forma de comparação para análise de subdimensionamento ou superdimensionamento do projeto.

A análise das citadas tabelas e figuras permitem verificar que, para a primeira série correspondente ao período de 1938 a 1959 houve um subdimensionamento do valor de projeto, uma vez que, para toda gama de distribuições ajustadas o valor da vazão decamilenar (valor recomendado para o tipo de obra) foi maior que o valor estabelecido pelos projetistas $\left(700 \mathrm{~m}^{3} / \mathrm{s}\right)$. As circunstâncias de como se procedeu ao cálculo da vazão de projeto não é conhecida, mas podem-se inferir algumas hipóteses.

A primeira hipótese é que o valor da vazão de projeto pode não ter sido submetida a uma análise probabilística visto que as distribuições clássicas utilizadas na 
época foram ajustadas a essa série e constatou-se nos resultados que o valor da vazão de projeto foi para um período de recorrência menor que 10000 anos.

Uma outra hipótese é que, caso tenha sido feita a análise probabilística na determinação do valor de projeto, a série utilizada neste exemplo pode ter sido diferente da série utilizada pelos hidrólogos da época, ou seja, a série utilizada para se definir o valor de $700 \mathrm{~m} 3 / \mathrm{s}$ estaria apontando valores menores que o disponível atualmente. Esta última hipótese, talvez, seja a mais convincente, pois o valor da vazão do ano 1946 da série atual foi de $720 \mathrm{~m} / \mathrm{s}$, um valor maior que o projetado na época. Isto comprovaria a evidência que os hidrólogos da época não dispunham de uma série representativa como a que se tem atualmente.

Diante dos resultados e do que foi comentado acima, nota-se que a forte dependência que a metodologia estatística tem com relação à extensão da série, aliado a dificuldade em determinar qual a distribuição escolher gera uma grande insegurança na aplicação dos resultados a valores de projeto. Só para evidenciar esta conclusão, observa-se que a utilização de distribuições recomendadas atualmente, como a GEV e a log-Pearson III, levaria ao hidrólogo a utilizar valores de projeto (Por Ex. 786 e 747 $\mathrm{m}^{3} / \mathrm{s}$ pelo MOM, respectivamente) menores que os valores observados na série completa (1938 a 1989) como por exemplo a vazão do ano 1967 que foi de 826 m³/s. Além disso, a consideração da hipótese de que o valor estabelecido na época de $700 \mathrm{~m}^{3} / \mathrm{s}$ tenha sido obtido através da análise probabilística, comprovaria a insegurança e o risco em se utilizar a metodologia estatística.

Analisando agora os resultados inferidos pelas distribuições probabilísticas ajustadas a série de 1938 a 1977, observa-se que todos os valores foram inferiores ao valor estabelecido pelos hidrólogos para cheia de projeto. As diferenças chegaram a ser na maioria dos casos superior a $100 \%$, comprovando o conservadorismo adotado pelos hidrólogos em definir a vazão de projeto $(2.500 \mathrm{~m} 3 / \mathrm{s})$ como $80 \%$ da enchente máxima provável calculada na época $\left(3.082 \mathrm{~m}^{3} / \mathrm{s}\right)$. Acredito que a utilização desse valor tão alto deveu-se aos acidentes ocorridos na época em UHE's próximas a usina de Caconde o que gerou uma expectativa numa possível tendência de crescimento ascensional da série que poderia resultar em valores maiores que o valor estabelecido utilizando o método estatístico ajustado na época (Log-Normal - $1.270 \mathrm{~m}^{3} / \mathrm{s}$ ).

Observa-se que a hipótese conservadora de crescimento ascensional da série estava errada, pois analisando os resultados inferidos pelas distribuições ajustadas a série disponível atualmente, correspondente ao período de 1938 a 1989, observa-se que 
a diferença percentual entre os valores inferidos e os valores estabelecidos pelos hidrólogos manteve-se a mesma tendência, resultando diferenças na maioria dos casos de mais de $100 \%$ nos valores de projeto. Este exemplo, demonstra que a utilização de uma metodologia que não se fundamenta em algum tipo de análise de risco, como é a metodologia determinística, pode ocasionar em valores muito superiores aos valores realmente prováveis de ocorrer. Isto ocasiona, por conseqüiência, um superdimensionamento da obra na qual implica num aumento de custos tornando a usina bastante onerosa.

Agora, a partir da aplicação do método conjugado, apresenta-se na figuras 29 para cada método de estimação dos parâmetros as curvas de distribuição probabilística do método conjugado ajustadas para as diferentes séries. A tabela 40 apresenta para cada método de estimação dos parâmetros as vazões máximas decamilenares, inferidas a partir das distribuições probabilísticas ajustadas a cada uma das séries de vazões. Esta tabela apresenta as mesmas colunas utilizadas na utilização da metodologia estatística.

A análise da citada tabela permite verificar que, para a primeira série correspondente ao período de 1938 a 1955, os valores foram bem superiores aos valores de projetos calculados pelos hidrólogos da época, onde se comprova o subdimensionamento do valor de projeto utilizado na construção da usina. Observa-se que a utilização da cheia de projeto definido método conjugado, por qualquer método de estimativa dos parâmetros, no início da obra, resultaria num vertedor seguro e com a sua respectiva probabilidade de ocorrência, uma vez que na análise da série atual (1938 a 1989) o maior valor observado foi de $854 \mathrm{~m}^{3} / \mathrm{s}$ que é um valor $28 \%$ menor que o menor valor determinado pelo método conjugado, utilizando a série de 1938 a 1955, que foi de $1190 \mathrm{~m}$ 3/s ajustado pelo método dos momentos.

Além disso, a diferença percentual máxima entre os valores inferidos pelo método conjugado, para cada método de estimação de parâmetros, ajustados para as três séries (1938-1955, 1938-1977 e 1938-1989) não passou de $16 \%$ para o método dos momentos, $6 \%$ para o método da máxima verossimilhança e $9 \%$ para o método dos mínimos quadrados. Portanto, confirma a segurança e a aplicabilidade do método conjugado na determinação de valores máximos de projeto (cheias de projeto).

A conclusão é que as metodologias atuais (metodologia estatística e metodologia determinística) para determinação de valores máximos de projeto podem subdimensionar ou superdimensionar as obras hidráulicas, principalmente as que se referem às barragens e que, embora o método conjugado permita uma melhora signifi- 
Tabela 37 - Vazão decamilenar $\left(T_{R}=10.000\right.$ ANOS $)$ ajustada pelo método MOM

\begin{tabular}{cccccccccc}
\hline \hline DIST. & & $1938-1959$ & & \multicolumn{3}{c}{$1938-1977$} & \multicolumn{3}{c}{$1938-1989$} \\
AJUST. & V.A.S & V.A.P. & DIF. $(\%)^{3}$ & V.A.S & V.A.P. & DIF.(\%) & V.A.S & V.A.P. & DIF.(\%) \\
\hline \hline GEV & 786 & 700 & 12 & 1173 & 2500 & 113 & 1191 & 2500 & 110 \\
P-III & 891 & 700 & 27 & 1245 & 2500 & 101 & 1270 & 2500 & 97 \\
LN3 & NC $^{4}$ & 700 & NC & 1267 & 2500 & 97 & 1291 & 2500 & 94 \\
GLOG & 1071 & 700 & 53 & 1534 & 2500 & 63 & 1565 & 2500 & 60 \\
EV1 & 1352 & 700 & 93 & 1555 & 2500 & 61 & 1599 & 2500 & 56 \\
GPAR & 634 & 700 & 10 & 878 & 2500 & 185 & 890 & 2500 & 181 \\
WEIB & 862 & 700 & 23 & 1166 & 2500 & 114 & 1189 & 2500 & 110 \\
N & 935 & 700 & 34 & 1050 & 2500 & 138 & 1077 & 2500 & 132 \\
EXP & $\mathrm{R}^{5}$ & 700 & $\mathrm{R}$ & 1802 & 2500 & 39 & 1855 & 2500 & 35 \\
LOG & 1123 & 700 & 60 & 1278 & 2500 & 96 & 1312 & 2500 & 90 \\
LN2 & 1317 & 700 & 88 & 1623 & 2500 & 54 & 1685 & 2500 & 48 \\
GAM & 1138 & 700 & 63 & 1343 & 2500 & 86 & 1386 & 2500 & 80 \\
LP-III & 747 & 700 & 7 & 1141 & 2500 & 119 & 1148 & 2500 & 118 \\
WK4 & - & 700 & - & - & 2500 & - & - & 2500 & - \\
WK5 & - & 700 & - & - & 2500 & - & - & 2500 & - \\
\hline \hline
\end{tabular}

${ }^{1}$ V.A.S - VAZÃO AJUSTADA COM A SÉRIE DISPONIVEL

${ }^{2}$ V.A.P - VAZÃO ADMITIDA NO PROJETO

${ }^{3}$ DIF (\%) - DIFERENÇA PERCENTUAL MÁXIMA ENTRE AS VAZÕES CONSIDERADAS

NC - NÃO HOUVE CONVERGENCIA NOS PARAMETROS

R - VALOR REJEITADO NOS TESTES QUI -QUADRADO E KOLMOGORV-SMIRNOV
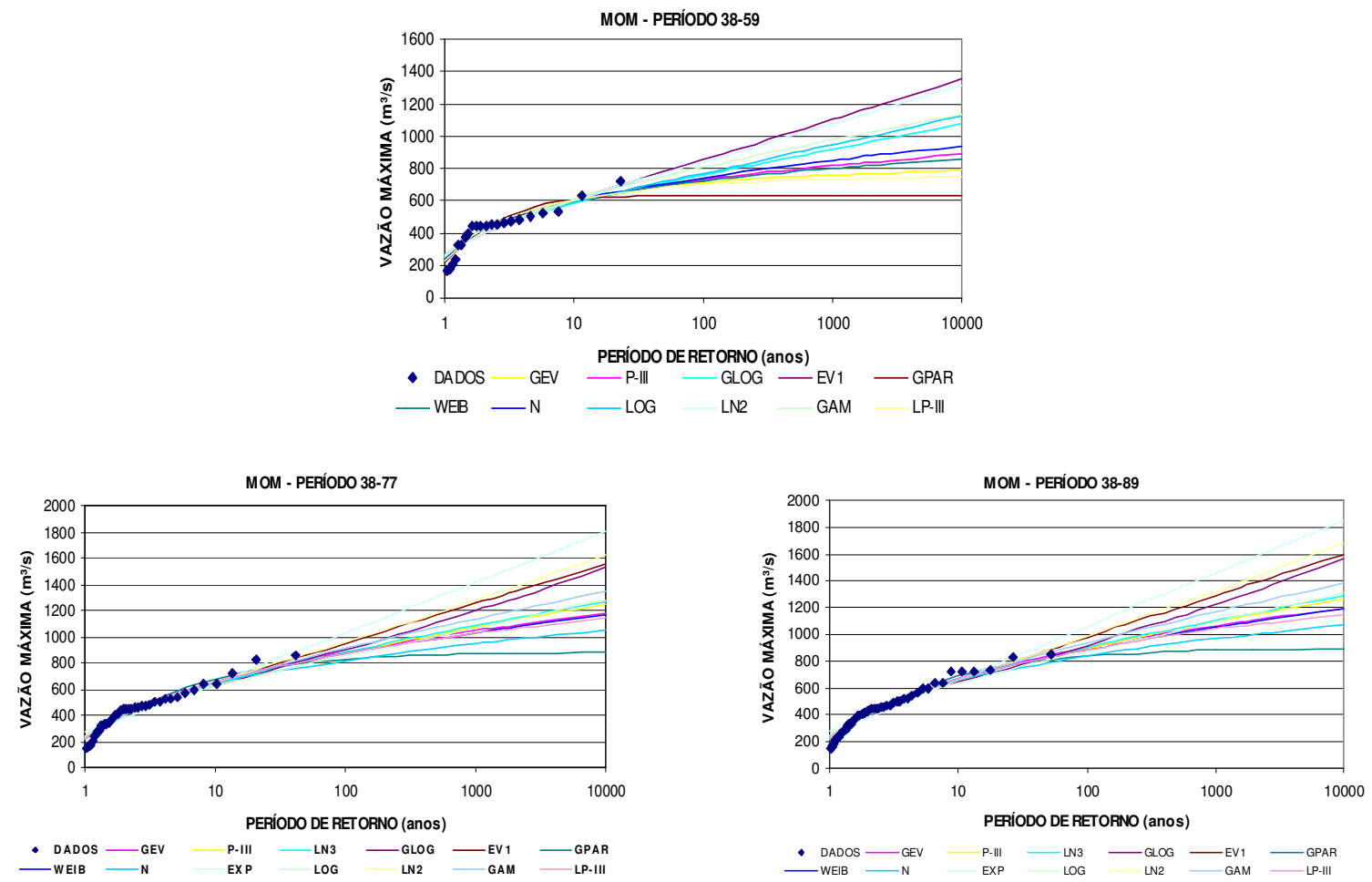

Figura 26 - Método estatístico - Comparação das distribuições ajustadas pelo método MOM 
Tabela 38 - Vazão decamilenar $\left(T_{R}=10.000\right.$ ANOS $)$ ajustada pelo método ML

\begin{tabular}{cccccccccc}
\hline \hline DIST. & \multicolumn{3}{c}{$1938-1959$} & & & $1938-1977$ & & & $1938-1989$ \\
AJUST. & V.A.S & V.A.P. $^{2}$ & DIF. $(\%)^{3}$ & V.A.S & V.A.P. & DIF. $\%$ ) & V.A.S & V.A.P. & DIF.(\%) \\
\hline \hline GEV & 805 & 700 & 15 & 1150 & 2500 & 117 & 1219 & 2500 & 105 \\
P-III & NC & 700 & NC & 1290 & 2500 & 94 & 1429 & 2500 & 75 \\
LN3 & 923 & 700 & 32 & 1300 & 2500 & 92 & 1438 & 2500 & 74 \\
GLOG & 957 & 700 & 37 & 1821 & 2500 & 37 & 2369 & 2500 & 6 \\
EV1 & 1589 & 700 & 127 & 1670 & 2500 & 50 & 1690 & 2500 & 48 \\
GPAR & NC & 700 & NC & 890 & 2500 & 181 & 877 & 2500 & 185 \\
WEIB & NC & 700 & NC & 1206 & 2500 & 107 & NC & 2500 & NC \\
N & 935 & 700 & 34 & 1050 & 2500 & 138 & 1077 & 2500 & 132 \\
EXP & R & 700 & $\mathrm{R}$ & $\mathrm{R}$ & 2500 & $\mathrm{R}$ & $\mathrm{R}$ & 2500 & $\mathrm{R}$ \\
LOG & 1120 & 700 & 60 & 1275 & 2500 & 96 & 1327 & 2500 & 88 \\
LN2 & 1618 & 700 & 131 & 1880 & 2500 & 33 & 1924 & 2500 & 30 \\
GAM & 1204 & 700 & 72 & 1365 & 2500 & 83 & 1401 & 2500 & 78 \\
LP-III & NC & 700 & NC & NC & 2500 & NC & NC & 2500 & NC \\
WK4 & - & 700 & - & - & 2500 & - & - & 2500 & - \\
WK5 & - & 700 & - & - & 2500 & - & - & 2500 & - \\
\hline \hline
\end{tabular}
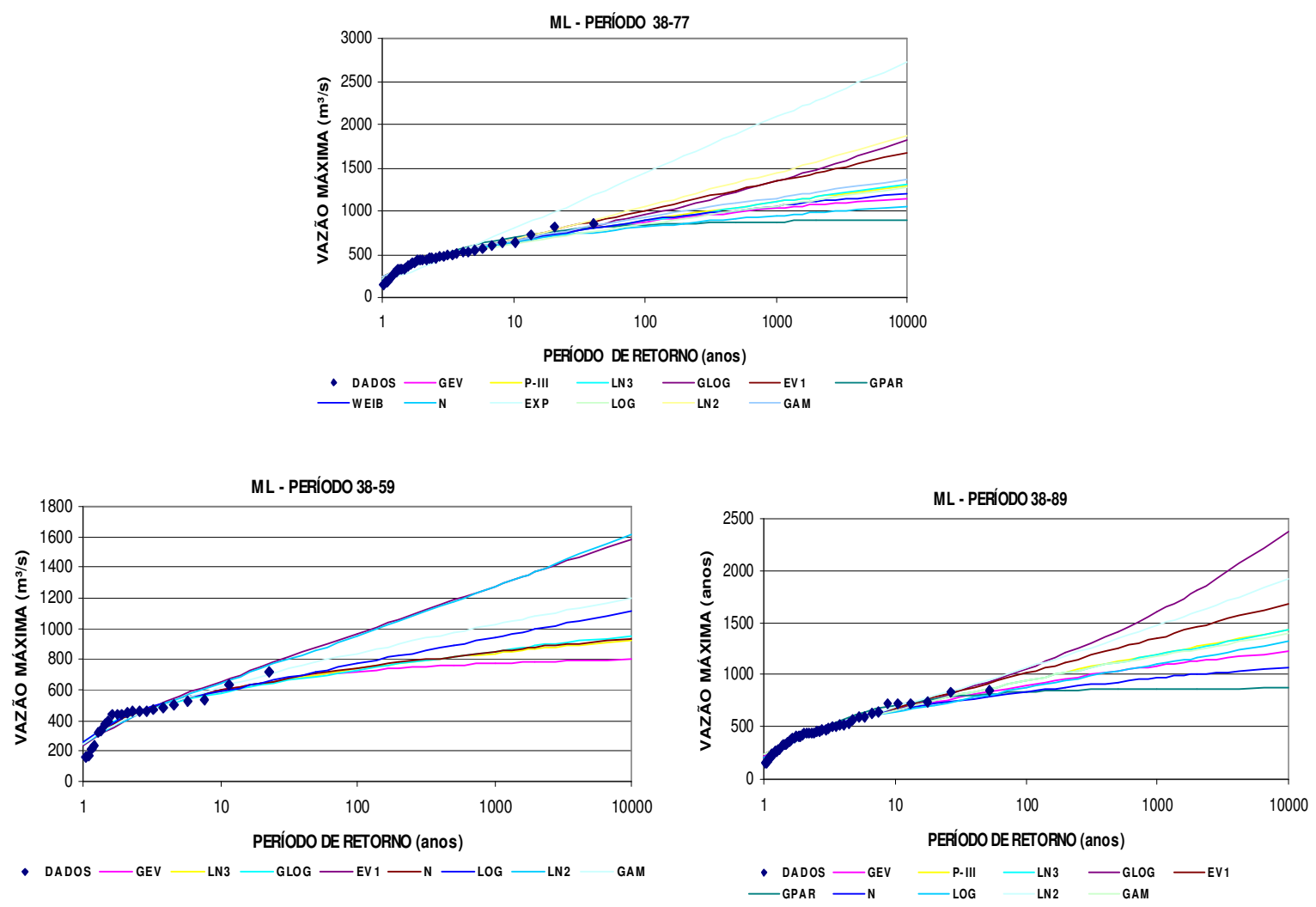

Figura 27 - Método estatístico - Comparação das distribuições ajustadas pelo método ML 
Tabela 39 - Vazão decamilenar $\left(T_{R}=10.000\right.$ ANOS) ajustada pelo método PWM

\begin{tabular}{cccccccccc}
\hline \hline DIST. & \multicolumn{3}{c}{$1938-1959$} & \multicolumn{3}{c}{$1938-1977$} & \multicolumn{3}{c}{$1938-1989$} \\
AJUST. & V.A.S & V.A.P. $^{2}$ & DIF.(\%) & V.A.S & V.A.P. & DIF.(\%) & V.A.S & V.A.P. & DIF.(\%) \\
\hline \hline GEV & 712 & 700 & 2 & 1117 & 2500 & 124 & 1251 & 2500 & 100 \\
P-III & 1080 & 700 & 54 & 1222 & 2500 & 105 & 1325 & 2500 & 89 \\
LN3 & NC & 700 & NC & 1243 & 2500 & 101 & 1368 & 2500 & 83 \\
GLOG & 929 & 700 & 33 & 1653 & 2500 & 51 & 1874 & 2500 & 33 \\
EV1 & 1381 & 700 & 97 & 1601 & 2500 & 56 & 1657 & 2500 & 51 \\
GPAR & $\mathrm{R}$ & 700 & $\mathrm{R}$ & 782 & 2500 & 220 & 837 & 2500 & 199 \\
WEIB & 805 & 700 & 15 & 1127 & 2500 & 122 & 1214 & 2500 & 106 \\
N & 929 & 700 & 33 & 1048 & 2500 & 138 & 1080 & 2500 & 131 \\
EXP & $\mathrm{R}$ & 700 & $\mathrm{R}$ & 1974 & 2500 & 27 & 2046 & 2500 & 22 \\
LOG & 1131 & 700 & 62 & 1295 & 2500 & 93 & 1338 & 2500 & 87 \\
LN2 & 1351 & 700 & 93 & 1722 & 2500 & 45 & 1816 & 2500 & 38 \\
GAM & 1139 & 700 & 63 & 1363 & 2500 & 83 & 1421 & 2500 & 76 \\
LP-III & 648 & 700 & 8 & 1007 & 2500 & 148 & 1202 & 2500 & 108 \\
WK4 & 1174 & 700 & 68 & 1049 & 2500 & 138 & 1015 & 2500 & 146 \\
WK5 & NC & 700 & NC & 2430 & 2500 & 3 & 1250 & 2500 & 100 \\
\hline \hline
\end{tabular}
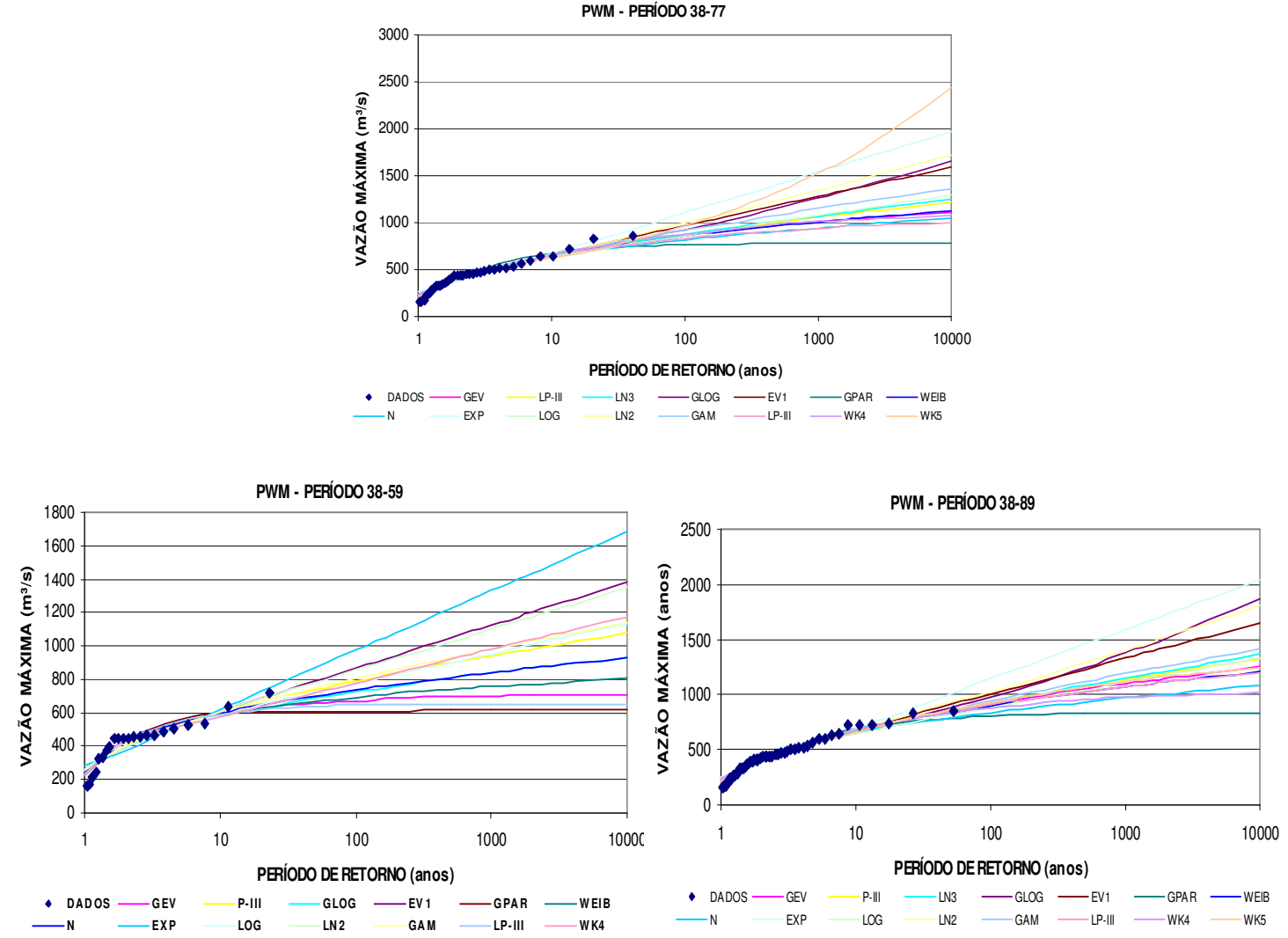

Figura 28 - Método estatístico - comparação das distribuições ajustadas pelo método PWM. 
Tabela 40 - Vazão decamilenar $\left(T_{R}=10.000\right.$ ANOS $)$ ajustada pelo método conjugado

\begin{tabular}{cccccccccc}
\hline \hline \multirow{2}{*}{ ESTIMADORES } & \multicolumn{3}{c}{$1938-1959$} & \multicolumn{3}{c}{$1938-1977$} & \multicolumn{3}{c}{$1938-1989$} \\
& V.A.S & V.A.P. & DIF(\%) & V.A.S & V.A.P. & DIF(\%) & V.A.S & V.A.P. & DIF(\%) \\
\hline \hline MOM & 1190 & 700 & 70 & 1347 & 2500 & 86 & 1381 & 2500 & 81 \\
ML & 1349 & 700 & 93 & 1409 & 2500 & 77 & 1426 & 2500 & 75 \\
MLS & 1352 & 700 & 93 & 1456 & 2500 & 72 & 1470 & 2500 & 70 \\
\hline \hline
\end{tabular}

MÉTODO CONJUGADO - MOM

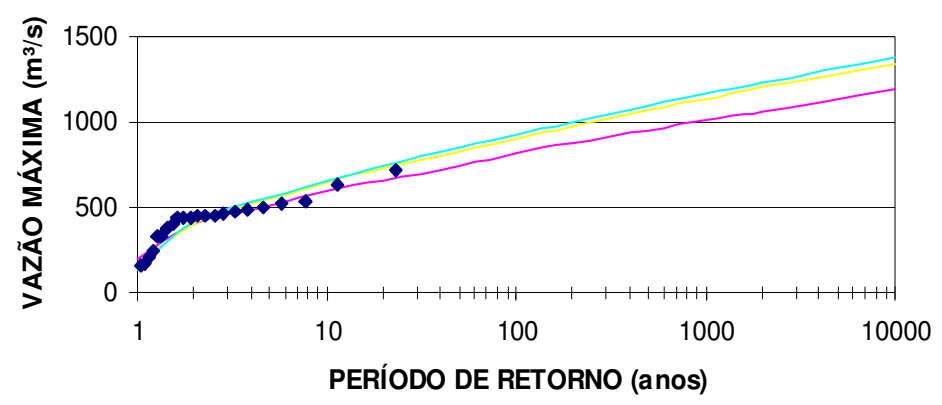

- DADOS $\longleftarrow 38-59 \longleftarrow 38-77 \longleftarrow 38-89$

MÉTODO CONJUGADO - ML

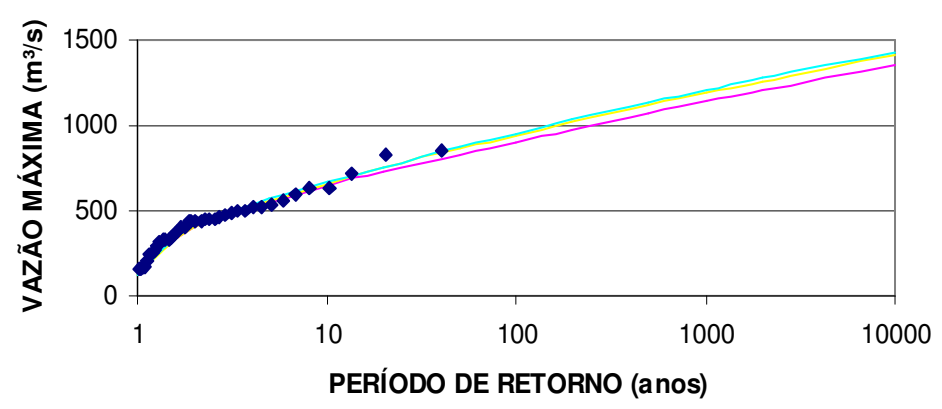

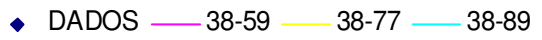

MÉTODO CONJUGADO - MLS

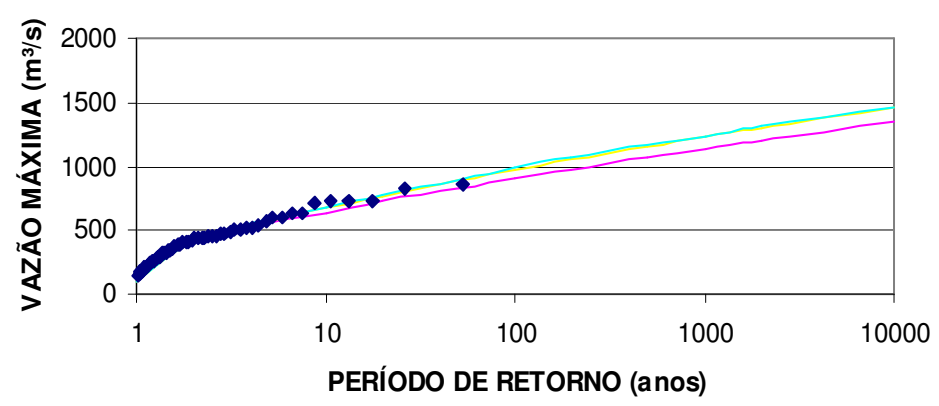

- DADOS $\longleftarrow 38-59-38-77-38-89$

Figura 29 - Método conjugado - curva da distribuição probabilística ajustadas para as diferentes séries utilizando o método MOM, ML e MLS 
cativa na estimativa dos valores extremos das variáveis hidrológicas, deve ser interpretado e utilizado com o necessário cuidado. Primeiramente, deve ser visto somente como uma forma de racionalizar uma decisão ao invés de se considerar uma verdade cientifica, uma vez que as incertezas estarão sempre presentes e de forma mais intensa nos fenômenos hidroclimáticos (como em outros fenômenos geofísicos) do que em outras áreas de ciência aplicada. A razão desta grande incerteza reside na dificuldade fundamental em aplicar conceitos probabilísticos, desenvolvidos com base em experimentos repetitivos, em processos geofísicos, não repetitivos, não estacionários e com séries de observações extremamente pequenas e na impossibilidade intrínseca de qualquer verificação prática das estimativas.

\subsection{Aplicação do Método Conjugado em Séries de Vazões Médias Diárias e Séries Vazões Máximas Instantâneas}

\subsubsection{Introdução}

Nos projetos de obras de controle de inundações como bueiros, condutos e vertedouros são necessários conhecer a vazão máxima instantânea de projeto, com risco definido.

No Brasil, os postos de hidrometria que permitem o conhecimento contínuo dos níveis dos rios em todas as condições de descarga são bastante escassos. Desta forma, a determinação da vazão máxima instantânea de projeto para locais que não possuem medições contínuas de descarga se faz por metodologias que se baseiam nas informações disponíveis.

Quando se dispõe de valores de vazões diárias, faz-se a utilização de coeficientes que permitem relacionar os valores medidos com o máximo ocorrido. Caso contrário, adotam-se metodologias de transposição ou regionalização de dados obtidos em outros locais. Estes processos geram incertezas muitas vezes significativas nos valores obtidos. Geralmente, os modelos utilizados foram desenvolvidos para condições físicas, climáticas e hidrológicas particulares que nem sempre equivalem às condições regionais em estudo. Devido à importância destas condições no processo de formação das cheias, a aplicação destes modelos pode gerar valores inadequados (SILVA E TUCCI, 1997). 
Tucci (In: TUCCI (1993)) afirma que a diferença entre o máximo instantâneo e o máximo diário depende do tempo de concentração da bacia, ou seja, do tempo de resposta. Para bacias pequenas, o tempo de concentração é reduzido com grande gradiente de vazão e variância. Á medida que a bacia aumenta, o gradiente fica reduzido e a diferença entre a vazão máxima instantânea $\left(Q_{m x}\right)$ e vazão máxima diária $\left(Q_{m d}\right)$ diminui. Outros fatores com a declividade e comprimento do rio, densidade de drenagem, intensidade e distribuição da precipitação influenciam na relação citada.

Sangal (1983) analisou 387 postos fluviográficos do Canadá com áreas de drenagem de até $100.000 \mathrm{~km}^{2}$. Nestes, foram selecionados 3946 hidrogramas registrados até 1979. As variáveis utilizadas no método são as vazões médias diárias de três dias consecutivos, com o valor máximo ocupando a posição central.

De acordo com o estudo, a razão entre o pico e a máxima média diária depende do tempo de base do hidrograma, da sua forma e do tempo de pico. Portanto, conhecendo-se o instante de ocorrência do pico e a forma do hidrograma, é possível verificar o comportamento da variação da razão entre os valores.

Foram considerados três dias para a definição do hidrograma, obtendo-se a equação básica que pode ser utilizada para prever a vazão máxima instantânea de acordo com os dados utilizados:

$$
Q_{m x}=\left(4 Q_{2}-Q_{1}-Q_{3}\right) / 2
$$

em que $\mathrm{Q}_{\mathrm{mx}}$ é a vazão máxima instantânea predita; $\mathrm{Q}_{2}$, vazão máxima média diária correspondente ao dia de ocorrência do pico; $\mathrm{Q}_{1}$, vazão máxima média diária antecedente a $\mathrm{Q}_{2} ; \mathrm{Q}_{3}$, vazão média diária posterior ao pico.

Tucci (In: TUCCI, 1993b apud FULLER (1914)) ${ }^{12}$ estabeleceu a relação entre $\mathrm{Q}_{\mathrm{mx}}$ e $\mathrm{Q}_{\mathrm{md}}$, onde $\mathrm{Q}_{\mathrm{md}}$ não ocorre necessariamente no mesmo dia. Na realidade, o autor estabeleceu a distribuição estatística das duas séries para obter a relação. Esta análise foi realizada para dados de grandes bacias do leste americano, resultando na seguinte expressão:

$$
K=\frac{Q_{m x}}{Q_{m d}}=1+2,66 A^{-0,3}
$$

\footnotetext{
12 FULLER, W.E. (1914), Flood Flows. Transactions. American Society of Civil Engineers, New York, v.77, p.564-617
} 


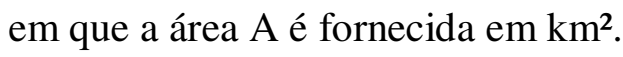

Tucci(In: TUCCI (1993b) apud GRAY (1973)1) ${ }^{13}$ relacionou os resultados de outros estudos apresentados por Ellis para algumas regiões dos Estados Unidos. Na Tabela 41 estão os resultados apresentados por Gray (1973), Fuller (1914) e Correia $(1983)^{14}$.

A aplicação do método estatístico ao estudo de vazões máximas, pressupõe o tratamento de variáveis aleatórias, ou seja, de eventos independentes. Para tanto, definise na região em estudo, em função de histogramas de médias mensais de chuva, o "ano hidrológico" como sendo a sequiência de doze meses contados a partir do início da estação chuvosa.

Tabela 41- Equações entre $Q_{m x}$ e $Q_{m d}$ da literatura

\begin{tabular}{ccc}
\hline \hline Região & Equação & Amostra \\
\hline Leste USA (Fuller) & $\mathrm{K}=1+2,66 \mathrm{~A}^{-0,3}$ & \\
Mont. Rochosas (foothills) & $\mathrm{K}=3,9 \mathrm{~A}_{\mathrm{e}}^{-0,22}$ & $60-300 \mathrm{mi}^{2}$ \\
Cypress Hills & $\mathrm{K}=10 \mathrm{~A}_{\mathrm{e}}^{-0,46}$ & $50-200 \mathrm{mi}^{2}$ \\
Central Plains & $\mathrm{K}=11 \mathrm{~A}_{\mathrm{e}}^{-0,36}$ & $45-255 \mathrm{mi}^{2}$ \\
Portugal (Correia) & $\mathrm{K}=1+1,2 \mathrm{~A}^{-0,036}$ & $4-3460 \mathrm{~km}^{2}$ \\
\hline \hline
\end{tabular}

$\mathrm{A}_{\mathrm{e}}=$ Área efetiva que contribui para a cheia média anual

Fonte: Tucci (In: TUCCI (1993b)

Nakano et al (1979) comenta que cuidado especial tem que ser dado à interpretação das vazões médias diárias dos cursos d'água com pequenas área de drenagem, onde normalmente os hidrogramas de vazões apresentam tempos de enchente e vazante relativamente pequenos. Nestes casos, comentam eles, as médias das leituras de vazões das 7 e 17 hs, podem mascarar significativamente as vazões máximas médias diárias. Como exemplo típico, pode ser citado o posto de São José do Rio Pardo, instalado no Rio Pardo, Estado de São Paulo, com área de drenagem de $3.880 \mathrm{~km}^{2}$, onde foi estimada para a cheia excepcional de janeiro de 1977, uma vazão média em 24 horas consecutivas de $1.197 \mathrm{~m}^{3} / \mathrm{s}$, sendo que a média das vazões instantâneas observadas às 7 e $17 \mathrm{hs}$, foi somente de $793 \mathrm{~m} 3 / \mathrm{s}$.

Outro fato que merece ser frisado, é que as vazões médias diárias são normalmente calculadas a partir da média das cotas limnimétricas observadas às 7 e 17

\footnotetext{
${ }^{13}$ GRAY, D.M. (1973). Handbook on Principles of Hydrology. Huntington: Water Information Center.

${ }^{14}$ CORREIA, F.N., (1983), Métodos de Análise e Determinação de Caudais de Cheia, Lisboa: LNEC.
} 
hs, e não sendo linear as relações cota x descarga, tal estimativa da vazão média diária não é necessariamente representativa.

Os fatos descritos acima, invalidam a aplicação sem uma análise acurada de fórmulas empíricas de cálculo da cheia instantânea, baseadas na vazão média diária, para bacias com pequenas e médias áreas de drenagem. Para o mesmo posto descrito anteriormente, o valor máximo instantâneo calculado pela multiplicação da média diária pelo coeficiente fornecido pela fórmula de Fuller conduz a $1.460 \mathrm{~m} 3 / \mathrm{s}$, sendo o valor considerado mais próximo do real e de $1.870 \mathrm{~m}^{3} / \mathrm{s}$.

Diante da importância da influência existente que a vazão máxima instantânea causa na inferência dos valores de projeto, o presente estudo objetiva verificar como é o comportamento da curva de frequiência ajustada pelo método conjugado e uma análise quantitativa dos valores inferidos utilizando as séries de valores máximos instantâneos e valores máximos médios diários.

\subsubsection{Série de Dados}

Para fazer as análises propostas pelo estudo foi utilizada a série histórica de vazões médias diárias máximas observadas no Rio Paraguaçu em Pedra Cavalo, no período de 1941 a 1978. A bacia hidrográfica do Rio Paraguaçu situa-se na região centro oriental do Estado da Bahia. Apresenta aspecto levemente retângula de posição Norte-Este, estendendo-se desde as encostas da chapada Diamantina, até a Baia de Todos os Santos, onde o rio Paraguaçu tem sua foz (TUNG E TEIXEIRA, 1979).

A região de interesse ao estudo localiza-se a montante do local do aproveitamento denominado Pedra Cavalo, situado entre os municípios de Cachoeira e São Félix, e compreende uma área de aproximadamente $53.500 \mathrm{~km}^{2}$.

Para a definição das séries de vazões máximas instantâneas foram utilizados os métodos convencionais que relacionam as vazões máximas instantâneas e as vazões máximas médias diárias. Diante dos resultados obtidos e da análise de alguns trabalhos relacionados a bacias de mesmo porte (SILVA E TUCCI, 1997; GARCIA, 1996 apud THEMAG, 1991) optou-se por utilizar dois fatores multiplicativos (K) para a relação “vazão de ponta/vazão média diária" que foram 1,3 e 1,4. Aplicando-se estes fatores a série de vazões médias diárias máximas anuais, resultaram as séries de vazões máximas anuais apresentadas na tabela 42. 
Após definidas as séries foram aplicados os testes estatísticos para verificação das hipóteses de independência, homogeneidade, estacionaridade e verificação da presença de "outliers".

Para verificar a presença de outliers nas séries foi aplicado o teste de Grubbs e Beck (GRUBBS e BECK, 1972) nas séries de vazões com 38 elementos determinou um coeficiente estatístico $\mathrm{K}_{\mathrm{N}}=2,661$, para um nível de significância de $10 \%$, que resultou nos limites superior $X_{H}=11.431 \mathrm{~m}^{3} / \mathrm{s}$ e inferior $X_{L}=84 \mathrm{~m}^{3} / \mathrm{s}$ para série de vazões médias diárias, $\mathrm{X}_{\mathrm{H}}=14.860 \mathrm{~m}^{3} / \mathrm{s} \mathrm{X}_{\mathrm{L}}=109 \mathrm{~m} 3 / \mathrm{s}$ para série de vazões máximas instantâneas com fator multiplicativo de 1,3 e $X_{H}=16.003 \mathrm{~m}^{3} / \mathrm{s} X_{\mathrm{L}}=118 \mathrm{~m}^{3} / \mathrm{s}$ para série de vazões máximas instantâneas com fator multiplicativo de 1,4. Uma vez que os valores de vazões máximas das séries estão dentro destes limites, conclui-se que não existem "outliers" nas séries.

As séries de vazões foi submetida ao teste de Wald-Wolfowitz (RAO E HAMED, 2000) para verificação da independência e estacionaridade dos valores. A aplicação deste teste para as diferentes séries resultou, invariavelmente, em coeficientes estatísticos $\mathrm{u}<\mathrm{u}_{\alpha / 2}=1,96$, que permite aceitar a hipótese de independência para um nível de significância $\alpha=5 \%$.

Foi aplicado o teste de Mann-Whitney (RAO E HAMED, 2000) para verificação das hipóteses de homogeneidade e estacionaridade das séries de vazões. Para isso, a séries foram divididas em diferentes sub-séries complementares. A aplicação deste teste para diferentes amostras resultou, invariavelmente, em coeficientes estatísticos $u<u_{\alpha / 2}$ $=1,96$, que permite aceitar a hipótese de homogeneidade para um nível de significância $\alpha=5 \%$.

Portanto, conclui-se que as séries de vazões máximas podem ser consideradas consistentes, significativas e representativas.

\subsubsection{Aplicação do Método Conjugado}

Como já comentado, para aplicação do método conjugado uma boa definição do parâmetro VMP é de fundamental importância, pois ele vai servir como ponto determinante na boa definição dos valores máximos de projetos para altos períodos de retorno. Assim é importante sempre uma boa descrição dos procedimentos utilizados para determinação da PMP e a posteriori determinação da EMP, uma vez que o conheci- 
Tabela 42 - Série de Vazões Médias Diárias Máximas e Instantâneas com fator multiplicativo $\left(Q_{m x} / Q_{m d}\right) K=1,3$ e $K=1,4$ do rio Paraguaçu em Pedra Cavalo.

\begin{tabular}{cccc}
\hline \hline Ano & $\mathrm{Q}_{\mathrm{md}}$ & $\begin{array}{c}\mathrm{Q}_{\mathrm{mx}} \text { com } \\
\mathrm{K}=1,3\end{array}$ & $\begin{array}{c}\mathrm{Q}_{\mathrm{mx}} \text { com } \\
\mathrm{K}=1,4\end{array}$ \\
\hline 1941 & 1492 & 1940 & 2089 \\
1942 & 385 & 501 & 539 \\
1943 & 1825 & 2373 & 2555 \\
1944 & 689 & 896 & 965 \\
1945 & 2027 & 2635 & 2838 \\
1946 & 450 & 585 & 630 \\
1947 & 360 & 468 & 504 \\
1948 & 4450 & 5785 & 6230 \\
1949 & 2600 & 3380 & 3640 \\
1950 & 1530 & 1989 & 2142 \\
1951 & 305 & 397 & 427 \\
1952 & 264 & 343 & 370 \\
1953 & 2020 & 2626 & 2828 \\
1954 & 1740 & 2262 & 2436 \\
1955 & 3200 & 4160 & 4480 \\
1956 & 620 & 806 & 868 \\
1957 & 1550 & 2015 & 2170 \\
1958 & 450 & 585 & 630 \\
1959 & 470 & 611 & 658 \\
1960 & 6550 & 8515 & 9170 \\
1961 & 260 & 338 & 364 \\
1962 & 234 & 304 & 328 \\
1963 & 307 & 399 & 430 \\
1964 & 6253 & 8129 & 8754 \\
1965 & 926 & 1204 & 1296 \\
1966 & 1926 & 2504 & 2696 \\
1967 & 458 & 595 & 641 \\
1968 & 1326 & 1724 & 1856 \\
1969 & 2950 & 3835 & 4130 \\
1970 & 950 & 1235 & 1330 \\
1971 & 1647 & 2141 & 2306 \\
1972 & 360 & 468 & 504 \\
1973 & 1951 & 2536 & 2731 \\
1974 & 690 & 897 & 966 \\
1975 & 958 & 1245 & 1341 \\
1976 & 465 & 605 & 651 \\
1977 & 538 & 699 & 753 \\
1978 & 1405 & 1827 & 1967 \\
\hline \hline & Fonte: Nakano et al $(1979)$ &
\end{tabular}


mento das técnicas que foram utilizadas permitirá que o decisor tenha uma decisão mais crítica a cerca dos valores inferidos, além de permitir o prévio conhecimento das características hidrometeorológicas da bacia.

A descrição resumida dos processos de obtenção do valor da PMP e, por conseguinte o valor da EMP utilizado nesta seção de análise foi retirado de um trabalho desenvolvido por Chu Tung e Teixeira (1979a e 1979b) que descreveram objetivamente os estudos desenvolvidos para a estimativa da precipitação máxima provável e em fase posterior a determinação do hidrograma da vazão máxima provável, no local da barragem de Pedra Cavalo localizado na bacia do rio Paraguaçu.

\section{- Estimativa da Precipitação Máxima Provável (PMP)}

Para determinação da PMP foi feito, inicialmente, um estudo das características climatológicas, meteorológicas e pluviométricas da bacia do rio Paraguaçu. Foram identificados os tipos de clima predominantes da região, a ocorrência das massas de ar que influenciam nos processos de formação de chuvas na bacia e os regimes pluviométricos da bacia identificando os períodos chuvosos, a distribuição espacial e temporal das precipitações que ocorrem na região.

Para determinação da razão de maximização foi feito um levantamento de dados na bacia, na qual se constatou uma grande deficiência dos mesmos, isso impediu que fossem selecionados postos que fornecessem informações relativas a pontos de orvalho ideais, representativos para a bacia em estudo.

Tal deficiência de dados obrigou a se usar valores de pontos de orvalho, obtidos através da Estação Meteorológica do Aeroporto de Salvador, pertencente à rede operacional do Ministério da Aeronáutica.

Os valores dos pontos de orvalho foram considerados representativos para o estudo, pelos seguintes motivos:

a - Foram obtidos em local próximo à bacia.

b - Trata-se de valores horários e altamente confiáveis.

Foram pesquisados valores de ponto de orvalho máximo persistentes por 12 horas, não só durante os períodos chuvosos estudados, como, também, durante alguns anos, para verificação da série histórica. Os valores obtidos foram reduzidos ao nível 
padrão de $1000 \mathrm{mb}$, para fins comparativos, de acordo com as normas adotadas pelo WMO (1973).

Os valores finais do ponto de orvalho, reduzidos os níveis padrão, em função da altitude média de $450 \mathrm{~m}$ considerada para a bacia, redundam nos seguintes resultados: - período de 03 a 12 de março de $1960=24,0^{\circ} \mathrm{C}$;

- histórico de alguns anos $=25,0^{\circ} \mathrm{C}$.

Como as condições climato-meteorológicas da Estação Meteorológica do Aeroporto de Salvador não se enquadram perfeitamente com os da bacia em estudo, foram efetuadas correções nos valores do ponto de orvalho obtidos, tornando-os mais representativos para a maximização. Desta forma, foram subtraídos $0,5^{\circ} \mathrm{C}$ dos valores pesquisados, obtendo-se:

- período de 03 a 12 de março de $1960=23,5^{\circ} \mathrm{C}$;

- histórico de alguns anos $=24,5^{\circ} \mathrm{C}$.

Os valores do ponto de orvalho foram aplicados no cálculo da água precipitável para a bacia e, consequentemente, no cálculo da razão de maximização (Rm). Assim tem-se:

a - período de 03 a 12/03/1960 - ponto de orvalho de $23,5^{\circ} \mathrm{C}-68,3 \mathrm{~m}-8,9 \mathrm{~m}=59,4$ $\mathrm{m}$;

$\mathrm{b}$ - histórico de alguns anos - ponto de orvalho de $24,5^{\circ} \mathrm{C}-77,7 \mathrm{~m}-9,5 \mathrm{~m}=68,2 \mathrm{~m}$.

A razão de maximização $(\mathrm{Rm})$ é obtida pela relação entre o valor máximo histórico e o valor máximo da precipitação ocorrida, sendo a seguinte:

$R_{m}=\frac{68,2}{59,4}=1,148$

Valor adotado no estudo: $\mathrm{Rm}=1,15$.

Para a estimativa da precipitação máxima provável foi feita à pesquisa de índices pluviométricos, no decorrer da série histórica, de diversos postos situados ao longo da bacia e em regiões limítrofes, permitiram determinar períodos chuvosos representativos de condições críticas, ou seja, os mais chuvosos dos períodos chuvosos detectados ao longo da época pesquisada. Desta forma, foram pesquisados períodos chuvosos de 1, 2, 3, 5 e 10 dias, resultando no seguinte:

- período de 1 dia - 08/03/60; 
- período de 2 dias - 07 a 08/03/60;

- período de 3 dias - 07 a 09/03/60;

- período de 5 dias - 04 a 08/03/60;

- período de 10 dias - 03 a 12/03/60.

A partir destes períodos foram feitas as análises isoietais e utilizando a razão de maximização $(1,15)$, permitiram os traçados das respectivas curvas finais de precipitação máxima provável.

\section{- Estimativa da Enchente Máxima Provável}

Com base no valor da PMP obtido anteriormente, e mediante uso de um modelo determinístico da simulação hidrológica, obteve-se a estimativa do hidrograma EMP ou Enchente Máxima Provável, para a seção de controle pré-estabelecida da bacia de drenagem do rio Paraguaçu. Um modelo de simulação deste gênero permite retratar, com maior aproximação, o processo hidrológico. $\mathrm{O}$ hidrograma EMP obtido corresponde ao limite superior físico da bacia, quanto à vazão de ponta, não sendo possível associar uma probabilidade de ocorrência.

O simulador Hidrocomp, utilizado no estudo para determinação da enchente máxima provável aqui descrito, se constitui numa bateria de programas. Em resumo, a etapa inicial na aplicação deste modelo consiste na análise da bacia objeto do estudo e sua segmentação em sub-bacias, com características topográficas, geológicas, de cobertura vegetal e hidroclimatológicas uniformes. Uma vez definidas as sub-bacias, é preciso definir uma condição inicial em termos de umidade do solo e, a seguir, fornecer os insumos básicos, para que se inicie o processo de simulação.

O modelo aceita como insumos valores de precipitação em intervalos de tempo que variam entre 5 e 60 minutos, e valores diários para a evapotranspiração potencial. $\mathrm{O}$ intervalo de tempo elementar da simulação foi de 6 horas. Dezesseis parâmetros são necessários para promover a transformação de precipitação em deflúvio superficial. Desses, dez são estimados a partir das características físicas da bacia e os outros por tentativa. Dos seis que são obtidos dessa última maneira, três são essenciais ao bom funcionamento do modelo, sendo que os restantes podem ser estimados "a priori" com suficiente precisão.

Para a aplicação da PMP e determinação da EMP, considerou-se a bacia do rio Paraguaçu, a montante de Pedra Cavalo, como único setor, em decorrência da análise 
meteorológica da área e da pesquisa dos fenômenos de chuva, em intensidade e extensão.

Para uma dada PMP, os valores resultantes da EMP são funções das condições de contorno pré-estabelecidas, tais como:

- localização do núcleo chuvoso;

- condições de umidade de solo no início da simulação;

- sincronização de chuvas de setores independentes; e,

- distribuição temporal da chuva.

Baseado em análise dos dados do período histórico, examinou-se as várias possibilidades de localização do núcleo da PMP na bacia. A EMP a ser adotada, corresponderá ao posicionamento do núcleo chuvoso em sua posição mais crítica.

A aplicação da PMP na bacia do rio Paraguaçu, constituiu-se essencialmente das seguintes etapas:

a - Delimitação da área de estudo - para efeito da aplicação da PMP na bacia do rio Paraguaçu, a área de estudo ficou delimitada, a jusante, pelo eixo da barragem em Pedra Cavalo.

b - Localização do núcleo da PMP - foram selecionados dois casos: no caso I, o núcleo da PMP foi localizado próximo à região de Iaçu e no caso II, o núcleo se localizou na região de Argoim.

c - Condições iniciais de umidade do solo - para as condições iniciais de umidade do solo, foram selecionados os valores máximos observados nos meses de novembro a março do período de 1967 a 1969 (período de calibragem).

d - Repartição temporal da chuva - os aspectos de distribuição temporal da chuva afetam sensivelmente a composição da forma e da ponta da EMP. Portanto, a seleção dos coeficientes de distribuição devem ser extremos históricos e/ou envoltórias. A distribuição final correspondeu à curva de distribuição acumulada no período considerado.

e - Repartição espacial da PMP - a repartição espacial da chuva segue aquela orientada pelas curvas isoietais das PMP's. Porém, como a modelagem não consegue reproduzir integralmente os valores pontuais, é utilizada a curva DAD (Depth, Área, Duration) para se obter as chuvas médias equivalentes nas áreas segmentadas para o modelo.

Assim, os hidrogramas EMP's para a seção de Pedra Cavalo, foram obtidos através de hidrogramas parciais em diversas seções de controle. Ressalta-se que estes 
hidrogramas parciais não representam as EMP's, nas seções respectivas, mas sim aquelas que formarão a EMP em Pedra Cavalo.

Desta forma, tem-se a seguir os resultados obtidos de dois casos de localização do núcleo chuvoso PMP sobre a bacia, embora diversas hipóteses tenham sido analisadas.

Caso I - corresponde à hipótese do núcleo da PMP localizado na região central da bacia, e que conduz à condição mais crítica. A vazão de ponta alcançada foi de $15.160 \mathrm{~m}^{3} / \mathrm{s}$, na seção de controle de Pedra Cavalo.

Caso II - Corresponde à hipótese do núcleo chuvoso da PMP localizado em local bem mais próximo ao eixo do barramento. A vazão de ponta alcançado foi de $14.382 \mathrm{~m}^{3} / \mathrm{s}$, em Pedra Cavalo.

Para efeito de análise de sensibilidade, foram examinados também os efeitos decorrentes da variação das condições iniciais de umidade, resultando:

Caso III - com a mesma localização do núcleo da PMP do caso II, porém, com condição de umidade inicial $10 \%$ menor. A vazão de ponta obtida foi de $12.497 \mathrm{~m}^{3} / \mathrm{s}$.

Caso IV - com a mesma localização do núcleo PMP do caso I, porém, com condição de umidade inicial $10 \%$ menor. A vazão de ponta obtida foi de $13.193 \mathrm{~m} 3 / \mathrm{s}$.

Diante dos casos analisados, concluiu-se que a vazão de ponta da EMP é mais sensível à variação da umidade inicial do que a pequenos deslocamentos do núcleo chuvoso, a localização do núcleo chuvoso na seção central da bacia provoca a maior vazão de ponta.

O hidrograma da enchente máxima provável adotado foi aquele cujos parâmetros condicionam aos resultados mais críticos, portanto, o caso I ( EMP = 15160 $\mathrm{m}^{3} / \mathrm{s}$ ) é tomado como o hidrograma EMP em Pedra Cavalo. Vale ressaltar, como visto na seção 4.3, que a utilização do valor da VMP para qualquer caso citado acima, não resultaria em grandes diferenças nos valores inferidos aplicando o método conjugado.

A partir do valor do parâmetro VMP obtido a partir dos procedimentos descritos para o cálculo da EMP, aplicou-se o método conjugado, apresenta-se nas figuras 30 a 32 para cada método de estimação dos parâmetros as curvas de distribuição probabilística do método conjugado ajustadas para as diferentes séries. As tabelas 43 a 45 apresentam para cada método de estimação dos parâmetros as vazões máximas para diferentes períodos de retorno, inferidas a partir das distribuições probabilísticas ajustadas a cada uma das séries de vazões. 
As análises das citadas tabelas permitem verificar que, para os valores com períodos de retorno de mesma ordem de grandeza da extensão da série as diferenças nos valores de vazão são proporcionais aos incrementos colocados na série de médios diários máximos, por exemplo, um incremento na série de médios máximos diários de $40 \%$ representou um aumento para os valores inferidos pelo método conjugado para um período de retorno de 50 anos de $37 \%$ para o método dos momentos, de $40 \%$ para o método da máxima verossimilhança e $40 \%$ para o método dos mínimos quadrados. Este exemplo comprova a boa habilidade descritiva (habilidade de interpolação) que o método conjugado apresenta, uma vez que os valores inferidos para série de máximos instantâneos acompanharam na mesma proporção os valores inferidos para a série de máximos diários.

Já os valores obtidos, a partir da extrapolação da curva de freqüência conjugada (tempo de retorno superior a 100 anos) para as séries de máximos instantâneos, apresentaram uma diferença percentual menor em relação à série de valores médios diários máximos do que o incremento (40\% e $30 \%$ ) adotado nas séries inicialmente. Como exemplo tem-se para vazões com período de retorno de 10.000 anos a diferença entre a série de valores médios diários e a série de valores máximos instantâneos com fator multiplicativo de 1,4 (incremento de $40 \%$ ) foi de $25 \%$ para o método dos momentos, $31 \%$ para o método da máxima verossimilhança e $24 \%$ para o método dos mínimos quadrados.

Isso comprova que a aplicação do método conjugado para determinação de valores que necessitam da extrapolação da curva de freqüência proporciona uma melhoria nas estimativas, uma vez que os valores extrapolados são controlados pelo valor máximo provável que faz com que a cauda superior seja direcionada para esse valor máximo. Isto impede que os valores extrapolados utilizando a série de máximos instantâneos acompanhem na mesma proporção (sendo o coeficiente de proporcionalidade o fator multiplicativo para a relação "vazão de ponta/vazão média diária”) os valores inferidos para a série de médios máximos diários como ocorre utilizando a metodologia estatística. Por exemplo, utilizando a metodologia estatística um incremento de $40 \%$ na série de médios máximos diários resultará num aumento de $40 \%$ nos valores inferidos. 
Tabela 43 - Método Conjugado - análise utilizando as séries de valores máximos instantâneos e valores médios diários máximos - método MOM.

\begin{tabular}{|c|c|c|c|c|c|c|}
\hline \multicolumn{7}{|c|}{ Vazões Máximas (m³/s) - MÉTODO DOS MOMENTOS - MOM } \\
\hline \multirow{2}{*}{$\begin{array}{l}\text { Probabilidade de } \\
\text { Excedência }\end{array}$} & \multirow{2}{*}{$\begin{array}{c}\text { Período de } \\
\text { Retorno (anos) }\end{array}$} & \multicolumn{3}{|c|}{ Vazões Máximas para Séries } & \multirow{2}{*}{$\begin{array}{c}\mathrm{D}(\%) \text { entre } \\
\mathrm{Q}_{\mathrm{md}} \text { e } \mathrm{Q}_{\mathrm{mx}} \\
\mathrm{c} / \mathrm{k}=1,3\end{array}$} & \multirow{2}{*}{$\begin{array}{c}\mathrm{D}(\%) \text { entre } \\
\mathrm{Q}_{\mathrm{md}} \text { e } \mathrm{Q}_{\mathrm{mx}} \mathrm{c} / \\
\mathrm{k}=1,4\end{array}$} \\
\hline & & $\mathrm{Q}_{\mathrm{md}}$ & $\begin{array}{l}\mathrm{Q}_{\mathrm{mx}} \mathrm{c} / \\
\mathrm{k}=1,3\end{array}$ & $\begin{array}{l}\mathrm{Q}_{\mathrm{mx}} \mathrm{c} / \\
\mathrm{k}=1,4\end{array}$ & & \\
\hline 0,0001 & 10000 & 8954 & 10714 & 11210 & 20 & 25 \\
\hline 0,0005 & 2000 & 7978 & 9724 & 10236 & 22 & 28 \\
\hline 0,001 & 1000 & 7511 & 9233 & 9745 & 23 & 30 \\
\hline 0,002 & 500 & 7014 & 8696 & 9205 & 24 & 31 \\
\hline 0,005 & 200 & 6307 & 7911 & 8407 & 25 & 33 \\
\hline 0,01 & 100 & 5730 & 7253 & 7732 & 27 & 35 \\
\hline 0,02 & 50 & 5113 & 6533 & 6987 & 28 & 37 \\
\hline 0,05 & 20 & 4227 & 5469 & 5874 & 29 & 39 \\
\hline 0,1 & 10 & 3489 & 4557 & 4911 & 31 & 41 \\
\hline
\end{tabular}

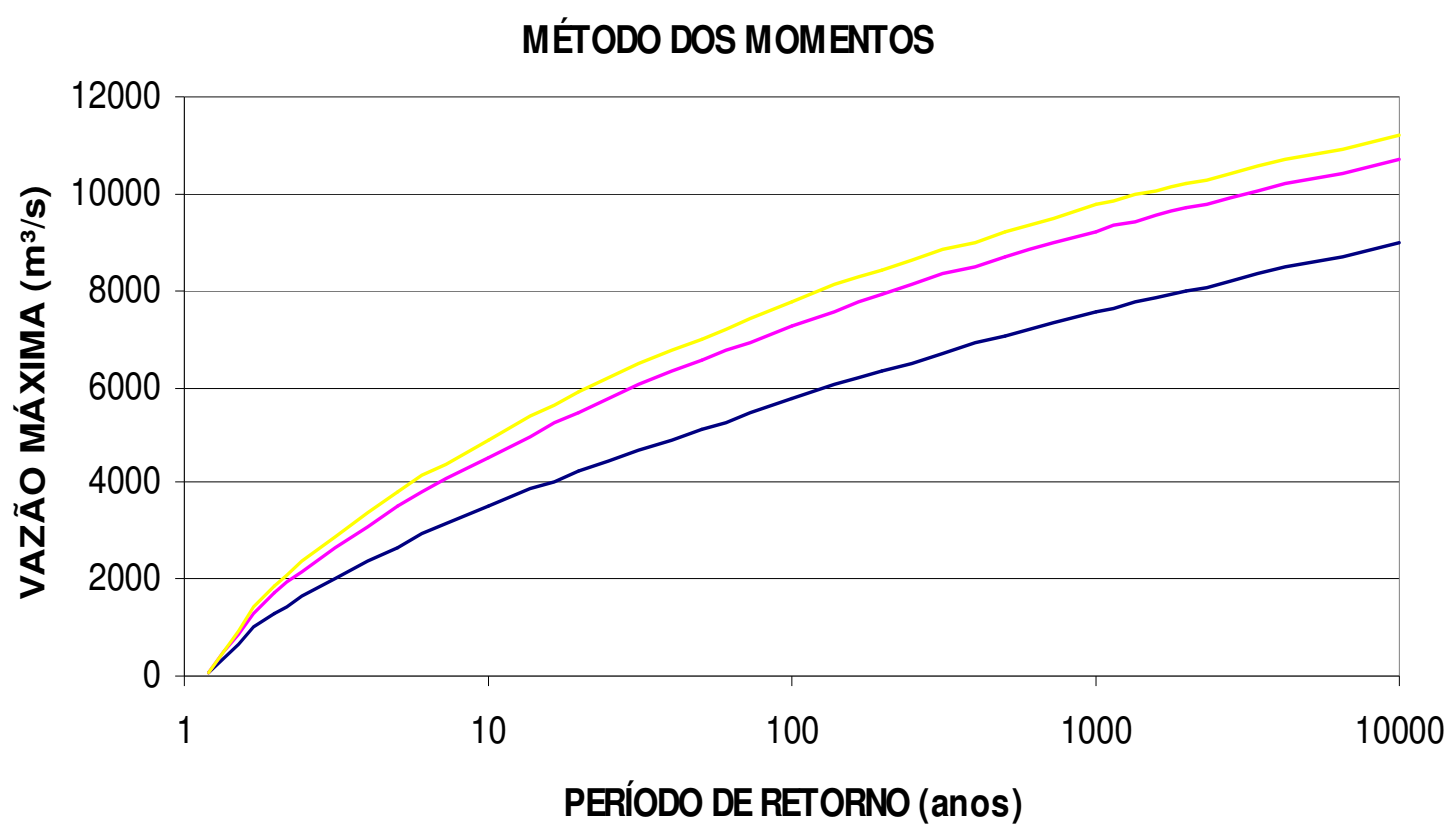

- Qmd $-Q m x c / K=1,3 ـ Q m x c / K=1,4$

Figura 30 - Método conjugado - curva da distribuição probabilística ajustadas para as diferentes séries (médias diárias e instantâneas) utilizando o método MOM 
Tabela 44 - Método Conjugado - análise utilizando as séries de valores máximos instantâneos e valores médios diários máximos - método ML.

\begin{tabular}{|c|c|c|c|c|c|c|}
\hline \multicolumn{7}{|c|}{ Vazões Máximas (m³/s) - MÉTODO DA MÁXIMA VEROSSIMILHANÇA } \\
\hline \multirow{2}{*}{$\begin{array}{l}\text { Probabilidade de } \\
\text { Excedência }\end{array}$} & \multirow{2}{*}{$\begin{array}{c}\text { Período de } \\
\text { Retorno (anos) }\end{array}$} & \multicolumn{3}{|c|}{ Vazões Máximas para Séries } & \multirow{2}{*}{$\begin{array}{c}\mathrm{D}(\%) \text { entre } \\
\mathrm{Q}_{\mathrm{md}} \text { e } \mathrm{Q}_{\mathrm{mx}} \mathrm{c} / \\
\mathrm{k}=1,3\end{array}$} & \multirow{2}{*}{$\begin{array}{c}\mathrm{D}(\%) \text { entre } \\
\mathrm{Q}_{\mathrm{md}} \text { e } \mathrm{Q}_{\mathrm{mx}} \mathrm{c} / \\
\mathrm{k}=1,4\end{array}$} \\
\hline & & $\mathrm{Q}_{\mathrm{md}}$ & $\begin{array}{l}\mathrm{Q}_{\mathrm{mx}} \mathrm{c} / \\
\mathrm{k}=1,3\end{array}$ & $\begin{array}{l}\mathrm{Q}_{\mathrm{mx}} \mathrm{c} / \\
\mathrm{k}=1,4\end{array}$ & & \\
\hline 0,0001 & 10000 & 7425 & 9162 & 9698 & 23 & 31 \\
\hline 0,0005 & 2000 & 6557 & 8212 & 8737 & 25 & 33 \\
\hline 0,001 & 1000 & 6153 & 7757 & 8272 & 26 & 34 \\
\hline 0,002 & 500 & 5731 & 7273 & 7774 & 27 & 36 \\
\hline 0,005 & 200 & 5141 & 6583 & 7058 & 28 & 37 \\
\hline 0,01 & 100 & 4669 & 6020 & 6470 & 29 & 39 \\
\hline 0,02 & 50 & 4174 & 5418 & 5837 & 30 & 40 \\
\hline 0,05 & 20 & 3476 & 4552 & 4919 & 31 & 42 \\
\hline 0,1 & 10 & 2906 & 3831 & 4149 & 32 & 43 \\
\hline
\end{tabular}

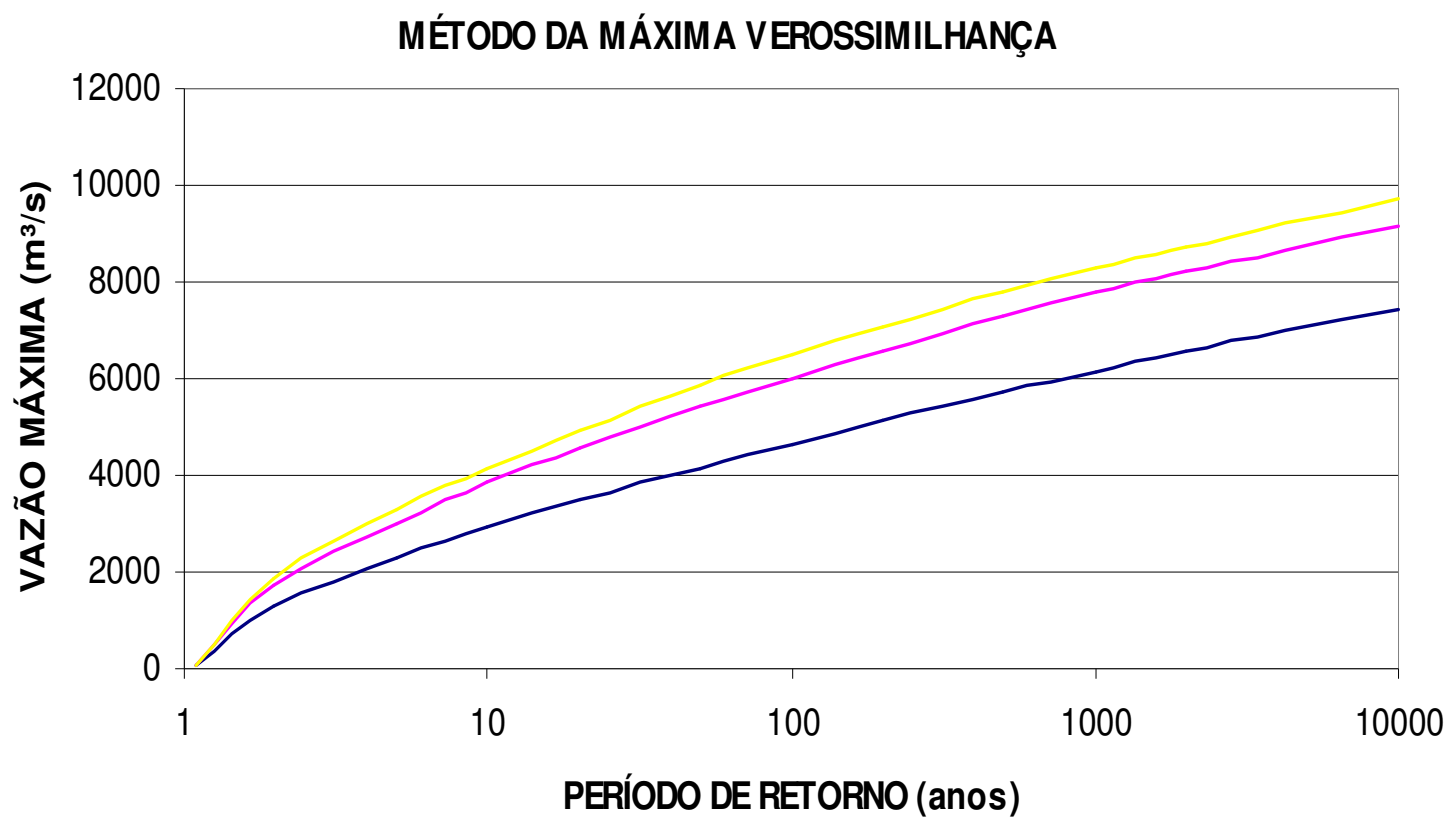

- Qmd $\longrightarrow$ Qmx c/ K=1,3 - Qmx c/ K=1,4

Figura 31 - Método conjugado - curva da distribuição probabilística ajustadas para as diferentes séries (médias diárias e instantâneas) utilizando o método ML 
Tabela 45 - Método Conjugado - análise utilizando as séries de valores máximos instantâneos e valores médios diários máximos - método MLS.

\begin{tabular}{|c|c|c|c|c|c|c|}
\hline \multicolumn{7}{|c|}{ Vazões Máximas (m³/s) - MÉTODO DOS MÍNIMOS QUADRADOS } \\
\hline \multirow{2}{*}{$\begin{array}{l}\text { Probabilidade de } \\
\text { Excedência }\end{array}$} & \multirow{2}{*}{$\begin{array}{c}\text { Período de } \\
\text { Retorno (anos) }\end{array}$} & \multicolumn{3}{|c|}{ Vazões Máximas para Séries } & \multirow{2}{*}{$\begin{array}{c}\mathrm{D}(\%) \text { entre } \\
\mathrm{Q}_{\mathrm{md}} \mathrm{e} \mathrm{Q}_{\mathrm{mx}} \mathrm{c} \\
\mathrm{k}=1,3\end{array}$} & \multirow{2}{*}{$\begin{array}{c}\mathrm{D}(\%) \text { entre } \\
\mathrm{Q}_{\mathrm{md}} \text { e } \mathrm{Q}_{\mathrm{mx}} \mathrm{c} / \\
\mathrm{k}=1,4\end{array}$} \\
\hline & & $\mathrm{Q}_{\mathrm{md}}$ & $\begin{array}{l}\mathrm{Q}_{\mathrm{mx}} \mathrm{c} / \\
\mathrm{k}=1,3\end{array}$ & $\begin{array}{l}\mathrm{Q}_{\mathrm{mx}} \mathrm{c} / \\
\mathrm{k}=1,4\end{array}$ & & \\
\hline 0,0001 & 10000 & 10437 & 12374 & 12904 & 19 & 24 \\
\hline 0,0005 & 2000 & 9414 & 11449 & 12043 & 22 & 28 \\
\hline 0,001 & 1000 & 8908 & 10962 & 11578 & 23 & 30 \\
\hline 0,002 & 500 & 8357 & 10410 & 11043 & 25 & 32 \\
\hline 0,005 & 200 & 7552 & 9567 & 10210 & 27 & 35 \\
\hline 0,01 & 100 & 6879 & 8829 & 9468 & 28 & 38 \\
\hline 0,02 & 50 & 6144 & 7991 & 8612 & 30 & 40 \\
\hline 0,05 & 20 & 5061 & 6698 & 7266 & 32 & 44 \\
\hline 0,1 & 10 & 4136 & 5540 & 6039 & 34 & 46 \\
\hline
\end{tabular}

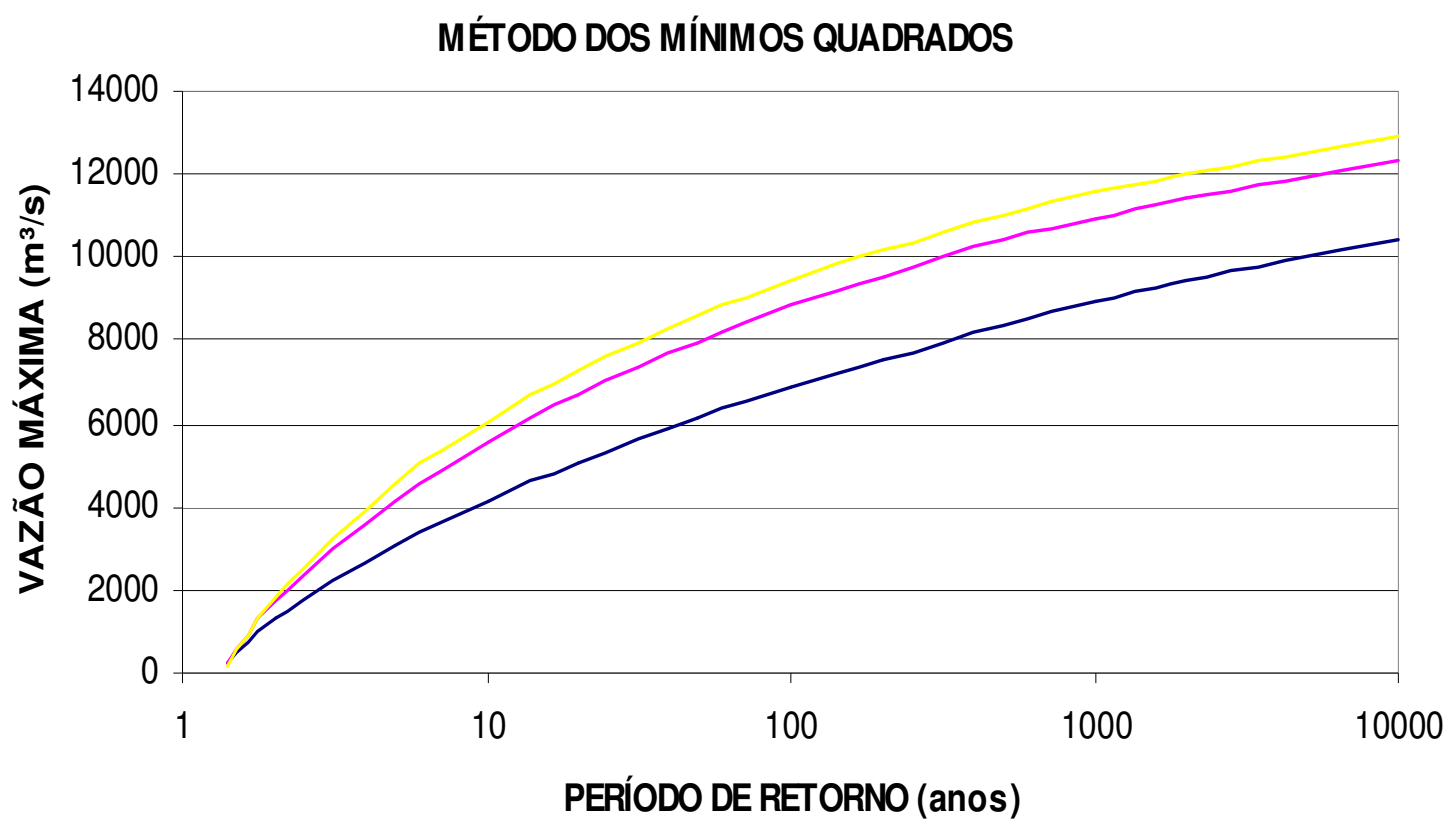

$\longrightarrow$ Qmd - Qmx c/ K=1,3 $\longrightarrow$ Qmx c/ K=1,4

Figura 32 - Método conjugado - curva da distribuição probabilística ajustadas para as diferentes séries (médias diárias e instantâneas) utilizando o método MLS 
A conclusão é que diante das imprecisões e das variabilidades apresentadas pelos métodos que relacionam a vazão máxima instantânea com a vazão média diária, o método conjugado pode proporcionar uma menor diferença entre os resultados inferidos. Essa menor diferença pode caracterizar uma amortização nas imprecisões para valores inferidos com períodos de retorno altos, uma vez que os valores da cauda superior da distribuição estão sendo balizados pelo valor máximo provável e as incertezas presentes nas relações vazão de ponta/vazão média diária podem ter uma influência menor nos erros das estimativas obtidos a partir da extrapolação.

\subsection{Aplicação do Método Conjugado em Séries Parciais e Séries de Máximos Anuais}

\subsubsection{Introdução}

O objetivo da análise de frequiência de cheias é obter uma relação entre uma magnitude de vazão $q(\mathrm{t})$ e o tempo de recorrência $\mathrm{T}$, a ela associado, para uma determinada seção de um curso d'água. Uma forma de tratar o problema é considerar unicamente a série de vazões afluentes à seção em estudo como sendo uma realização de um processo estocástico cujos mecanismos de geração não são tratados um a um, mas sim de forma global. Nesta série são procuradas evidencias estatísticas que possam caracterizar tal processo, cuja identificação permitiria resolver o problema. Os métodos que usam este procedimento são chamados métodos de análise direta de frequiência de cheias (FILL, 1981). Constitui o objetivo deste estudo a investigação do comportamento de alguns destes métodos com relação à determinação de vazões com tempos de recorrência muito elevados, como é o caso das vazões de projeto de vertedores. Dada a pequena extensão dos registros usualmente existentes e face ao grande tempo de recorrência de interesse é de fundamental importância extrair-se dos registros a maior quantidade possível de informação.

Seria ideal que na análise direta de freqüência de cheias, fossem utilizadas todas as informações contidas nos registros de vazões diárias. Todavia, esta série apresenta uma estrutura de dependência muito complexa (MOREIRA et al., 1983). Assim, o procedimento usualmente adotado na prática consiste em extrair-se destes registros de 
vazões diárias as chamadas séries de vazões extremas, centrando desta forma a atenção nas vazões que apresentam interesse mais direto na análise de extremos.

Como mostrado na seção 2.1.2, existem basicamente dois tipos de séries de vazões extremas: as séries de máximos anuais e as séries parciais. As primeiras são constituídas pelos maiores valores de vazões ocorridas a cada ano enquanto que as últimas compreendem as maiores vazões ocorridas a cada cheia.

A simplicidade de modelos matemáticos usados na análise de máximos anuais, aliada à facilidade com que estas séries são obtidas, faz com que seu uso seja mais difundido que as séries parciais, cuja análise exige o emprego de modelos matemáticos mais sofisticados. Além disso, a obtenção das séries parciais a partir de registros de vazões diárias exige uma definição das cheias ocorridas no histórico, o que geralmente dá margem a controvérsias. Devido a esta dificuldade costumam-se definir séries parciais como as séries contendo todos os picos cujas magnitudes excedam um determinado valor usualmente chamado de nível de truncamento.

Moreira et al (1983) comentam alguns estudos (NERC, 1975; YEVJEVICH e TAESOMBUT, 1976) ${ }^{15}$ que tem sido desenvolvido com o objetivo de comparar o uso de séries de máximos anuais com o uso de séries parciais. Uma aparente vantagem dos métodos de séries parciais, comentam eles, é a possibilidade de se manipularem amostras maiores. Entretanto, existem duvidas sobre a qualidade destas amostras, principalmente porque dois picos de variáveis hidrológicas consecutivos podem guardar entre si um elevado grau de dependência o que anularia a aparente vantagem. Além disso, os métodos de máximos anuais consideram uma informação adicional: cada elemento da amostra é a maior vazão ocorrida em um ano (NERC, 1975). O que acontece é que as realizações destes estudos comparativos esbarram em algumas dificuldades. Por um lado, as comparações feitas em bases analíticas são limitadas por inúmeras hipóteses simplificadoras enquanto que as comparações diretas necessitam de um número muito grande de histograma das variáveis hidrológicas.

O objetivo deste estudo de caso é de fazer uma análise comparativa entre os resultados inferidos pela série parcial de precipitação e pela série de máximos anuais de precipitação utilizando tanto a método estatístico como o método conjugado. Essa análise não só almeja quantificar a diferença entre o ajuste da série parcial (com maior quantidade de dados) com a série de máximo anual (com menor quantidade de dados)

\footnotetext{
15 YeVJeVICH, V. E TAESOMBUT, V. (1979), Information on Flood Peaks in Daily Flow Series, Proc. Int. Symp. On Risk and Reliability in Water Resources, Ontario, Canadá.
} 
devido ao número de informações (análise análoga à feita na seção que quantificou a influência da extensão da série), mas discorrer sobre todas as dificuldades intrínsecas de uma análise feita utilizando séries parciais. Além disso, serve como exemplificação da aplicação do método conjugado às séries de precipitações e de mais uma descrição de um caso prático e real referente à obtenção da precipitação máxima provável (PMP).

\subsubsection{Série de Dados}

Para fazer as análises propostas pelo estudo foi utilizada a série histórica de precipitação máximas de 12 horas, observadas na estação do observatório IAG localizado no município de São Paulo pertencente à bacia hidrográfica do rio Tamanduateí. A bacia hidrográfica do rio Tamanduateí, com $310 \mathrm{~km}^{2}$, é a principal subbacia do Alto Tiete, pois abrange as zonas centrais de importantes municípios como São Paulo, São Bernardo, São Caetano, Diadema e Mauá, núcleos urbanos de intenso desenvolvimento e com alta densidade demográfica.

A série estende-se de 1934 a 1998, com 45 anos de precipitações máximas anuais, uma vez que a série apresenta inúmeros anos sem observação. Esse problema motivou a criação de uma série parcial de valores, adotando como o valor de referência (nível de truncamento) o menor valor obtido na série de máximos anuais (24 mm), assim todos os valores dentro de um ano quaisquer maiores que o valor de referência era selecionado para a formação da série de duração parcial. Esta série foi a mesma utilizada na seção 2.1.2 para exemplificar a diferença entre uma série parcial e uma série de máximos anuais. A tabela 46 e 47 apresentam os valores referentes a série de máximos anuais e a série parcial, respectivamente.

Após definidas as séries foram aplicados os testes estatísticos para verificação das hipóteses de independência, homogeneidade, estacionaridade e verificação da presença de "outliers".

Para verificar a presença de outliers nas séries foi aplicado o teste de Grubbs e Beck (GRUBBS e BECK, 1972) nas séries de precipitações com 45 elementos determinou um coeficiente estatístico $\mathrm{K}_{\mathrm{N}}=2,7278$, para um nível de significância de 10 $\%$, que resultou nos limites superior $X_{H}=149 \mathrm{~mm}$ e inferior $X_{L}=21 \mathrm{~mm}$. Uma vez que os valores de vazões máximas das séries estão dentro destes limites, conclui-se que não existem "outliers" nas séries. 
As séries de precipitações foram submetidas ao teste de Wald-Wolfowitz (RAO E HAMED, 2000) para verificação da independência e estacionaridade dos valores. A aplicação deste teste para as diferentes séries resultou, invariavelmente, em coeficientes estatísticos $(\mathrm{u}=1,32$ para séries de máximos anuais e $\mathrm{u}=1,33$ para série parcial) $\mathrm{u}<$ $\mathrm{u}_{\alpha / 2}=1,96$, que permite aceitar a hipótese de independência para um nível de significância $\alpha=5 \%$.

Tabela 46 - Série de duração parcial de precipitações máxima de 12 horas da estação do observatório IAG localizado em São Paulo/SP

\begin{tabular}{cccccccccc}
\hline \hline ANO & $\mathrm{P}(\mathrm{mm})$ & ANO & $\mathrm{P}(\mathrm{mm})$ & ANO & $\mathrm{P}(\mathrm{mm})$ & ANO & $\mathrm{P}(\mathrm{mm})$ & ANO & $\mathrm{P}(\mathrm{mm})$ \\
\hline 1934 & 38 & 1964 & 46 & 1979 & 33 & 1987 & 38 & 1993 & 41 \\
1936 & 48 & 1964 & 33 & 1979 & 49 & 1987 & 60 & 1993 & 45 \\
1938 & 72 & 1964 & 31 & 1979 & 34 & 1988 & 48 & 1993 & 25 \\
1944 & 68 & 1964 & 26 & 1980 & 33 & 1988 & 55 & 1993 & 45 \\
1945 & 58 & 1965 & 53 & 1980 & 71 & 1988 & 48 & 1993 & 41 \\
1947 & 46 & 1965 & 28 & 1980 & 77 & 1988 & 76 & 1994 & 34 \\
1948 & 75 & 1965 & 67 & 1981 & 30 & 1989 & 54 & 1994 & 40 \\
1951 & 53 & 1966 & 57 & 1981 & 46 & 1989 & 36 & 1994 & 57 \\
1956 & 30 & 1966 & 139 & 1981 & 42 & 1989 & 35 & 1995 & 38 \\
1956 & 40 & 1966 & 32 & 1982 & 75 & 1989 & 45 & 1995 & 43 \\
1957 & 35 & 1966 & 42 & 1982 & 94 & 1989 & 40 & 1995 & 64 \\
1957 & 58 & 1969 & 61 & 1982 & 42 & 1989 & 63 & 1995 & 55 \\
1957 & 48 & 1971 & 125 & 1982 & 62 & 1989 & 30 & 1995 & 29 \\
1958 & 45 & 1972 & 65 & 1983 & 87 & 1989 & 59 & 1996 & 58 \\
1959 & 60 & 1972 & 84 & 1983 & 35 & 1990 & 55 & 1996 & 35 \\
1959 & 32 & 1972 & 48 & 1983 & 41 & 1990 & 38 & 1996 & 31 \\
1959 & 30 & 1972 & 67 & 1983 & 45 & 1990 & 43 & 1997 & 35 \\
1960 & 55 & 1974 & 27 & 1983 & 38 & 1990 & 32 & 1997 & 31 \\
1961 & 27 & 1974 & 25 & 1984 & 35 & 1990 & 29 & 1997 & 40 \\
1961 & 58 & 1975 & 29 & 1984 & 25 & 1991 & 55 & 1997 & 39 \\
1961 & 27 & 1976 & 29 & 1984 & 37 & 1991 & 56 & 1998 & 30 \\
1961 & 69 & 1976 & 54 & 1984 & 51 & 1991 & 40 & 1998 & 25 \\
1961 & 34 & 1976 & 43 & 1985 & 36 & 1991 & 78 & 1998 & 34 \\
1961 & 42 & 1977 & 43 & 1986 & 52 & 1991 & 44 & & \\
1961 & 47 & 1977 & 82 & 1987 & 58 & 1992 & 42 & & \\
\hline \hline
\end{tabular}

Fonte: www.daee.org.br

Tabela 47 - Série de máximos anuais de precipitações máxima de 12 horas da estação do observatório IAG localizado em São Paulo/SP

\begin{tabular}{cccccccccc}
\hline \hline ANO & $\mathrm{P}(\mathrm{mm})$ & ANO & $\mathrm{P}(\mathrm{mm})$ & ANO & $\mathrm{P}(\mathrm{mm})$ & ANO & $\mathrm{P}(\mathrm{mm})$ & ANO & $\mathrm{P}(\mathrm{mm})$ \\
\hline 1934 & 38 & 1957 & 58 & 1969 & 61 & 1981 & 46 & 1990 & 55 \\
1936 & 48 & 1958 & 45 & 1971 & 125 & 1982 & 94 & 1991 & 78 \\
1938 & 72 & 1959 & 60 & 1972 & 84 & 1983 & 87 & 1992 & 42 \\
1944 & 68 & 1960 & 55 & 1974 & 27 & 1984 & 51 & 1993 & 45 \\
1945 & 58 & 1961 & 69 & 1975 & 29 & 1985 & 36 & 1994 & 57 \\
1947 & 46 & 1963 & 24 & 1976 & 54 & 1986 & 52 & 1995 & 64 \\
1948 & 75 & 1964 & 46 & 1977 & 82 & 1987 & 60 & 1996 & 58 \\
1951 & 53 & 1965 & 67 & 1979 & 49 & 1988 & 76 & 1997 & 40 \\
1956 & 40 & 1966 & 139 & 1980 & 77 & 1989 & 63 & 1998 & 34 \\
\hline \hline
\end{tabular}


Foi aplicado o teste de Mann-Whitney (RAO E HAMED, 2000) para verificação das hipóteses de homogeneidade e estacionaridade das séries de precipitações. Para isso, as séries foram divididas em diferentes sub-séries complementares. A aplicação deste teste para diferentes amostras resultou, invariavelmente, em coeficientes estatísticos $\mathrm{u}<$ $\mathrm{u}_{\alpha / 2}=1,96$, que permite aceitar a hipótese de homogeneidade para um nível de significância $\alpha=5 \%$.

Portanto, conclui-se que as séries de vazões máximas anuais e parciais podem ser consideradas consistentes, significativas e representativas.

\subsection{3 - Aplicação do Método Estatístico}

Na utilização da metodologia estatística foram testadas 13 distribuições. Estas distribuições foram verificadas utilizando os testes qui-quadrado e KolmogorovSmirnov (K-S). Foram analisadas as seguintes distribuições: normal (N), log-normal 2 parâmetros (LN2), log-normal 3 parâmetros (LN3), gama (GAM), Pearson tipo III (PIII), log-Pearson tipo III (LP-III), Gumbel (EV1), Weibull (WEIB), logística (LOG), GEV, wakeby, pareto generalizado (GPAR) e logística generalizado (GLOG).

As distribuições foram ajustadas à série de precipitações máximas, cuja posição de plotagem foi definida pela fórmula de Weibull. A estimativa dos parâmetros das diferentes distribuições foi feita pelo método da máxima verossimilhança (ML), método dos momentos (MOM) e método dos momentos com pesos probabilísticos (PWM).

A partir da aplicação da metodologia estatística, apresenta-se na figura 33 a 35 para cada método de estimação dos parâmetros, as curvas das distribuições probabilísticas ajustadas para as duas séries (parcial e anual). As tabelas 48 a 50 apresentam para cada método de estimação dos parâmetros, as vazões máximas decamilenares, milenares e centenárias, inferidas a partir das distribuições probabilísticas ajustadas a cada uma das séries de vazões. Estas tabelas apresentam a diferença percentual (D\%) entre os valores inferidos, utilizando diversas distribuições e estimadores. 
Tabela 48 -Método Estatístico - Vazões máximas decamilenares $\left(Q_{10000}\right)$, milenares $\left(Q_{1000}\right)$ e centenárias $\left(\mathbf{Q}_{100}\right)$ ajustada pelo método $\mathrm{ML}$ para as diferentes séries (duração parcial (DP) e máxima anual (MA))

\begin{tabular}{cccccccccr}
\hline \hline DIST. & & Q $_{10000}$ & & & Q $_{1000}$ & & \multicolumn{2}{c}{ Q $_{100}$} \\
AJUST. & M.A & D.P. $^{2}$ & DIF.(\%) & M.A & D.P. & DIF.(\%) & M.A & D.P. & DIF.(\%) \\
\hline GEV & 219 & 331 & 51 & 174 & 205 & 18 & 131 & 124 & 6 \\
P-III & 189 & & & 158 & & & 126 & & \\
LN3 & 211 & 258 & 22 & 169 & 181 & 7 & 128 & 120 & 7 \\
GLOG & 362 & & & 226 & & & 141 & & \\
EV1 & 206 & 157 & 32 & 167 & 127 & 31 & 128 & 98 & 30 \\
GPAR & 153 & 158 & 3 & 146 & 139 & 5 & 132 & 112 & 17 \\
WEIB & 138 & 120 & 15 & 129 & 112 & 16 & 117 & 101 & 17 \\
N & 144 & 118 & 23 & 130 & 106 & 23 & 113 & 91 & 23 \\
EXP & 360 & 236 & 52 & 275 & 183 & 50 & 191 & 130 & 47 \\
LOG & 165 & 134 & 23 & 138 & 112 & 23 & 111 & 90 & 24 \\
LN2 & 211 & 162 & 30 & 169 & 130 & 29 & 128 & 100 & 28 \\
GAM & 172 & 137 & 26 & 147 & 117 & 26 & 120 & 95 & 25 \\
LP-III & 216 & 312 & 45 & 171 & 200 & 17 & 129 & 124 & 4 \\
\hline \hline
\end{tabular}
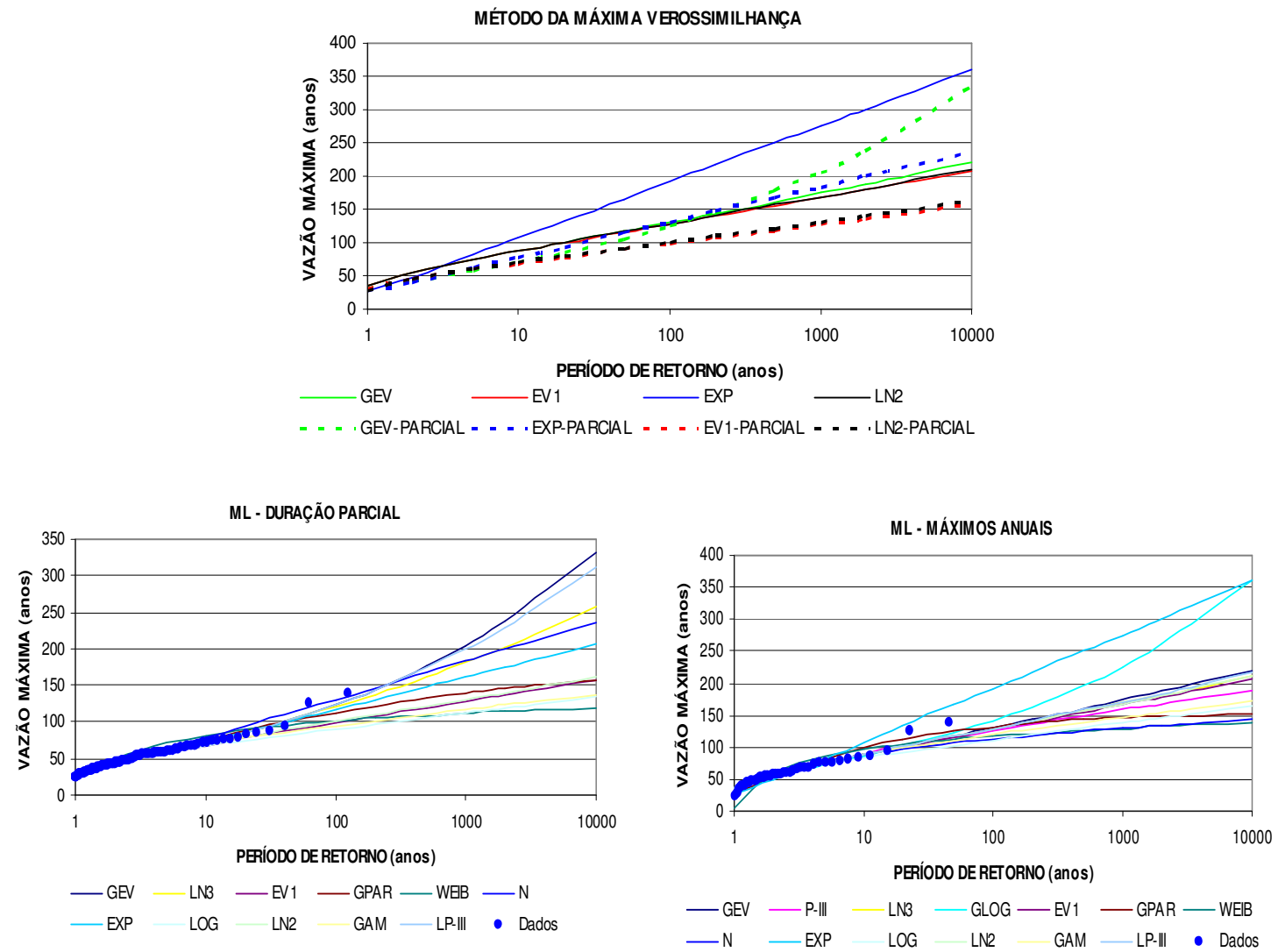

Figura 33 - Método Estatístico- comparação das distribuições ajustadas pelo método ML utilizando as diferentes séries (parcial-anual, duração parcial e máximos anuais). 
Tabela 49 - Método Estatístico - Vazões máximas decamilenares $\left(Q_{10000}\right)$, milenares $\left(Q_{1000}\right)$ e centenárias $\left(Q_{100}\right)$ ajustada pelo método MOM para as diferentes séries (duração parcial (DP) e máxima anual (MA))

\begin{tabular}{|c|c|c|c|c|c|c|c|c|c|}
\hline \multirow{2}{*}{$\begin{array}{l}\text { DIST. } \\
\text { AJUST. }\end{array}$} & \multicolumn{3}{|c|}{$\mathrm{Q}_{10000}$} & \multicolumn{3}{|c|}{$\mathrm{Q}_{1000}$} & \multicolumn{3}{|c|}{$\mathrm{Q}_{100}$} \\
\hline & M. $A^{1}$ & D.P. ${ }^{2}$ & DIF. $(\%)^{3}$ & M.A & D.P. & DIF.(\%) & M.A & D.P. & DIF.(\%) \\
\hline GEV & 237 & 225 & 6 & 183 & 162 & 13 & 134 & 112 & 20 \\
\hline P-III & 220 & 200 & 10 & 177 & 156 & 14 & 134 & 114 & 18 \\
\hline LN3 & 235 & 217 & 8 & 182 & 161 & 13 & 134 & 113 & 19 \\
\hline GLOG & 275 & 250 & 10 & 192 & 166 & 16 & 132 & 110 & 21 \\
\hline EV1 & 213 & 174 & 22 & 172 & 140 & 22 & 131 & 107 & 23 \\
\hline GPAR & 190 & 189 & 0 & 166 & 153 & 9 & 134 & 114 & 18 \\
\hline WEIB & 209 & 193 & 8 & 173 & 154 & 12 & 134 & 114 & 18 \\
\hline$N$ & 144 & 118 & 23 & 130 & 106 & 23 & 113 & 91 & 23 \\
\hline EXP & 246 & 202 & 22 & 194 & 159 & 22 & 142 & 115 & 23 \\
\hline LOG & 175 & 143 & 22 & 146 & 119 & 23 & 117 & 95 & 23 \\
\hline LN2 & 219 & 182 & 20 & 174 & 143 & 21 & 131 & 107 & 22 \\
\hline GAM & 183 & 150 & 21 & 155 & 127 & 22 & 125 & 102 & 23 \\
\hline LP-III & 238 & 224 & 7 & 183 & 162 & 13 & 134 & 112 & 19 \\
\hline
\end{tabular}
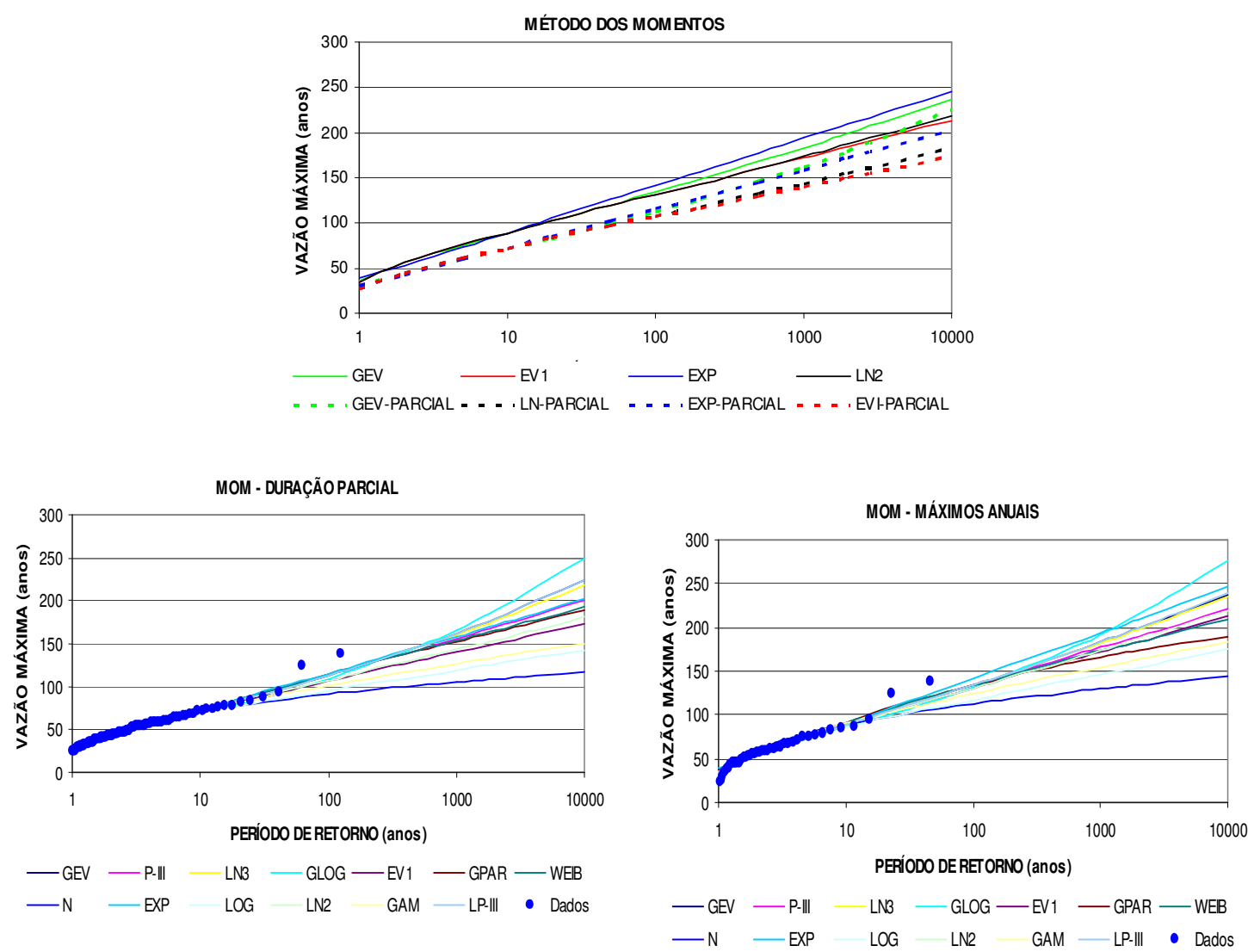

Figura 34 - Método Estatístico - comparação das distribuições ajustadas pelo método MOM utilizando as diferentes séries (parcial-anual, duração parcial e máximos anuais). 
Tabela 50 - Método Estatístico - Vazões máximas decamilenares $\left(\mathbf{Q}_{10000}\right)$, milenares $\left(\mathbf{Q}_{1000}\right)$ e centenárias $\left(Q_{100}\right)$ ajustada pelo método PWM para as diferentes séries (duração parcial (DP) e máxima anual (MA))

\begin{tabular}{cccrrrrrrr}
\hline \hline DIST. & & Q $_{10000}$ & & & \multicolumn{1}{c}{ Q $_{1000}$} & & Q $_{100}$ & \\
AJUST. & M.A $^{1}$ & D.P. $^{2}$ & DIF.(\%) & M.A & D.P. & DIF.(\%) & M.A & D.P. & DIF.(\%) \\
\hline \hline GEV & 234 & 250 & 7 & 182 & 173 & 5 & 134 & 115 & 16 \\
P-III & 204 & 182 & 12 & 167 & 146 & 15 & 130 & 109 & 19 \\
LN3 & 227 & 219 & 4 & 178 & 161 & 10 & 132 & 113 & 17 \\
GLOG & 347 & 361 & 4 & 221 & 206 & 7 & 140 & 119 & 17 \\
EV1 & 209 & 168 & 25 & 169 & 136 & 25 & 129 & 104 & 25 \\
GPAR & 137 & 135 & 1 & 131 & 123 & 7 & 119 & 104 & 15 \\
WEIB & 186 & 169 & 10 & 158 & 139 & 13 & 127 & 108 & 18 \\
N & 139 & 111 & 25 & 126 & 101 & 25 & 109 & 88 & 25 \\
EXP & 257 & 207 & 24 & 202 & 162 & 25 & 146 & 117 & 25 \\
LOG & 170 & 137 & 25 & 143 & 115 & 25 & 115 & 92 & 25 \\
LN2 & 214 & 172 & 24 & 171 & 137 & 24 & 129 & 104 & 25 \\
GAM & 175 & 141 & 24 & 149 & 120 & 24 & 121 & 97 & 25 \\
LP-III & 207 & 249 & 21 & 167 & 173 & 4 & 128 & 116 & 10 \\
\hline \hline
\end{tabular}
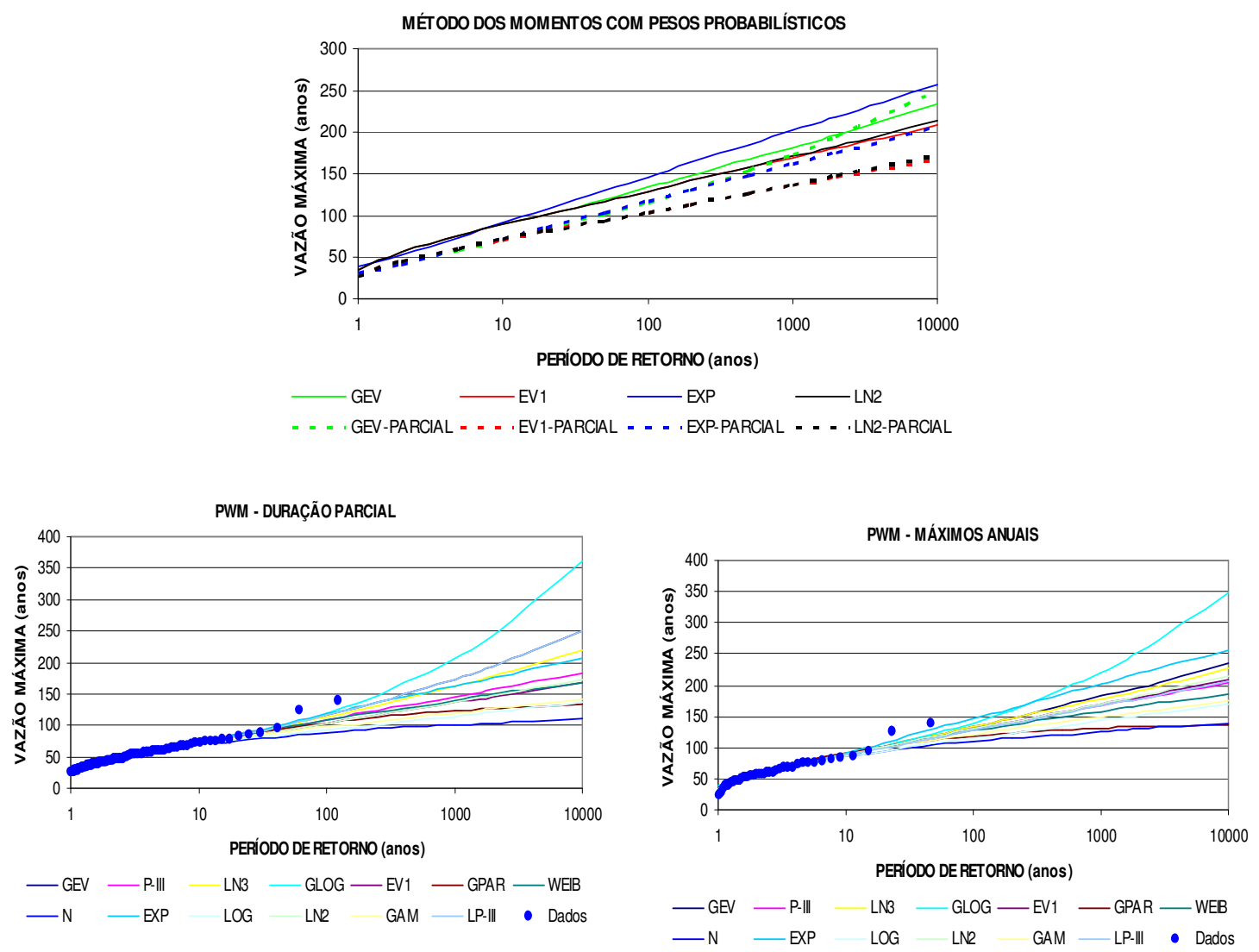

Figura 35 - Método Estatístico- comparação das distribuições ajustadas pelo método PWM utilizando as diferentes séries (parcial-anual, duração parcial e máximos anuais). 
A análise das citadas tabelas e figuras permitem verificar que, de uma forma geral as influências da extensão da série de precipitação não resultou em diferenças tão significativas (diferença máxima de $52 \%$ ) quanto os resultados para série de vazões (diferença máxima de $201 \%$ obtida na seção 2.1.3). Observa-se que as diferenças se mostraram mais contundentes para o ajuste através do método da máxima verossimilhança. Ressalta-se a grande diferença obtida nos valores utilizando diferentes distribuições ajustadas para as mesmas séries, um exemplo é que para séries de máximos anuais a diferença máxima foi de $162 \%$ para vazões decamilenares ajustadas pelo método da máxima verossimilhança, $91 \%$ pelo método dos momentos e $153 \%$ pelo método dos momentos com pesos probabilísticos.

Essas diferenças demonstram o mesmo problema verificado para série de vazões, ou seja, apesar do bom ajuste da distribuição em relação aos pontos, não garante a consistência da extrapolação. Vale salientar que no caso da série de precipitações estas diferenças se deram numa proporção bem maior. Esses inconvenientes no caso de série de precipitações podem ser agravados no decorrer do processo de definição da vazão de projeto através de um modelo chuva-vazão, pois os condicionantes empregados no modelo podem levar a resultados ainda mais discrepantes e irreais.

\subsection{4 - Aplicação do Método Conjugado}

Como já comentado, para aplicação do método conjugado uma boa definição do parâmetro VMP é de fundamental importância, pois ele vai servir como ponto determinante na boa definição dos valores máximos de projetos para altos períodos de retorno. Assim é importante sempre uma boa descrição dos procedimentos utilizados para determinação da PMP (Para o caso de séries de precipitação), uma vez que o conhecimento das técnicas que foram utilizadas permitirá que o decisor tenha uma decisão mais crítica a cerca dos valores inferidos, além de permitir o prévio conhecimento das características hidrometeorológicas da bacia.

A descrição resumida dos processos de obtenção do valor da PMP utilizado nesta seção de análise foi retirada de um trabalho desenvolvido por Gomes et al. (1983) que descreveram objetivamente os estudos desenvolvidos para a estimativa da razão de 
maximização e a posteriori a definição da precipitação máxima provável para qualquer duração para séries da bacia do rio Tamanduateí.

O procedimento para definição da PMP para séries da bacia do rio Tamanduateí foi feito através da maximização de tormentas observadas, fazendo a avaliação da máxima água precipitável. A maximização das tormentas sobre a bacia do rio Tamanduateí pode ser sintetizado nos seguintes passos:

- Determinação da distribuição isoiética responsável pela produção de vazões máximas na bacia. Normalmente faz-se a determinação da distribuição isoiética percentual das principais tormentas observadas. Esta distribuição é obtida pela superposição das isoietas médias anuais para levar-se em conta o efeito orográfico. No caso da bacia do rio Tamanduateí, a tormenta que produziu os maiores deflúvio registrados em seu histórico hidrológico ocorreu no dia 6 de fevereiro de 1982. Para uma bacia de $310 \mathrm{~km}^{2}$, estimou-se o pico de onda de cheia entre 400 e $450 \mathrm{~m} 3 / \mathrm{s}$.

- Determinação do máximo ponto de orvalho de 12 horas consecutivas, máxT $0(12 \mathrm{~h})$, antecedentes à ocorrência da tormenta, representativo do máximo potencial de suprimento de umidade de massa de ar geradora da tormenta. Foram utilizados os pontos de orvalhos registrados nos dias 6 e 7 de fevereiro de 1982 no instituto Astronômico e Geofísico (IAG) da USP, situado na bacia em estudo. Esta estação é a mesma da série de precipitações utilizadas no presente estudo. Observou-se que o máximo ponto de orvalho médio de 12 horas consecutivas relativo ao dia 6 de fevereiro de 1982 foi de $18,5^{\circ} \mathrm{C}$.

- Redução do máxT ${ }_{0}(12 \mathrm{~h})$ para o nível médio do mar. Esta redução é feita através de diagrama pseudo-adiabático utilizando tabelas dispostas na literatura (Bertoni, 1993 In: TUCCI, 1993), em função da altitude do posto meteorológico que forneceu os dados. Este ponto de orvalho é designado por máx $\mathrm{T}_{0}(12 \mathrm{~h}, \mathrm{NMM})$ e no caso em estudo é igual a $21{ }^{\circ} \mathrm{C}$.

- Determinação da máxima água precipitável $\mathrm{PW}_{1}(\mathrm{NMM})$ correspondente ao máxT $T_{0}(12 \mathrm{~h}, \mathrm{NMM})$. A máxima água precipitável $\mathrm{PW}_{1}(\mathrm{NMM})$ foi avaliada em função do máx $\mathrm{T}_{0}(12 \mathrm{~h}, \mathrm{NMM})$ conforme recomendação da World Meteorological Organization contidas na sua publicação Manual for Estimation of Probable Maximum Precipitation (1973), correspondendo a $57 \mathrm{~mm}$.

- Determinação das barreiras de afluência. A barreira de influencia é estabelecida pelo contorno dos pontos mais elevados do terreno que se antepõem ao fluxo de umidade. A presença de uma barreira causa uma redução de água precipitável que poderia afluir à 
bacia em virtude da sua altitude. Definiu-se a barreira de afluência do trecho do Planalto Paulistano em que se insere a bacia do rio Tamanduateí na cota $600 \mathrm{~m}$.

- Determinação da máxima água precipitável $\mathrm{PW}_{1}\left(\mathrm{H}_{\mathrm{B}}\right)$ correspondente à tormenta observada, descontando-se o efeito da barreira de afluência. O fator de desconto da barreira de afluência $\triangle \mathrm{PW}_{1}\left(\mathrm{NMM}, \mathrm{H}_{\mathrm{B}}\right)$ correspondente à água precipitável entre o nível do mar e topo da barreira de afluência.

- Determinação do máximo ponto de orvalho de projeto para cada mês do ano. A partir das séries históricas de máxT $T_{0}(12 \mathrm{~h})$ mensais no posto do Instituto Astronômico e Geofísico da USP, foram feitos os estudos de probabilidade de ocorrência de máx $\mathrm{T}_{0}(12 \mathrm{~h})$ para os diferentes meses do ano. A distribuição normal revelou o melhor ajuste à série de dados. As séries foram ajustadas para pressão de $1000 \mathrm{mb}$ através do diagrama pseudo-adiabático. Em função do mês de ocorrência da tormenta a ser maximaizada e do período de retorno, determina-se:

$\bar{T}_{0}(12 h, N M M)=24,5^{\circ} C$

A água precipitável correspondente, descontando-se os efeitos da barreira de afluência foi avaliada em $65,0 \mathrm{~mm}$.

- Determinação do coeficiente $K_{0}$ de maximização da tormenta correspondente à máxima água precipitável. $\mathrm{O}$ fator de maximização $\mathrm{K}_{0}$ corresponde à relação entre a água precipitável no dia em que ocorreu a tormenta a ser maximizada. No caso da bacia do rio Tamanduateí o fator $\mathrm{K}_{0}$ foi igual 1,38.

Na determinação da PMP para as análises pretendidas neste estudo, multiplicouse o fator de maximização pelo maior valor registrado na série de máximos de precipitação do Observatório Instituto Astronômico e Geofísico (IAG). O valor obtido foi de $191,8 \mathrm{~mm}$ e arredondado para $200 \mathrm{~mm}$.

A partir do valor do parâmetro VMP obtido a partir dos procedimentos descritos para o cálculo da PMP, aplicou-se o método conjugado. Apresenta-se na figura 36 para cada método de estimação dos parâmetros as curvas de distribuição probabilística do método conjugado ajustadas para as duas séries. A tabela 51 apresenta para cada método de estimação dos parâmetros as vazões máximas para diferentes períodos de retorno, inferidas a partir das distribuições probabilísticas ajustadas a cada uma das séries de vazões. 
As análises da citada tabela permitem verificar que a influência do uso do modelo de duração parcial (série com maior número de dados) utilizando o método conjugado mostrou-se pequena para valores de precipitação com altos períodos de retorno. Para baixos períodos de retorno observou-se uma diferença maior em virtude da grande diferença entre os dados de cada uma das séries concentrados na cauda inferior. Essa diferença é refletida nos ajustes da curva de freqüência conjugadas aos dados. Uma comparação entre os valores obtidos utilizando as mesmas séries, permite concluir uma pequena diferença entre os valores obtidos para diferentes métodos de estimação de parâmetros. Um exemplo é que para séries de máximos anuais a diferença máxima foi de $13 \%$ para vazões decamilenares e para séries de duração parcial a diferença máxima foi de $11 \%$.

Esses resultados demonstram que a utilização de séries parciais tem pouca influência nos valores inferidos para altos períodos de retorno utilizando o método conjugado. Como visto anteriormente, a aplicação de conceitos probabilísticos em série de dados hidrometeorológicos parte do princípio que foram atendidos os critérios estatísticos de aleatoriedade, independência, homogeneidade e estacionaridade. Foi comentado também, que um dos maiores inconvenientes práticos com a utilização de séries de durações parciais é a garantia da hipótese de independência. Essa questão é minimizada no método conjugado, uma vez que, conforme mostrados neste trabalho, os valores extremos das variáveis hidrológicas não dependem significativamente da extensão da série hidrológica. Assim, quando existe dificuldade em garantir a hipótese de independência de uma série extensa de dados, pode-se optar por utilizar apenas uma parte dessa série ou a série de máximos anuais nas quais esses critérios sejam atendidos sem prejuízo dos resultados a serem inferidos pelo método conjugado.

Ressalta-se que as análises utilizando série de precipitações aplicadas neste trabalho e em outras publicações (SOUZA, 2005a, GARCIA, 1996) mostraram que o método conjugado é aplicável a esse tipo de série, mantendo as mesmas características apresentadas nas análises utilizando séries de vazões. 
Tabela 51 - Método Conjugado - análise utilizando as séries de duração parcial e série de máximos anuais utilizando os métodos MOM, ML e MLS.

\begin{tabular}{ccccccccccc}
\hline \hline $\begin{array}{c}\text { Probabilidade } \\
\text { de Excedência }\end{array}$ & $\begin{array}{c}\text { Período } \\
\text { de } \\
\text { Retorno } \\
\text { (anos) }\end{array}$ & Anual & Parcial & $\begin{array}{c}\text { Máxima } \\
(\%)\end{array}$ & Anual & Parcial & $\begin{array}{c}\text { Máxima } \\
(\%)\end{array}$ & $\begin{array}{c}\text { MLS } \\
\text { Anual }\end{array}$ & $\begin{array}{c}\text { Diferença } \\
\text { Parcial }\end{array}$ & $\begin{array}{c}\text { Máxima } \\
(\%)\end{array}$ \\
\hline 0,0001 & 10000 & 151 & 135 & 12 & 158 & 139 & 13 & 171 & 150 \\
0,0005 & 2000 & 141 & 123 & 14 & 147 & 128 & 15 & 161 & 138 \\
0,001 & 1000 & 136 & 118 & 15 & 142 & 122 & 16 & 156 & 132 \\
0,002 & 500 & 130 & 112 & 16 & 136 & 116 & 17 & 150 & 126 \\
0,005 & 200 & 122 & 103 & 18 & 127 & 107 & 19 & 141 & 116 \\
0,01 & 100 & 115 & 96 & 19 & 120 & 100 & 21 & 133 & 108 \\
0,02 & 50 & 107 & 89 & 21 & 112 & 92 & 22 & 124 & 100 \\
0,05 & 20 & 96 & 78 & 23 & 100 & 80 & 25 & 111 & 87 \\
0,1 & 10 & 87 & 69 & 26 & 90 & 71 & 28 & 98 & 76 \\
\hline \hline
\end{tabular}

MÉTODO DA MÁXIMA VEROSSIMILHANÇA

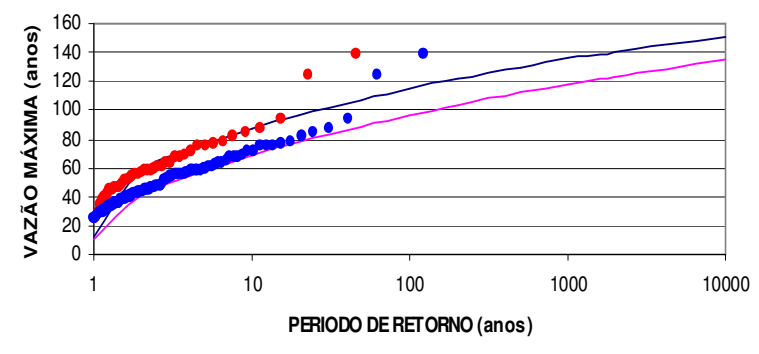

- MÁXIMOS ANUAIS —DURAÇÃO PARCIAL

- dados anuals - Dados parcials
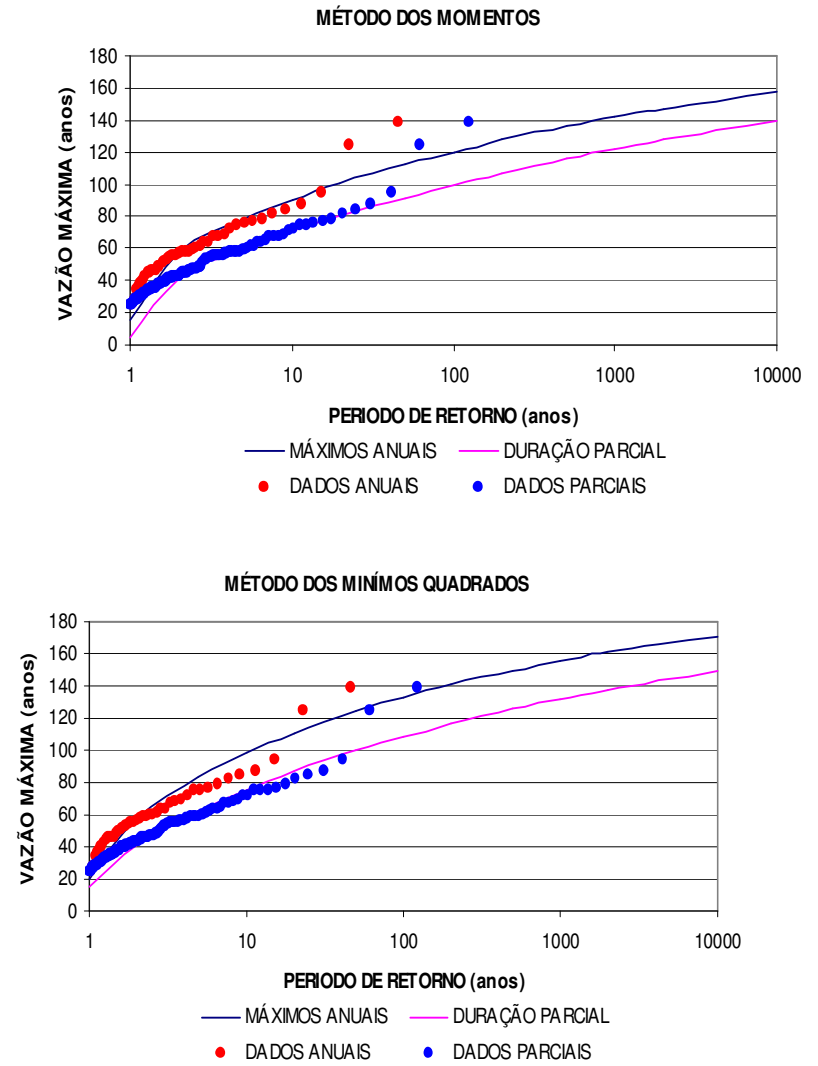

Figura 36 - Método conjugado - curva da distribuição probabilística ajustadas para as diferentes séries (duração parcial e máximos anuais) utilizando os método MOM, ML e MLS 


\subsection{Aplicação do Método Conjugado Utilizando a Distribuição Logística Generalizada Ajustada pelo Método dos Momentos com Pesos Probabilísticos}

\subsubsection{Introdução}

Como comentado na seção 3.2, o método conjugado caracteriza-se por um novo conceito e não por uma nova distribuição probabilística ou formulação matemática. Assim, é conveniente testar outros modelos probabilísticos de forma a comparar o desempenho dessa nova distribuição com o desempenho da distribuição GEV adotada por Garcia (1996). Foram pesquisadas diferentes distribuição e optou-se por utilizar a distribuição Logística Generalizada (GLOG) uma vez que atendia a todos os requisitos apresentados na seção 3.2. A aplicação da distribuição probabilística logística generalizada ao método conjugado e o método de estimação dos parâmetros utilizadas nesta análise está apresentado na seção 3.5.1 e 3.5.2.

O objetivo deste tipo de análise, de uma forma geral, é aplicar outra distribuição teórica de probabilidades mantendo o conceito de definição da distribuição do método conjugado através do ajustes aos dados observados e da fixação de um limite superior.

Serão aplicadas as mesmas análises feitas na seção 4.2 e 4.3, desta forma todos os critérios utilizados naquela análise serão utilizados neste exemplo. Serão colocados apenas os resultados e explicados em uma só seção de forma a tornar a comparação com as duas distribuições utilizando o método conjugado mais prática.

\subsubsection{Aplicação da Distribuição Logística Generalizada ao Conceito do método conjugado}

A partir da aplicação do método conjugado utilizando a distribuição logística generalizada, apresentam-se nas figuras 37 a 40, para o método dos momentos com pesos probabilísticos, as curvas de distribuição probabilística ajustadas para as diferentes séries em diversas análises (influência da extensão da série, influência da presença de outliers, influência dos menores valores da série de máximos e análise da sensibilidade do parâmetro VMP). As tabelas 56 a 60 apresentam as vazões máximas para diferentes períodos de retorno $\left(\mathrm{T}_{\mathrm{r}}\right)$, inferidas a partir das distribuições probabilísticas ajustadas a cada uma das séries das diferentes análises. Essas tabelas 
apresentam na ultima coluna, para cada período de retorno, a diferença percentual máxima entre as vazões inferidas para as diferentes séries. Nas tabela 52 a 55 apresenta os parâmetros do método conjugado utilizando a distribuição GLOG.

A análise das citadas tabelas e figuras permitem verificar que:

- Na análise da influência da extensão das séries, para toda gama de probabilidades (períodos de retorno), a diferença entre as vazões é, no máximo, de $12 \%$. Assim, através deste exemplo demonstra-se que o método conjugado utilizando a distribuição logística generalizada depende muito pouco da extensão da série de vazões e os valores obtidos para as vazões de projeto (por exemplo, $\mathrm{PR}=10.000$ anos) não diferem significativamente.

- Na análise da influência da presença de outliers, verifica-se que a inclusão do outlier provoca um incremento de, apenas, $6 \%$ na vazão decamilenar. Assim, este exemplo demonstra a diminuta influência de eventos extraordinários (outliers) na determinação dos valores máximos e na definição das vazões de projeto utilizando a análise de freqüência conjugada utilizando a distribuição logística generalizada.

- Na análise da influência dos menores valores da série de máximos verifica-se que a minoração em $20 \%$ dos valores mínimos da série de vazões resulta em diminuição dos valores extremos de, no máximo, 0,01\%. Por sua vez, a majoração entre 12 a $20 \%$ dos valores mínimos das séries de vazões resulta no incremento dos valores extremos de, no máximo, $1 \%$. Assim, constata-se que, na análise de freqüência conjugada utilizando a distribuição logística generalizada, os valores extremos não são influenciados significativamente pelos valores mínimos da série de valores máximos.

- Na análise da sensibilidade do parâmetro VMP verificou-se que as variações de $20 \%$ no valor do VMP refletem-se em variações de, no máximo, 3 \% nos valores extremos. Isto se deve ao comportamento assintótico do ramo superior da distribuição probabilística logística generalizada aplicada ao conceito do método conjugado. Portanto, constata-se que as variações no valor do VMP utilizando a distribuição logística generalizada não influenciam significativamente as vazões extremas.

A tabela 61 apresenta uma análise comparativa entre os valores obtidos na seção 4.2 (utilizou a distribuição GEV) com os obtidos nesta seção para algumas análises. A coluna representada por $\mathrm{Q}_{\mathrm{gev}}$ são os valores inferidos na seção 4.2 e a representada por $\mathrm{Q}_{\text {glog }}$ são os inferidos nesta seção. D (\%) representa a diferença máxima dos resultados. Verifica-se que os resultados inferidos resultaram uma diferença máxima de $16 \%$. Observa-se também que os valores inferidos aplicando o método conjugado utilizando a 
distribuição GEV resultaram em valores um pouco superiores aos valores inferidos aplicando o método utilizando a distribuição GLOG.

Por fim, conclui-se que o conceito do método conjugado se mostrou consistente uma vez que o uso de outro modelo probabilístico resultou em diferenças próximas aos obtidos utilizando o método conjugado utilizando a distribuição GEV. E numa análise comparativa com os valores apresentados na seção 4.2 (método conjugado utilizando a distribuição GEV) e nesta seção não diferiram significativamente.

Tabela 52- Parâmetros do MC/GLOG das sub-séries de vazões máximas da UHE de Sobradinho/BA - Método dos momentos com pesos probabilísticos $(\mathrm{PWM})-\mathrm{VMP}=36.300 \mathrm{~m}^{3} / \mathrm{s}$

\begin{tabular}{|c|c|c|c|}
\hline \multirow{2}{*}{$\mathrm{n}^{\mathrm{o}}$} & \multirow{2}{*}{ Série de vazões } & \multicolumn{2}{|c|}{ Parâmetros } \\
\hline & & Forma k & Posição $\varepsilon$ \\
\hline 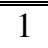 & $1931-1950$ & 0,03853 & 6707,689 \\
\hline 2 & $1931-1970$ & 0,031916 & 6249,163 \\
\hline 3 & $1931-2001$ & 0,034943 & 6181,178 \\
\hline 4 & $1951-2001$ & 0,033535 & 5970,899 \\
\hline 5 & $1971-2001$ & 0,039456 & 6093,889 \\
\hline
\end{tabular}

Tabela 53 - Parâmetros do MC/GLOG para análise da influência da presença do "outlier" da série de vazões máximas da UHE de Sobradinho/BA - Método dos momentos com pesos probabilísticos $(P W M)-V M P=36.300 \mathrm{~m}^{3} / \mathrm{s}$

\begin{tabular}{crr}
\hline \hline \multirow{2}{*}{ Série de Vazões } & \multicolumn{2}{c}{ Parâmetros } \\
& \multicolumn{1}{c}{ Forma k } & \multicolumn{1}{c}{ Posição $\varepsilon$} \\
\hline \hline 1948-1994 (sem outlier) & 0,034943 & 6181,178 \\
1948-1994 (com outlier) & 0,03859 & 6328,728 \\
\hline \hline
\end{tabular}

Tabela 54 - Parâmetros do MC/GLOG para análise da influência dos menores valores da série de valores máximos da série de vazões máximas da UHE de Sobradinho/BA - Método dos momentos com pesos probabilísticos $(\mathrm{PWM})-\mathrm{VMP}=36.300 \mathrm{~m}^{3} / \mathrm{s}$

\begin{tabular}{ccc}
\hline \multirow{2}{*}{ Série de Vazões } & \multicolumn{2}{c}{ Parâmetros } \\
& Forma k & Posição $\varepsilon$ \\
\hline \hline Original & 0,034943 & 6181,178 \\
Minorada & 0,035807 & 6156,376 \\
Majorada & 0,034195 & 6202,626 \\
\hline \hline
\end{tabular}

Tabela 55 - Parâmetros da MC/GLOG para análise de sensibilidade do parâmetro VMP da série de valores máximos da série de vazões máximas da UHE de Sobradinho/BA - Método dos momentos com pesos probabilísticos $(\mathrm{PWM})-\mathrm{VMP}=36.300 \mathrm{~m}^{3} / \mathrm{s}$

\begin{tabular}{cccc}
\hline \hline VMP & Variação & \multicolumn{2}{c}{ Parâmetros } \\
$\left(\mathrm{m}^{3} / \mathrm{s}\right)$ & $(\%)$ & Forma k & Posição u \\
\hline \hline 29040 & -20 & 0,046012 & 6200,333 \\
32670 & -10 & 0,039721 & 6189,449 \\
36300 & (original) & 0,034943 & 6181,178 \\
39930 & 10 & 0,031191 & 6174,681
\end{tabular}




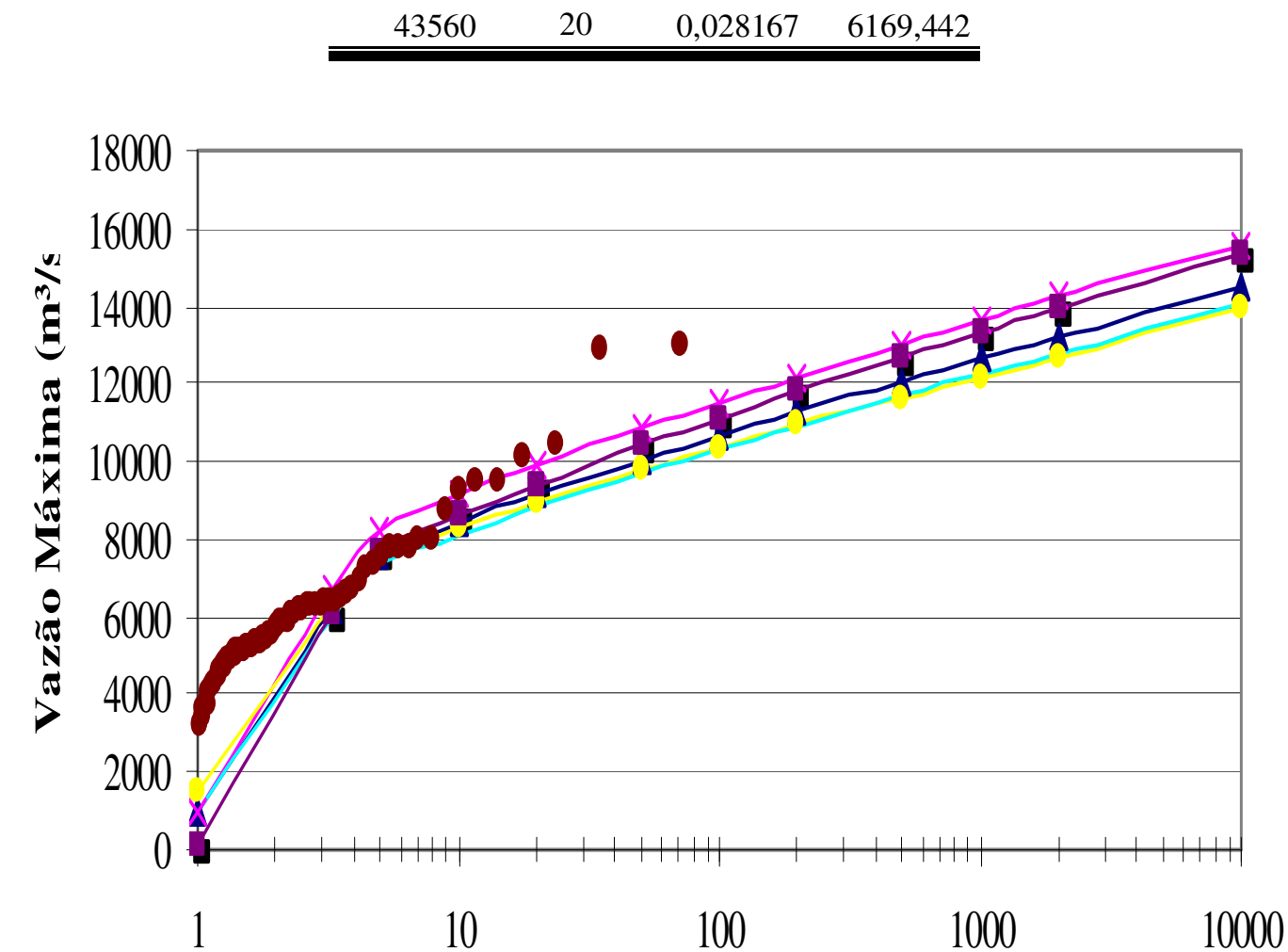

Período de Retorno (anos)

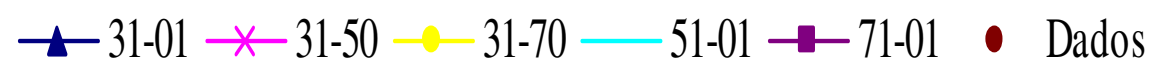

Figura 37 - Análise de freqüência conjugada/GLOG - Análise da influência da extensão da série de valores

Tabela 56 - Análise da influência da extensão da série de valores

\begin{tabular}{cccccccc}
\hline \hline $\begin{array}{c}\text { Probabilidade } \\
\text { de Excedência }\end{array}$ & $\begin{array}{c}\text { Período } \\
\text { de } \\
\text { Retorno } \\
\text { (anos) }\end{array}$ & $31-50$ & $31-70$ & $31-01$ & $51-01$ & $71-01$ & $\begin{array}{c}\text { Diferença } \\
\text { Máxima } \\
(\%)\end{array}$ \\
\hline \hline 0,0001 & 10000 & 15548 & 13903 & 14469 & 14030 & 15297 & 12 \\
0,0005 & 2000 & 14220 & 12722 & 13206 & 12795 & 13920 & 12 \\
0,001 & 1000 & 13622 & 12194 & 12639 & 12241 & 13299 & 12 \\
0,002 & 500 & 13007 & 11654 & 12059 & 11675 & 12660 & 12 \\
0,005 & 200 & 12167 & 10920 & 11267 & 10904 & 11787 & 12 \\
0,01 & 100 & 11509 & 10348 & 10649 & 10302 & 11103 & 12 \\
0,02 & 50 & 10828 & 9759 & 10011 & 9682 & 10394 & 12 \\
0,05 & 20 & 9881 & 8945 & 9126 & 8823 & 9407 & 12 \\
0,1 & 10 & 9110 & 8284 & 8407 & 8125 & 8602 & 12 \\
\hline \hline
\end{tabular}




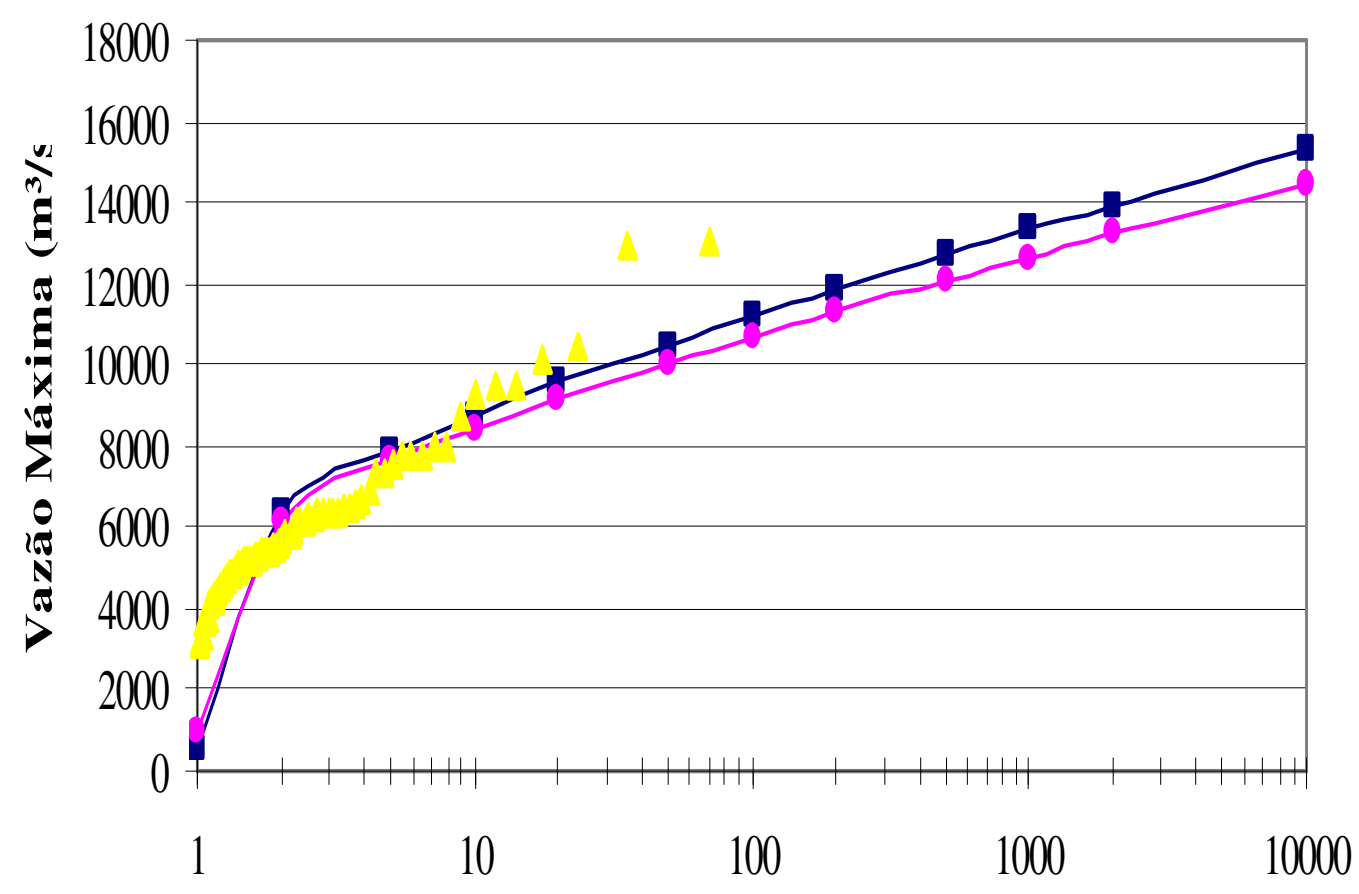

Período de Retorno (anos)

$\rightarrow$-com "outlier" do ano $1979 \rightarrow$ — semo "outlier" $\triangle$ Dados

Figura 38 - Análise de frequiência conjugada - Análise da influência da presença de "outliers"

Tabela 57 - Análise da influência da presença de "outliers"

\begin{tabular}{|c|c|c|c|c|}
\hline \multirow{2}{*}{$\begin{array}{l}\text { Probabilidade } \\
\text { de Excedência }\end{array}$} & \multirow{2}{*}{$\begin{array}{c}\text { Período } \\
\text { de } \\
\text { Retorno } \\
\text { (anos) } \\
\end{array}$} & \multicolumn{2}{|c|}{ Distribuições Probabilísticas } & \multirow{2}{*}{$\begin{array}{c}\text { Diferença } \\
\text { Máxima } \\
(\%)\end{array}$} \\
\hline & & $\mathrm{C} / O U T L I E R$ & S/OUTLIER & \\
\hline 0,0001 & 10000 & 15294 & 14469 & 6 \\
\hline 0,0005 & 2000 & 13947 & 13206 & 6 \\
\hline 0,001 & 1000 & 13341 & 12639 & 6 \\
\hline 0,002 & 500 & 12718 & 12059 & 5 \\
\hline 0,005 & 200 & 11866 & 11267 & 5 \\
\hline 0,01 & 100 & 11199 & 10649 & 5 \\
\hline 0,02 & 50 & 10508 & 10011 & 5 \\
\hline 0,05 & 20 & 9548 & 9126 & 5 \\
\hline 0,1 & 10 & 8765 & 8407 & 4 \\
\hline
\end{tabular}




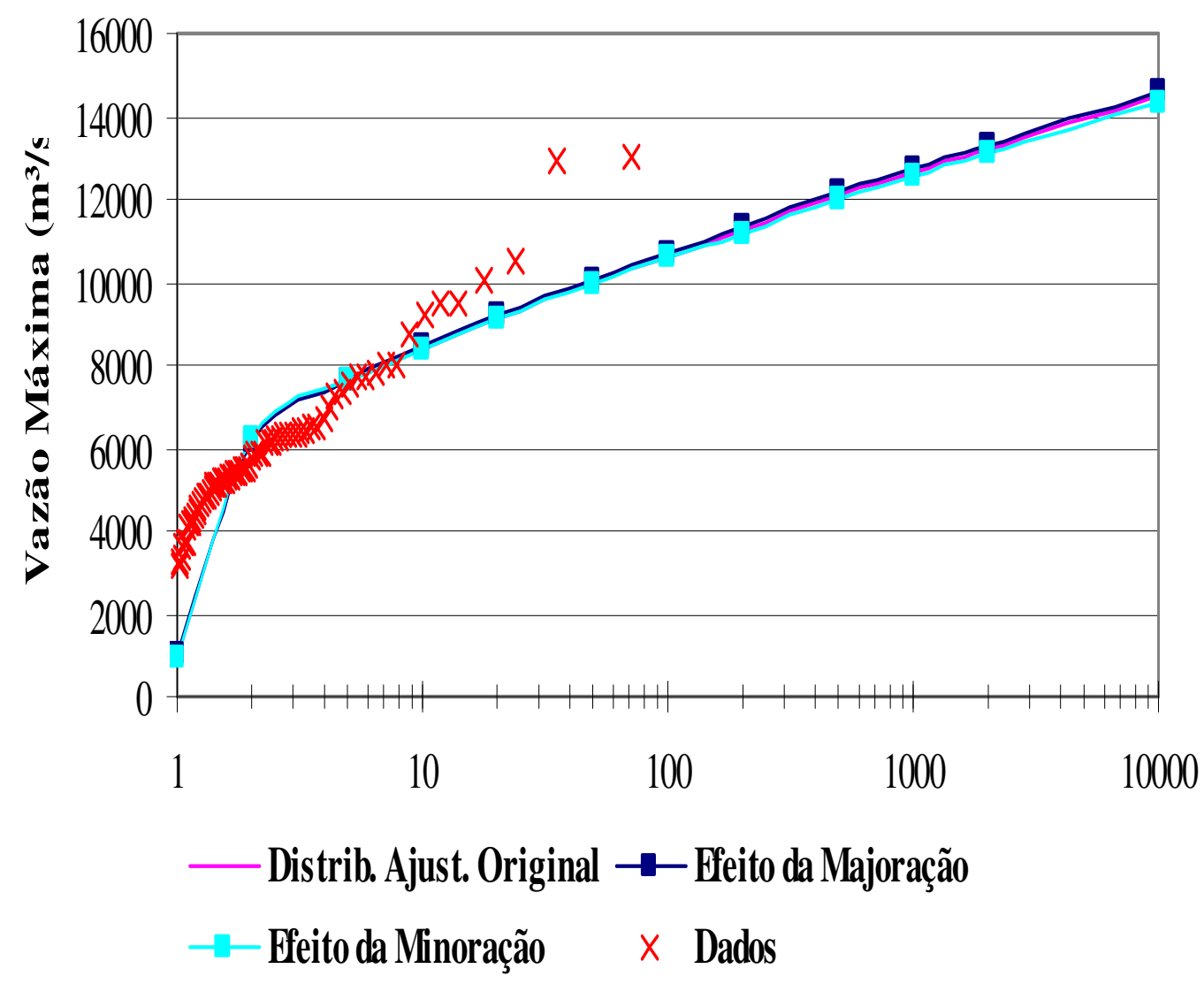

Figura 39 - Análise de freqüência conjugada - Análise da influência dos menores valores da série de valores máximos

Tabela 58 - Análise da influência dos menores valores da série de valores máximos

\begin{tabular}{|c|c|c|c|c|c|c|}
\hline $\begin{array}{c}\text { Probabilidade } \\
\text { de } \\
\text { Excedência }\end{array}$ & $\begin{array}{l}\text { Período } \\
\text { de } \\
\text { Retorno } \\
\text { (anos) }\end{array}$ & $\begin{array}{c}\text { Série } \\
\text { ORIGINAL }\end{array}$ & $\begin{array}{c}\text { Série com } \\
\text { valores } \\
\text { mínimos } \\
\text { MINORADOS }\end{array}$ & $\begin{array}{c}\text { Série com } \\
\text { valores } \\
\text { mínimos } \\
\text { MAJORADOS }\end{array}$ & $\begin{array}{l}\text { Diferenças das } \\
\text { vazões } \\
\text { máximas em } \\
\text { relação a série } \\
\text { original (\%) - } \\
\text { MINORADOS }\end{array}$ & $\begin{array}{l}\text { Diferenças das } \\
\text { vazões } \\
\text { máximas em } \\
\text { relação a série } \\
\text { original (\%) - } \\
\text { MAJORADOS }\end{array}$ \\
\hline 0,0001 & 10000 & 14469 & 14334 & 14625 & 0,01 & 1 \\
\hline 0,0005 & 2000 & 13206 & 13091 & 13338 & 0,01 & 1 \\
\hline 0,001 & 1000 & 12639 & 12534 & 12761 & 0,01 & 1 \\
\hline 0,002 & 500 & 12059 & 11963 & 12168 & 0,01 & 1 \\
\hline 0,005 & 200 & 11267 & 11186 & 11361 & 0,01 & 1 \\
\hline 0,01 & 100 & 10649 & 10579 & 10730 & 0,01 & 1 \\
\hline 0,02 & 50 & 10011 & 9953 & 10077 & 0,01 & 1 \\
\hline 0,05 & 20 & 9126 & 9085 & 9173 & 0,00 & 1 \\
\hline 0,1 & 10 & 8407 & 8381 & 8437 & 0,00 & 0 \\
\hline
\end{tabular}




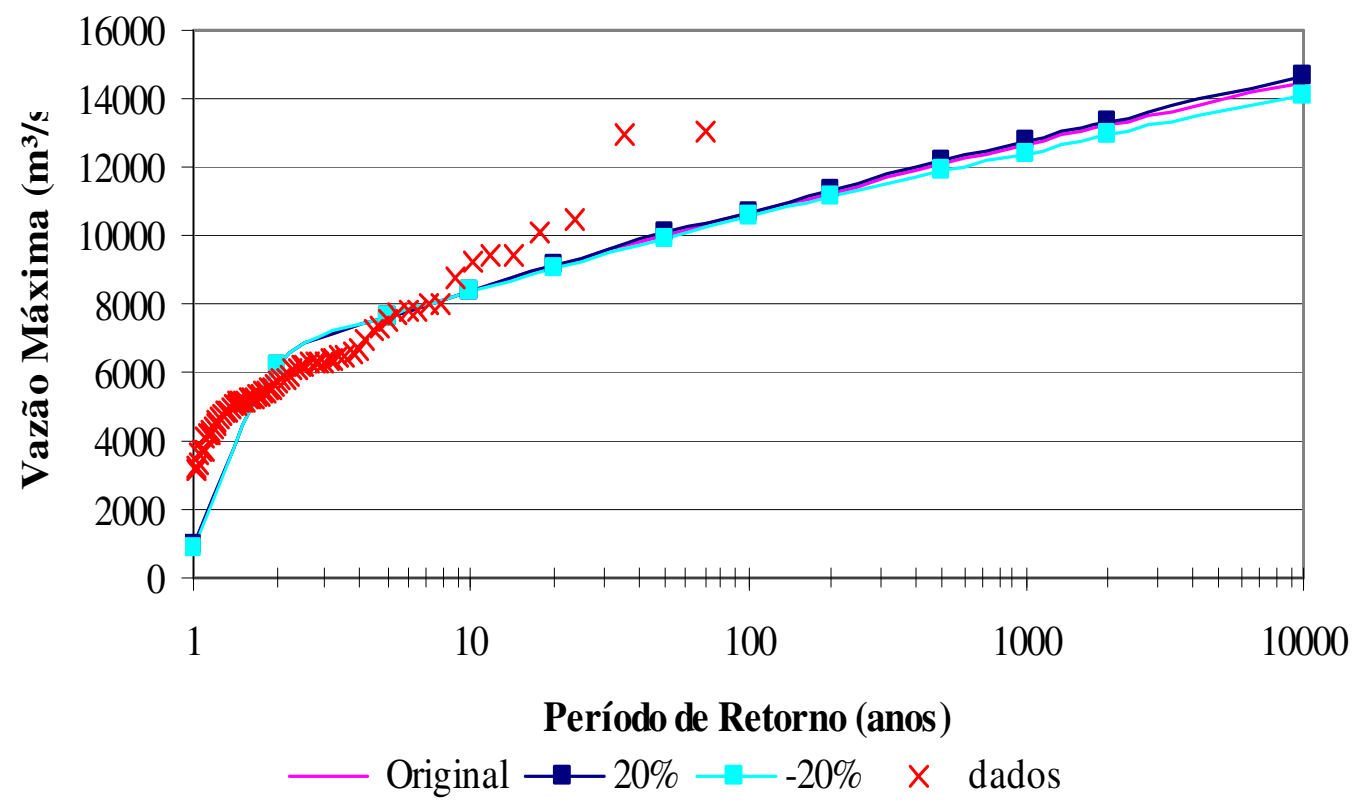

Figura 40 - Análise de freqüência conjugada - Análise de sensibilidade do parâmetro VMP

Tabela 59 - Análise de sensibilidade do parâmetro VMP

\begin{tabular}{ccrrrrr}
\hline \hline \multirow{2}{*}{$\begin{array}{c}\text { Probabilidade } \\
\text { de Excedência }\end{array}$} & $\begin{array}{c}\text { Período } \\
\text { de }\end{array}$ & \multicolumn{5}{c}{ Valor Máximo Provável VMP $\left(\mathrm{m}^{3} / \mathrm{s}\right)$} \\
\cline { 3 - 7 } & Retorno & $-20 \%$ & $-10 \%$ & original & $10 \%$ & $20 \%$ \\
\cline { 3 - 7 } (anos) & 29040 & 32670 & 36300 & 39930 & 43560 \\
\hline \hline 0,0001 & 10000 & 14090 & 14303 & 14469 & 14603 & 14713 \\
0,0005 & 2000 & 12940 & 13090 & 13206 & 13299 & 13375 \\
0,001 & 1000 & 12418 & 12543 & 12639 & 12717 & 12780 \\
0,002 & 500 & 11879 & 11980 & 12059 & 12121 & 12172 \\
0,005 & 200 & 11137 & 11211 & 11267 & 11312 & 11349 \\
0,01 & 100 & 10553 & 10607 & 10649 & 10682 & 10709 \\
0,02 & 50 & 9945 & 9982 & 10011 & 10033 & 10052 \\
0,05 & 20 & 9094 & 9112 & 9126 & 9137 & 9145 \\
0,1 & 10 & 8397 & 8403 & 8407 & 8411 & 8413 \\
\hline \hline
\end{tabular}

Tabela 60 - Análise de sensibilidade do parâmetro VMP - diferenças percentuais dos valores máximos

\begin{tabular}{|c|c|c|c|c|c|}
\hline \multirow{3}{*}{$\begin{array}{l}\text { Probabilidade } \\
\text { de Excedência }\end{array}$} & \multirow{3}{*}{$\begin{array}{l}\text { Período } \\
\text { de } \\
\text { Retorno } \\
\text { (anos) }\end{array}$} & \multicolumn{4}{|c|}{ "Variação dos Valores das Vazões Máximas } \\
\hline & & $-20 \%$ & $-10 \%$ & $10 \%$ & $20 \%$ \\
\hline & & 29040 & 32670 & 39930 & 43560 \\
\hline 0,0001 & 10000 & 3 & 1 & 1 & 2 \\
\hline 0,0005 & 2000 & 2 & 1 & 1 & 1 \\
\hline 0,001 & 1000 & 2 & 1 & 1 & 1 \\
\hline 0,002 & 500 & 2 & 1 & 1 & 1 \\
\hline 0,005 & 200 & 1 & 1 & 0 & 1 \\
\hline 0,01 & 100 & 1 & 0 & 0 & 1 \\
\hline 0,02 & 50 & 1 & 0 & 0 & 0 \\
\hline 0,05 & 20 & 0 & 0 & 0 & 0 \\
\hline 0,1 & 10 & 0 & 0 & 0 & 0 \\
\hline
\end{tabular}


Tabela 61 - Método Conjugado - Análise comparativa entre os valores obtidos utilizando a distribuição GEV com os obtidos utilizando a distribuição GLOG para diferentes análises

Vazões Máximas ( $\left.\mathrm{m}^{3} / \mathrm{s}\right)$ - Influência do Outliers

\begin{tabular}{|c|c|c|c|c|c|c|c|c|c|c|c|c|c|}
\hline \multirow[t]{2}{*}{$\mathrm{PE}^{1}$} & \multirow[t]{2}{*}{$\mathrm{TR}^{2}$} & \multicolumn{2}{|c|}{$\mathrm{S}-31-01^{1}$} & \multirow{2}{*}{$\begin{array}{l}\mathrm{D}^{3} \\
(\%)\end{array}$} & \multicolumn{2}{|c|}{$\mathrm{S}-$ outliers $^{2}$} & \multirow{2}{*}{$\begin{array}{l}\mathrm{D} \\
(\%)\end{array}$} & \multicolumn{2}{|c|}{$\begin{array}{c}\mathrm{S}- \\
\text { majorados }^{3}\end{array}$} & \multirow{2}{*}{$\begin{array}{l}\mathrm{D} \\
(\%)\end{array}$} & \multicolumn{2}{|c|}{$\begin{array}{c}\mathrm{S}-\mathrm{VMP}= \\
43560^{4}\end{array}$} & \multirow{2}{*}{$\begin{array}{c}\mathrm{D} \\
(\%)\end{array}$} \\
\hline & & $\mathrm{Q}_{\mathrm{gev}}$ & $\mathrm{Q}_{\mathrm{glog}}$ & & $\mathrm{Q}_{\mathrm{gev}}$ & $\mathrm{Q}_{\mathrm{glog}}$ & & $\mathrm{Q}_{\mathrm{gev}}$ & $\mathrm{Q}_{\mathrm{glog}}$ & & $\mathrm{Q}_{\mathrm{gev}}$ & $\mathrm{Q}_{\mathrm{glog}}$ & \\
\hline 0,0001 & 10000 & 16310 & 14469 & 13 & 16983 & 15294 & 11 & 17018 & 14625 & 16 & 16690 & & 13 \\
\hline 0,0005 & 2000 & 14717 & 13206 & 11 & 15325 & 13947 & 10 & 15343 & 13338 & 15 & 14977 & & 12 \\
\hline 0,001 & 1000 & 13992 & 12639 & 11 & 14568 & 13341 & 9 & 14577 & 12761 & 14 & 14206 & 12780 & 11 \\
\hline 0,002 & 500 & 13242 & 12059 & 10 & 13783 & 12718 & 8 & 137 & 12168 & 13 & 13413 & 12172 & 10 \\
\hline 0,005 & 200 & 12212 & 11267 & 8 & 12701 & 11866 & 7 & 126 & 11361 & 12 & 12332 & & 9 \\
\hline & 100 & 11400 & 10649 & 7 & 118 & 11199 & 6 & 11820 & 10730 & 10 & 11487 & 10709 & 7 \\
\hline 0,02 & 50 & 10558 & 10011 & 5 & 10957 & 10508 & 4 & 10919 & 10077 & 8 & 10615 & 10052 & 6 \\
\hline 0,05 & 20 & 9389 & 9126 & 3 & 9721 & 9548 & 2 & 9665 & 9173 & 5 & 9415 & 9145 & 3 \\
\hline 0,1 & 10 & & 8407 & 1 & & & 0 & & & 3 & 8458 & & 1 \\
\hline 0,2 & 5 & 16310 & 14469 & 13 & 16983 & 15294 & 11 & 17018 & 14625 & 16 & 16690 & 14713 & 13 \\
\hline 0,5 & 2 & 14717 & 13206 & 11 & 15325 & 13947 & 10 & 15343 & 13338 & 15 & 14977 & 13375 & 12 \\
\hline
\end{tabular}

${ }^{1}$ Série completa 31-71 sem a presença do outlier

${ }^{2}$ Série completa 31-01 com a presença do outlier

${ }^{3}$ Série completa 31-01 com o 3 menores valores da série majorados em $20 \%$

${ }^{4}$ Série completa 31-01 considerando o VMP $=43560$ 


\section{ANÁLISE CRÍTICA DO MÉTODO CONJUGADO}

No capítulo anterior foram feitas análises que permitiram constatar o método conjugado como um avanço em termos de melhoria que se tem quando deparado com alguns inconvenientes encontrados na prática Como, por exemplo, a pouca quantidade de dados e a necessidade em estabelecer um valor de projeto com determinado período de retorno mantendo a coerência física. No entanto a metodologia apresentada por Garcia (1996) ainda abre margem pra muitas questões a cerca de sua validade prática.

Primeiramente o método conjugado por combinar a metodologia estatística e determinística herdará, inevitavelmente, as incertezas intrínsecas de cada metodologia. Inicialmente parte do pressuposto que a população da variável analisada, seja ela vazão ou precipitação, segue uma mesma distribuição. Diante do avanço de pesquisas em novas distribuições com características assintóticas a um valor máximo definido, poderá resultar no mesmo problema apontado no presente trabalho, ao qual se questionou sobre qual distribuição escolher (seção 2.1.3).

Uma outra questão que deve ser enfatizada é a da falta de sensibilidade que o parâmetro VMP apresenta no modelo. Essa falta de sensibilidade por um lado tem a vantagem de filtrar possíveis imprecisões acerca dos cálculos necessários para determinação da VMP. Por outro lado a falta de sensibilidade pode descaracterizar a influência da parte determinística do método.

Há também de se considerar uma possível visão ambígua sobre a verdadeira definição do método, pois, embora o método conjugado tenha sido apresentado como uma metodologia que combina características de dois métodos (estatistico e determinístico), dando uma idéia de uma metodologia hibrida. Ele pode também ser entendido como uma metodologia estatística que se utiliza da informação determinística para melhorar suas estimativas. 
Um outro ponto a ser destacado é com relação aos diversos resultados obtidos nas diversas análises colocadas e que foram apresentadas nos estudos de casos (capítulo 4). Observa-se que alguns valores determinados para as variáveis (precipitação e vazão) com períodos de retorno de 10.000 anos estiveram muito próximos dos valores mais altos pertencentes à série histórica observada. Para fazer uma análise sobre essa questão foram selecionadas 15 séries de vazões máximas anuais de diferentes localidades do país mais as que já foram analisadas no capítulo anterior, essas séries estão apresentadas no anexo II. Foi aplicado o método conjugado a cada uma dessas séries.

As diferentes séries de vazões máximas foram ordenadas e a sua posição de plotagem foi definida pela fórmula de Weibull. Os parâmetros foram estimados através do método dos momentos (MOM), da máxima verossimilhança (ML), e dos mínimos quadrados (MLS). Os valores máximos prováveis (VMP) foram retirados de diversos trabalhos como Tung e Texeira (1981), Larrosa et al. (1983), Siciliano et al. (1981), Anjos e Almeida (1981) e Eletrobrás (1987a). A tabela 52 apresenta para a série de cada posto (barragem) o valor mais alto registrado na série histórica, sua posição de plotagem (P.P) definida pela fórmula de Weibull e os valores de vazão de 10.000 anos (decamilenar) inferidos aplicando o método conjugado para cada método de estimação dos parâmetros. A tabela 62 apresenta ainda, para cada método de estimação dos parâmetros, a diferença máxima entre a vazão decamilenar $\left(\mathrm{Q}_{10000}\right)$ e a maior vazão $\left(\mathrm{Q}_{\mathrm{obs}}\right)$ observada no registro histórico.

A análise da citada tabela permite verificar que os valores inferidos $\left(T_{r}=10.000\right.$ anos) apresentam, como mencionado acima, números muito próximos dos maiores valores observados da série histórica, observa-se que, por exemplo, para a série da UHE de Segredo o valor inferido é $5 \%$ menor que o maior valor registrado. Esses resultados deixam em dúvida a confiabilidade do método, pois considerar que em média os valores inferidos para período de retorno de 10.000, ajustados pelo método ML, seja apenas 25 $\%$ maior que o maior valor registrado para séries com 70, 40 e 30 elementos é de difícil aceitação.

Essas dúvidas acerca do verdadeiro valor definido para a variável para um período de retorno de 10.000 anos utilizando o método conjugado, recai em outro tipo de análise. Esta análise é a relação entre o Valor Máximo Provável e a vazão decamilenar utilizando o método conjugado. O objetivo não é procurar associar uma probabilidade ao valor máximo provável, mas sim assegurar o quão confiável pode ser as estimativas tomando como referência o valor da VMP. Ressalta-se a importância 
deste tipo de análise, pois permite de certa forma avaliar mais diretamente a segurança do método. Uma vez que, tendo um valor inferido muito próximo do valor da VMP dá certa idéia de segurança, no entanto um valor muito menor que o valor da VMP causa uma sensação inversa.

Para este tipo de análise foram selecionadas as mesmas séries e os mesmos métodos de estimação dos parâmetros utilizados no exemplo anterior. A tabela 63 apresenta para a série de cada posto (barragem) o valor da VMP e os valores de vazão de 10.000 anos (decamilenar) inferidos aplicando o método conjugado para cada método de estimação dos parâmetros. A tabela 53 apresenta ainda, para cada método de estimação dos parâmetros, a diferença máxima $\mathrm{D}(\%)$ entre o valor da VMP e o valor da vazão decamilenar $\left(\mathrm{Q}_{10000}\right)$.

A análise da citada tabela permite verificar que os valores inferidos $\left(T_{r}=10.000\right.$ anos) apresentam, no geral, valores bem inferiores ao valor do VMP. Observa-se que a diferença chegou, para o método MOM, a $123 \%$ para a série da UHE de Caconde/SP. Observa-se que em média o valor da VMP foi de $59 \%$ mais alto que o valor da $\mathrm{Q}_{10000}$, para o método ML, isto provoca insegurança e desestimula a utilização do método, pois estas diferenças obrigam ao projetista reavaliar as séries, o próprio valor da VMP e a aplicar outras metodologias.

Tabela 62 - Comparação entre a vazão de 10.000 anos inferida pelo método conjugado e o maior valor observado no registro histórico das diferentes séries

\begin{tabular}{|c|c|c|c|c|c|c|c|c|}
\hline \multirow{2}{*}{ SÉRIES } & \multirow{2}{*}{ P.P. (anos) } & \multirow{2}{*}{ Qobs } & \multicolumn{2}{|c|}{ ML } & \multicolumn{2}{|c|}{ MOM } & \multicolumn{2}{|c|}{ MLS } \\
\hline & & & $\mathrm{Q}_{10000}$ & $\mathrm{D}(\%)$ & $\mathrm{Q}_{10000}$ & $\mathrm{D}(\%)$ & $\mathrm{Q}_{10000}$ & $\mathrm{D}(\%)$ \\
\hline Sobradinho & 72 & 15676 & 16983 & 8 & 18524 & 18 & 20332 & 30 \\
\hline Caconde & 66 & 854 & 1426 & 67 & 1381 & 62 & 1470 & 72 \\
\hline Funil & 43 & 1388 & 2146 & 55 & 2112 & 52 & 2249 & 62 \\
\hline Volta Grande & 30 & 9951 & 11690 & 17 & 11863 & 19 & 12159 & 22 \\
\hline Itumbiara & 72 & 7917 & 10068 & 27 & 10324 & 30 & 10806 & 36 \\
\hline Tucuruí & 34 & 64931 & 81321 & 25 & 81254 & 25 & 86154 & 33 \\
\hline Santa Isabel & 34 & 35726 & 41544 & 16 & 42321 & 18 & 45694 & 28 \\
\hline Segredo & 36 & 10808 & 10274 & -5 & 10907 & 1 & 12443 & 15 \\
\hline Porto Colômbia & 72 & 8367 & 10736 & 28 & 10961 & 31 & 11396 & 36 \\
\hline Marimbondo & 72 & 10368 & 13727 & 32 & 13646 & 32 & 14087 & 36 \\
\hline Água Vermelha & 72 & 11107 & 14279 & 29 & 14167 & 28 & 14517 & 31 \\
\hline São Simão & 43 & 13870 & 18338 & 32 & 18987 & 37 & 19881 & 43 \\
\hline Furnas & 72 & 7497 & 8240 & 10 & 8484 & 13 & 9010 & 20 \\
\hline Estreito & 72 & 7794 & 8996 & 15 & 9271 & 19 & 9714 & 25 \\
\hline Jaguara & 72 & 7803 & 9249 & 19 & 9511 & 22 & 9967 & 28 \\
\hline Passo Real & 63 & 3550 & 4440 & 25 & 4490 & 26 & 4596 & 29 \\
\hline Itapebi & 67 & 9784 & 14035 & 43 & 14586 & 49 & 15312 & 56 \\
\hline Pedra Cavalo & 39 & 6550 & 7425 & 13 & 8954 & 37 & 10437 & 59 \\
\hline MÉDIA & & & & 25 & & 29 & & 37 \\
\hline
\end{tabular}


Assim, estas diferenças na relação $\mathrm{VMP} / \mathrm{Q}_{10000}$ apresentada para cada série retrata a necessidade de uma análise mais aprofundada da sensibilidade do desempenho do modelo na cauda superior da distribuição, pois é nessa região em que se concentram os valores com períodos de retorno altos. Deve-se neste tipo de análise de sensibilidade cotejar a capacidade de extrapolação de diversos modelos existentes (mantendo a definição do método) na literatura.

Essas evidências comprovam a necessidade de cautela na aplicação imediata do método conjugado, visto que os valores apontados apesar de se mostrarem consistentes para inúmeros inconvenientes práticos (extensão da série, presença de outlier, influência dos menores valores na série de máximos, imprecisões nos valores da VMP e etc...), os mesmos podem não representarem fidedignamente a probabilidade atribuídas a eles.

Tabela 63 - Comparação entre o valor máximo provével (VMP) e a vazão de 10.000 anos $\left(Q_{10000}\right)$ inferida pelo método conjugado

\begin{tabular}{cccccccc}
\hline \hline \multirow{2}{*}{ SÉRIES } & \multirow{2}{*}{ VMP } & \multicolumn{2}{c}{ ML } & \multicolumn{2}{c}{ MOM } & \multicolumn{2}{c}{ MLS } \\
& & $\mathrm{Q}_{10000}$ & $\mathrm{D}(\%)$ & $\mathrm{Q}_{10000}$ & $\mathrm{D}(\%)$ & $\mathrm{Q}_{10000}$ & $\mathrm{D}(\%)$ \\
\hline Sobradinho & 36300 & 16983 & 114 & 18524 & 96 & 20332 & 79 \\
Caconde & 3082 & 1426 & 116 & 1381 & 123 & 1470 & 110 \\
Funil & 4400 & 2146 & 105 & 2112 & 108 & 2249 & 96 \\
Volta Grande & 12840 & 11690 & 10 & 11863 & 8 & 12159 & 6 \\
Itumbiara & 16200 & 10068 & 61 & 10324 & 57 & 10806 & 50 \\
Tucuruí & 110000 & 81321 & 35 & 81254 & 35 & 86154 & 28 \\
Santa Isabel & 54000 & 41544 & 30 & 42321 & 28 & 45694 & 18 \\
Segredo & 13000 & 10274 & 27 & 10907 & 19 & 12443 & 4 \\
Porto Colômbia & 16000 & 10736 & 49 & 10961 & 46 & 11396 & 40 \\
Marimbondo & 21400 & 13727 & 56 & 13646 & 57 & 14087 & 52 \\
Água Vermelha & 20000 & 14279 & 40 & 14167 & 41 & 14517 & 38 \\
São Simão & 27400 & 18338 & 49 & 18987 & 44 & 19881 & 38 \\
Furnas & 13000 & 8240 & 58 & 8484 & 53 & 9010 & 44 \\
Estreito & 13000 & 8996 & 45 & 9271 & 40 & 9714 & 34 \\
Jaguara & 14100 & 9249 & 52 & 9511 & 48 & 9967 & 41 \\
Passo Real & 5400 & 4440 & 22 & 4490 & 20 & 4596 & 17 \\
Itapebi & 25600 & 14035 & 82 & 14586 & 76 & 15312 & 67 \\
Pedra Cavalo & 15160 & 7425 & 104 & 8954 & 69 & 10437 & 45 \\
MÉDIA & & & 59 & & 54 & & 45 \\
\hline \hline
\end{tabular}




\section{CONCLUSÕES}

Através das análises de cada metodologia percebeu-se a importância que os estudos de valores máximos de variáveis hidrológicas (precipitação e vazão) exercem no meio prático e acadêmico, os inúmeros trabalhos desenvolvidos na área demonstram uma enorme complexidade no tratamento dessas variáveis máximas. Verificou-se no campo das pesquisas certo distanciamento entre os adeptos de uma ou outra metodologia, já no campo prático observou-se uma forte tendência em unificar as duas metodologias seja pra efeito de economia seja pra efeito de segurança.

Pôde-se concluir que a grande vantagem do método conjugado é de permite fazer essa ponte entre as duas metodologias, possibilitando ao hidrólogo um senso crítico mais apurado a cerca dos valores extremos em uma bacia. $\mathrm{O}$ método conjugado aplicado neste trabalho foi avaliado sobre inúmeros aspectos que intrigam os pesquisadores da área. Esses aspectos permitiram avaliar não só as vantagens que a metodologia proposta por Garcia (1996) oferece, mais abriu margem para outras discussões. Estas discussões permitiram desenvolver uma análise crítica sem que compromete-se ou invalida-se a eficiência apresentada pelo método.

Assim, diante das avaliações feitas através das análises apresentadas nos estudos de casos concluiu-se que o método conjugado é eficiente, pois:

- Na análise da influência da extensão da série os resultados apresentados demonstraram que o método depende muito pouco da extensão da série de valores uma vez que os valores obtidos para as vazões de projeto (Por exemplo $T_{r}=10.000$ anos) não diferem significativamente.

- Na análise da influência da presença de "outliers" na série de valores os resultados apresentados demonstraram que a inclusão do outlier provoca um pequeno incremento nos valores máximos de projeto, mostrando a diminuta influencia de eventos 
extraordinários (outliers) na determinação dos valores máximos e na definição da vazões de projeto utilizando a análise de freqüência conjugada.

- Na análise da influência dos menores valores da série de valores máximos verificou-se que a cauda superior da distribuição sugerida pela análise de frequiência conjugada não é influenciada pelos menores valores da série de máximos.

- Observou-se que as imprecisões advindas do cálculo da VMP (EMP/PMP) não influenciam significativamente as vazões extremas.

- Na análise comparativa com a metodologia estatística utilizando a distribuição GEV, a metodologia conjugada apresentou, em todas as análises feitas, resultados bem superiores aos obtidos pela metodologia estatística. Ressalta-se que a distribuição GEV utilizada na metodologia estatística é a mesma utilizada na análise de freqüência conjugada aplicada neste trabalho, o que reforça ainda mais a importância da fixação de um limite superior na distribuição.

- Na verificação da vazão de projeto de uma barragem os valores inferidos pelo método conjugado mostraram-se para todos os períodos analisados uma superioridade em relação aos inferidos pela metodologia estatística e pela metodologia determinística. Verificou-se que o uso das metodologias convencionais pode subdimensionar ou superdimensionar os valores de projeto, o que aplicando o método conjugado resultaram em valores bastante razoáveis em relação série observada.

- Na aplicação do método conjugado em séries de vazões médias diárias e vazões instantâneas observou-se que ao contrário da metodologia estatística (diretamente proporcionais) os valores obtidos, pelo método conjugado, a partir da extrapolação $\left(T_{r}>\right.$ 100 anos) da curva ajustada para todas as séries têm uma diferença menor. Esta menor diferença permite que uma imprecisão no cálculo do fator multiplicativo que relaciona $\left(\mathrm{Q}_{\mathrm{mx}} / \mathrm{Q}_{\mathrm{md}}\right)$ tenha uma influência menor.

- Aplicando a análise de freqüência conjugada a uma série de duração parcial de precipitação de 12 horas não resultou em diferenças significativas em relação ao valores inferidos utilizando a série de máximos anuais. Assim, quando existir dificuldade em garantir a hipótese de independência de uma série extensa de dados, pode-se optar por utilizar apenas uma parte dessa série ou a série de máximos anuais na qual esse critério seja atendido sem prejuízo dos resultados a serem inferidos pelo método conjugado.

- O conceito do método conjugado se mostrou consistente uma vez que o uso de outros modelo probabilístico resultou em diferenças próximas aos obtidos utilizando o método conjugado utilizando a distribuição GEV. E numa análise comparativa com os valores 
apresentados na seção 4.2 (método conjugado utilizando a distribuição GEV) e 4.8 (método conjugado utilizando a distribuição GLOG) observou-se que os valores para todas as análises não diferiram significativamente.

Concluiu-se, também, que para fins práticos o método conjugado ainda não deve ser usado isoladamente, devido à insuficiência de estudos que comprovem a sua confiabilidade. Desta forma, deve-se utilizar o método conjugado para efeito de comparação sendo necessário o uso das outras metodologias já consagradas para definição mais segura dos valores de projeto.

A priori recomenda-se a utilização da metodologia estatística quando existir disponível no local estudado ou em sua proximidade (utilizando técnicas de regionalização) uma estação fluviométrica com extenso registro de dados e se a obra em questão não altera significativamente o regime de cheias (o que ocorre dificilmente para uma obra isolada).

Se ainda se dispor de registros fluviométricos, mas de pequena extensão $(<20$ anos) pode-se estender esses registros com auxilio de dados pluviométricos e aplicar ainda modelos de análise estatística de vazões.

Recomenda-se o uso da metodologia determinística quando dispor de registros fluviométricos bastante curtos ( $<10$ anos) e caso a obra, uma vez construída, alterar significativamente o regime de cheias do rio, independentemente da extensão da série, a cheia de projeto só pode ser obtida via modelos determinísticos, uma vez que compromete os critérios estatísticos de estacionaridade e homogeneidade das séries. A correta avaliação da influência da obra nas cheias é de grande importância.

Uma prática bastante apropriada consiste em calcular cheias de projeto por mais de um método. No caso de se obter cheias muito díspares segundo os diversos enfoques metodológicos explorados, as análises acerca da seleção da cheia de projeto deverão ser precedidas por pesquisas minuciosas a respeito das possíveis causas que conduziram às diferenças. O projetista deve sempre exercitar o seu senso crítico cotejando os resultados fornecidos pelo modelo com aqueles obtidos por outros métodos e com a experiência empírica.

Como comentado anteriormente, as análises feitas nos estudos de casos somados com as análises particulares de cada metodologia convencional propiciou um desenvolvimento inicial de uma análise crítica particularizada para o método conjugado. Sendo assim, sugere-se como complemento deste estudo uma análise de confiabilidade da metodologia conjugada. Ou seja, recomenda-se modelar uma série de máximos com 
o intuito de gerar séries com diferentes tamanhos (1000, 5000, 10000 anos) e aplicar o método conjugado confrontando os resultados obtidos com os estimados utilizando a série real. $\mathrm{O}$ erro médio quadrático pode ser usado como critério para proceder uma análise de sensibilidade do desempenho de método conjugado, avaliando assim uma provável confiabilidade do método.

Para proceder essa análise de confiabilidade sugere-se, também, o uso de outros modelos probabilísticos que porventura possam vir a apresentar um desempenho melhor. Ressalta-se que o conceito de definição da distribuição através do ajuste aos dados observados e da fixação de um limite superior seja seguido.

Por fim, Apesar das questões abordadas e mediante ao dilema existente por diversos autores em diversos trabalhos sobre qual a metodologia (estatística e determinística) mais apropriada para a determinação da cheia de projeto, o método conjugado vem como mais uma das alternativas em unir a metodologia estatística com a metodologia determinística, ou seja, usar as qualidades intrínsecas de ambas as metodologias. Os contrastes e mesmo divergências entre diversos engenheiros e pesquisadores adeptos de uma ou outra linha de conduta ao longo do tempo, mostrou-se completamente inócua e infrutífera, pois na verdade, embora ainda, o método conjugado, não seja uma metodologia consagrada para unir estes dois conceitos, é racional e conveniente uma união dos benefícios advindos destes dois enfoques, resultando numa onda de cheia de projeto com particularidades mais coerentes do ponto de vista de segurança e economia para as grandes obras envolvidas. 


\section{REFERENCIAS BIBLIOGÁFICAS}

AHMAD, M.I., C.D. SINCLAIR, AND A. WERRITY (1988). "Log-Logistic Flood Frequency Analysis", Journal of Hydraulics, Vol. 98, pp. 205-224.

ANJOS, N.F.R., ALMEIDA, S.B., (1981), Diagnóstico Preliminar dos Critérios Utilizados pelo Setor Elétrico para o Cálculo das Vazões de Projeto de Vertedouros, IV Simpósio Brasileiro de Hidrologia e Recursos Hídricos, Vol. 4, pp. 452-463, FortalezaCE.

ASBAHR, L., TEIXEIRA, H.J., LARROSA, E.A, (1985) Estudos de Precipitação Máxima Provável em Grandes Bacias Hidrográficas, VI Simpósio Brasileiro de Hidrologia e Recursos Hídricos, Vol. 1, pp. 165-177, São Paulo-SP.

BERTONI, J.C., Elementos de Hidrometeorologia In: TUCCI, C. E. M. (Org), (1993) Hidrologia - Ciência e Aplicação, Editora da Universidade do Rio Grande do Sul, Edusp, ABRH.

BERTONI, J.C., TUCCI, C.E.M., Precipitação In: TUCCI, C. E. M. (Org), (1993) Hidrologia - Ciência e Aplicação, Editora da Universidade do Rio Grande do Sul, Edusp, ABRH.

BOBÉE, B., E F. ASHKAR (1991) "The Gamma Family and Derived Distribuitions Applied in Hydrology", Water Resources Publications, Littleton, CO.

BOBÉE, B. et. al. (1993), Towards a Systems Approach to Comparing Distributions Used in Flood Frequency Analysis. J. of Hydrology, v. 142, p. 121-136.

BRADLEY, J.V.,(1968) “Distribution - Free Statistical Test”, Prentice Hall.

BUSSAB, W.O., MORETTIN, P.A. (2004). Estatística Básica, Editora Saraiva, 5 edição, São Paulo-SP. 
CHOW, V.T. (1964). Editor-in-Chief, Handbook of Applied Hydrology, McGraw-Hill, New York, NY.

CLARKE, R. T., Hidrologia Estatística In: TUCCI, C. E. M. (Org), (1993) Hidrologia Ciência e Aplicação, Editora da Universidade do Rio Grande do Sul, Edusp, ABRH.

CLARKE, R. T., (1994) Statistical Modelling in Hydrology, John Wiley \& Sons, England.

COSTA J.P., DAMAZIO J. M., PEREIRA M.V.F., KELMAN J.(1981), Confiabilidade na Estimação de Vazões Extremas, IV Simpósio Brasileiro de Hidrologia e Recursos Hídricos, Vol. 1, pp. 516-523, Fortaleza-CE.

COSTA J.P., KELMAN J., DAMAZIO J. M., (1987) Cálculo do Desvio Padrão de Estimadores de Parâmetros Hidrológicos, VII Simpósio Brasileiro de Hidrologia e Recursos Hídricos, Vol. 1, pp.630-641, Salvador-CE.

CONWAY, K.M. (1971). Flood Frequency Analysis of Some New South Wales Coastal Rivers. University of New South Wales, Sydney, N.S.W.

CUNNANE, C. (1973). "A Particular Comparison of Annual Maxima and Partial Duration Series Methods of Flood Frequency Prediction", Journal of Hydrology, pp.257-271

CUNNANE, C. (1978). Unbiased Plotting Positions - A Review. Journal of Hydrology, Amsterdam, v.37. p.205-222

CUNNANE, C. (1988). "Methods and Merits of Regional Flood Frequency Analysis". World Meteorological Organization Operational Hydrology, Report, No. 33, WMO-No. 718, Geneva, Switzerland.

DAMÁZIO, J. M., MOREIRA, J. C., DA COSTA, J. P., KELMAN, J. (1983), Seleção de Métodos para Estimação de vazões com Tempos de Retorno Elevados, V Simpósio Brasileiro de Hidrologia e Recursos Hídricos, Vol. 2, pp. 145-165, Blumenau-SC.

DAEE - Departamento de Águas e Energia Elétrica. 1998. Banco de Dados Pluviométricos do Estado de São Paulo. Cth/Daee/Srh. Cd-Rom. 
ELETROBRÁS, CENTRAIS ELETRICAS BRASILEIRAS AS (1987a). Guia para Cálculo de Cheia de Projeto de Vertedores, Departamento de Planejamento e Engenharia, Rio de Janeiro.

ELETROBRÁS, CENTRAIS ELETRICAS BRASILEIRAS AS (1987b). Avaliação da Segurança de Barragens Existentes (United States Departament of the Interior Bureau of Reckamation), Ministério das Minas e Energia, Rio de Janeiro.

ELETROBRÁS, (1996) Grupo coordenador do planejamento dos sistemas elétricos (GCPS) Plano Decenal de Expansão 1996-2005, Ministério de Minas e Energia, Governo Federal.

FILL, H.D., ZSCHOERPER,D.J., (1981), Comparação da Máxima Precipitação Provável com o Método de Gumbel na Bacia do Rio Iguaçu, IV Simpósio Brasileiro de Hidrologia e Recursos Hídricos, Vol. , pp. 311-323, Fortaleza-CE.

FILL, H.D. (1981), Determinação de Cheias de Projeto, IV Simpósio Brasileiro de Hidrologia e Recursos Hídricos, Vol. , pp. 439-449, Fortaleza-CE.

GARCIA, L. A. V. de; BRAGA JR., B. P. F. (1997), Análise de Freqüência Conjugada, Revista Brasileira de Recursos Hídricos, ABRH, v.2, n.2, p.21-44.

GARCIA, L.A.V.(1996), Método Conjugado Combinação dos Métodos Estatístico e Determinístico para Determinação de Valores Máximos e de Variáveis Hidrológicas, Tese de Doutorado apresentada na Escola Politécnica da Universidade de São Paulo.

GOMES, A.M., PALERMO, M.A., NAKAYAMA, P.T. (1983), Concepção de Tormentas de Projeto - Cotejo entre as Aplicações dos Enfoques Hidrometeorológicos e Estatístico para a Bacia do Rio Tamanduateí, V Simpósio Brasileiro de Hidrologia e Recursos Hídricos, Vol. 2, pp. 341-358, Blumenau-SC.

GOMIDE, F.L.S., KAVISKI, E., (1981), Poder de Testes de Adequação de Ajuste: Uma Investigação Experimental, IV Simpósio Brasileiro de Hidrologia e Recursos Hídricos, Vol. 1, pp. 551-568, Fortaleza-CE.

GOTTSCHALK, L. E KUNDZEWICSZ, Z. W.(1994), Analysis of Outliers in Norwegian Flood Data.

GRUBBS, F. E G. BECK (1972). "Extension of Sample Sizes and Percentage Points for Significance Tests of Outlying Observations", Technometrics, Vol. 14 (4), pp. 847-854 
GUNASEKARA, T.A.G.; CUNNANE, C., (1992) Splait sampling technique for selecting a flood frequency analysis procedure. J. Hydrology, v.130, p.189-200.

HAAN, C. T. (1977) Statistical Methods in Hydrology, The Iowa State University Press, Ames, Iowa, USA, 1977, 378 p.

HOEL, P.G. (1984). Estatística Matemática. Rio de Janeiro: Guanabara dois, p373.

HOSKING, J.R.M.; WALLIS, J.R.; WOOD, E.F. (1985a). Estiamtion of the generalized extreme value distribution by the method of probability weighted moments. Technometrics, v.27, n.3, p.251-261.

HOSKING, J. R. M. (1986), The Theory of Probability Weighted Moments", Res. Rep. RC 12210, IBM Research Division, Yorktown Heights, NY. 10598.

HOSKING, J. R. M., (1990) L-Moments: Analysis and Estiamtion of distributions Using Linear Combinations of Order Statistics, J. R. Statist. Soc, Ser. B, v. 52, n. 2, p. 105-124.

JENKINSON, A. F. (1955), The frequency distribution of the annual maximum (or minimum) of meteorological elements. Quarterly Journal of the Royal Meteorological Society, v.81, p.158-171.

KITE, G. W., (1978) Frequency and Risk Analysis in Hydrology, Water Resources Publications, Fort Collins, Colorado, USA.

KLEMES, V., (1986) Operational Testing Of Hydrologic Simulation Models, Hydrologic Sciences Journal, 31, 13-24.

KLEMES, V., (1993) Probability of extreme hydrometeorological events - a different approach, Extreme Hydrological Events: Precipitation, Floods and Drought (Z. W. Kundzewics et al., editors). IAHS Publications N. 213.

KLEMES, V., (1995) Probability of Extremes Hydrometeorological Events (Sensitivity of Return Period Estimates), Report for B. C. Hydro, Vancouver, B. C., Canada. 
LANNA, E. A., Elementos de Estatística e Probabilidades In: TUCCI, C. E. M. (Org), (1993) Hidrologia - Ciência e Aplicação, Editora da Universidade do Rio Grande do Sul, Edusp, ABRH.

LARROSA, E.A., SILVEIRA, O.V., ORLEANS, L.C., LÔU, W.C., (1983) Precipitação Máxima Provável (PMP) - Fator de Maximização, V Simpósio Brasileiro de Hidrologia e Recursos Hídricos, Vol. 2, pp. 359-371, Blumenau-SC.

LINSLEY, R.K. (1986). "Flood Estimates: How Good Are They?", Water Resource Research, Vol. 22, No. 9, pp. 1595-1645.

MADSEN, H., RASMUSSEN, P. F.; ROSBJERG, D. (1997a) Comparation of annual maximum series and partial duration series methods for modeling extreme hydrologic events. 1, at-site modeling. Water Resources Research, v.33, n.4, p.747-758, 1997a

MADSEN, H., RASMUSSEN, P. F.; ROSBJERG, D. (1997b) Comparation of annual maximum series and partial duration series methods for modeling extreme hydrologic events. 2, Regional modeling. Water Resources Research, v.33, n.4, p.759-770, 1997b

MARTINS, S.E.; STENDINGER, J.R.(2000), Generalized maximum-likelihood generalized extreme-value quantile estimators for hydrologic data.. Water Resources Research, v.36, n.3, p.737-744

MCCUEN, R.H. (1993). Microcomputer Applications in Statistical Hydrology, Prentice Hall, Englewood Cliffs, NJ.

MORAN, P. M. P., (1957) The statistical treatment of flood flow., Transactions AGU, 38.

MOREIRA, J. C., DAMÁZIO, J. M., DA COSTA, J. P., KELMAN, J. (1983), Estimação de Vazões Extremas: Séries Parciais ou Máximos Anuais?, V Simpósio Brasileiro de Hidrologia e Recursos Hídricos, Vol. 2, pp. 135-143, Blumenau-SC.

MORETTIN, P.A., TOLOI, C.M.C. (1981), Modelos para Previsões de Séries Temporais, $13^{\circ}$ Colóquio Brasileiro de Matemática, Vol. 1, Poços de Caldas-MG.

MULLER, I.I., KRUGER, C.M., KAVISKI, E., (1998) Análise da Estacionaridade de Séries Hidrológicas na Bacia Incremental de Itaipu, Revista Brasileira de Recursos Hídricos, ABRH, v.3, n.4, p.51-71 
MUÑOZ-ESPINOSA H. R.(1981), Chuvas de Projeto na Bacia do Rio Uruguai: Comparação de Resultados Mediante Análise de Freqüência e o Método Hidrometeorológico, IV Simpósio Brasileiro de Hidrologia e Recursos Hídricos, Vol. 2, pp. 443-457, Fortaleza-CE

NAKANO, R.S., ISHISAKI, K., NAKAYAMA, P.T. (1979), Considerações Sobre Análises Estatísticas para Cálculo de Vazões de Cheias, III Simpósio Brasileiro de Hidrologia e Recursos Hídricos, Vol. 1, pp. 369-377, Fortaleza-CE

NATIONAL ENVIROMENT RESEARCH COUNCIL - NERC, (1975) Flood Studies report, v-1. London.

ONOZ, B.; BAYAZIT, M., (1995) Best - Fit Distributions of Largest Available Flood Samples. J. Hydrology, v.167, p.195-208.

ONS, (2004) Operador Nacional do Sistema Elétrico. Vazões Médias Mensais nos Aproveitamentos Hidroelétricos - Período de 1931 a 2001 (Anexo), Rio de Janeiro: ONS 2004 (RE 3/121/2004).

PEARSON, C. P.; McKERCHAR, A. I.; WOODS, R. A., (1991) Regional flood frequency analysis of Western Australian data using L-moments. In: Proc. Int. Hydrolo. \& Water Resour. Symp., Perth,2-4 october 1991, p.631-632

PILGRIM, D.H. (1986). "Bridging the Gap Between Flood Research and Practice" Water Resource Research, Vol. 22, No. 9, pp. 1655-1765

PILON, P.J., E K. ADAMOWSKI (1993). “Asymptotic Variance of Flood Quantile in Log Pearson Type III Distribution with Historical Information”, Journal of Hydraulic, Vol. 133, pp. 481-503

PINHEIRO M. C., DAMAZIO J. M., KELMAN J. (1981), Análise de freqüência de cheias para as Regiões Sul e Sudeste do Brasil, IV Simpósio Brasileiro de Hidrologia e Recursos Hídricos, Vol. 1, pp. 326-336, Fortaleza-CE.

PINHEIRO M. C., GUERREIRO-SALAZAR P.(1981), Sobre a Freqüência de Cheias Parte I: Seleção de uma Distribuição de Probabilidades, IV Simpósio Brasileiro de Hidrologia e Recursos Hídricos, Vol. 2, pp. 547-568, Fortaleza-CE. 
QUEIROZ, M. M. F., (2002) Análise de Cheias Anuais Segundo Distribuição Generalizada, Tese de Doutorado apresentada na Escola de Engenharia de São Carlos, Universidade de São Paulo, São Carlos.

RAO, A. R. e HAMED, K. H., (2000) Flood Frequency Analysis, CRC Press LLC, Florida, USA.

RIGHETTO, A. M., (1998) Hidrologia e Recursos Hídricos, EESC/USP Projeto REENGE, São Carlos.

ROSBJERG, D. (1977). "Return Periods of Hydrological Events", Nordic Hydrology, Vol. 8, pp. 57-61

SANGAL, B.P. (1983), Practical Method of Estimating Peak Flow. Journal of Hydraulic Engineering, V. 109, n. 4, p. 549-563, Abr.

SICILIANO M. A., SILVEIRA O. V., CAMPOS J. D.(1981), Aplicação da Precipitação Máxima Provável a Grandes Bacias para Determinação da Vazão Máxima Provável, IV Simpósio Brasileiro de Hidrologia e Recursos Hídricos, Vol. 2, pp. 429442, Fortaleza-CE

SIEGEL, S. (1956). Nonparametric Statistics for the Behavioral Sciences. New York: MacGraw-Hill, p312.

SILVA, E. A., TUCCI, C.E.M. (1997), Estimativa da Vazão Máxima Instantânea com Base em Vazões Máximas, XII Simpósio Brasileiro de Hidrologia e Recursos Hídricos, Vol.2, pp. 326-336, Vitoria-ES.

SOUZA, S. A., BARRETO, C.E.A.G, MARCUSSI, F.F.N., (2005a) Análise de Freqüência de Precipitações Utilizando o Método Conjugado, AGUASUL $-1^{\circ}$ Simpósio de Recursos Hídricos do Sul, Santa Maria, RS.

SOUZA, S.A., PORTO, R.M., (2005b) Análise Conceitual da Metodologia Estatística para Determinação de Valores Máximos de Variáveis Hidrológicas, XVI Simpósio Brasileiro de Recursos Hídricos, João Pessoa, PB.

SOUZA, S.A., PORTO, R.M., MARCUSSI, F.F.N., (2005c) Análise Crítica da Metodologia Estatística para Determinação de Valores Máximos de Variáveis Hidrológicas, XVI Simpósio Brasileiro de Recursos Hídricos, João Pessoa, PB. 
SPIEGEL, M.R. (1978). Probabilidade e Estatística. São Paulo: MacGraw-Hill, p518. (Coleção Schaum).

STAICO, J., (1981), Subsídio ao Estudo das Cheias no Vale Principal da Bacia do Rio São Francisco, IV Simpósio Brasileiro de Hidrologia e Recursos Hídricos, Vol. 2, pp. 03-18, Fortaleza-CE

STEDINGER, J.R.; VOGEL, R.M.; FOUFOULA-GEORGIOU, E. (1993). Frequency analysis of extreme events. In: Handbook of Hydrology, p. 18.1-18.66, McGraw-Hill, New York.

SUGAI, M. R. VON B., E H.D.O. A. FILL; (1990) Tempo de Recorrência Associado a Precipitação Máxima Provável na Região Sul do Brasil, Revista Brasileira de Engenharia, Vol. 8, n 1, 81-110.

TAVARES, L. VALADARES, E J.E. DA SILVA (1983). "Partial Duration Series Method Revisited", Journal of Hydrology, Vol. 64, pp. 1-14

TODD, D.K. (1957). "Frequency Analysis of Streamflow Data", Journal of the Hydraulics Division, Proc. ASCE HY1, pp. 1166-1, 1166-16

TUCCI, C.E.M. Vazão Máxima e Hidrograma de Projeto In: TUCCI, C. E. M. (Org), (1993a) Hidrologia - Ciência e Aplicação, Editora da Universidade do Rio Grande do Sul, Edusp, ABRH.

TUCCI, C.E.M. Regionalização de Vazões In: TUCCI, C. E. M. (Org), (1993b) Hidrologia - Ciência e Aplicação, Editora da Universidade do Rio Grande do Sul, Edusp, ABRH.

TUNG, C., TEIXEIRA, H.J. (1979a), Estimativa da Precipitação Máxima Provável na Bacia do Rio Paraguaçu, III Simpósio Brasileiro de Hidrologia e Recursos Hídricos, Vol.1, pp. 324-339, Fortaleza-CE.

TUNG, C., TEIXEIRA, H.J. (1979b), Estimativa da Vazão Máxima Provável na Bacia do Rio Paraguaçu, III Simpósio Brasileiro de Hidrologia e Recursos Hídricos, Vol.1, pp. 340-360, Fortaleza-CE.

US WATER RESOURCES COUNCIL HYDROLOGY COMMITE, (1981) Guidelines For Determining Flood Flow Frequency, Bulletin 17 B, Washington D.C., EUA. 
WANG, BI-HUEI E RUSSEL W. REVELL, (1983) Conservatism of probable maximum flood estimates, Journal of Hydraulic Engineering, ASCE, Vol. 109, N.3.

WANG, Q. J. (1997a), Using higher probability weighted moments for flood frequency. J. Hydrology, v.194, p.95-106.

WANG, Q. J. (1997b), LH moments for statistical analysis of extreme events. Water Resources Research, v.33, n.12, p.2841-2848.

WORLD METEOROLOGICAL ORGANIZATION (WMO), (1973) Estimation of Probable Maximum Precipitation, WMO-N. 332, Secretariat of de WMO, Geneva.

YEVJEVICH, V., (1972) Probability and Statistics in Hydrology, Water Resources Publications, Fort Collins, Colorado, USA. 


\section{ANEXO A - Critérios para o Cálculo das Vazões de Projeto de Vertedores}

É apresentado a seguir um resumo dos principais critérios de projeto adotado em alguns aproveitamentos hidrelétricos brasileiros. Estes critérios foram reunidos e analisados pelos pesquisadores da CEPEL (centro de pesquisas de energia elétrica) e um resumo dos principais dados recebidos, de alguns aproveitamentos selecionados, bem como da metodologia utilizada na determinação de cheias de projeto, foram apresentadas por Anjos e Almeida (1983).

Inventário dos critérios utilizados para o cálculo das vazões de projeto de vertedores

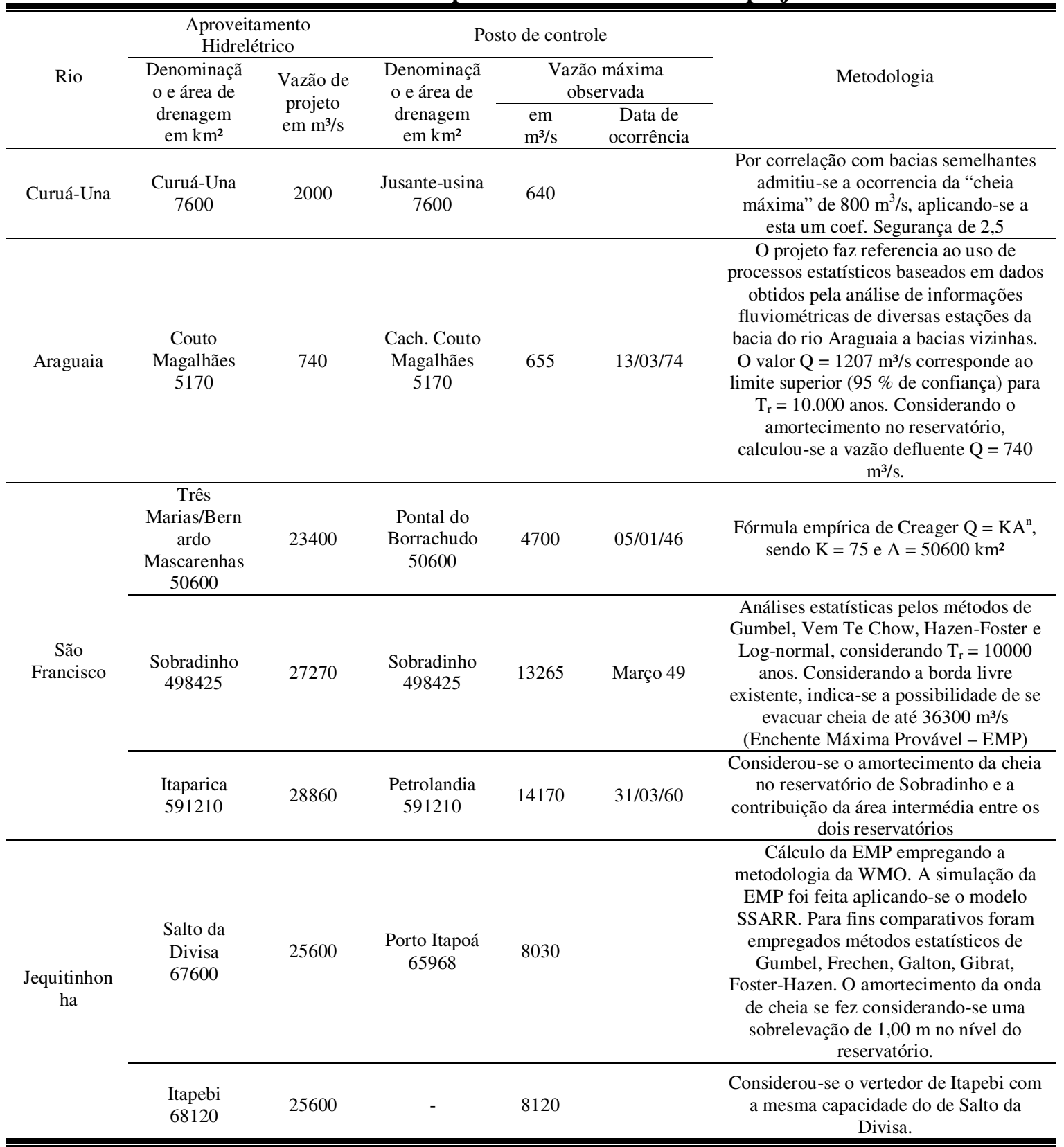

Fonte: Anjos e Almeida (1983) 
Inventário dos critérios utilizados para o cálculo das vazões de projeto de vertedores

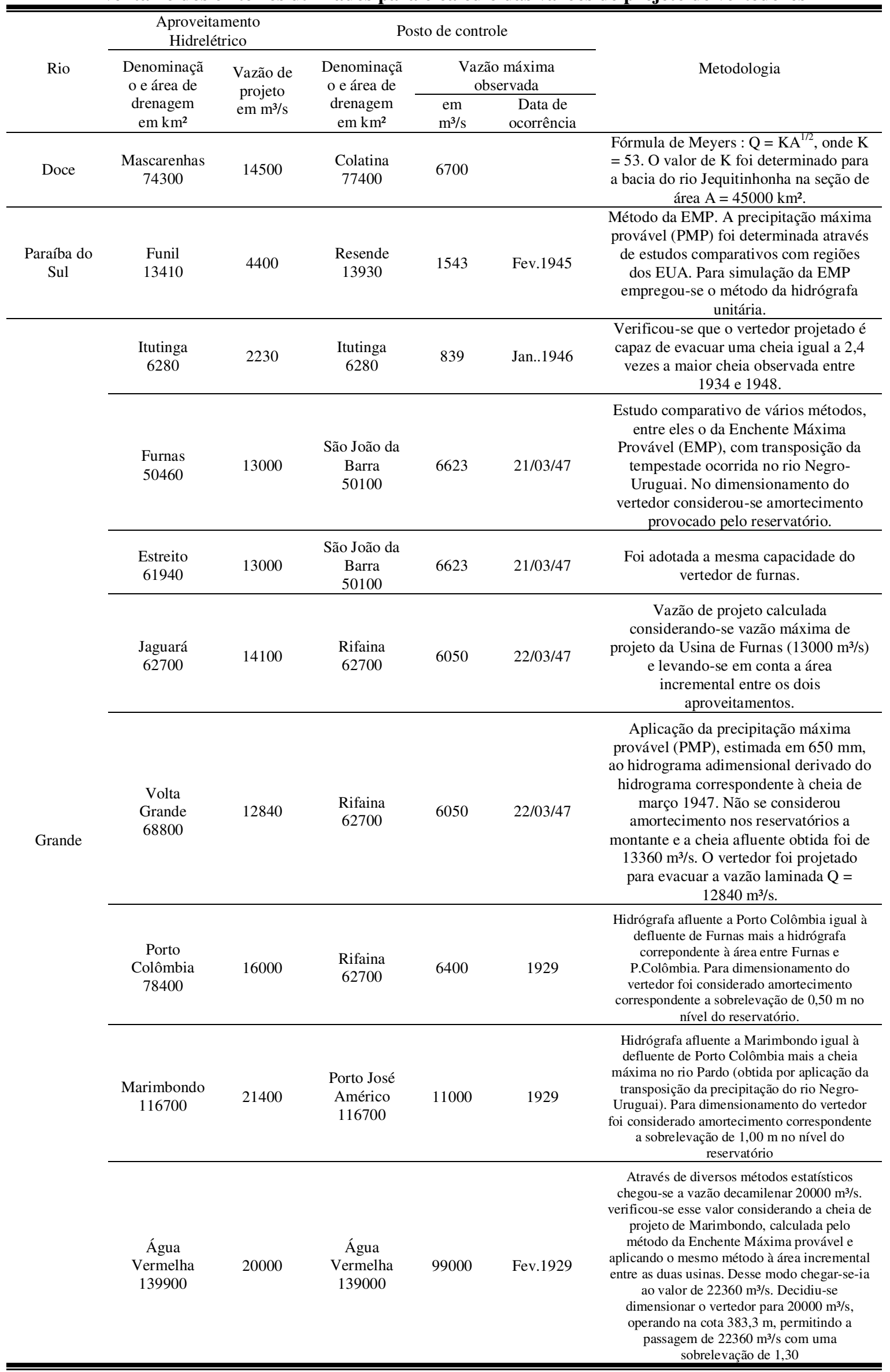


Inventário dos critérios utilizados para o cálculo das vazões de projeto de vertedores

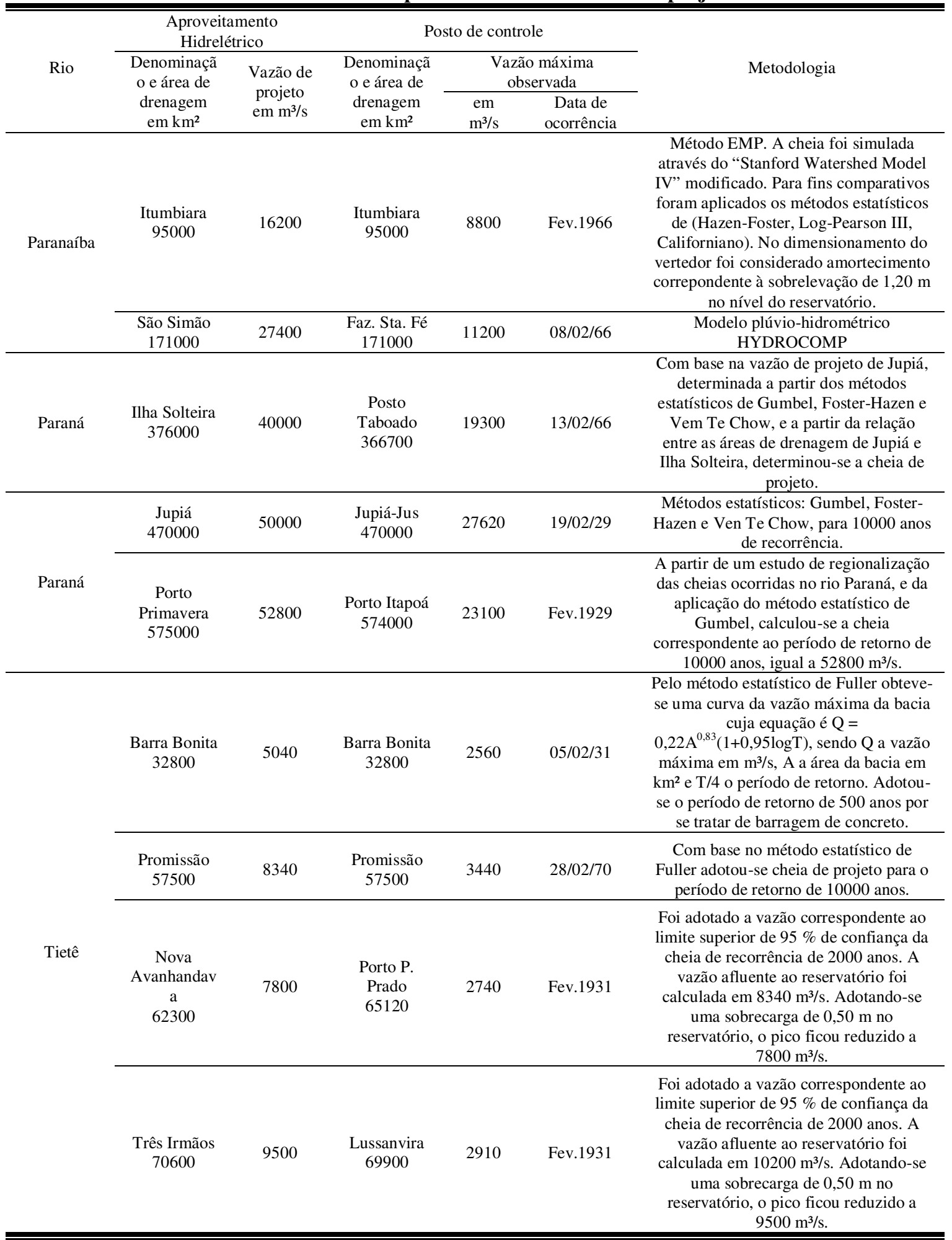

Fonte: Anjos e Almeida (1983) 
Inventário dos critérios utilizados para o cálculo das vazões de projeto de vertedores

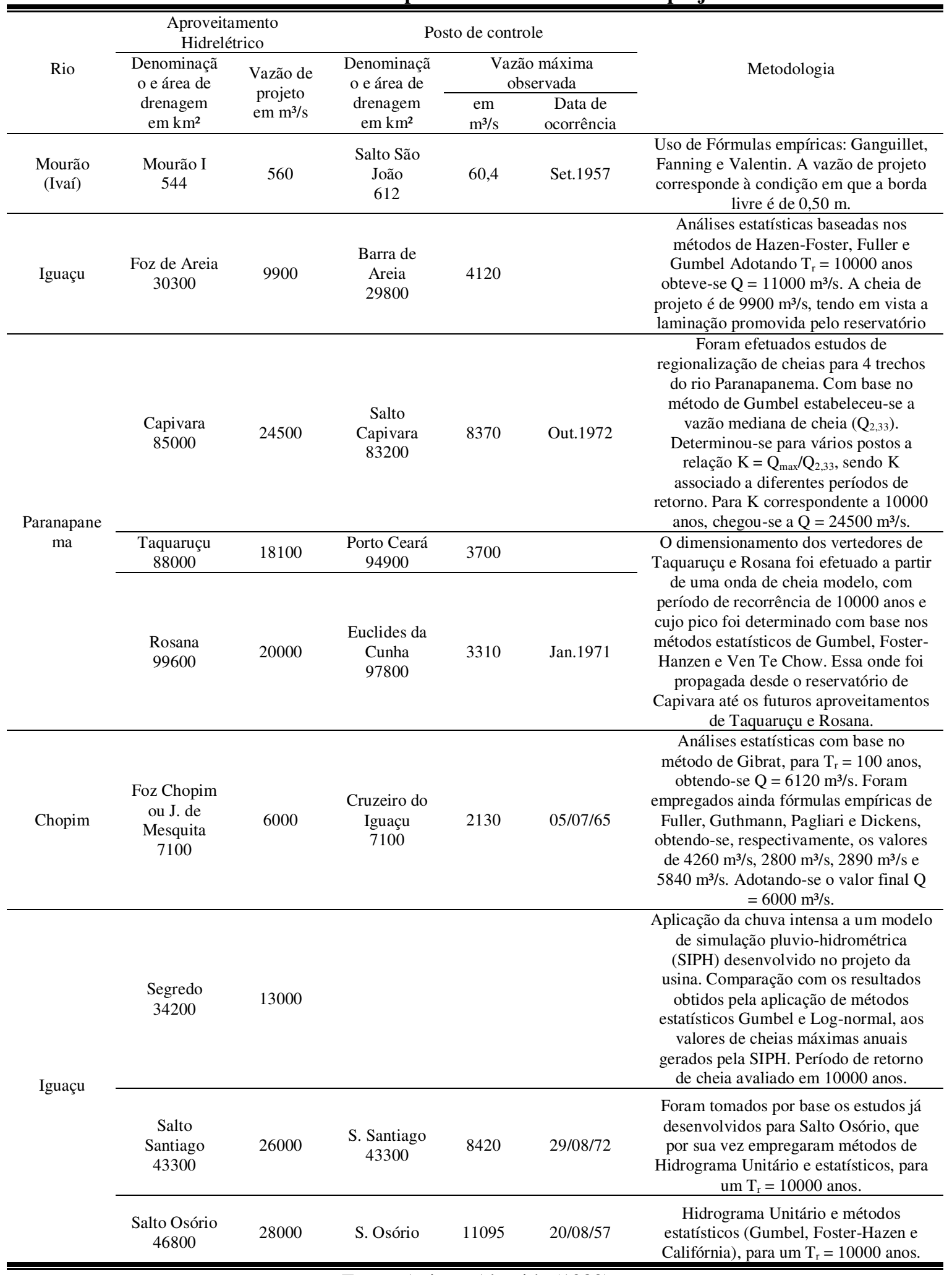

Fonte: Anjos e Almeida (1983) 
Inventário dos critérios utilizados para o cálculo das vazões de projeto de vertedores

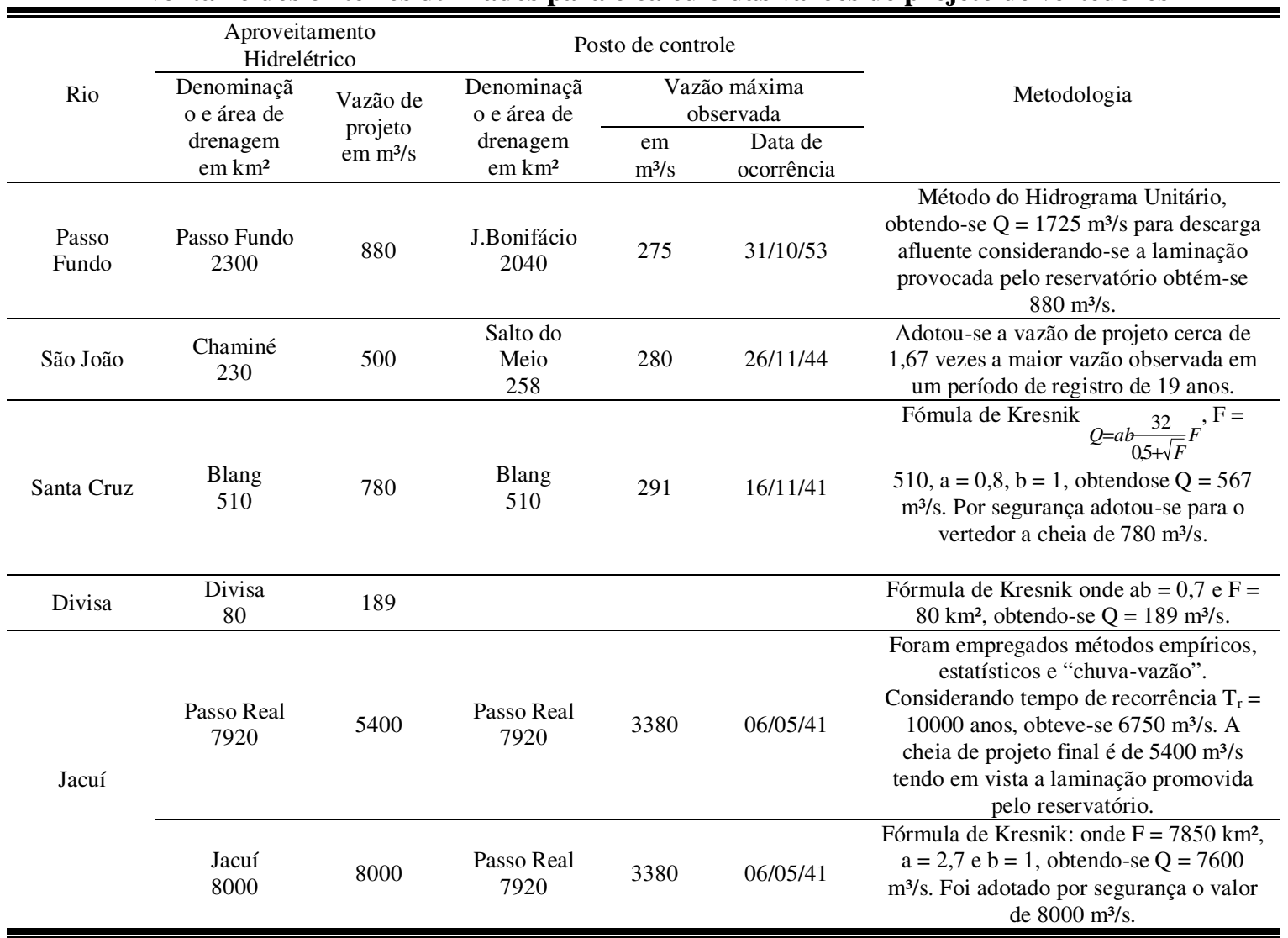

Fonte: Anjos e Almeida (1983) 
ANEXO B - Séries de Vazões Máximas Anuais

Séries de vazões médias diárias máximas

\begin{tabular}{|c|c|c|c|c|c|c|}
\hline \multirow{2}{*}{ ANO } & Sobradinho & Caconde & Funil & Volta Grande & Itumbiara & Tucuruí \\
\hline & VMP $=36300$ & VMP = 3082 & $\mathrm{VMP}=4400$ & $\mathrm{VMP}=12840$ & $\mathrm{VMP}=16200$ & $\mathrm{VMP}=110000$ \\
\hline 1931 & 7333 & & & & 4518 & \\
\hline 1932 & 4531 & & & & 3031 & \\
\hline 1933 & 5516 & & & & 2224 & \\
\hline 1934 & 6110 & & & & 3050 & \\
\hline 1935 & 5442 & & & & 3798 & \\
\hline 1936 & 4174 & & & & 2888 & \\
\hline 1937 & 5598 & 163 & & & 4085 & \\
\hline 1938 & 6307 & 199 & & & 3272 & \\
\hline 1939 & 5897 & 279 & & & 4626 & \\
\hline 1940 & 5500 & 247 & & & 4389 & \\
\hline 1941 & 5004 & 77 & & & 3275 & \\
\hline 1942 & 5277 & 145 & & & 2984 & \\
\hline 1943 & 9469 & 264 & & & 4836 & \\
\hline 1944 & 6328 & 104 & & & 2772 & \\
\hline 1945 & 8764 & 270 & & & 3548 & \\
\hline 1946 & 10080 & 332 & & & 6452 & \\
\hline 1947 & 7283 & 357 & & & 6918 & \\
\hline 1948 & 6343 & 337 & & & 3406 & \\
\hline 1949 & 13034 & 189 & & & 3836 & \\
\hline 1950 & 4716 & 364 & & & 3926 & \\
\hline 1951 & 4855 & 187 & & & 3235 & \\
\hline 1952 & 6938 & 181 & & & 4111 & \\
\hline 1953 & 3741 & 159 & & & 1838 & \\
\hline 1954 & 4405 & 451 & & & 2459 & \\
\hline 1955 & 4051 & 272 & & & 2242 & \\
\hline 1956 & 5370 & 263 & & & 3230 & \\
\hline 1957 & 7965 & 213 & & & 3371 & \\
\hline 1958 & 5212 & 326 & & & 2538 & \\
\hline 1959 & 3660 & 273 & & & 2894 & \\
\hline 1960 & 6124 & 306 & 917 & & 4018 & \\
\hline 1961 & 7765 & 242 & 1144 & & 5131 & \\
\hline 1962 & 5406 & 330 & 1165 & & 4799 & \\
\hline 1963 & 6556 & 310 & 735 & & 4081 & \\
\hline 1964 & 7732 & 221 & 761 & & 3943 & \\
\hline 1965 & 5836 & 251 & 773 & & 4895 & \\
\hline 1966 & 6708 & 564 & 1247 & & 5672 & \\
\hline 1967 & 5105 & 234 & 1344 & & 5475 & \\
\hline 1968 & 6495 & 146 & 659 & & 3345 & \\
\hline 1969 & 4879 & 143 & 628 & & 3285 & 10695 \\
\hline 1970 & 6441 & 457 & 871 & & 3033 & 32403 \\
\hline 1971 & 6411 & 122 & 727 & & 3566 & 17932 \\
\hline 1972 & 4959 & 162 & 837 & & 3329 & 21782 \\
\hline 1973 & 4644 & 175 & 856 & 2651 & 3271 & 26950 \\
\hline 1974 & 5184 & 210 & 825 & 4256 & 3110 & 39535 \\
\hline 1975 & 4301 & 168 & 890 & 3721 & 3569 & 29787 \\
\hline 1976 & 4818 & 229 & 633 & 4557 & 3637 & 19983 \\
\hline 1977 & 5751 & 213 & 790 & 4515 & 4562 & 34524 \\
\hline 1978 & 6259 & 155 & 831 & 6409 & 4055 & 43439 \\
\hline 1979 & 15676 & 257 & 569 & 7988 & 3772 & 43776 \\
\hline 1980 & 10490 & 238 & 577 & 8233 & 4466 & 64931 \\
\hline 1981 & 6170 & 493 & 774 & 5563 & 4551 & 34325 \\
\hline 1982 & 7990 & 256 & 742 & 7509 & 5170 & 38553 \\
\hline 1983 & 9245 & 493 & 857 & 9951 & 7337 & 33844 \\
\hline 1984 & 6328 & 190 & 526 & 3797 & 5318 & 25741 \\
\hline 1985 & 7789 & 278 & 1266 & 7626 & 7093 & 38532 \\
\hline 1986 & 7556 & 379 & 980 & 4803 & 4631 & 36907 \\
\hline 1987 & 3709 & 272 & 819 & 3976 & 4617 & 27113 \\
\hline 1988 & 5163 & 148 & 889 & 4406 & 2783 & 30126 \\
\hline 1989 & 5073 & 239 & 789 & 6793 & 3313 & 40380 \\
\hline 1990 & 9467 & 281 & 477 & 5626 & 3677 & 45732 \\
\hline 1991 & 5139 & 411 & 1112 & 7105 & 4553 & 32387 \\
\hline 1992 & 12915 & 197 & 1032 & 8545 & 7917 & 39634 \\
\hline 1993 & 5840 & 200 & 561 & 4598 & 3027 & 24521 \\
\hline 1994 & 5366 & 155 & 538 & 5447 & 2960 & 34463 \\
\hline 1995 & 3244 & 339 & 1081 & 4907 & 4851 & 28365 \\
\hline 1996 & 4478 & 312 & 1067 & 2739 & 3616 & 20971 \\
\hline 1997 & 6202 & 219 & 789 & 7574 & 5746 & 48261 \\
\hline 1998 & 3360 & 130 & 686 & 3217 & 2568 & 20045 \\
\hline 1999 & 4212 & 209 & 966 & 3998 & 3492 & 22978 \\
\hline 2000 & 5271 & 340 & 1388 & 5903 & 5389 & 35557 \\
\hline 2001 & 3158 & 109 & 572 & 4523 & 1883 & 26292 \\
\hline
\end{tabular}

Fonte: www.ons.org.br 
Séries de vazões médias diárias máximas

\begin{tabular}{|c|c|c|c|c|c|c|}
\hline \multirow[t]{2}{*}{ ANO } & Santa Isabel & Segredo & P. Colômbia & Marimbondo & A. Vermelha & São Simão \\
\hline & $\mathrm{VMP}=54000$ & $\mathrm{VMP}=13000$ & VMP $=16000$ & $\mathrm{VMP}=21400$ & $V M P=20000$ & VMP $=27400$ \\
\hline 1931 & & & 5099 & 8371 & 9674 & \\
\hline 1932 & & & 3523 & 4549 & 5204 & \\
\hline 1933 & & & 2496 & 3170 & 3839 & \\
\hline 1934 & & & 3444 & 4483 & 5173 & \\
\hline 1935 & & & 4262 & 6310 & 7265 & \\
\hline 1936 & & & 3241 & 4551 & 5196 & \\
\hline 1937 & & & 4611 & 6004 & 6894 & \\
\hline 1938 & & & 3691 & 4975 & 5663 & \\
\hline 1939 & & & 5205 & 6046 & 6952 & \\
\hline 1940 & & & 4478 & 6998 & 8069 & \\
\hline 1941 & & & 4005 & 4339 & 5065 & \\
\hline 1942 & & & 3371 & 4761 & 5449 & \\
\hline 1943 & & & 5413 & 6281 & 7232 & \\
\hline 1944 & & & 3122 & 3848 & 4407 & \\
\hline 1945 & & & 3988 & 5032 & 5786 & \\
\hline 1946 & & & 7013 & 7339 & 8449 & \\
\hline 1947 & & & 7117 & 7419 & 8559 & \\
\hline 1948 & & & 3842 & 4458 & 5145 & \\
\hline 1949 & & & 4211 & 4903 & 5643 & \\
\hline 1950 & & & 4423 & 5816 & 6683 & \\
\hline 1951 & & & 3632 & 5395 & 6173 & \\
\hline 1952 & & & 4642 & 5348 & 6163 & \\
\hline 1953 & & & 2030 & 2626 & 3023 & \\
\hline 1954 & & & 2771 & 3705 & 4265 & \\
\hline 1955 & & & 2475 & 2962 & 3360 & \\
\hline 1956 & & & 3414 & 4834 & 4865 & \\
\hline 1957 & & & 3737 & 4189 & 5225 & \\
\hline 1958 & & & 2863 & 3736 & 4305 & \\
\hline 1959 & & & 3255 & 4887 & 5437 & \\
\hline 1960 & & & 4474 & 5613 & 6394 & 6222 \\
\hline 1961 & & & 5794 & 7571 & 7920 & 9495 \\
\hline 1962 & & & 5165 & 6238 & 6570 & 10794 \\
\hline 1963 & & & 4329 & 5646 & 6033 & 7985 \\
\hline 1964 & & & 4323 & 5082 & 6533 & 7200 \\
\hline 1965 & & & 5499 & 6846 & 7400 & 9576 \\
\hline 1966 & & & 6177 & 7400 & 7476 & 12963 \\
\hline 1967 & & 1629 & 5851 & 7350 & 8043 & 7639 \\
\hline 1968 & & 1585 & 3537 & 3949 & 4384 & 7087 \\
\hline 1969 & 3294 & 3015 & 3445 & 3743 & 3977 & 5510 \\
\hline 1970 & 14768 & 3291 & 3304 & 5528 & 5737 & 8014 \\
\hline 1971 & 7116 & 3164 & 3939 & 4781 & 5222 & 6880 \\
\hline 1972 & 11284 & 3728 & 3743 & 4714 & 5372 & 7955 \\
\hline 1973 & 12047 & 2924 & 3617 & 4350 & 4786 & 7552 \\
\hline 1974 & 20735 & 1727 & 3429 & 4854 & 5366 & 7212 \\
\hline 1975 & 13291 & 4220 & 3757 & 4881 & 5635 & 5909 \\
\hline 1976 & 10281 & 2625 & 4198 & 5976 & 6609 & 6895 \\
\hline 1977 & 18082 & 2007 & 4987 & 6859 & 7818 & 7227 \\
\hline 1978 & 21941 & 1492 & 4515 & 5617 & 6266 & 8411 \\
\hline 1979 & 29066 & 4126 & 4051 & 5452 & 6466 & 9780 \\
\hline 1980 & 35726 & 2742 & 4925 & 6032 & 6670 & 11425 \\
\hline 1981 & 15405 & 2232 & 4990 & 6835 & 7259 & 7316 \\
\hline 1982 & 19768 & 4291 & 5799 & 7370 & 8121 & 13371 \\
\hline 1983 & 19557 & 10808 & 8018 & 10368 & 11107 & 13870 \\
\hline 1984 & 13156 & 3784 & 6024 & 7857 & 8457 & 6577 \\
\hline 1985 & 19353 & 1483 & 7803 & 9213 & 9481 & 11203 \\
\hline 1986 & 15750 & 1549 & 4907 & 6315 & 5970 & 7857 \\
\hline 1987 & 10631 & 4412 & 4954 & 6485 & 6824 & 6970 \\
\hline 1988 & 15458 & 3543 & 3105 & 4274 & 4762 & 6808 \\
\hline 1989 & 13766 & 4582 & 3544 & 4814 & 5749 & 9961 \\
\hline 1990 & 16803 & 4589 & 4056 & 5551 & 6367 & 9161 \\
\hline 1991 & 15907 & 2396 & 5311 & 6589 & 6758 & 11339 \\
\hline 1992 & 16753 & 8704 & 8367 & 9234 & 9463 & 10568 \\
\hline 1993 & 13017 & 4028 & 3498 & 5035 & 5166 & 7055 \\
\hline 1994 & 16201 & 2401 & 3186 & 4316 & 5076 & 8348 \\
\hline 1995 & 15115 & 3455 & 5337 & 7805 & 8896 & 7595 \\
\hline 1996 & 9906 & 3426 & 3698 & 4920 & 5329 & 5252 \\
\hline 1997 & 24425 & 4402 & 6539 & 8026 & 8268 & 10159 \\
\hline 1998 & 11072 & 5165 & 2885 & 3997 & 4432 & 5516 \\
\hline 1999 & 10380 & 3543 & 3826 & 5235 & 5662 & 5867 \\
\hline 2000 & 17161 & 3968 & 5857 & 7555 & 8019 & 8300 \\
\hline 2001 & 11816 & 4158 & 2012 & 2978 & 3191 & 6472 \\
\hline
\end{tabular}

Fonte: www.ons.org.br 
Séries de vazões médias diárias máximas

\begin{tabular}{|c|c|c|c|c|c|c|}
\hline \multirow{2}{*}{ ANO } & Furnas & Estreito & Jaguara & Passo Real & Itapebi & Pedra Cavalo \\
\hline & $\mathrm{VMP}=13000$ & $\mathrm{VMP}=13000$ & VMP $=14100$ & $\mathrm{VMP}=5400$ & $\mathrm{VMP}=25600$ & $\mathrm{VMP}=15160$ \\
\hline 1931 & 3729 & 4190 & 4214 & & & \\
\hline 1932 & 2491 & 2828 & 2824 & & & \\
\hline 1933 & 1707 & 2064 & 2073 & & & \\
\hline 1934 & 2448 & 2822 & 2837 & & & \\
\hline 1935 & 3161 & 3512 & 3543 & & & \\
\hline 1936 & 2411 & 2667 & 2688 & & 1270 & \\
\hline 1937 & 3359 & 3849 & 3863 & & 7704 & \\
\hline 1938 & 3532 & 3356 & 3262 & & 1426 & \\
\hline 1939 & 3719 & 4282 & 4303 & & 3801 & \\
\hline 1940 & 3573 & 4129 & 4133 & 2031 & 3677 & \\
\hline 1941 & 2591 & 2936 & 2940 & 3141 & 5733 & 1492 \\
\hline 1942 & 2411 & 2772 & 2779 & 1494 & 6808 & 385 \\
\hline 1943 & 3930 & 4506 & 4516 & 704 & 9318 & 1825 \\
\hline 1944 & 2244 & 2568 & 2569 & 1266 & 5398 & 689 \\
\hline 1945 & 3333 & 3365 & 3345 & 781 & 8430 & 2027 \\
\hline 1946 & 5178 & 5974 & 6001 & 1000 & 4370 & 450 \\
\hline 1947 & 5525 & 6370 & 6428 & 940 & 3564 & 360 \\
\hline 1948 & 2720 & 3146 & 3161 & 1111 & 5768 & 4450 \\
\hline 1949 & 3063 & 3536 & 3558 & 804 & 5410 & 2600 \\
\hline 1950 & 3172 & 3638 & 3655 & 2270 & 2174 & 1530 \\
\hline 1951 & 2730 & 3056 & 3079 & 736 & 2337 & 305 \\
\hline 1952 & 3288 & 3792 & 3820 & 608 & 4549 & 264 \\
\hline 1953 & 1600 & 1758 & 1715 & 1805 & 3110 & 2020 \\
\hline 1954 & 2006 & 2293 & 2300 & 1814 & 4437 & 1740 \\
\hline 1955 & 1860 & 2120 & 2124 & 1258 & 7691 & 3200 \\
\hline 1956 & 2758 & 3155 & 3173 & 2233 & 4541 & 620 \\
\hline 1957 & 2456 & 2973 & 3038 & 1353 & 4955 & 1550 \\
\hline 1958 & 2032 & 2343 & 2360 & 1995 & 2588 & 450 \\
\hline 1959 & 2314 & 2677 & 2693 & 1922 & 2270 & 470 \\
\hline 1960 & 3345 & 3788 & 3809 & 1197 & 5630 & 6550 \\
\hline 1961 & 4347 & 4835 & 4834 & 1575 & 3006 & 260 \\
\hline 1962 & 4274 & 4622 & 4624 & 240 & 3594 & 234 \\
\hline 1963 & 3780 & 3987 & 3978 & 1305 & 2270 & 307 \\
\hline 1964 & 3522 & 3778 & 3778 & 855 & 5759 & 6253 \\
\hline 1965 & 3481 & 4297 & 4355 & 1471 & 2615 & 926 \\
\hline 1966 & 4995 & 5420 & 5435 & 1411 & 2278 & 1926 \\
\hline 1967 & 4300 & 5204 & 5246 & 1591 & 6602 & 458 \\
\hline 1968 & 2980 & 3277 & 3264 & 525 & 6433 & 1326 \\
\hline 1969 & 3060 & 3208 & 3212 & 488 & 6389 & 2950 \\
\hline 1970 & 2701 & 2898 & 2898 & 953 & 7025 & 950 \\
\hline 1971 & 3050 & 3465 & 3459 & 2160 & 7336 & 1647 \\
\hline 1972 & 2697 & 3058 & 3056 & 2742 & 3779 & 360 \\
\hline 1973 & 2445 & 3049 & 3078 & 2217 & 4032 & 1951 \\
\hline 1974 & 2755 & 2977 & 2979 & 1843 & 2588 & 690 \\
\hline 1975 & 3390 & 3568 & 3539 & 1327 & 2145 & 958 \\
\hline 1976 & 2797 & 3156 & 3203 & 1914 & 1529 & 465 \\
\hline 1977 & 3136 & 3893 & 3981 & 1240 & 3527 & 538 \\
\hline 1978 & 3706 & 3888 & 3889 & 1409 & 4022 & 1405 \\
\hline 1979 & 3331 & 3693 & 3697 & 2108 & 9784 & \\
\hline 1980 & 3718 & 4154 & 4186 & 1447 & 4066 & \\
\hline 1981 & 4236 & 4418 & 4395 & 738 & 7410 & \\
\hline 1982 & 4223 & 4832 & 4856 & 2434 & 4346 & \\
\hline 1983 & 4678 & 6462 & 6539 & 3060 & 3556 & \\
\hline 1984 & 3618 & 4595 & 4714 & 2799 & 2352 & \\
\hline 1985 & 5606 & 6594 & 6590 & 1420 & 3921 & \\
\hline 1986 & 4098 & 4471 & 4487 & 2552 & 4604 & \\
\hline 1987 & 3438 & 4312 & 4363 & 2014 & 2093 & \\
\hline 1988 & 2385 & 2671 & 2666 & 1759 & 2818 & \\
\hline 1989 & 2689 & 3099 & 3117 & 2660 & 5092 & \\
\hline 1990 & 2780 & 3309 & 3354 & 2089 & 2525 & \\
\hline 1991 & 3209 & 3985 & 4022 & 648 & 2189 & \\
\hline 1992 & 7497 & 7794 & 7803 & 3550 & 5230 & \\
\hline 1993 & 2499 & 2767 & 2757 & 1550 & 2136 & \\
\hline 1994 & 2774 & 2911 & 2881 & 1190 & 2997 & \\
\hline 1995 & 3809 & 4311 & 4345 & 1060 & 2100 & \\
\hline 1996 & 3525 & 3632 & 3613 & 987 & 2937 & \\
\hline 1997 & 4845 & 5296 & 5330 & 2675 & 2890 & \\
\hline 1998 & 2116 & 2423 & 2427 & 1849 & 3280 & \\
\hline 1999 & 2434 & 3073 & 3122 & 767 & 2680 & \\
\hline 2000 & 5017 & 5289 & 5275 & 1629 & 2514 & \\
\hline 2001 & 1793 & 1875 & 1865 & 1959 & 1435 & \\
\hline
\end{tabular}

Fonte: www.ons.org.br 